\title{
Simple strategy-based technique to reduce emissions from SCR- equipped heavy-duty diesel engine over different engine-out calibrations
}

\author{
Michelangelo Ardanese \\ West Virginia University
}

Follow this and additional works at: https://researchrepository.wvu.edu/etd

\section{Recommended Citation}

Ardanese, Michelangelo, "Simple strategy-based technique to reduce emissions from SCR-equipped heavy-duty diesel engine over different engine-out calibrations" (2008). Graduate Theses, Dissertations, and Problem Reports. 2856.

https://researchrepository.wvu.edu/etd/2856

This Dissertation is protected by copyright and/or related rights. It has been brought to you by the The Research Repository @ WVU with permission from the rights-holder(s). You are free to use this Dissertation in any way that is permitted by the copyright and related rights legislation that applies to your use. For other uses you must obtain permission from the rights-holder(s) directly, unless additional rights are indicated by a Creative Commons license in the record and/ or on the work itself. This Dissertation has been accepted for inclusion in WVU Graduate Theses, Dissertations, and Problem Reports collection by an authorized administrator of The Research Repository @ WVU.

For more information, please contact researchrepository@mail.wvu.edu. 


\title{
Simple Strategy-Based Technique to Reduce Emissions from
} SCR-equipped Heavy-Duty Diesel Engine over Different Engine-Out Calibrations

\author{
Michelangelo Ardanese \\ Dissertation submitted to the \\ College of Engineering and Mineral Resources \\ at West Virginia University \\ in partial fulfillment of the requirements \\ for the degree of
}

\author{
Doctor of Philosophy \\ in \\ Mechanical Engineering \\ Committee Members: \\ Dr. Mridul Gautam, Ph.D., Chair \\ Dr. Nigel N. Clark, Ph.D. \\ Dr. Benjamin C. Shade, Ph.D. \\ Dr. Gary H. Ganser, Ph.D. \\ Dr. Mario Perhinschi, Ph.D.
}

Department of Mechanical and Aerospace Engineering

\author{
Morgantown, West Virginia \\ 2008
}

Keywords: Diesel Engines, Engine Calibrations, Exhaust Aftertreatment, SCR

Copyright 2008 Michelangelo Ardanese 


\title{
Simple Strategy-Based Technique to Reduce Emissions from SCR-equipped Heavy- Duty Diesel Engines over Different Engine-Out Calibrations
}

\author{
Michelangelo Ardanese
}

\begin{abstract}
Heavy-duty diesel engine manufacturers, regulators and operators in Europe and US have judged the Selective Catalytic Reduction (SCR) system to be the most suitable exhaust aftertreatment technology to meet the Euro V and US 2010 emission standards for oxides of nitrogen (NOx). The choice of the SCR as the exhaust aftertreatment system has been accompanied by engine calibrations with higher engine-out NOx emissions. Temporary deactivation of the exhaust aftertreatment device, due to malfunction or disrepair could result in excessively high NOx emissions at the tailpipe. Therefore, there is a need to evaluate alternative engine calibrations that would limit in-use NOx emissions during SCR inefficiencies.

The objective of this study was to develop and implement a technique to program an engine with different calibrations, which were optimized for exhaust aftertreatment performance. Two very distinct calibrations were evaluated over transient and steady state conditions. The implementation of these calibrations helped meet the emission standards under conditions, which are critical for the SCR operation under real worldconditions, but may not be encountered during the engine certification testing. Multiple calibrations were designed by means of a simple multivariate optimization technique involving the variation of only four engine parameters, namely EGR rate, boost pressure, injection pressure and injection timing. In addition, an empirical model for accurate NOx and fuel consumption (FC) prediction was developed, assuming independency of the parameters.

The technique developed in this study was found to be quick to implement, simple and efficient; requiring very little engine test cell time. The main calibrations proved to be engine cycle independent, since comparable emission levels were measured over ESC, FTP and ETC cycles.

Low-NOx map was obtained by raising the injection pressure and increasing EGR rates. A NOx emissions reduction of $20 \%$ was achieved, with a penalty in fuel economy of less than $3 \%$ from the baseline. Several fuel efficient calibrations were generated by advancing injection timing and increasing injection pressure; the highest improvement brought a reduction in FC of more than $6 \%$.

Multiple calibrations can be generated by this technique and alternatively used by the engine control system depending upon the thermodynamic conditions of the exhaust stream at the inlet of the SCR system
\end{abstract}




\section{TABLE of CONTENTS}

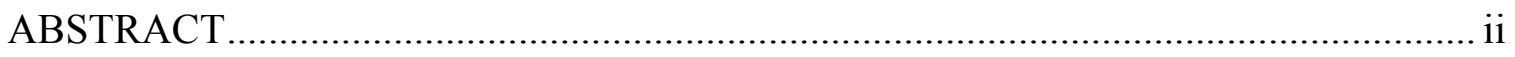

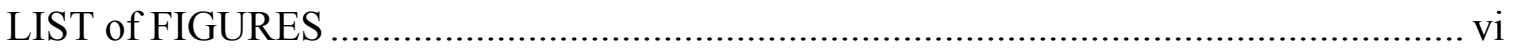

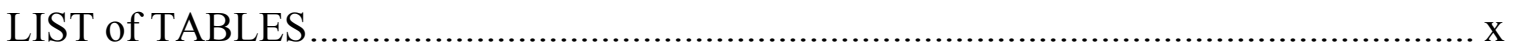

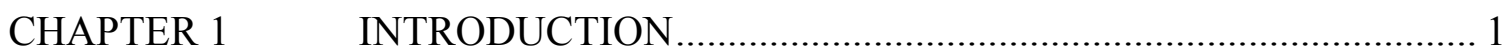

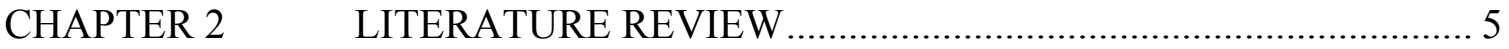

2.1 Impact of Engine Parameters on Emissions and Combustion........... 5

2.1.1 EGR Valve Position ........................................................................ 5

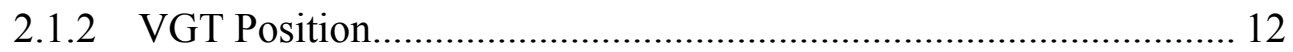

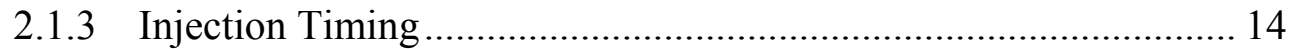

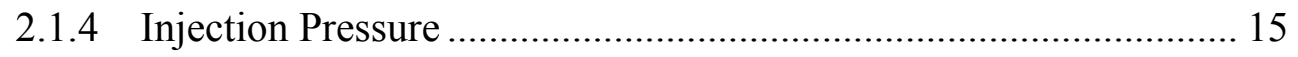

$2.2 \quad$ Emission Reduction Strategies..................................................... 18

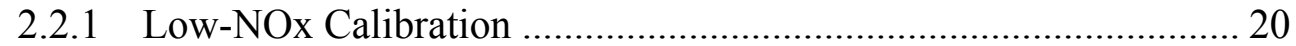

2.2.2 Urea Consumption Trade-off ..................................................... 22

$2.3 \quad$ Optimization Technique ............................................................ 22

2.3.1 Design of Experiment Techniques ................................................. 23

$2.4 \quad$ Summary of the Literature Review ................................................. 26

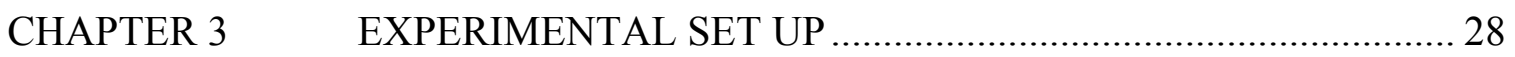

$3.1 \quad$ Test Engines ......................................................................... 28

3.2 Variable Geometry Turbocharger ................................................ 30

3.3 Advanced Injection System (EUI3) …………………………...... 31

3.4 Exhaust Gas Aftertreatment ........................................................ 34

3.5 In-cylinder Pressure High Speed Acquisition .................................. 36

3.6 Engine Test Cell and Laboratory Instrumentation ………………... 37

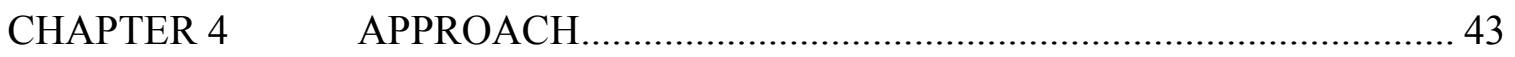

4.1 Model Selection..................................................................... 43

4.2 Parameter Range Selection........................................................... 44

4.3 Single Parameter Study on Combustion........................................... 45

4.4 Level Assignment and Strategy Implementation ............................. 46

4.5 Orthogonal Matrix Testing ......................................................... 48 
4.6 Identification of the Optimum Control Factor Levels.................... 49

$4.7 \quad$ Predictive Model .......................................................................... 50

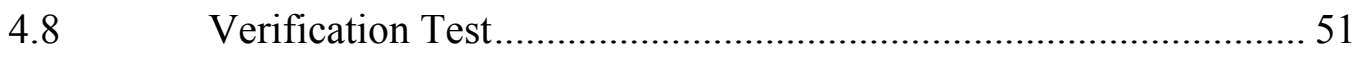

Analysis of Variance (ANOVA) .................................................. 52

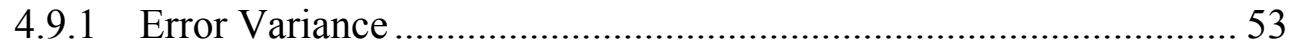

4.10 Second Stage of Emission Reduction........................................ 53

Engine Calibrations Evaluation.............................................. 54

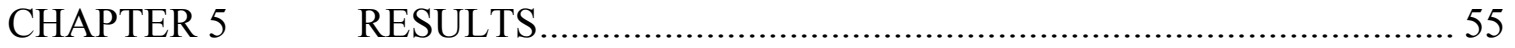

5.1 Single Mode Study (MY04 Engine)......................................... 55

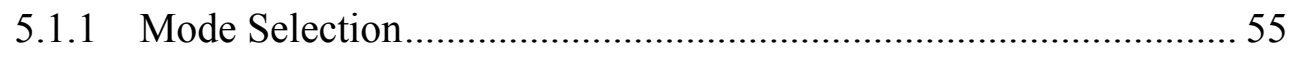

5.1.2 Orthogonal Array Testing and Optimal Solution ......................... 57

5.1.3 ANOVA of the Results ............................................................. 60

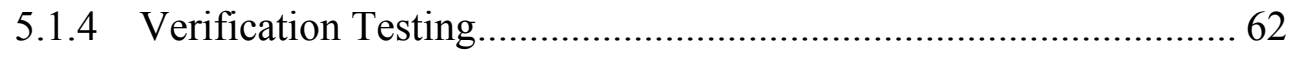

5.1.5 Analysis of the Optimal Engine Configurations .......................... 64

5.1.6 Study on the Single Parameter Effect ........................................ 66

5.2 Multi-mode Study to Optimize the MY07 Volvo MD11 Engine ... 74

5.2.1 EGR Flow Sensitivity Study .................................................. 74

5.2.2 Level Assignment Matrixes ..................................................... 76

5.2.3 Optimal Settings Selection and Verification Test ........................ 78

Engine Map Optimization ....................................................... 82

5.4 Evaluation of the Engine Calibrations (FTP/ESC cycles).............. 89

5.5 Low-FC Calibration at Higher Exhaust Temperature .................... 95

5.6 Alternative Methods to Generate Heat in the Exhaust Stream........ 99

5.7 Evaluation of the Calibrations over ETC Cycle........................... 107

CHAPTER 6 CONCLUSIONS AND RECOMMENDATIONS....................... 110

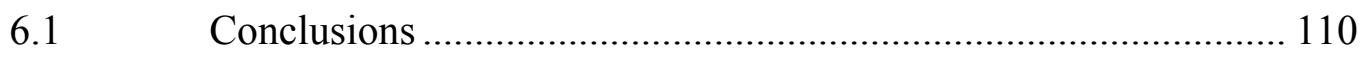

Recommendations ............................................................ 111

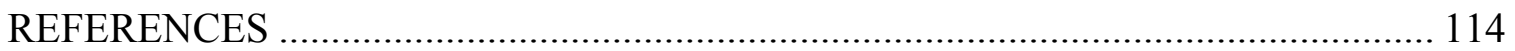

APPENDIX A Heat Release Calculation .................................................... 120

APPENDIX B High-speed in-Cylinder Pressure Acquisition Program ............... 132

APPENDIX C $\quad$ Optimization Algorithm Program ........................................... 137 


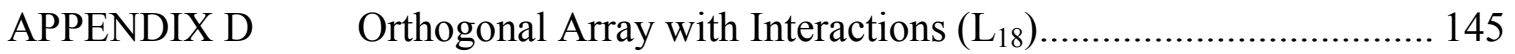

APPENDIX E $\quad$ Uncertainty Analysis ............................................................... 148

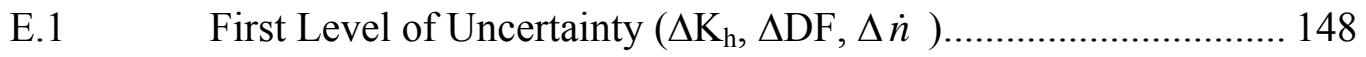

E.2 Second Level of Uncertainty $(\Delta \mathrm{H}, \Delta \mu, \Delta \mathrm{Mmix}, \Delta \delta) \ldots \ldots \ldots \ldots \ldots \ldots . . . . . .149$

E.3 Third Level of Uncertainty $\left(\Delta \mathrm{R}_{\mathrm{i}}, \Delta \mathrm{p}_{\mathrm{d}}, \Delta \mathrm{p}_{\mathrm{B}}, \Delta \mathrm{x}_{\mathrm{H} 2 \mathrm{O}}, \Delta \mathrm{C}_{\mathrm{f}}\right) \ldots \ldots \ldots \ldots . . . .150$

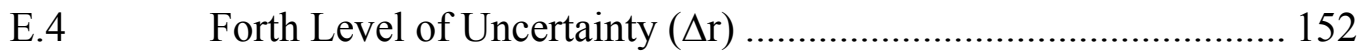

E.5 Final Level of Uncertainty ................................................. 152

APPROVAL OF THE EXAMINING COMMITTEE................................................ 156 


\section{LIST of FIGURES}

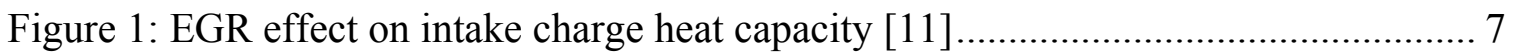

Figure 2: EGR effect on the combustion flame shape [11] ....................................... 7

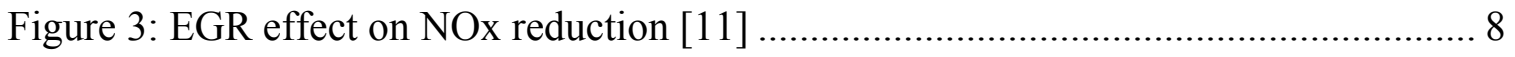

Figure 4: EGR and retarded injection effect on NOx-PM trade off [11] ......................... 9

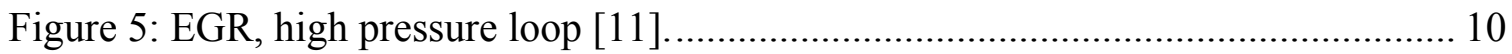

Figure 6: Closed loop control with look up table and air flow feedback variable [27] .... 11

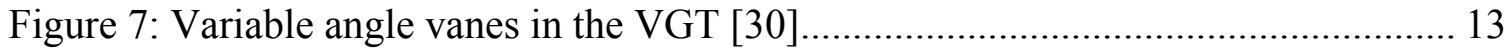

Figure 8: Injection timing retard effect on in cylinder pressure [9] ............................. 14

Figure 9: Injection pressure effect on in-cylinder pressure [9] ................................... 15

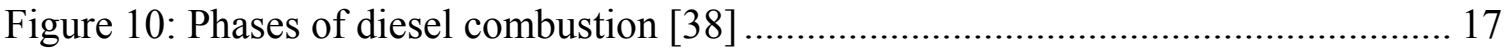

Figure 11: Effect of NOP increase on injection pressure curve [33] ............................ 18

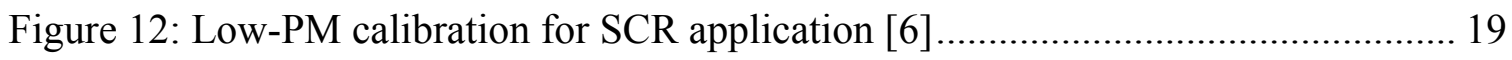

Figure 13: Aftertreatment technologies comparison on the basis of their cost of operation

[6] 20

Figure 14: Emission reduction strategies (EURO III, EURO IV) [24]........................... 21

Figure 15: Volvo MY04, 355 hp @ 1800 / 1360 lb-ft @1200 rpm................................. 28

Figure 16: Volvo MY07, 339 hp @ 1800 / 1298 lb-ft @1306 rpm.................................. 29

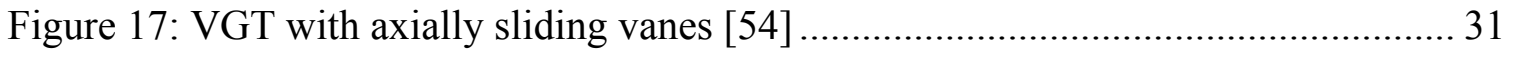

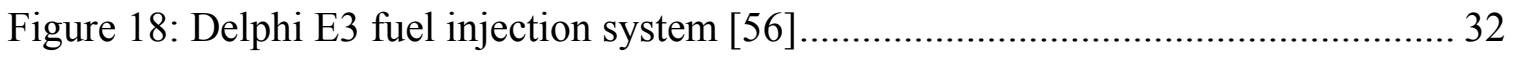

Figure 19: Working principle of the injector nozzle of the EUI system [52] .................. 32

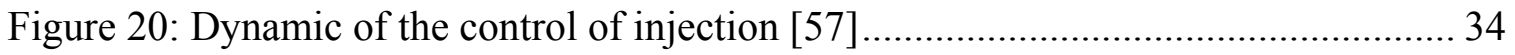

Figure 21: Fleetguard compact saver DOC-DPF system [53] .................................... 35

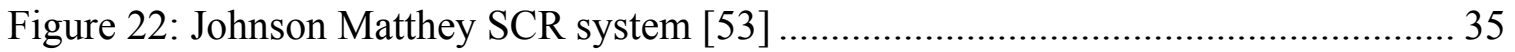

Figure 23: Exhaust aftertreatment system installed at the EERL ................................. 36

Figure 24: In cylinder pressure acquisition system (top); pressure sensor Kistler 6125B21

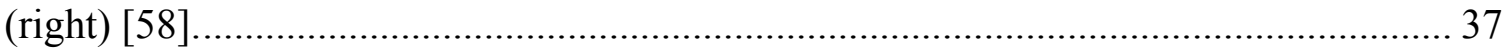

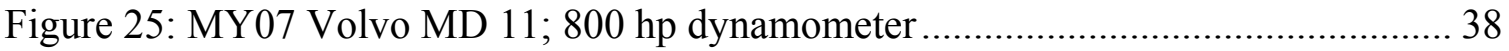

Figure 26: Sub-sonic venturi in the total exhaust CVS............................................. 39 
Figure 27: Variable speed blower.....

Figure 28: Analyzer bench (Chemiluminescence, FID, NDIR analyzers, gas divider, temp. controller box). 39

Figure 29: NDUV analyzer; ABB Limas $11 \mathrm{HW}$ 40

Figure 30: PM filters: $47 \mathrm{~mm}$ Teflo filters; engine-out, SCR-out collection..... 41

Figure 31: PM box for filter collection. 41

Figure 32: PM weighing room (view from the observation window) 42

Figure 33: AVL cycle [59] 43

Figure 34: Selection of modes for low-NOx map (ESC circled and all AVL modes) ..... 44

Figure 35: Control factor effects on NOx, PM and FC. 59

Figure 36: Factors contribution to NOx reduction. 61

Figure 37: Factors contribution to PM variation. 61

Figure 38: Model predictions and verification measurements for low-NOx optimal solution. 64

Figure 39: Heat Release curves for the four optimal configurations 65

Figure 40: Combustion parameters for the four optimal configurations 66

Figure 41: Effect of VGT variation on emission and combustion parameters ("+" and “++" indicates increasing values of VGT as shown in Table 11). 68

Figure 42: VGT effect on combustion parameter broadcasted by the ECU 68

Figure 43: EGR effect on parameter broadcasted by the ECU (“-_" and "--." indicates decreasing values of EGR as shown in Table 11).... 69

Figure 44: SOI variation effect on heat release curve............................................ 70

Figure 45: Effect of NOP on injection pressure and needle lift.................................... 71 Figure 46: Effect of NOP on combustion parameters ("+" and "++" indicates increasing

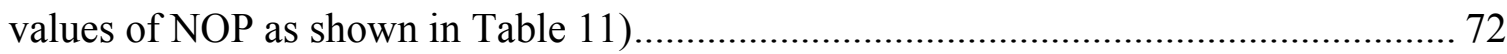

Figure 47: NOx-PM trade off for the different control factors .................................... 73

Figure 48: NOx-FC trade off for the different control factors..................................... 73

Figure 49: Effect of EGR valve sweep on NOx and EGR flow, MODE 10.................. 75

Figure 50: Effect of VGT sweep on EGR flow and NOx (MODE 10) ......................... 75

Figure 51: Prediction and verification measurements for ESC modes, low-NOx map .... 82

Figure 52: EGR static optimized map, low NOx calibration. 84 


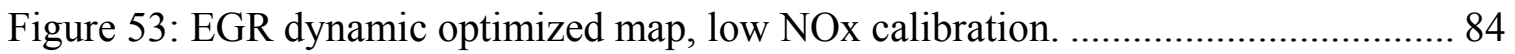

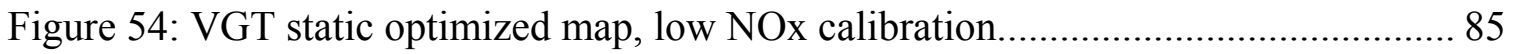

Figure 55: VGT dynamic optimized map, low NOx calibration. ................................. 85

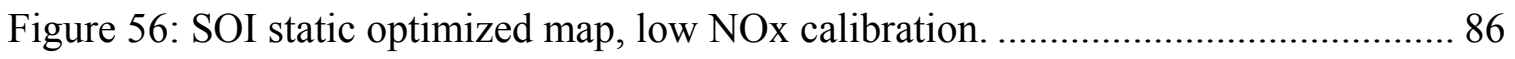

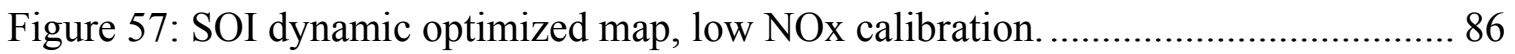

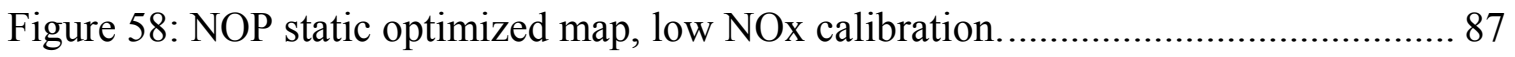

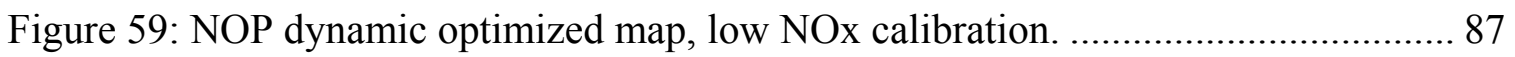

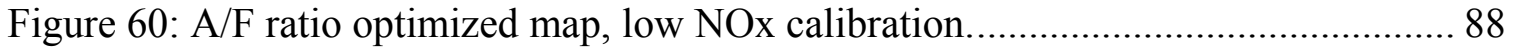

Figure 61: Burned fraction optimized map, low NOx calibration................................ 88

Figure 62: NOx emissions comparison over FTP ................................................. 91

Figure 63: CO emissions comparison over FTP ...................................................... 92

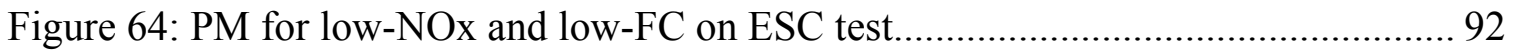

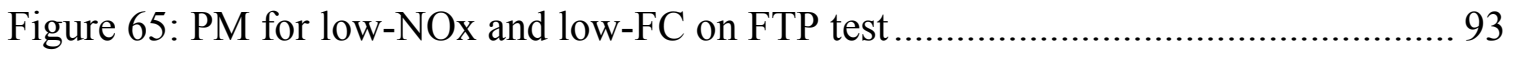

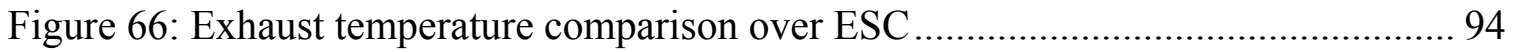

Figure 67: Exhaust temperature comparison over FTP ….......................................... 94

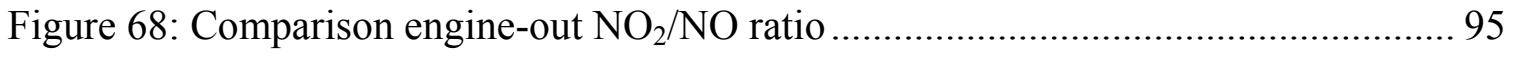

Figure 69: Maximum in-cylinder pressure for low-FC at higher boost pressure ............ 96

Figure 70: Effect on exhaust temperature of low-FC calibration which targets high

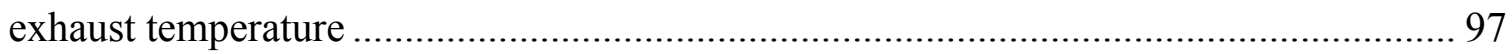

Figure 71: Effect on NOx concentration of low-FC/exh. temp. calibration .................... 98

Figure 72: Effect on PM of low-FC/exh. temp. calibration .......................................... 99

Figure 73: Exhaust valve early opening, idle mode, at constant flow .......................... 100

Figure 74: Laboratory data during early opening of exhaust valve at idle mode and

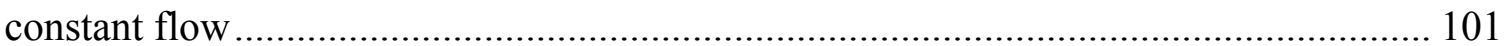

Figure 75: Early exhaust valve opening at $1000 \mathrm{rpm}, 10 \mathrm{Nm}$ load; heat release and needle lift curve. 102

Figure 76: Laboratory data during early opening of exhaust valve at $1000 \mathrm{rpm}, 10 \mathrm{Nm}$ load.

Figure 77: Early exhaust valve opening at 1000 rpm, $200 \mathrm{Nm}$; heat release and needle lift curve 
Figure 78: Laboratory data during early opening of exhaust valve at $1000 \mathrm{rpm}$ and 200 Nm....... 104

Figure 79: Early exhaust valve opening at $650 \mathrm{rpm}, 0$ deg timing; heat release and needle lift curve. 104

Figure 80: Early exhaust valve opening at $650 \mathrm{rpm}, 5 \mathrm{deg}$ timing; heat release and needle lift curve. 105

Figure 81: Laboratory data during early opening of exhaust valve at $650 \mathrm{rpm}, 0$ deg ... 105 Figure 82: Laboratory data during early opening of exhaust valve at $650 \mathrm{rpm}$ and $5 \mathrm{deg}$

Figure 83: FTP and ETC NOx emissions for low-NOx and low-FC 107

Figure 84: NOx concentration over ETC cycle; low-NOx, low-FC. 108

Figure 85: NTE events during ETC cycle. 109

Figure 86: Experimental heat release and Weibe function fit using least squares method

Figure 87: Front panel of the high-speed acquisition program 132

Figure 88: Acqusition Pressure Main Code ...................................................................... 133

Figure 89: Encoder Calibration Main Code............................................................... 134

Figure 90: Maximum Pressure Program ................................................................. 136

Figure 91: Antisynergistic interactions between NOP and EGR .................................... 145

Figure 92: Synergistic interactions between NOP and EGR ......................................... 146 


\section{LIST of TABLES}

Table 1: Single-parameter-at-a-time approach, 7 factor and two levels [51] ................... 24

Table 2: Full factorial approach for 7 factors, 2 levels [51] ......................................... 25

Table 3: Orthogonal array approach for 7 factors, 2 levels [51]..................................... 26

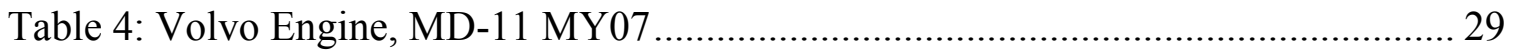

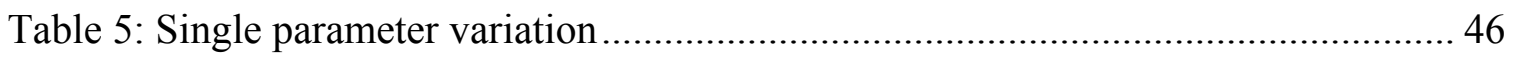

Table 6: High NOP-high EGR strategy implementation for Low-NOx map ................... 47

Table 7: Level assignment for low-FC map (high NOP-advanced injection) ................... 48

Table 8: Orthogonal array design, 9 experiments-4 control factors $\left(\mathrm{L}_{9}\right)$......................... 48

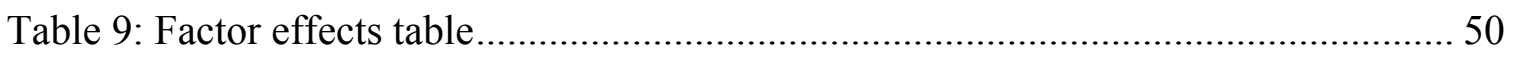

Table 10: Mode 3 of ESC cycle ................................................................................. 56

Table 11: Strategy implementation for low-NOx optimization ........................................ 56

Table 12: Orthogonal array parameter settings.............................................................. 57

Table 13: Orthogonal array and NOx, PM and FC measurements .................................. 58

Table 14: Optimal configuration for four different target functions.................................. 59

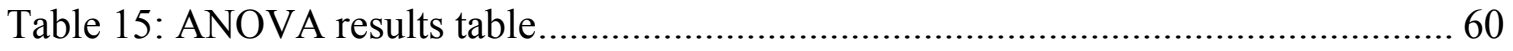

Table 16: NOx prediction results for the four characteristic functions ............................. 62

Table 17: PM prediction results for the four characteristic functions ............................... 62

Table 18: FC prediction results for the four characteristic functions ................................ 63

Table 19: Emission reduction and performance improvement of the optimal solutions .. 64

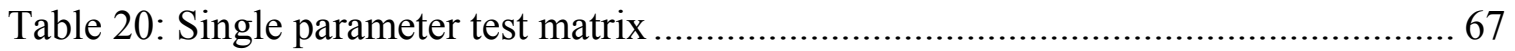

Table 21: Level assignment for low-NOx calibration, (6 ESC modes).............................. 77

Table 22: Level assignment for low-FC calibration, ESC modes ...................................... 78

Table 23: Verification test for the low-NOx calibration (ESC modes) ……………......... 80

Table 24: Verification test for the low-FC calibration (ESC modes) ................................ 81

Table 25: Emissions levels in g/bhp-hr for low-NOx, low-FC and Baseline calibrations 90

Table 26: Comparison of low-FC at higher in-cylinder pressure with the baseline......... 97

Table 27: NTE events during ETC and FTP cycle ………….................................... 108

Table 28: Brake specific NOx emissions within the NTE region.................................... 109 
Table 29: Orthogonal matrix, $\mathrm{L}_{18}$, with interaction between EGR and VGT ............... 147

Table 30: Uncertainties of pressure and temperature sensors................................... 154

Table 31: Uncertainties of temperature sensors, gas analyzers, gas dividers and

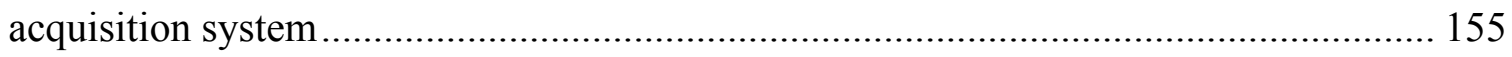




\section{CHAPTER 1 INTRODUCTION}

The choice of the Selective Catalytic Reduction (SCR) system as the exhaust aftertreatment system in heavy-duty diesel engines has been accompanied by engine calibrations with higher engine-out emissions of oxides of nitrogen (NOx). Temporary deactivation of the exhaust aftertreatment device, due to malfunction or disrepair could result in excessively high NOx emissions at the tailpipe. Therefore, there is the need to evaluate alternative engine calibrations that would limit in-use NOx emissions during SCR inefficiencies.

This study focused on two main objectives:

1. To develop and validate a simple strategy-based technique capable of minimizing the emissions and achieving FC improvements for an SCR-equipped heavy duty diesel engine.

2. Evaluate and compare two distinct calibrations over transient and steady state conditions.

The SCR is a valuable emissions catalyst technology which has been widely used for more than thirty years. A large number of heavy-duty diesel engine manufacturers in Europe and the US have judged the SCR to be the most suitable exhaust aftertreatment technology to meet the Euro V and US 2010 emission legislations. It is able to achieve high efficiency in NOx reduction; thus, engines can be programmed for optimum fuel consumption (FC) during in-use operation. Engines with advanced injection timing, decreased exhaust gas recirculation (EGR) rates, increased injection pressures; hence, high levels of engine-out NOx emissions are more likely to be fitted with SCR systems. However, such engines may emit high levels of NOx emissions when the SCR is challenged with conditions, such as insufficient heat available in the exhaust gases to sustain the catalytic reaction and very low exhaust temperatures to initiate the urea hydrolyzation. In such cases, alternative engine calibrations should be considered. It is proposed that two different engine maps, a low-NOx and a low-FC be alternatively used 
by the engine control system depending upon the thermodynamic conditions of the exhaust stream at the inlet of the SCR system.

An engine calibration is accomplished by optimizing a range of engine parameters to achieve the desired engine performance and meet emissions targets. The high number of parameters and their interactions make the task of optimization extremely tedious $[1,2]$. Time and cost significantly increase with the vast number of possible engine configurations that need to be tested. Traditionally, manufacturers adopt the "oneparameter-at-a-time" approach, which requires a large amount of testing, effort and time. Furthermore, the use of this methodology leads to the risk of missing important combinations; hence, the need for a multivariate optimization technique that does not neglect parameter interaction, and at the same time cuts down testing time and cost $[3,4]$. It is proposed that simple multivariate optimization technique involving the variation of only four engine parameters be used to program the engine with multiple calibrations, such as the low-NOx and low-FC calibrations. Such calibrations were developed to optimize the performance of the exhaust aftertreatment system selected for this study to achieve the 2010 emission standards and FC improvements.

The latest solution adopted by several manufacturers has been to develop an autonomous aftertreatment system (DPF-SCR) which can be directly installed as retrofit product on existing vehicles with no additional engine modification [5]. A limitation to this approach is that the aftertreatment efficiency will always depend upon the thermodynamic conditions of the engine exhaust. During the severly low load conditions of the JE05 Japanese test cycle or the first $600 \mathrm{sec}$ of the US FTP where the percentage of idle time is considerably high, or during any engine operation involving low loads for extended periods, the controller must interrupt the urea supply to prevent catalyst fouling by incomplete decomposition of $\mathrm{HNCO}$, cynuric acid, ammonium nitrate and compounds of $\mathrm{NH}_{3}$, whose concentration increases especially at temperatures are relatively low $[6,7]$. The long term goal of this study is to develop a technique to generate multiple calibrations, such that any engine can be matched with an aftertreatment system by producing optimal engine-out exhaust condition.

Many studies have already demonstrated the critical role that engine control strategies can play in emissions and performance management. For instance, the use of 
variable levels of EGR $[6,8]$ in regions where the aftertreatment system does not perform well will limit NOx emissions below desired levels. For regions such as these, this study is proposing the use of multiple engine calibrations, which should be developed over the whole region of engine operation. Hence, based upon the exhaust temperature or the realtime, on-board measurement of SCR conversion efficiency, the engine control strategy could switch to the low-NOx map in case of insufficient heat in the exhaust stream or to the low-FC map, when more favorable conditions exist for urea decomposition. The rationale of this study, therefore, is that the implementation of the low-NOx and low-FC calibrations will ensure the achievement of the 2010 emission standards under conditions, which are critical for the SCR operation, but may not be encountered during the engine certification testing.

The central hypothesis is that the four engine parameters selected, among the numerous parameters that affect engine emissions and performance, are sufficient to generate multiple calibrations, with a minimum number of experiments, in order to minimize NOx and FC. The parameters considered in this study, which are known to significantly affect the combustion process, are: EGR rate, boost pressure, injection pressure and injection timing, as pointed out already in a similar work [1].

The specific objectives of the project are to develop and implement the low-NOx map in order to achieve 2010 heavy-duty engine emission standards and to study the potentials of the technique in producing different calibrations, such as low-FC. The lowNOx map was obtained by raising the injection pressure and increasing EGR rates. Higher injection pressures contribute to enhance atomization and reduction in soot formation in the combustion chamber; hence, higher EGR rates can be tolerated. The low-FC map entails advancing the fuel injection and increasing the injection pressure at the same time. The former is known to improve the quality of combustion by bringing the combustion event closer to the top dead center (TDC); the latter to improve the cyclework by increasing the in-cylinder pressure [9]. Both effects contribute to better the fuel economy.

The significance of this work lies in its innovative approach to adapt an engine to a given aftertreatment system in order to meet the 2010 US emission limits. By considering different calibrations this approach takes into account the possible occurrence 
of malfunction and failure of the aftertreatment device during in-use engine operations. Furthermore, the simplicity of this technique allows quick implementation of calibrations targeting more specific parameters of aftertreatment performance. Multiple calibrations can be employed as the loads, $\mathrm{NO} / \mathrm{NO}_{2}$ ratios and exhaust conditions change during engine operation.

To accomplish the proposed objectives the following studies were undertaken:

1. Effect of engine parameters on combustion and emissions. High injection pressures improve the fuel atomization, and therefore, the air-fuel mixing process, but at the same time the consequent reduction of the combustion has the counter effect of increasing NOx. At this point the EGR can be employed as a de-NOx strategy. Since soot is minimized by high injection pressures, larger amounts of EGR can be tolerated without the soot levels in the oil becoming excessively high to adversely affect engine wear (low-NOx calibration). If advanced injection is accompanied with increased level of injection pressure instead, similar effects on the ignition delay; hence, on the combustion process are expected. Typically, advanced timing is accompanied with higher combustion temperatures and higher NOx emissions, and the combustion event could occur closer to the TDC thereby significantly benefiting the cycle efficiency (low-FC calibration).

2. NOx modeling through statistical technique based on Taguchi method. A methodology was developed that tested a small number of parameter combinations to obtain the optimal configuration of a vast number of possible solutions. The methodology development involved an analysis of variance to quantify the contribution of each parameter. In addition, an empirical model for NOx prediction was developed, under the assumption of independency of the parameters. Assumption that was tested by means of validation experiments. 


\section{CHAPTER 2 LITERATURE REVIEW}

Emission control can be performed by means of numerous engine parameters; for instance, those affecting the fuel injection characteristics, such as nozzle geometry (cone angle, hole size, number of holes) or multi-injection parameters (number of injections, dwell between injections, amount of fuel first injected); boost pressure, EGR flow rates and parameters that describe the combustion chamber, such as piston bowl shape, compression ratio, surface-to-volume ratio and swirl ratio [10].

Only four parameters were used, in this work, to develop engine calibrations capable of optimizing the aftertreatment performance. The EGR rate, boost pressure, injection pressure and injection timing were selected and their impact on emissions and combustion process was studied.

\subsection{Impact of Engine Parameters on Emissions and Combustion}

\subsubsection{EGR Valve Position}

EGR valve is mainly employed to perform NOx reduction; it does so by lowering the peak temperature of the combustion flame. The EGR valve can easily be controlled by the ECU and affects the EGR flow rate. The increase of EGR flow rate is accompanied by many drawbacks that need to be considered during the engine development. It is observed an increase in the insoluble fraction of PM, and this is caused by a drop in soot oxidation rate. The latter occur due to the displacement of a portion of the inlet oxygen by the exhaust gases. The increase of EGR rates leads to higher levels of $\mathrm{CO}$ and $\mathrm{HC}$; additional drawbacks are fuel economy penalty, potential engine wear and durability issues [11].

The EGR flow is also affected by boost pressure, which can be controlled by the position of the VGT vanes. 
EGR Effects on Flame Temperature: As stated above, EGR reduces NOx mainly by lowering the combustion flame peak temperature. This effect can be decomposed into four distinct components (see Figure 1) [12-15]:

1. Dilution effect: Diluting the intake charge air by means of exhaust gases has the effect of reducing the mass fraction of oxygen in the combustion chamber. Furthermore, replacing air with exhaust gases changes the average properties of the reacting mixture. Most of the NOx reduction is affected by means of the dilution effect $[16,17]$. The main combustion reaction occurs in the region of the flame where stoichiometry prevails; upon dilution, the shape and size of the flame adjusts so that the stoichiometric conditions are preserved (Figure 2). Some researchers believe that the "broadening out" of the combustion flame, due to the dilution effect, is the main mechanism of the flame temperature reduction [18].

2. Thermal effect: EGR acts as a heat sink, since it allows for an increase in average specific heat capacity of the intake charge. $\mathrm{CO}_{2}$ and water, present in the exhaust gases, each have a higher specific heat than air. $\mathrm{CO}_{2}$ does not contribute significantly to raise the heat capacity of the mixture, even though it has a considerably higher heat capacity than air $(1.24 \mathrm{~kJ} / \mathrm{kg}$ versus $1.16 \mathrm{~kJ} / \mathrm{kg}$, at 1000 $\mathrm{K}$ ); the amount of $\mathrm{CO}_{2}$ in $50 \% \mathrm{EGR}$, for instance, contributes only to $0.5 \%$ increase in the overall specific heat. The thermal effect is higher, instead, for the water vapor; its heat capacity is significantly higher than air $(2.56 \mathrm{~kJ} / \mathrm{kg}$ versus $1.16 \mathrm{~kJ} / \mathrm{kg}$, at $1000 \mathrm{~K}$ ). Therefore the specific heat of the mixture rises by $3.6 \%$ with the water content in 50\% of EGR [11] (see Figure 3). The amount of heat absorbed can also be maximized by increasing the temperature gradient between hot chamber and burned gases; this can be done, for instance, by cooling the burned gases. Cooled EGR is particularly beneficial when high engine loads are involved. Cooling the EGR flow leads to less fresh air being displaced, therefore, the $\mathrm{A} / \mathrm{F}$ ratio is less penalized and more capable of sustaining the combustion; hence, better combustion efficiency [2]. On the other hand, the cooling of the EGR gases is not always desirable, such as for idle condition or in cold weather application, where the temperature could be close to the dew point; in such a case, 
indeed, condensation may occur, and the condensate mixed with exhaust gases may produce sulfuric acid.

3. Added mass effect: higher EGR rate increases the mass flow, which brings about an additional heat capacity due to the increased mass.

4. Chemical effect: a portion of the heat released during the combustion process is adsorbed by the dissociation of $\mathrm{CO}_{2}$ and $\mathrm{H}_{2} \mathrm{O}$.

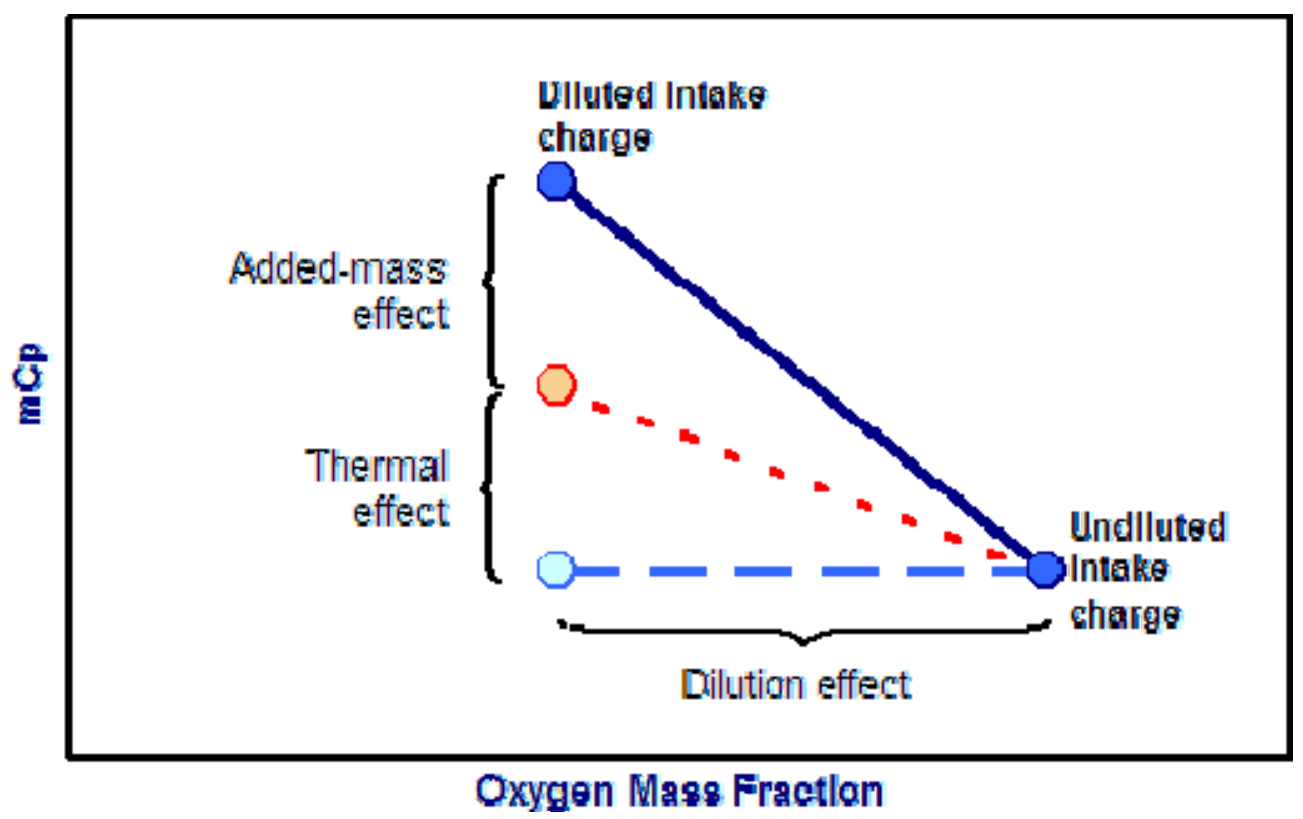

Figure 1: EGR effect on intake charge heat capacity [11]

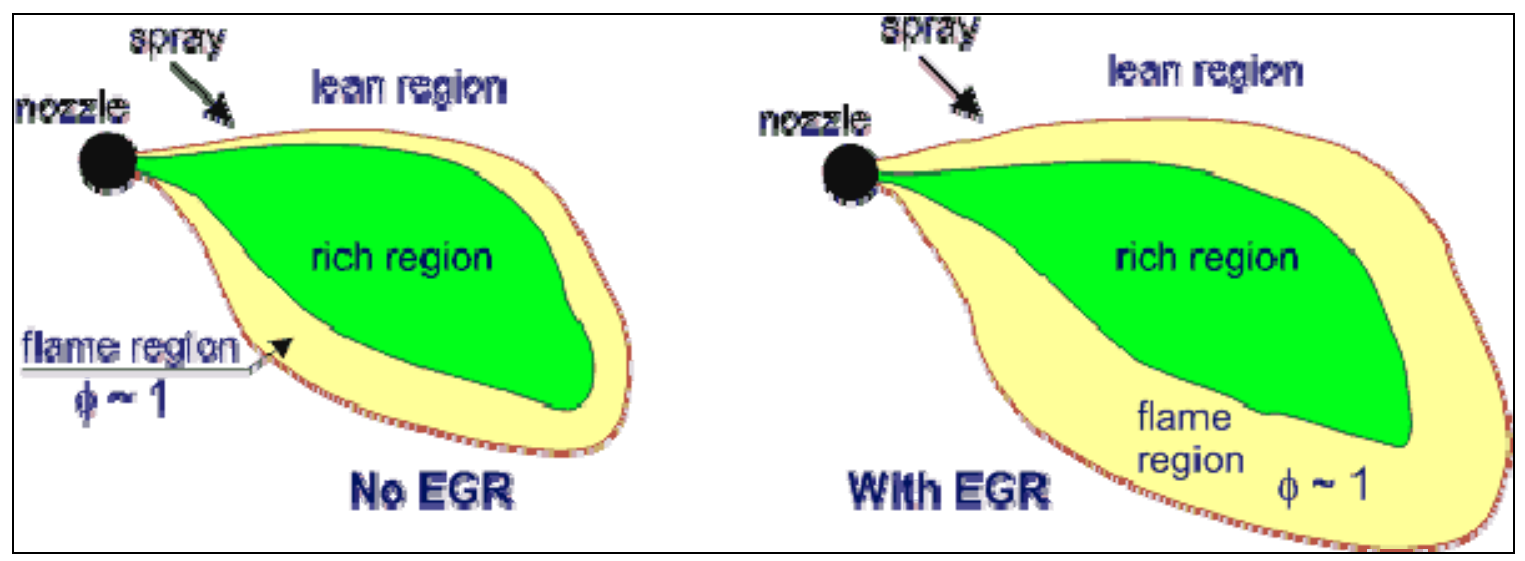

Figure 2: EGR effect on the combustion flame shape [11] 


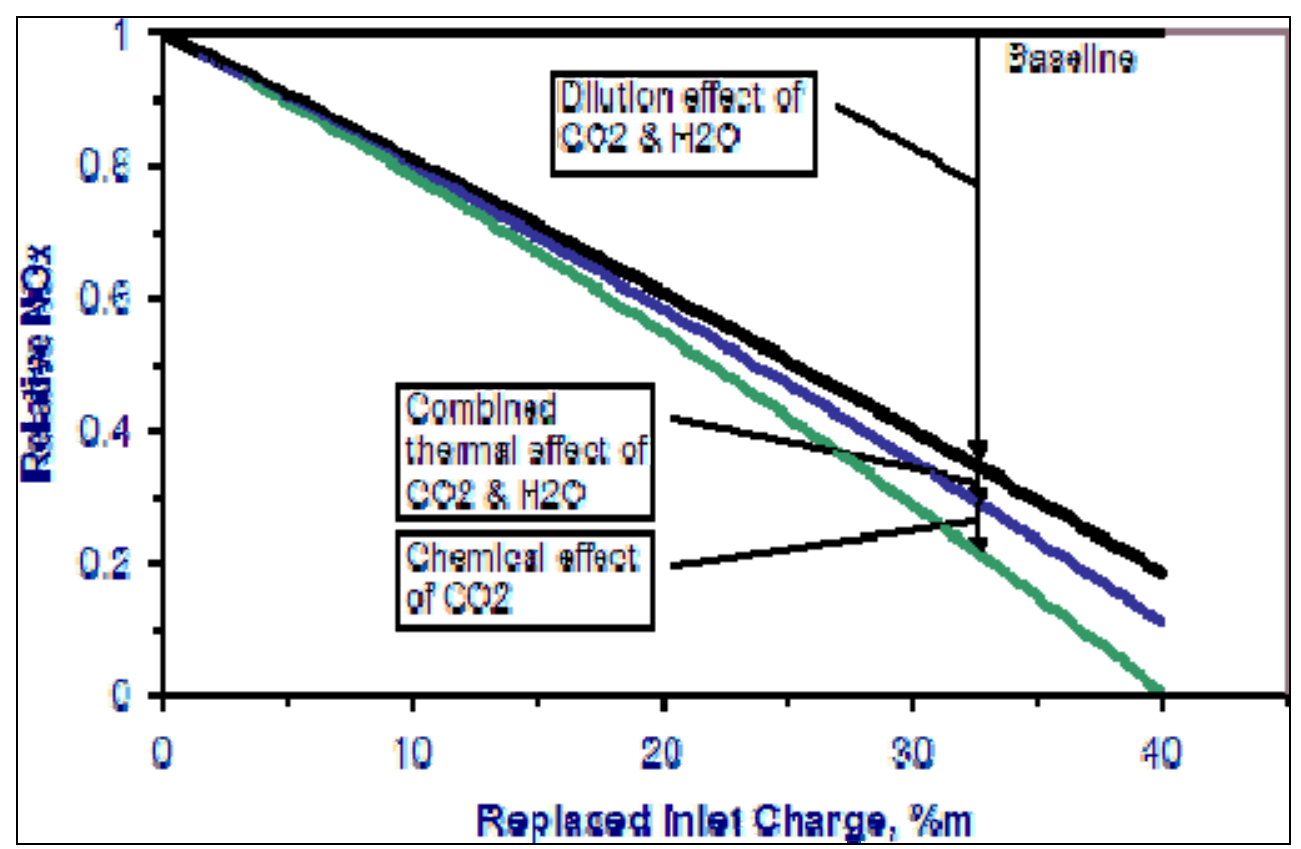

Figure 3: EGR effect on NOx reduction [11]

Effect of EGR on Emissions and Combustion Process: EGR is a widely used means of NOx control, but at the same time has the counter effect of increasing $\mathrm{CO}_{2}, \mathrm{HC}$, $\mathrm{CO}$ emissions and intake temperature. A small increase in NOx at higher EGR rates is observed for low loads, which could be probably related to the longer ignition delay.

EGR may also be used as a means of exhaust temperature control, thus benefiting especially applications involving exhaust aftertreatment [19]. For high loads and for non cooled EGR, the exhaust temperature was found to be higher when higher EGR rates were applied [20].

Cooled EGR, instead, allows greater intake charge mass, thus decreasing the peak of combustion temperature and lengthening the ignition delay. NOx is reduced because the first two effects outweigh the third [21].

PM, instead, increases due to a drop in soot oxidation rate, because the combustion temperature is significantly lowered by the oxygen displacement. EGR particles act as nuclei for new particles to agglomerate and form larger particles. The portion of PM which is mainly affected is the insoluble fraction, whereas the soluble fraction remains almost unchanged [22]. EGR represents a preferred means of NOx 
reduction over retarded injection, since it exhibits better NOx-PM trade off at similar level of FC [23].

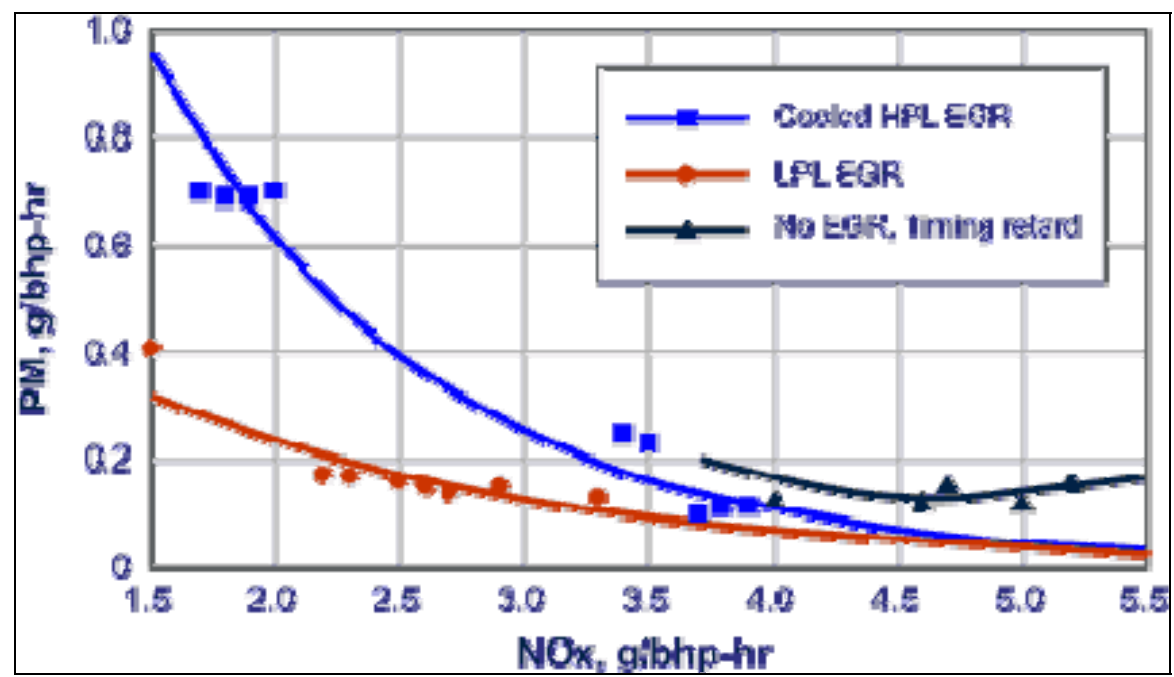

Figure 4: EGR and retarded injection effect on NOx-PM trade off [11]

The effect of EGR rates can be visualized by the changes in the shape of the heat release curve. For low load, for instance, the maximum rate of heat release increases as more EGR is provided; on the other hand, for high load the maximum rate of heat release is lowered as EGR is raised.

Moreover, high EGR rates are typically associated with peaks of premixed combustion, and higher volumes of EGR leads to longer ignition delay and combustion duration [24]; the latter determines is the cause of higher value of FC. The amount of EGR though is limited by the turbine inlet temperature, fuel consumption, compressor inlet vacuum and smoke opacity limits.

EGR Cooler: cooling the exhaust gases provides higher EGR heat absorbance, thus better combustion efficiency, since colder exhaust gases displace less oxygen. On the other hand, the EGR cooler efficiency can be easily compromised, "cooler fouling", by deposition of PM and condensation of HC; the cooler inefficiency is another limiting factor to the amount of EGR in the calibration.

EGR Configurations: The intake manifold pressure has to be lower than the exhaust pressure for the exhaust to recirculate, and this is one of the challenges that EGR system designers have to face, especially in case of exhaust gases being routed to the 
intake directly from downstream of the turbine. The "high pressure loop" configuration (see Figure 5), on the other hand, extracts high-pressure exhaust gases from upstream of the turbo-charger [22].

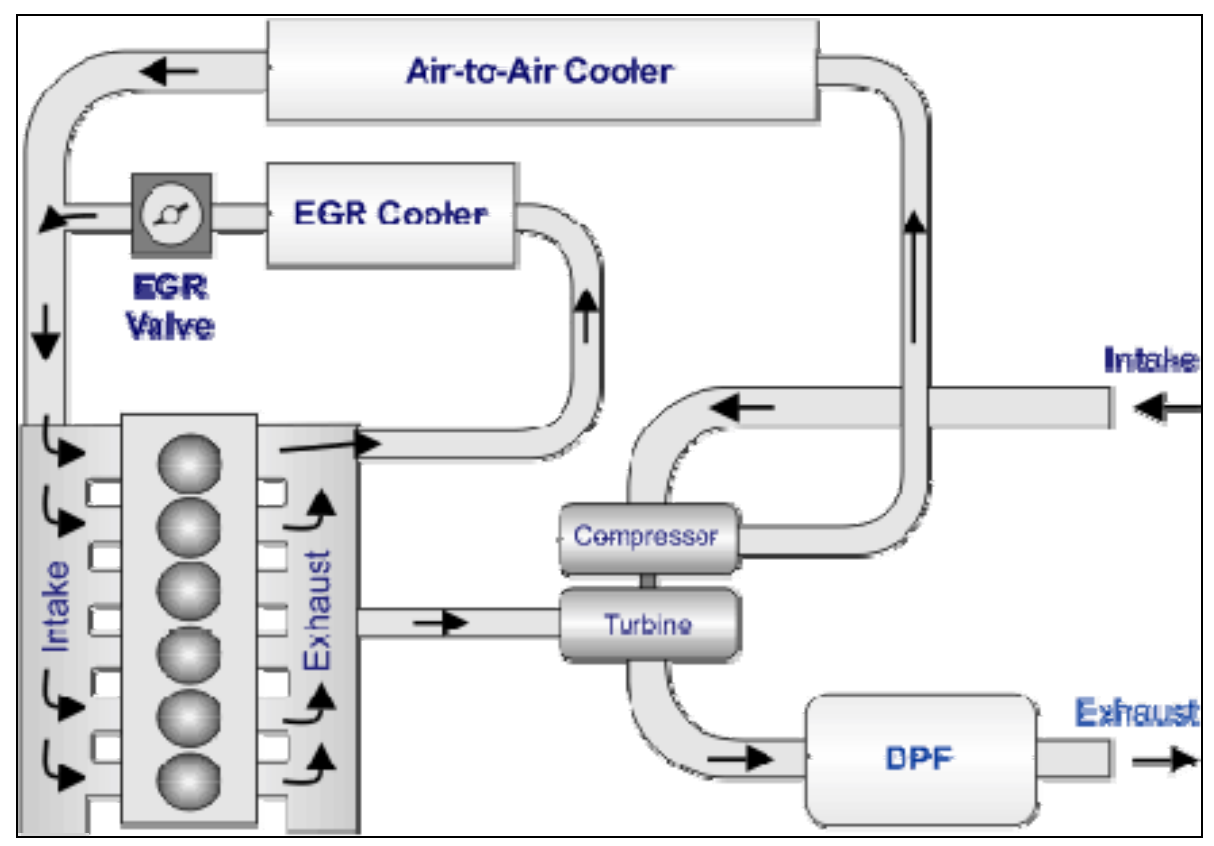

Figure 5: EGR, high pressure loop [11].

For this configuration the pressure gradient across the engine, responsible for the EGR flow, results from the difference between the intake and the exhaust manifold pressure; intake throttling, exhaust restrictions and venturi devices are means to control this pressure gradient $[25,26]$. However, this configuration leads to an increase in FC and PM emissions.

In the "low pressure loop" configuration the exhaust stream is intercepted downstream of the DPF and returns to the intake after being mixed with inlet air [11]:

- Advantages: Lower FC due to improved turbocharger performance; better engine durability, since the exhaust gases are filtered before returning to the intake; enhanced EGR heat capacity, due to the fact that the EGR temperature is lower, since the exhaust gases are collected downstream of the turbine. These factors allow for EGR cooler smaller in size and at better efficiency level. 
- Disadvantages: Even though the exhaust stream is filtered, carbon particles may still collect onto the intake walls and possibly cause corrosion of the compressor wheel. Moreover, unburned fuel from inefficient combustion could collect in the manifold ducts and convert into $\mathrm{CO}$ at high temperatures; thus, further lowering the efficiency of the combustion.

EGR Control Strategies: In order to keep good engine performance, good fuel economy and low levels of PM throughout the various engine operations, the EGR should be turned off during acceleration or idle, and significantly reduced near full load [27]. During full load the temperature and the exhaust flow rate are fairly high; increasing EGR would lead to higher intake temperatures, which may lead to even higher exhaust temperatures, if the EGR is not cooled enough; this may cause the turbine to burst.

NOx reduction can still be performed by means of EGR if VGT provides additional air; hence, the drop in $\mathrm{A} / \mathrm{F}$ ratio coming from higher EGR rates, can be restored by a higher level of VGT, thus resulting in better combustion quality. Inputs to EGR control are exhaust temperature, EGR flow, intake manifold temperature and pressure; exhaust backpressure, EGR valve position and mass air flow are additional input parameters that should be considered [27]. For a more advanced EGR control, a lean $\mathrm{O}_{2}$ sensor, boost pressure and SOI signal can be included as well (Figure 6).

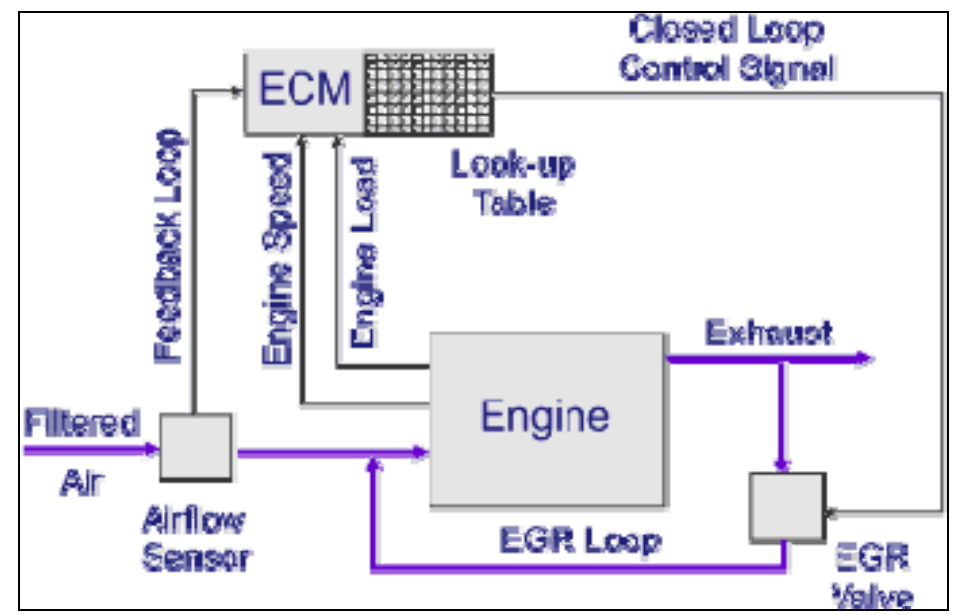

Figure 6: Closed loop control with look up table and air flow feedback variable [27] 


\subsubsection{VGT Position}

Turbochargers are engaged mainly to enhance the power output by increasing the air capacity. Inside the compressor, the filtered air flow makes a 90 degree turn on the impeller, from axial to radial direction, and diffuses into the housing and then into a collector at variable cross-sectional area [28,29]. The impeller blades are typically made of aluminum and are designed to minimize the turbulence between consecutive channels. The purpose of the compressor is to increase the air pressure, but results in simultaneous increase in intake temperature, thus a reduction in air density; therefore, in order to restore the air density drop an intercooler can be used.

The turbine wheel, which is typically made of nickel, exploits the energy content of the exhaust blowdown to drive the compressor. The turbine performance can be increased if the pulsations coming from the exhaust valves are dampened by a large connecting duct between the exhaust manifold and the turbine inlet. Among the major drawbacks of the turbochargers are the engine-turbo mismatch and the turbolag. The mismatch is mainly due to the fact that, while for a diesel engine the air demand is proportional to the power output, the output of a turbocharger is an exponential function of power. The turbolag instead, is the time lapse between the demand of power from the driver and the actual delivery of additional air by the compressor. In the effort to overcome the inherent turbocharger limitations and to achieve constant charge air pressure, the turbocharger technology has upgraded and variable geometric turbochargers have populated the market. VGT provides a variable boost pressure at the engine intake by converting the thermodynamic energy of the exhaust gases into kinetic energy of the compressor wheel.

Figure 7 shows the VGT housing, variable angle vanes and the adjusting ring respectively as component number 1,2 and 3 in the picture.

Boost pressure can be used by the engine control to optimize the $\mathrm{A} / \mathrm{F}$ ratio. If lower energy is available in the exhaust gases (low load, low speed) the flow area between two consecutive vanes is reduced by the variable geometry of the turbocharger; thus, providing more charge air into the cylinders [30]. 


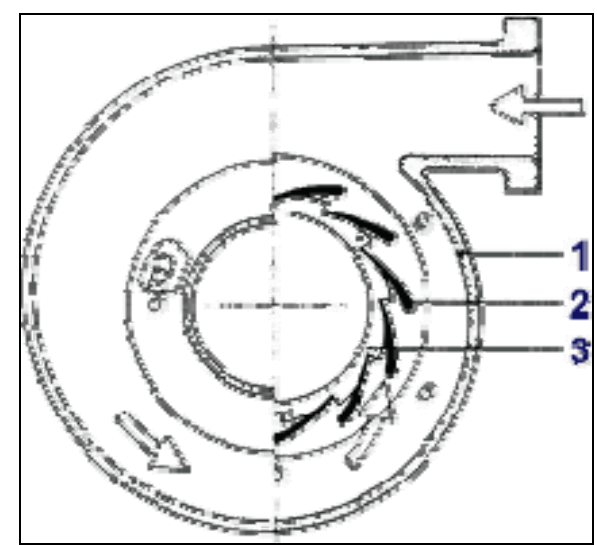

Figure 7: Variable angle vanes in the VGT [30]

Conversely, when high energy levels are present in the exhaust gases, the VGT modifies its geometry so that little of the available potential energy is exploited to increase the compressor speed; hence, the charge air, that otherwise would have distorted the injector spray pattern, is reduced, thus lowering the combustion efficiency [29,30].

Within the zone of low engine speed and full load, under the lug curve, VGT can compensate for the lack of charge air that would lead to excess of smoke production.

The VGT is more convenient than a well matched turbocharger at fixed geometry in zones of low speed-low intake pressure.

Control EGR Flow: The VGT can also be employed to control the pressure gradient between exhaust and intake manifold pressure, which is responsible for the EGR flow. Therefore, VGT is not just a means of engine power output control, but also a very effective means of emissions control. To vary the EGR flow rate, EGR valve position and VGT can be simultaneously changed; for instance, EGR targeting the air flow rate and VGT controlling the boost pressure. The EGR valve can be responsible for the majority of EGR flow rate control and the VGT can be used mainly for operating-point adjustments. Otherwise, both EGR and VGT can be used to produce the desired EGR level, taking into consideration the cross-influence between the EGR-boost pressure control loops [31]. Furthermore, the combination of EGR and VGT can be successfully used to keep the A/F ratio above designated thresholds [27] 


\subsubsection{Injection Timing}

Start of injection (SOI) is another well known means of emissions control. Retarding injection timing has been, in the past, a widely used technique of NOx reduction. The reduction of in-cylinder pressure, as a result of retarding the injection event, is the main cause of NOx emissions [32]. Inevitably this approach leads to undesired consequences. By reducing the peak pressure in the combustion chamber cycle work, the area between the combustion and compression pressure curves in Figure 8 is reduced, and to compensate for this loss more fuel is injected in order to deliver the requested work; this additional amount of fuel represents a fuel consumption penalty.

Lower combustion temperature is obtained as a result of retarding the injection, thus affecting the rate of the chemical reactions responsible for the combustion process [33]. Advancing the injection, instead, has the effect of increasing the ignition delay, because fuel is injected at lower pressure and lower temperature.

Higher ignition delay allows more fuel to be injected and better mixing of fuel and air. Therefore, the premixed portion of combustion is greater [34], and this leads to higher NOx and higher HC [35]. Cooling the intake charge affects the in-cylinder pressure in similar ways, but the actual magnitude of the impact is much smaller [9].

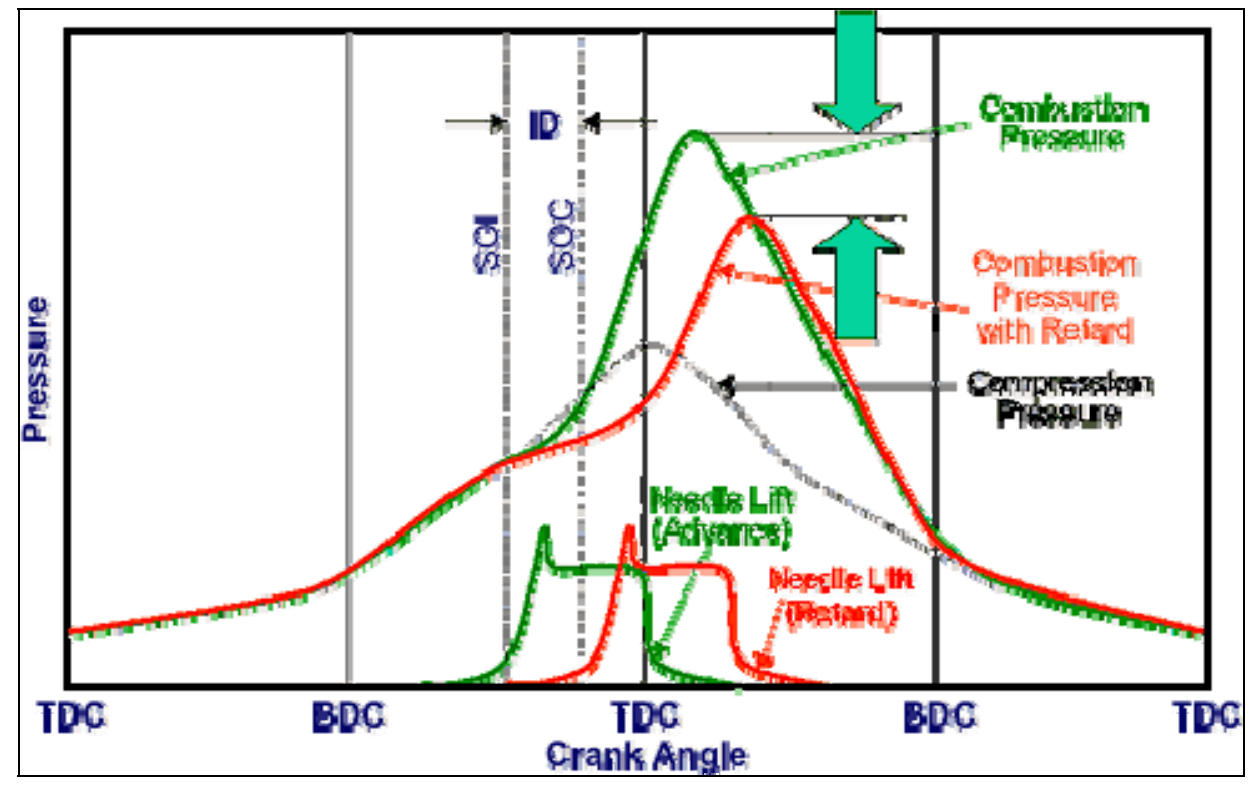

Figure 8: Injection timing retard effect on in cylinder pressure [9] 


\subsubsection{Injection Pressure}

There are many ways to increase injection pressure, and to offer a desired pressure level at the various engine operating conditions: Nozzle Opening Pressure (NOP), Nozzle Closing Pressure (NCP), pilot injection, late injection, multiple injection and rate shaping [36]. In this study NOP was selected as a means of varying injection pressure. Most of the technologies employed to reduce NOx emissions carry with them a fuel consumption penalty, which is due to loss in the work cycle. A recovery of this loss can be performed by raising the injection pressure [9].

Higher injection pressure leads to a better air-fuel mixing, which in turn favors a reduction in soot production [37]. As a matter of fact, soot formation is strictly dependent on the air-fuel mixing and chemical kinetics. Better fuel atomization, due to the increased level of injection pressure, is the main cause of faster air-fuel mixing. This translates into a shorter fuel rich mixture residence time, which ultimately leads to soot reduction [33].

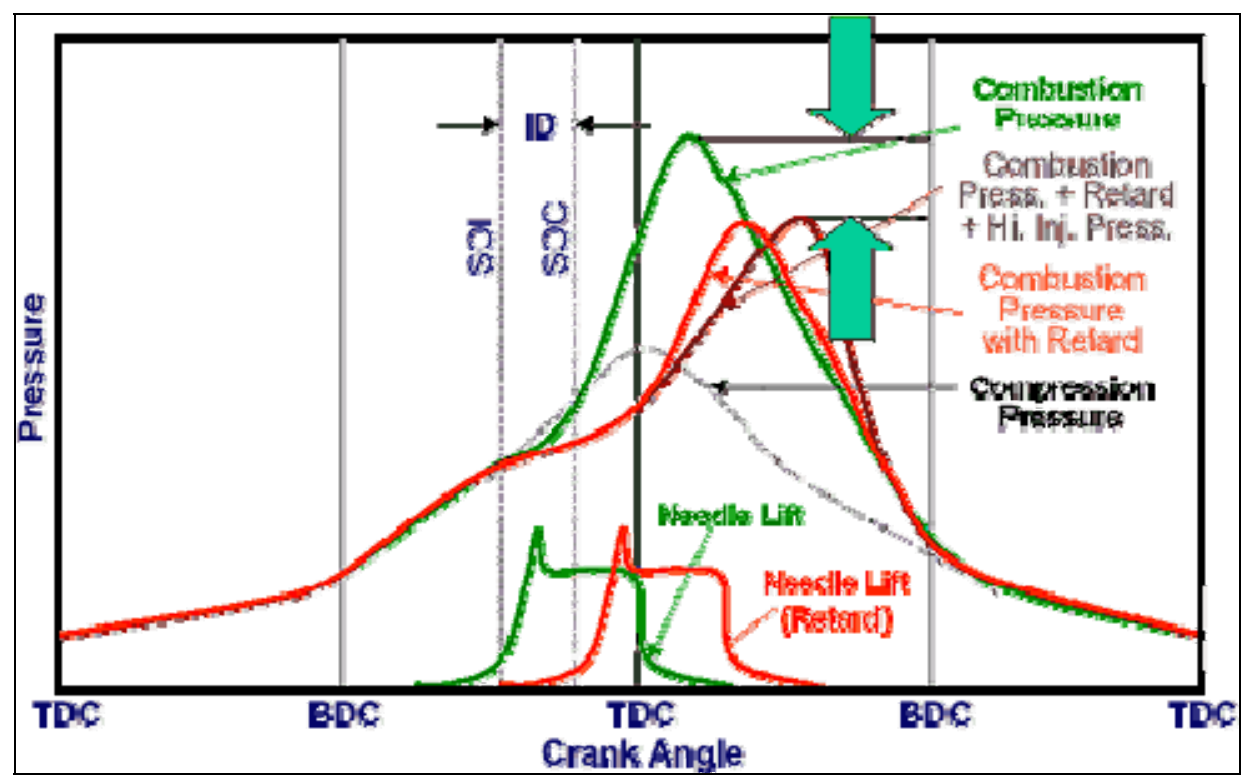

Figure 9: Injection pressure effect on in-cylinder pressure [9]

The newer engines equipped with advanced electronic actuated injectors are capable of providing high injection pressure independently of engine load and speed, whereas with older injection systems the injection pressure peak was generally a function of injection 
duration, cam lift and cam rate [33]; hence, one of the advantages of the modern injection systems is the capability of providing high pressure at low engine speed (see Section 3.3).

Effect of NOP on the Combustion Process: The combustion process can be decomposed into a physical and a chemical component. The former entails all the physical mechanisms that have a direct effect on combustion, such as fuel atomization, evaporation of fuel droplets and mixing of air and fuel. The chemical process, instead, is represented by the reactions occurring within the combustible mixture of fuel-air. These reactions are strongly dependent upon the in-cylinder temperature. If NOP is increased, the physical process is improved, since it leads to a better atomization, faster evaporation and increased rate of fuel-air mixing; all these factors cause a reduction of the ignition delay [33]. A rise in NOP leads to an increase in injection pressure, which results in peaks of premixed and diffusion combustion; combustion duration, on the other hand, is reduced and the overall combustion process is enhanced regardless of the load.

In premixed combustion (see Figure 10), the fuel mixes with air prior to the combustion event and forms a combustible mixture that quickly burns during the ignition delay. The fuel is atomized, fully evaporated and well mixed with air. When autoignition takes place the mixture burns quickly, raising the temperature and the pressure in the combustion chamber. This phase is more pronounced for low load conditions. The diffusion-like combustion is mainly controlled by fuel-air mixing rate. The rate with which the fuel, injected after the ignition, mixes with air dictates the burning rate. Lower heat release peaks are observed for this type of combustion. 


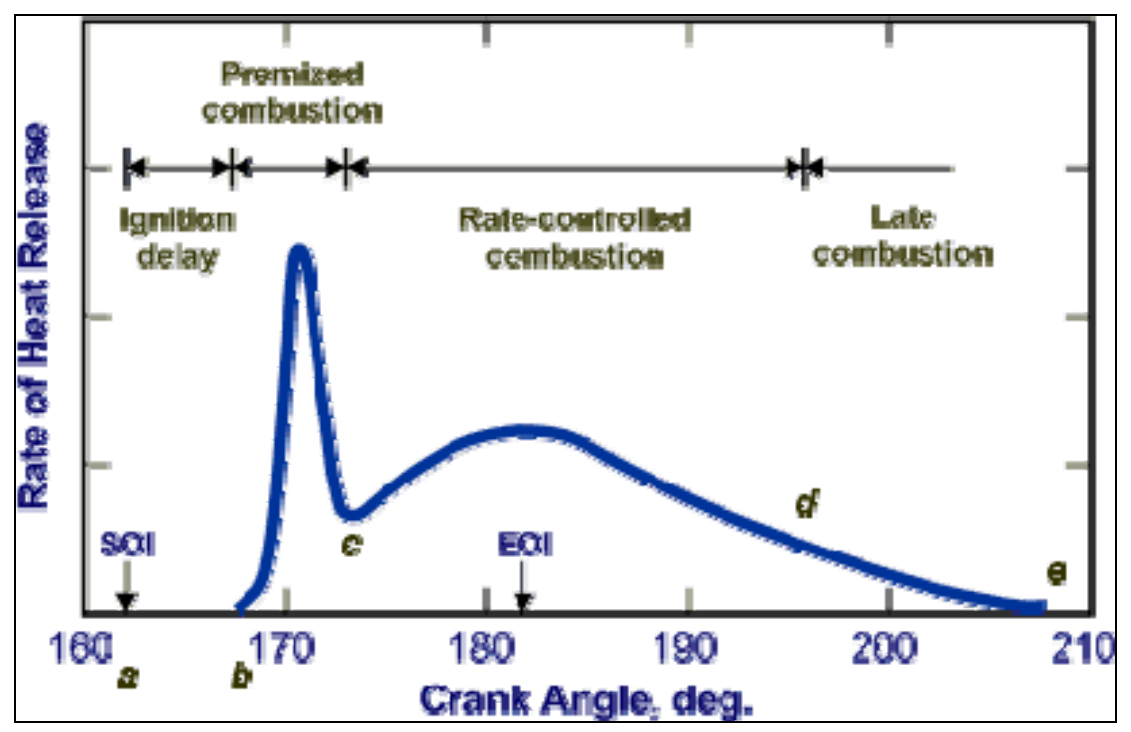

Figure 10: Phases of diesel combustion [38]

At low loads, higher values of NOP lead to higher premixed phase. Even though the ignition delay is shortened and the time for physical and chemical reactions is reduced, the increased pressure enhances the air-fuel mixing, thus the physical reaction is accelerated. For medium loads instead, an increase of NOP favors diffusion-type combustions.

If the injection pressure is plotted against crank angle, it exhibits a rising profile, which means that the main part of the fuel is injected at the end of the injection event, at high pressures; as NOP increases, the classical injection pressure profile converts into a dropping profile, where this time the main part of injection occurs at the beginning of the injection event, at high pressure; the remaining fuel instead, is injected at lower pressure. Moreover, as NOP increases, the needle lift profile is shortened (Figure 11), the injection pressure peak increases and the curve shifts towards the nozzle opening event. Its peak substantially increases due to the higher needle opening pressure [33]. 


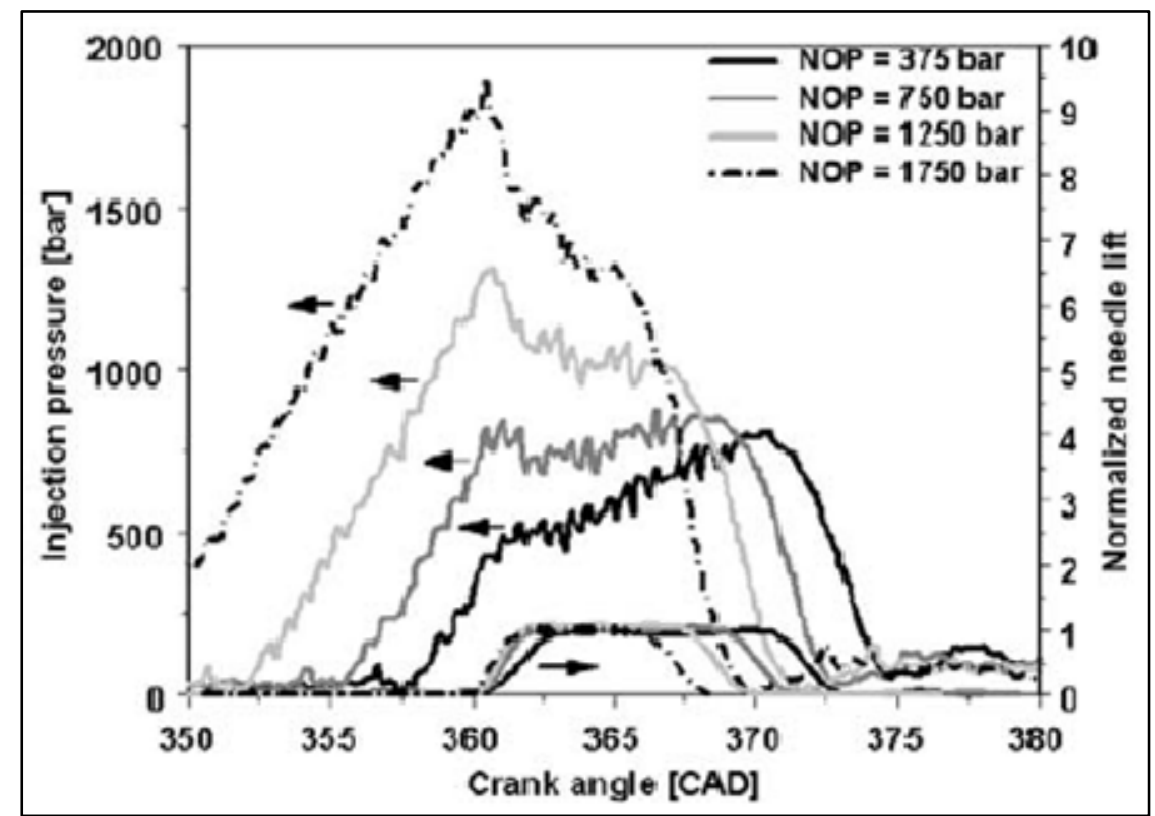

Figure 11: Effect of NOP increase on injection pressure curve [33].

The four engine parameters discussed above were varied in this work over different levels to achieve the low-NOx and low-FC calibrations for SCR applications.

\subsection{Emission Reduction Strategies}

A very attractive engine calibration for SCR applications is the low-PM that typically is a fuel efficient calibration (low-FC) (see Figure 12). It can be implemented by advancing injection timing and increasing injection pressure. Compared to the calibrations, which are based mainly on EGR technology, it is more fuel efficient, but produces a higher level of NOx. However, the increased engine-out NOx levels can be compensated by means of an SCR catalyst. It has been demonstrated that Euro V levels $(\mathrm{NOx}=2 \mathrm{~g} / \mathrm{KWh})$ can be achieved when this approach is applied to engines with Euro IV technology $(\mathrm{NOx}=3.5 \mathrm{~g} / \mathrm{KWh})$. With an SCR conversion efficiency of $80-85 \%$, the Euro $\mathrm{V}$ emissions target can be still met even with NOx higher than the EURO IV levels [39]. Reaching the US-2010 NOx standards from the US-2004 levels, instead, requires NOx conversion efficiency to be higher than $90 \%$. For this emissions target the SCR may not have the capability to handle the extra NOx coming form a fuel efficient calibration [40]. But, the US 2010 NOx standards can be attained if an improvement in SCR efficiency is achieved. Improving the mixing of urea with exhaust gases, redesigning the urea dosing 
strategy, controlling the $\mathrm{NO}_{2} / \mathrm{NO}$ ratio are possible means of SCR efficiency optimization. Due to the severe demands on the SCR performance, it is necessary to consider EGR as an additional de-NOx control strategy. Combined SCR and EGR technologies have proved to offer promising results in meeting the legislated emissions levels [41]. EGR technology, for instance, could be essential when dealing with low temperature conditions, since it can provide an effective means of NOx control in the occurrence of SCR deactivation [42].

Cost is another critical factor in the decision process regarding the selection of a calibration. Low-PM is a fuel efficient calibration and even though the fuel saving is offset by the cost of urea consumed, it still provides a more convenient solution than the one offered by the EGR-based calibration, not to mention the engine-deterioration effect from heavy EGR rates (Figure 13).

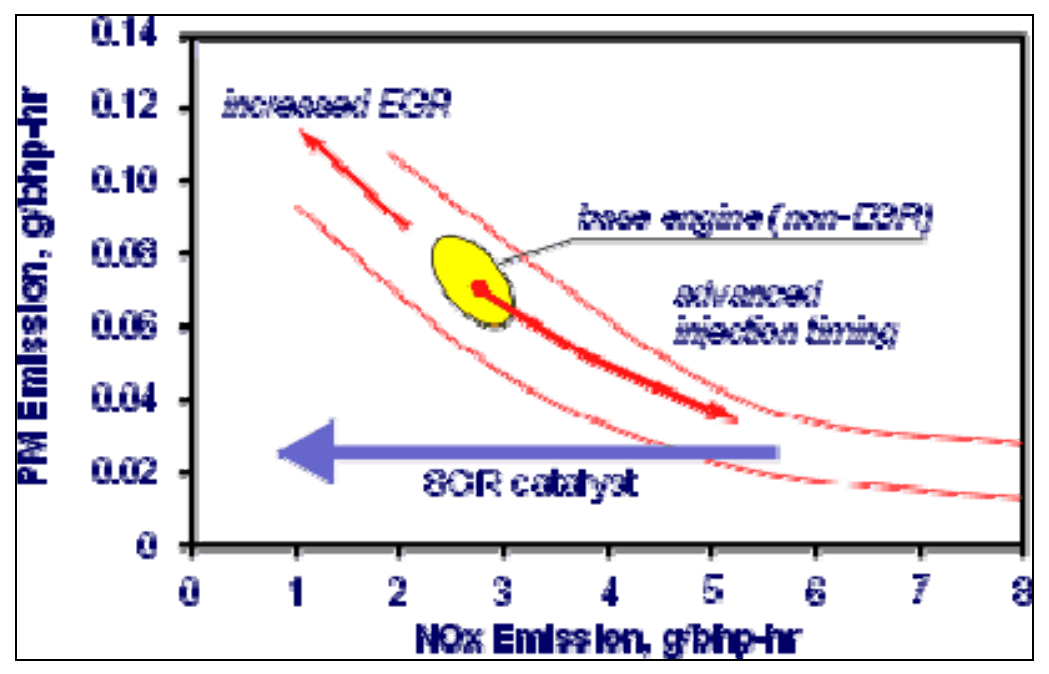

Figure 12: Low-PM calibration for SCR application [6] 


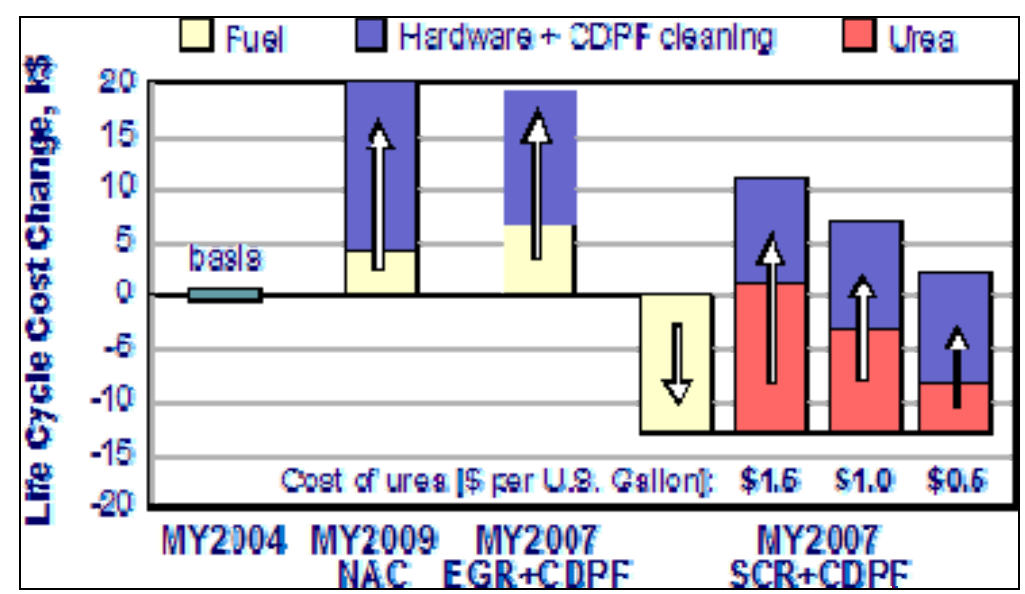

Figure 13: Aftertreatment technologies comparison on the basis of their cost of operation [6]

\subsubsection{Low-NOx Calibration}

NOP and EGR Variation: To obtain the low-NOx calibration NOP and EGR flow were increased simultaneously. This emission reduction approach has been engaged successfully by many European HDDE manufactures to meet the EURO IV standards. The strategy consisted in providing an injection pressure as high as possible for high loads and EGR rate as high as possible for low loads (see Figure 14).

The advances in the modern injection pressure systems offer great potential for emission reductions, especially for engines equipped with EGR. It is believed that an increase in injection pressure correlates with premixed combustion and high in-cylinder temperature; hence, high NOx emissions [24,43]. To compensate for the higher NOx levels EGR could be employed, rather than injection retard, with less impact on the cycle efficiency. The NOx reduction will then come from the combination of high NOP levels and high rates of EGR, the latter being mainly limited by the soot level in the engine oil [27]. 


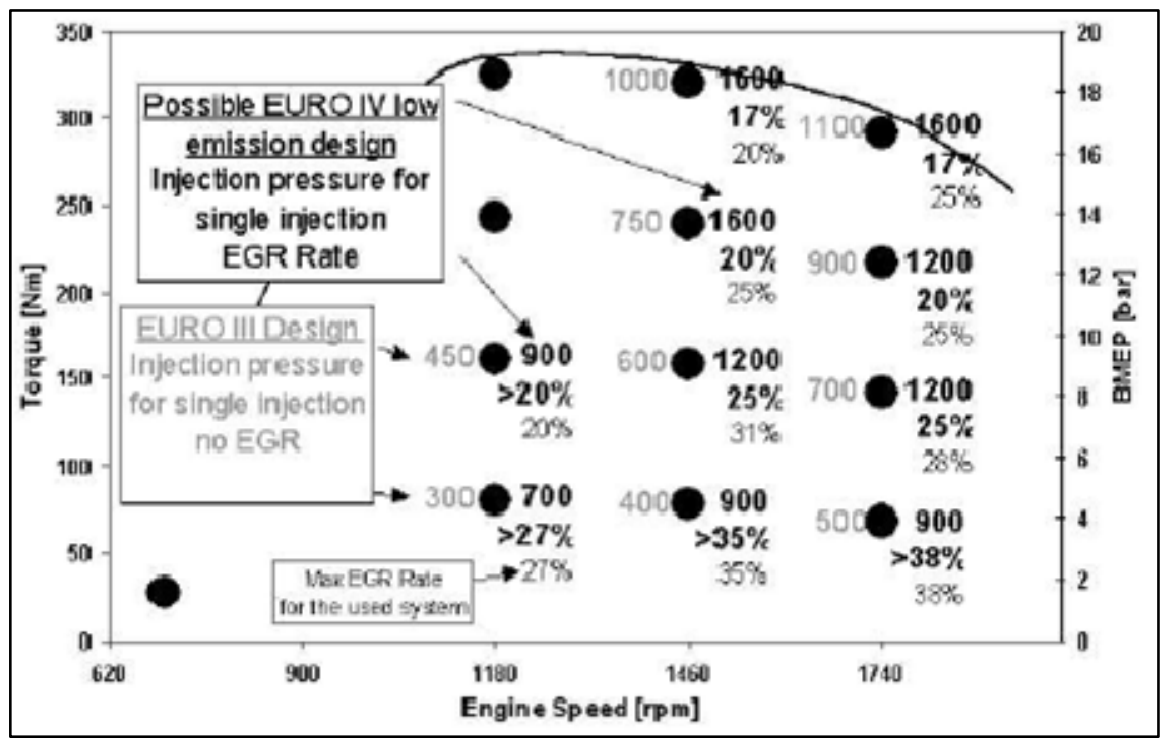

Figure 14: Emission reduction strategies (EURO III, EURO IV) [24].

The high value of NOP compensates for the fuel economy penalty, and reduces the risk of engine components wear. By increasing injection pressure, indeed, it is possible to keep the BSFC low even for high EGR rates; high EGR rates would typically increase the combustion duration, which, instead, is shortened by the higher injection pressure [33, 44].

NOP and SOI Variation: In case the start of combustion occurs after the TDC, a reduction of NOx can be achieved by retarding the fuel injection. The retarded injection timing shifts the combustion event further down from TDC in the exhaust stroke, inducing lower combustion temperatures and penalizing the cycle efficiency. Things could be adjusted if NOP is increased; high NOP shorten the ignition delay and brings the combustion event closer to the TDC, thus guaranteeing higher quality of combustion [36, 45].

NOP and VGT Variation: Varying VGT, as NOP is increased, provides positive outcomes especially during transient conditions. The sudden demand of higher load induces more fueling and the consequently increase in boost pressure might occur with a certain delay (turbolag). During this time a temporary increase in NOP value can be used to avoid soot production until the boost is restored [36]. Another way to minimize the effect of the turbolag consists in supplying more charge air in correspondence to sudden 
acceleration by means of the VGT. The ECU can be programmed to provide this additional air even before the onset of the acceleration event.

\subsubsection{Urea Consumption Trade-off}

The cost of urea partially offsets the fuel saved by engaging a fuel efficient calibration. The use of SCR as a de-NOx technology raises doubts about the impact on FC of the urea consumption during the engine operation. Some studies have reported that approximately $0.9 \%$ of the $32.5 \%$ urea solution is consumed per gram of NOx reduced when 1 bhp-hr of work is produced during an FTP test [46]. A demonstration on a US class-8 highway truck has exhibited a fuel consumption of $5.2 \mathrm{mpg}$, and a urea consumption of $94 \mathrm{mpg}$ [47]. Urea consumed has been estimated to be $3 \%$ by volume ( $4 \%$ by mass) of the fuel consumed.

\subsection{Optimization Technique}

The vast number of engine parameters responsible for diesel combustion and the complexity of their interactions make the engine development very time consuming [48]. Moreover, the use of sophisticated statistical tools has made the calibration work more complicated. This study proposes a methodology which employs design of experiments and statistical tools that is easy to implement, and based only on four engine parameters.

The adoption of the traditional "single parameter" approach (one parameter varies while all the others remain constant) to optimize an engine poses two major difficulties: the enormous amount of experiments that should be conducted, which increases with the number of factors, and the fact that the optimum value found may not remain as such when the parameters simultaneously change [10].

The advantage of using a design of experiment (DOE) approach, instead, is that only a few, among all the possible combinations of the parameter values, need to be tested in order to find the optimum engine setting with an acceptable precision level [49].

Furthermore, the engine deterioration during its useful life [10] requires highly reproducible results, which means solutions insensitive to factors change. The technique employed makes use of an orthogonal array, which considers the averaged parameter effects when the levels of the other factors are changing [2]. If a parameter has a non- 
negligible contribution even when the conditions of the other factors vary, then the parameter can be regarded as a reliable source. In such a case the result obtained has a good chance of being reproduced [50].

The technique makes use of ANOVA as a tool to quantify the magnitude of the parameter effects. ANOVA provides an indication of the contribution of each parameter to the response variation [3].

The optimization algorithm produces an empirical model which is accurate under the assumption of additivity of the parameter effects. This model assumes that the "total effect of several factors is equal to the sum of the individual factor effects" [50]. Such a model was used to predict NOx and FC for different engine calibrations.

\subsubsection{Design of Experiment Techniques}

The Design of Experiment (DOE) has encountered great success during the last century. The Degree Of Freedom (DOF) is an important tool to judge how many experiments are needed and to understand the amount of information that can be extracted from them. It gives an indication of the efficiency of the DOE [51].

Consider " $\mathrm{n}$ " as the number of factors, "l" as number of factor levels, " $y$ " as number of combinations or runs. The DOF associated to the " $y$ " experiments is given by:

$$
D O F_{\text {exp }}=y-1
$$

The objective is to gain enough information from experiments conducted so that the factor effects can be evaluated. The DOF associated to the factor effect is:

$$
D O F_{f a c}=n \times(l-1)
$$

To describe the efficiency of a set of experiments in providing enough information to evaluate the factor effect, the following parameter can be used:

$$
E f f=\frac{D O F_{f a c}}{D O F_{\text {exp }}}(100 \%)
$$

A DOE can be designed according to the following approaches:

1. Build-test-fix

2. One-factor-at-a-time

3. Full factorial

4. Orthogonal array 
The build-test-fix approach is very time consuming and intuitive; it does not allow to understand how the solution is close to the optimum.

The one-factor-at-a-time approach is more traditional and is often engaged in scientific research and in engineering applications. It consists of fixing all the factors except the one under investigation (see Table 1). The biggest drawbacks of this method are that it is time consuming and does not account for the effect of simultaneous variation of the other factors; therefore, it is not possible to guarantee that the optimum solution found through this approach will still hold when all the other parameters are subjected to simultaneous variation. In this case the DOF needed to estimate the factor effects and the ones available from the experiment are the same:

$$
D O F_{\text {factor }}=7 \times(2-1)=7, D O F_{\text {experim }}=8-1=7
$$

Therefore, the method is efficient in extracting enough information about the effect of parameter variation from the experiments. However, since the array is not balanced, the results can be deeply altered by the presence of interactions [51].

Table 1: Single-parameter-at-a-time approach, 7 factor and two levels [51]

\begin{tabular}{|c|c|c|c|c|c|c|c|}
\hline Run & A & B & C & D & E & F & G \\
\hline $\mathbf{1}$ & 1 & 1 & 1 & 1 & 1 & 1 & 1 \\
\hline $\mathbf{2}$ & 2 & 1 & 1 & 1 & 1 & 1 & 1 \\
\hline $\mathbf{3}$ & 2 & 2 & 1 & 1 & 1 & 1 & 1 \\
\hline $\mathbf{4}$ & 2 & 2 & 2 & 1 & 1 & 1 & 1 \\
\hline $\mathbf{5}$ & 2 & 2 & 2 & 2 & 1 & 1 & 1 \\
\hline $\mathbf{6}$ & 2 & 2 & 2 & 2 & 2 & 1 & 1 \\
\hline $\mathbf{7}$ & 2 & 2 & 2 & 2 & 2 & 2 & 1 \\
\hline $\mathbf{8}$ & 2 & 2 & 2 & 2 & 2 & 2 & 2 \\
\hline
\end{tabular}

The full factorial approach, instead, explores all the possible combinations of the factor levels $\left(y=l^{n}\right)$ (see Table 2). In order to find the optimum of the response characteristic each " $y$ " experiment needs to be measured and analyzed. Furthermore, this method is based on the assumption that there are no other factors affecting the variation 
under investigation other than those which are purposely kept constant. For this approach, the DOF required to evaluate the factor effects are

$$
D O F_{\text {factor }}=7 \times(2-1)=7, D O F_{\text {experim }}=128-1=127
$$

This approach provides extra 120 degrees of freedom therefore is highly inefficient because it provides much more information than is actually needed. When the number of control factors and levels is high the amount of experiments becomes extremely large.

The orthogonal array approach, instead, consists in requiring only a small portion of the total combinations of the full factorial. Orthogonality here is intended in the sense that each factor effect can be determined independently and that no factor weighs more than the other during the experiment.

Table 2: Full factorial approach for $\mathbf{7}$ factors, 2 levels [51]

\begin{tabular}{|c|c|c|c|c|c|c|c|}
\hline Run & A & B & C & D & E & F & G \\
\hline $\mathbf{1}$ & 1 & 1 & 1 & 1 & 1 & 1 & 1 \\
\hline $\mathbf{2}$ & 1 & 1 & 1 & 1 & 1 & 1 & 2 \\
\hline $\mathbf{3}$ & 1 & 1 & 1 & 1 & 1 & 2 & 1 \\
\hline$\cdot$ & $\cdot$ & $\cdot$ & $\cdot$ & $\cdot$ & $\cdot$ & $\cdot$ & $\cdot$ \\
\hline$\cdot \cdot$ & $\cdot \cdot$ & $\cdot \cdot$ & $\cdot \cdot$ & $\cdot \cdot$ & $\cdot \cdot$ & $\cdot \cdot$ & $\cdot \cdot$ \\
\hline $\mathbf{1 2 6}$ & 2 & 2 & 2 & 2 & 2 & 1 & 2 \\
\hline $\mathbf{1 2 7}$ & 2 & 2 & 2 & 2 & 2 & 2 & 1 \\
\hline $\mathbf{1 2 8}$ & 2 & 2 & 2 & 2 & 2 & 2 & 2 \\
\hline
\end{tabular}


Table 3: Orthogonal array approach for 7 factors, 2 levels [51]

\begin{tabular}{|c|c|c|c|c|c|c|c|}
\hline Run & A & B & C & D & E & F & G \\
\hline $\mathbf{1}$ & 1 & 1 & 1 & 1 & 1 & 1 & 1 \\
\hline $\mathbf{2}$ & 1 & 1 & 1 & 2 & 2 & 2 & 2 \\
\hline $\mathbf{3}$ & 1 & 2 & 2 & 1 & 1 & 2 & 2 \\
\hline $\mathbf{4}$ & 1 & 2 & 2 & 2 & 2 & 1 & 1 \\
\hline $\mathbf{5}$ & 2 & 1 & 2 & 1 & 2 & 1 & 2 \\
\hline $\mathbf{6}$ & 2 & 1 & 2 & 2 & 1 & 2 & 1 \\
\hline $\mathbf{7}$ & 2 & 2 & 1 & 1 & 2 & 2 & 1 \\
\hline $\mathbf{8}$ & 2 & 2 & 1 & 2 & 1 & 1 & 2 \\
\hline
\end{tabular}

The array in Table 3 exhibits a balanced factor levels combinations; the same number of factor levels, for instance, appear in the first two columns and in column B when considering the first four rows at the same level [51]. For this approach the DOF required to evaluate the factor effects are

$$
D O F_{\text {factor }}=7 \times(2-1)=7, D O F_{\text {exper }}=8-1=7
$$

The experiments provide the number of DOF needed to estimate the factor effects; therefore, the method is efficient and moreover is balanced.

The analysis of means (ANOM) can be engaged to process the data collected through the DOE. ANOM involves the comparison of the average of the characteristic function of factors that are at the same level.

\subsection{Summary of the Literature Review}

Among the numerous engine parameters employed for emissions reduction the EGR valve was revealed to be a very effective means of NOx reduction. It achieves this by controlling the EGR flow rates, which are responsible for lowering the peak temperature of the combustion flame, hence resulting in lower NOx emissions.

Another engine parameter which affects the EGR flow rate is the VGT, by controlling the pressure gradient between exhaust and intake manifold pressure.

EGR valve position and VGT can be simultaneously used to vary the EGR flow rate, and ultimately to lower NOx emissions. For instance, the EGR valve can be 
responsible for the majority of EGR flow rate control and the VGT can be used mainly for operating-point adjustments. On the other hand, the higher EGR flow rate has the counter effect of increasing $\mathrm{CO}_{2}, \mathrm{HC}, \mathrm{CO}$ emissions and intake temperature. Higher PM levels, mainly the insoluble fraction, higher fuel economy, potential engine wear and durability issues are among the other drawbacks of using EGR as means of NOx reduction.

Another issue resulting from high EGR flow rates is the drop in the EGR cooler efficiency, by deposition of PM and condensation of HC. The cooler inefficiency is a limiting factor to the amount of EGR in the calibration.

Increasing the injection pressure can be a valid means to exploit the benefits of the increased EGR flow rate, while limiting its drawbacks. Higher injection pressure enhances the air-fuel mixing, and leads to soot reduction. Furthermore, higher injection pressures allow for recovery of the loss in work and fuel economy caused by the increased EGR flow rate.

To obtain very low NOx emissions, NOP and EGR flow can be increased simultaneously. Most of the newer engines are equipped with advanced electronic actuated injectors, which are capable of providing high injection pressure independently of engine load and speed. Therefore, engines equipped with EGR and modern injection pressure systems offer great potential for the implementation of a high injection pressurehigh EGR strategy. This emission reduction strategy has been engaged successfully by many European HDDE manufactures to meet the EURO IV standards.

An engine calibration can be realized by optimizing EGR and injection pressures over several levels. The optimization, if conducted using a design of experiment (DOE) approach requires only a few, among all the possible combinations of the parameter values, in order to find the optimum engine setting with an acceptable precision level. Furthermore, engine calibrations can be made robust or insensitive to the high variability associated with engine manufacturing processes, by the use of orthogonal array techniques. 


\section{CHAPTER 3 EXPERIMENTAL SET UP}

\subsection{Test Engines}

The test engines provided by Volvo Powertrain were both 11 liter engines. The first was a MY04 Volvo MD11 (Figure 15) and the second was a MY07 Volvo MD11 (Figure 16) production series.

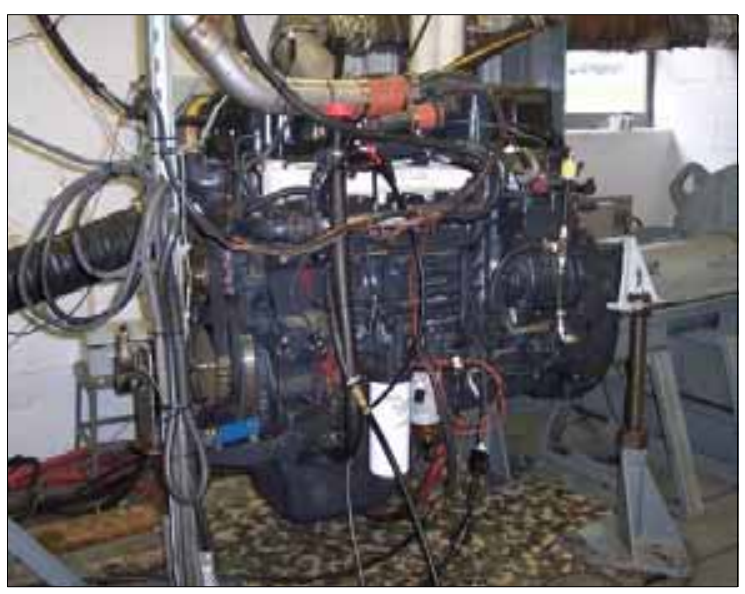

Figure 15: Volvo MY04, 355 hp @ 1800 / 1360 lb-ft @1200 rpm

The MY04 Volvo MD11 is typically used in refuse collection and refuse hauling vehicles. It was scheduled to be in production late 2005 for use in Mack, Volvo, and Renault heavy-duty vehicles (Table 4). It is equipped with a high pressure loop EGR system. The EGR is cooled through an air-to-liquid type heat exchanger, whereas the EGR valve is oil-cooled.

The MY07 was modified to be able to handle higher injection pressures and higher levels of EGR. It was equipped with a modified injector lobe overhead camshaft with unit mechanically actuated injectors; shorter injector rocker arms were introduced to maintain the proper stroke and a strengthened gear train to accommodate an injection pressure as high as 2400 bar. 


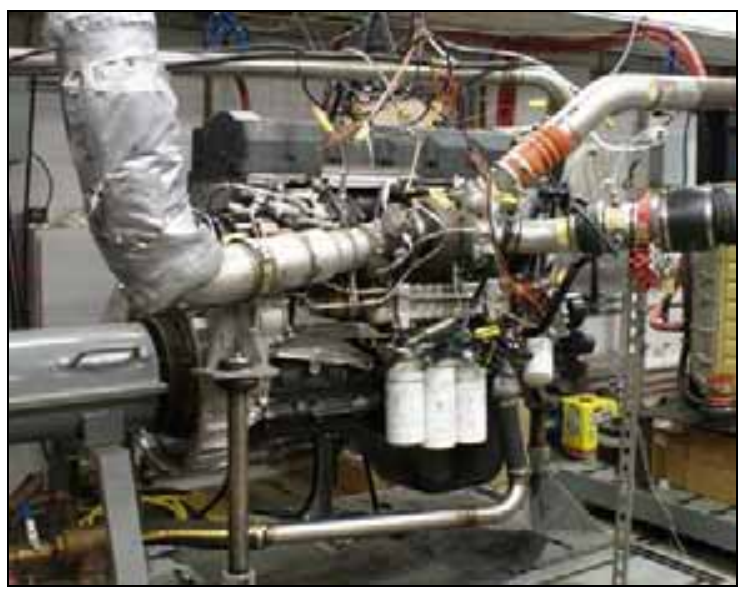

Figure 16: Volvo MY07, 339 hp @ 1800 / 1298 lb-ft @1306 rpm

The EGR cooler efficiency was enhanced by the use of a larger size cooler with increased piping diameter, a new EGR mixer and a venturi to measure more accurately the EGR flow rate. It is equipped with a sliding nozzle and electronically actuated VGT. In addition, the MY07 engine is equipped with a "seventh injector" for active regeneration of the DPF.

Table 4: Volvo Engine, MD-11 MY07

\begin{tabular}{|c|c|}
\hline Performance & $\begin{array}{c}\text { Power: } 339 \mathrm{hp} \\
\text { Torqe:1298 lb-ft @ } 1306 \mathrm{rpm}\end{array}$ \\
\hline Base Configuration & 4 cycle, 6 in-line cylinders \\
\hline Aftertreatment & DPF with DOC \\
\hline Aspiration & Sliding Nozzle Variable Turbocharger \\
\hline Injection System & Dual Solenoid Electronic Unit Injector \\
\hline Displacement & 661 cu in $(10.8 \mathrm{~L})$ \\
\hline Compression Ratio & $16: 1$ \\
\hline Bore \& Stroke & $4.84 \times 5.98$ in $(123 \times 152 \mathrm{~mm})$ \\
\hline Cylinder Spacing & 6.06 in $(154 \mathrm{~mm})$ \\
\hline
\end{tabular}

The test engines were installed at the Engine and Emissions Research Laboratory (EERL) and tested to verify their emission levels (baseline testing). An optimization technique (see Chapter 4) was implemented on the MY04 over a single mode. An 
additional study including a combustion analysis was performed on this engine to learn about the limitations of the technique. The optimized technique was then used on the newer engine (MY07 Volvo) to develop the two calibrations.

Both engines are equipped with axially sliding vanes turbochargers (Section 3.2) and with an advanced injection system, EUI 3 (see Section 3.3).

This study is part of a project whose aim was to demonstrate and evaluate the performance, durability and emission reduction potentials of an advanced diesel emission control system (ADECS) [52]. In the first part of the project, the engine was developed to

produce $1 \mathrm{~g} / \mathrm{bhp}$-hr NOx, through advanced combustion techniques; this was achieved by means of the low-NOx calibrations, presented in this study. The second part of the project required to retrofit the engine with an exhaust aftertreatment system and develop the integrated system to meet the 2010 emission limits. The procedures adopted and phases of the development work are described in details in [53].

In Section 3.4 is reported a brief description of the exhaust aftertreatment used.

\subsection{Variable Geometry Turbocharger}

The VGT on the MD 11 liter is designed such that the flow area between the turbine guide vanes varies in order to provide variable power (see Figure 17); the turbine power is then used to drive the compressor so that the desired level of boost can be achieved under different engine operating conditions. In this configuration the vanes do not pivot but slide axially. 


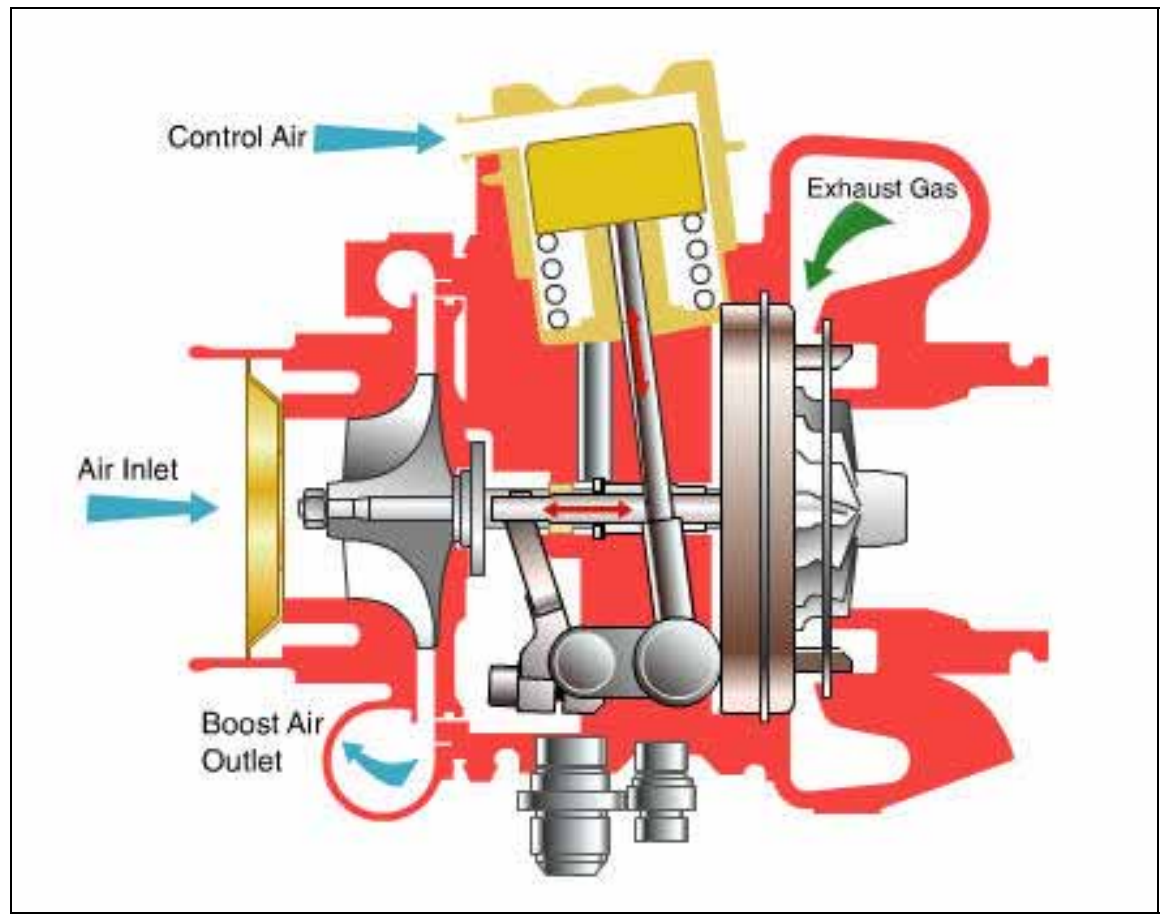

Figure 17: VGT with axially sliding vanes [54]

The numerous advantages associated with this design choice are the smaller size compared to a VGT with variable vanes; increased durability and reliability, due to the decreased number of parts in the hot stream; good transient response and enhanced compression brake capability. On the other hand, the cost is higher compared to the variable vane VGT [55].

\subsection{Advanced Injection System (EUI3)}

Both the test engines are equipped with E3 injection system from Delphi (see Figure 18). The injection pressure and timing are determined by the ECU, which controls two distinct valves: Spill control Valve (SCV) and Needle Control Valve (NCV) (Figure 19). When SCV is activated (valve closed) the pressure builds up in the injector; the pressure is released instead when SCV is deactivated (valve open). The NCV valve does not affect the injection mechanism, if activated, and the opening and closing of the nozzle is dictated by the needle return spring. 


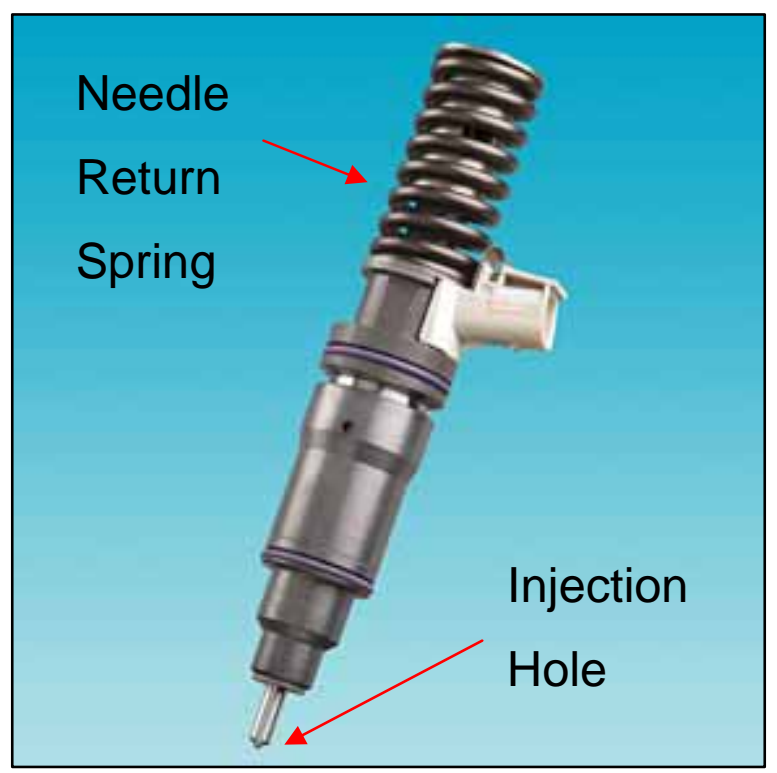

Figure 18: Delphi E3 fuel injection system [56]

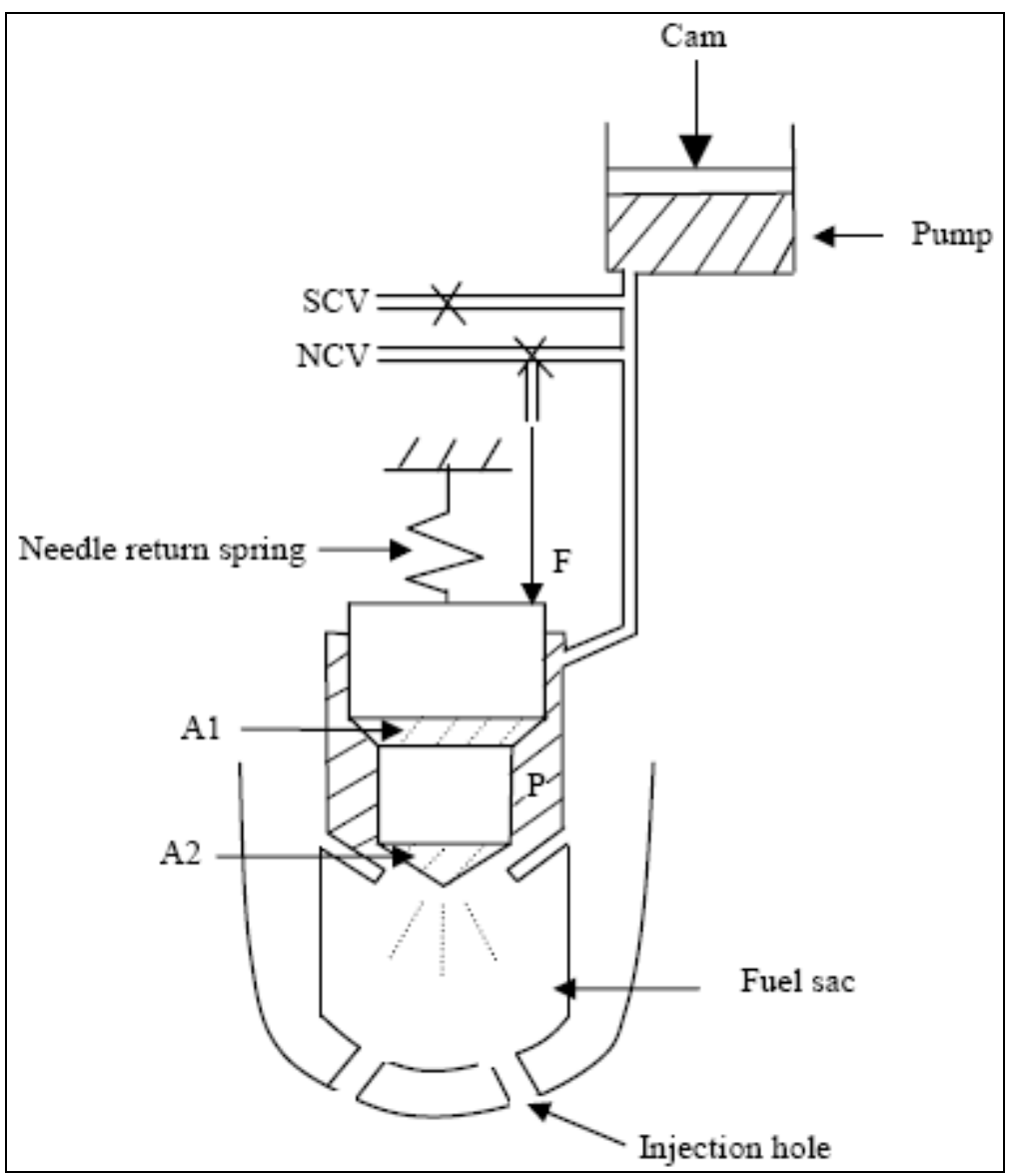

Figure 19: Working principle of the injector nozzle of the EUI system [52] 
During the injection event the ECU can decide to treat the two valves system as single or double actuators:

Single Actuator: In this configuration the potential of the system is not completely exploited because the NCV is always activated, which means that no additional forces are applied to the needle; hence, the whole injection event is regulated by SCV. The pressure rises when SCV is activated, and the only counteracting force counteracting is the one provided by the return spring. When SCV is opened the fuel escapes and the pressure is lowered, which leads to the closure of the needle.

Two Actuators: In this configuration the timing of the nozzle opening and closing is regulated by the NCV. As the NCV is deactivated it exercises an additional force on the needle that counteracts with the pressure build up coming from the activation of the SCV. By delaying the deactivation of NCV with respect to the closing of SCV the timing of the opening and closing of the nozzle can be varied. This action allows high pressure to build up [57]. 


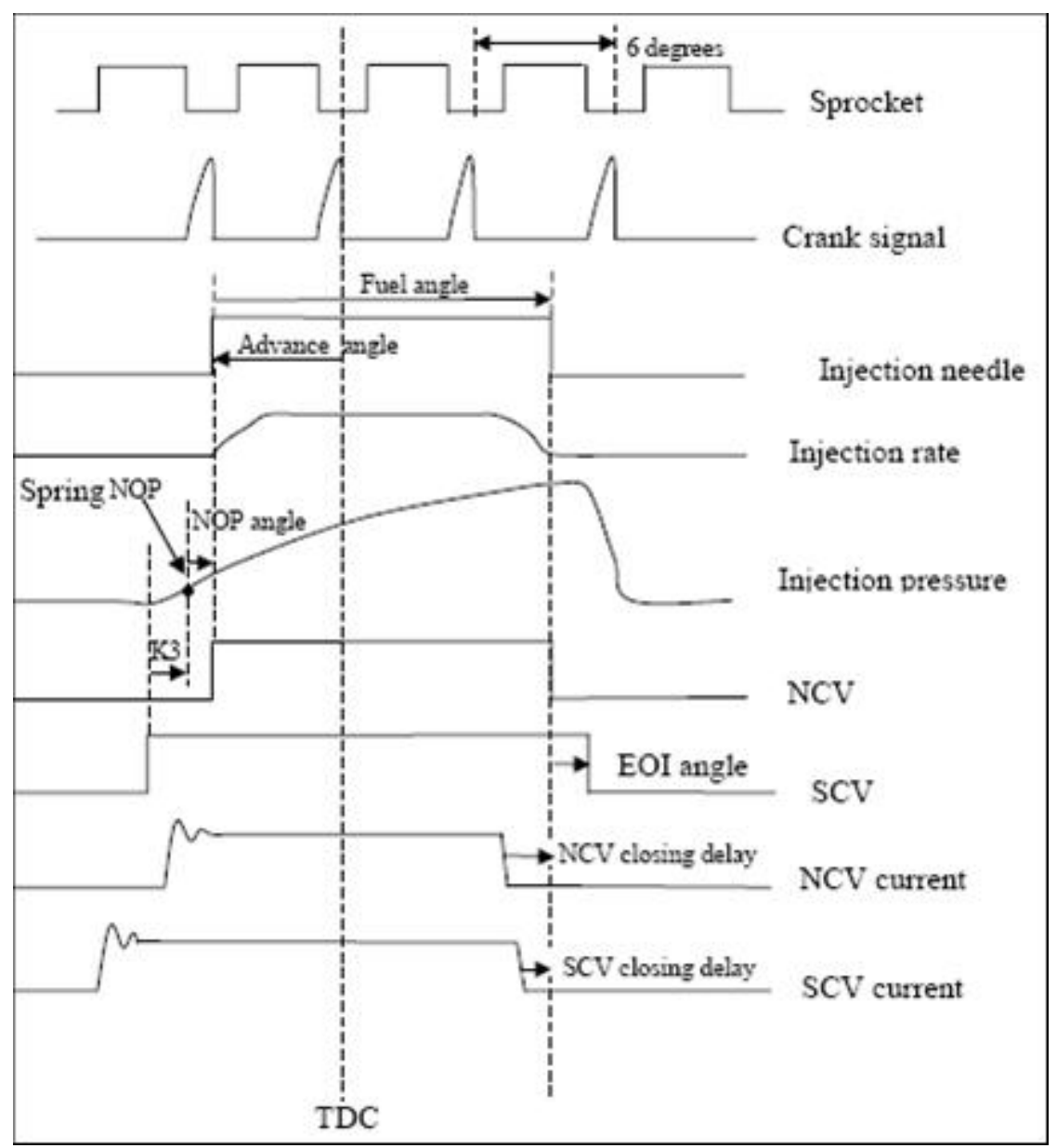

Figure 20: Dynamic of the control of injection [57]

\subsection{Exhaust Gas Aftertreatment}

The different calibrations produced, in this study, with the optimization algorithm were tested after the MY07 Volvo engine was equipped with an exhaust aftertreatment [53]. The exhaust aftertreatment consisted of DOC, DPF and SCR system. The DPF is a Fleetguard "space saver" (see Figure 21), with the DOC located upstream of the PM filter for continuous PM removal at low temperature conditions. A seventh injector is installed upstream of the DPF to enable active regeneration by injection of $\mathrm{HC}$, essentially diesel fuel, into the exhaust in order to increase the temperature up to the level of soot oxidation in the presence of oxygen $(600 \mathrm{C})$. 


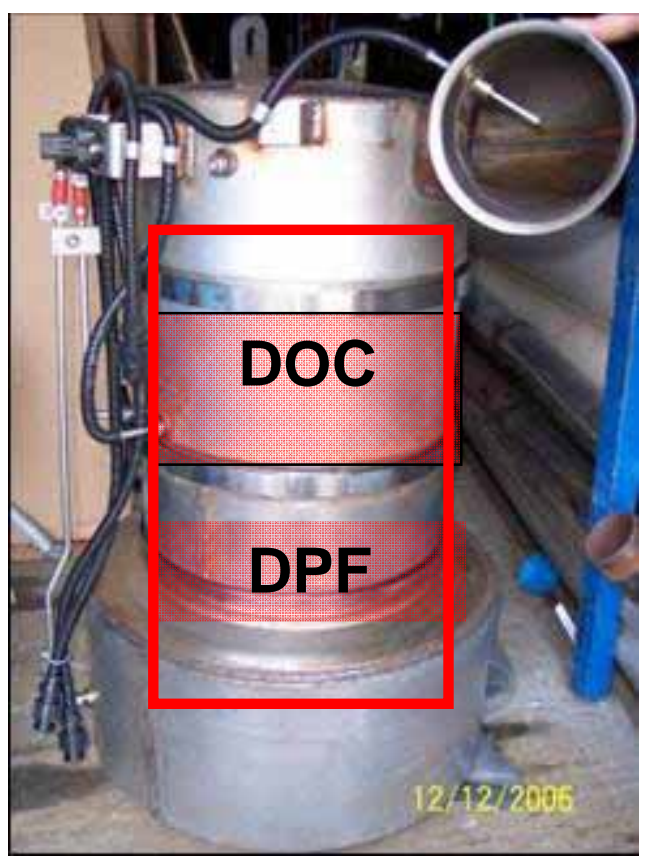

Figure 21: Fleetguard compact saver DOC-DPF system [53]

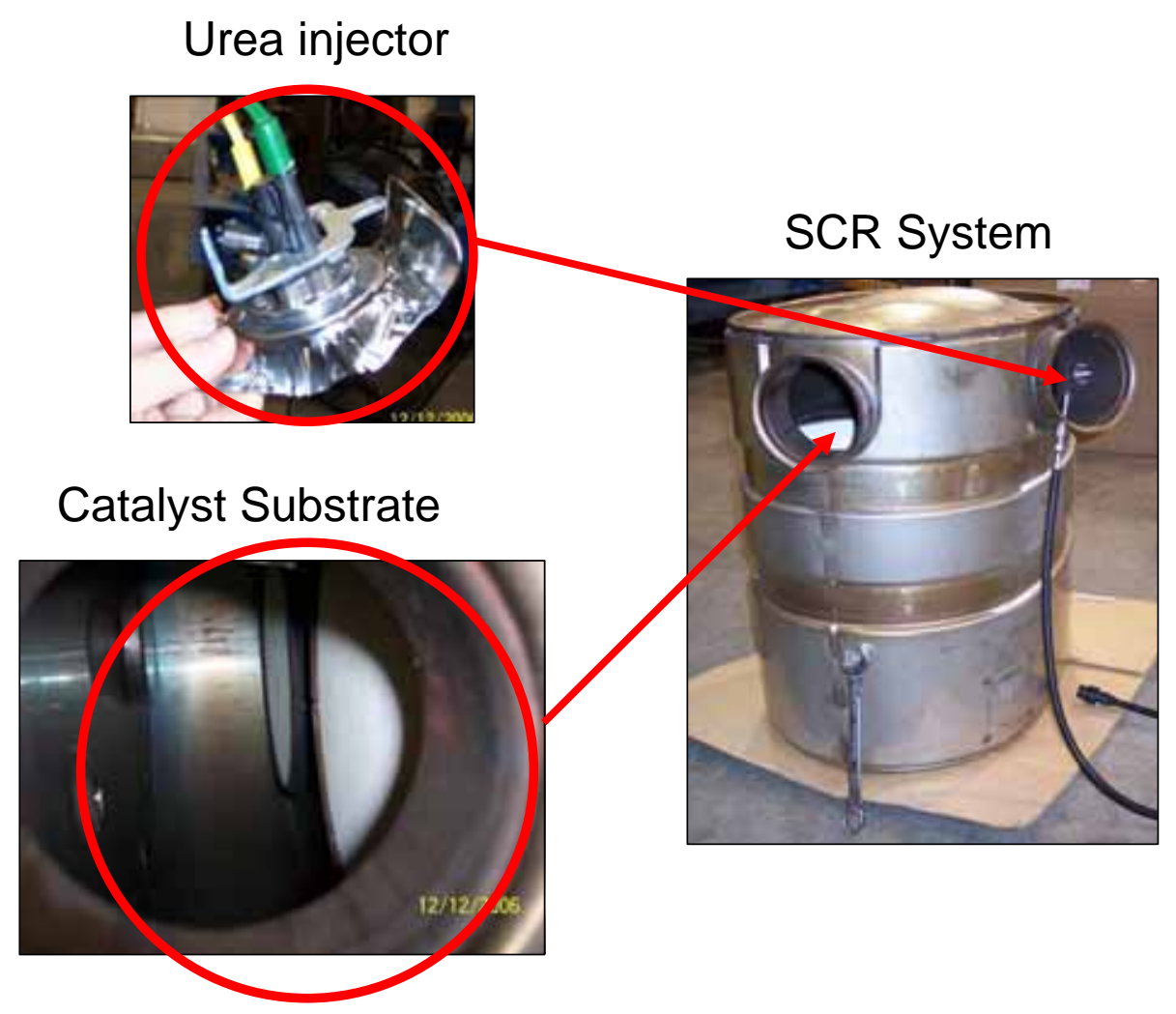

Figure 22: Johnson Matthey SCR system [53] 
The SCR system manufactured by Johnson Matthey, designed to meet the EURO IV, consisted of a urea injection system, urea pump, urea dosage valve and a urea tank (see Figure 22). For automotive applications the urea is used in a solution with water, called Adblue. The urea-water ratio is $32.5 \%$; this ratio provides the lowest freezing point (-11 C). The SCR catalyst is equipped with an oxidation catalyst to oxidize the ammonia slip. The Adblue pump unit is equipped with an independent controller, where the urea dosage maps are implemented. Figure 23 shows the overall system connected to the MY07 engine on a test bed in the EERL.

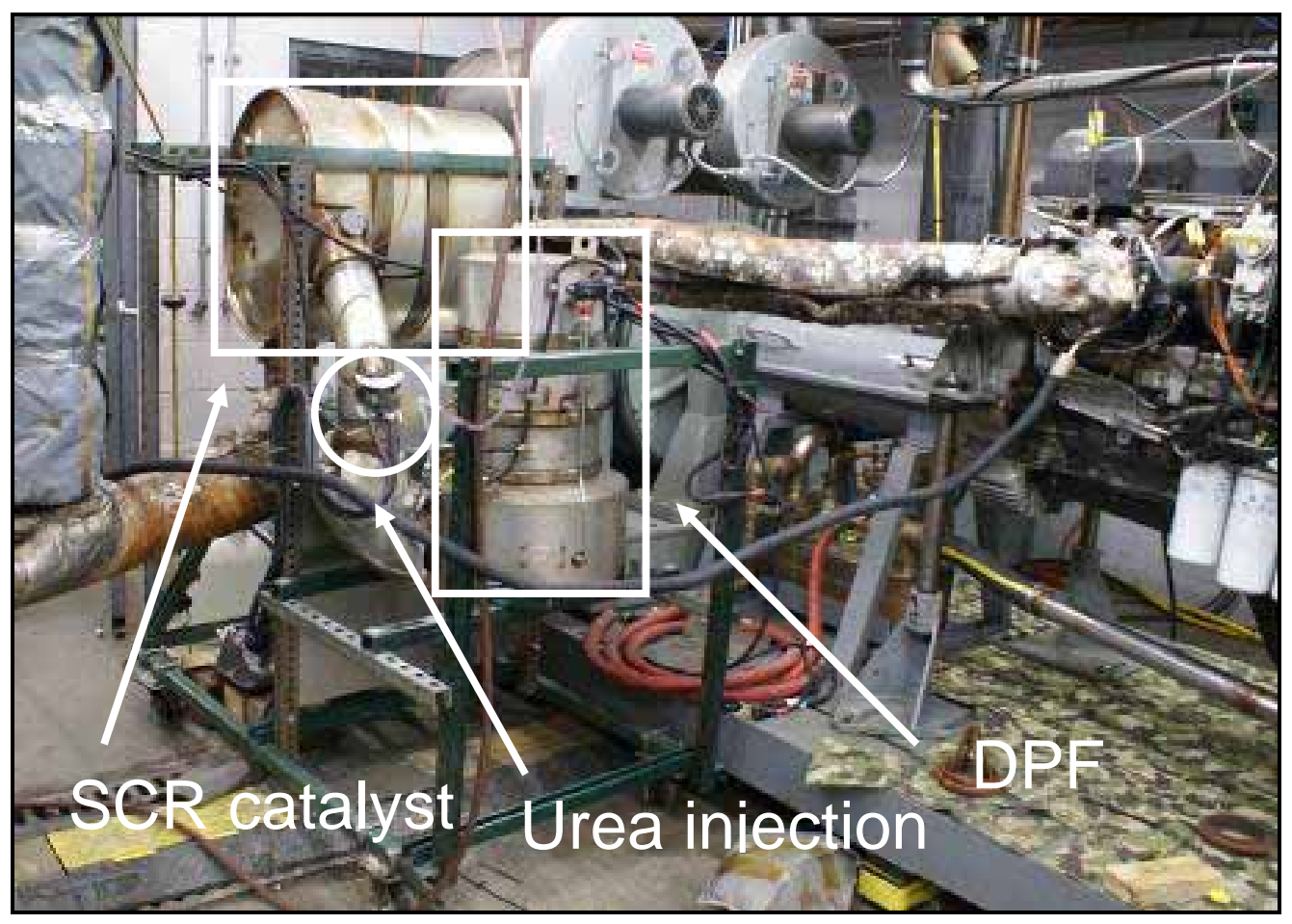

Figure 23: Exhaust aftertreatment system installed at the EERL

\subsection{In-cylinder Pressure High Speed Acquisition}

High speed in-cylinder pressure acquisition was set up on an external data acquisition system (see Figure 24). The system consisted of an in-cylinder pressure sensor, a charge amplifier, National Instruments card and a desktop computer. The incylinder pressure sensor is a non-cooled sensor, model 6125B21 from Kistler. Kistler claims that this sensor offers precise measurement of in-cylinder pressure for spark ignition and diesel engine, which guarantees practically a constant sensitivity over a wide 
range of temperatures; and that it is a high temperature, ground-insulated sensor to avoid electrical interference [58]. The signal is conditioned through a charge amplifier at low impedance, a National Instrument acquisition card, processed by a desktop computer and displayed real-time though a Labview program.

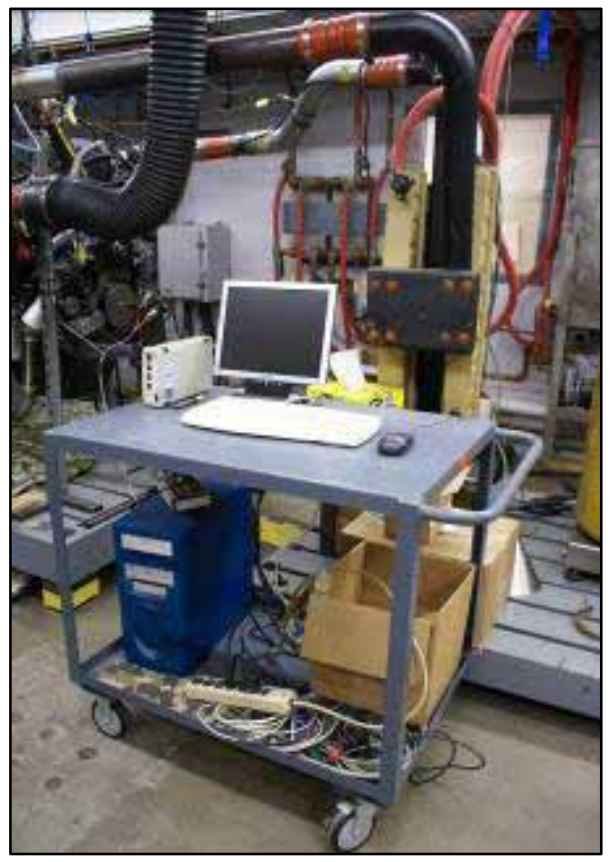

Figure 24: In cylinder pressure acquisition system (top); pressure sensor Kistler 6125B21

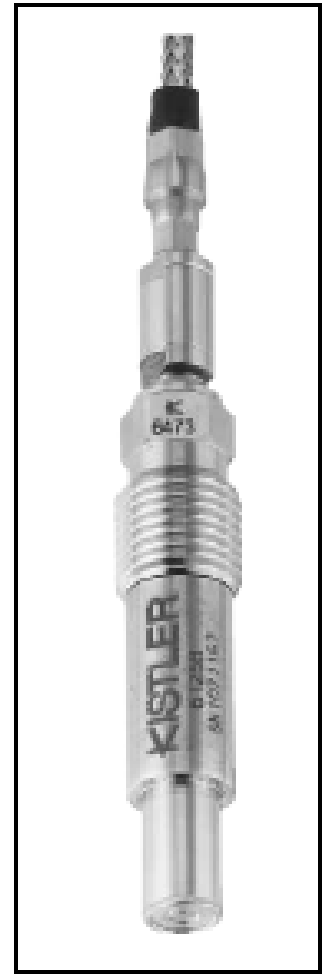
(right) [58].

\subsection{Engine Test Cell and Laboratory Instrumentation}

The EERL test cell is equipped to perform emission measurements testing according to the Code of Federal Regulations (CFR) 40 Parts 86, 89, 92, and 1065. DC dynamometers ( $800 \mathrm{hp}, 550 \mathrm{hp}$ ) are available in test cell, as well as an AC dynamometer (300 hp).The Volvo MD 11 MY04 was initially tested on $300 \mathrm{hp} \mathrm{AC} \mathrm{dynamometer} \mathrm{for}$ scoping and sensitivity studies on the engine actuators of interests. The engine had to be tested at lower power rating in order to comply with the limitations of this dynamometer. The engine was then tested on the higher power rating DC dynamometer (550 hp), where the optimization technique, which gave the best results in the previous testing, was used for emission reduction and combustion studies over a single engine operating mode. For 
this testing session the exhaust stream was routed to a total exhaust dilution tunnel; a critical flow venturi - constant volume sampler (CFV-CVS) based on CFR 40, part 86, subpart $\mathrm{N}$.

The MY07 Volvo engine instead was connected to the highest power rated DC dynamometer available at the EERL ( $800 \mathrm{hp}$ ) where the majority of the testing, such as baseline, engine calibration and aftertreatment development, were conducted (Figure 25).

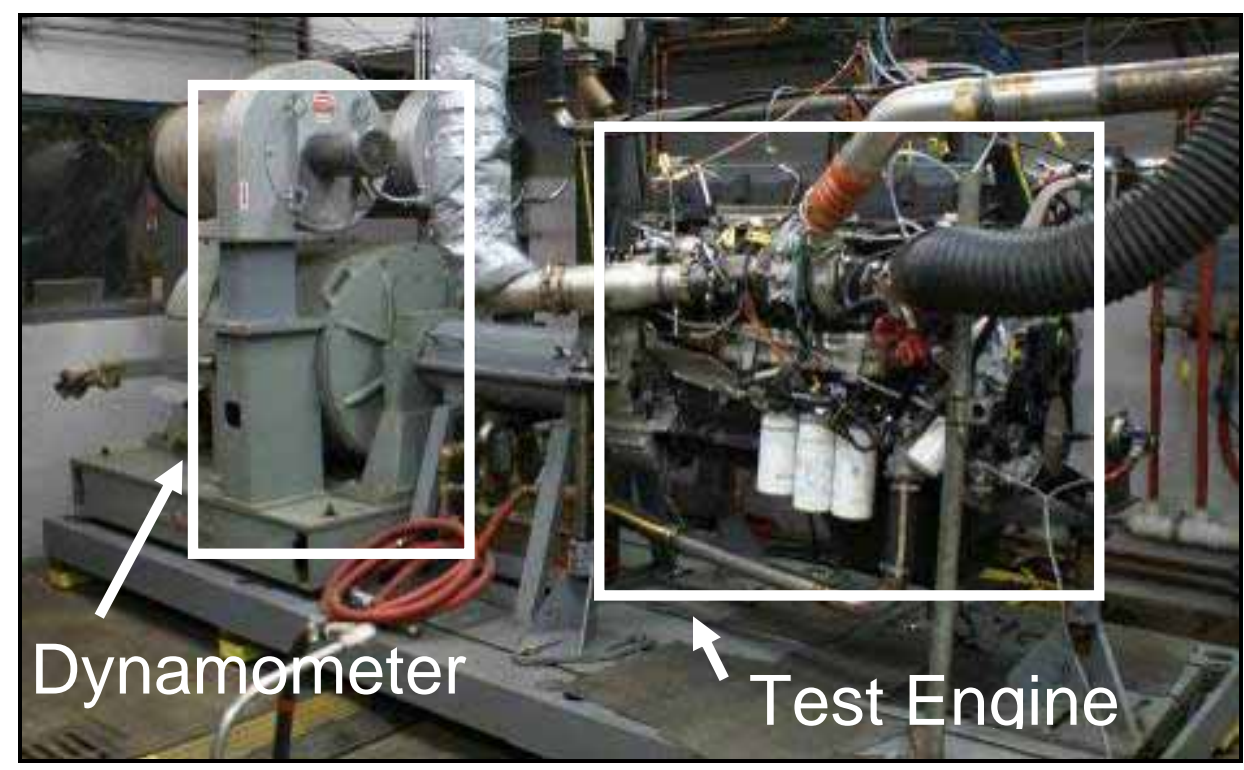

Figure 25: MY07 Volvo MD 11; 800 hp dynamometer

The exhaust stream was directed into a subsonic CVS venturi with variable speed blower, fabricated and controlled according to the CFR 40, Part 1065 (see Figure 26). The tunnel is designed to create a turbulent flow $(\operatorname{Re}>4000)$ of the dilution air-exhaust mixed stream. The dilution air is filtered through a cascade of HEPA filters, and controlled to the required temperature and humidity values.

A heated flame ionization detector (HFID) was employed to measure hydrocarbons; non-dispersive infrared (NDIR) to detect carbon monoxide (CO) and carbon dioxide $\left(\mathrm{CO}_{2}\right)$; chemiluminescent and non dispersive ultraviolet (NDUV) for simultaneous measurement of $\mathrm{NO}, \mathrm{NO}_{2}$ and ammonia $\left(\mathrm{NH}_{3}\right)$ (see Figure 28 and Figure 29) 


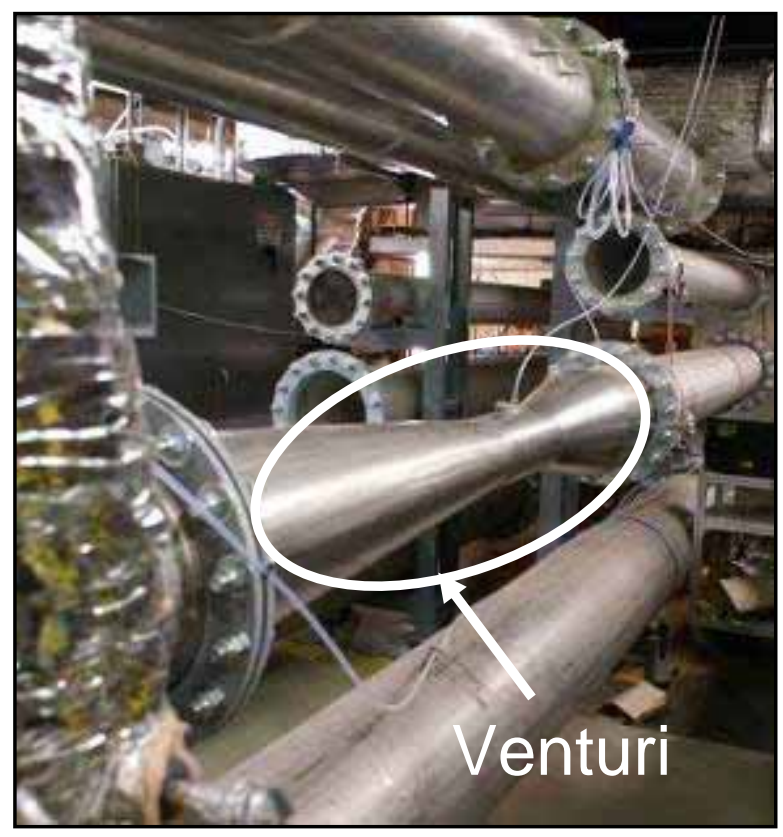

Figure 26: Sub-sonic venturi in the total exhaust CVS

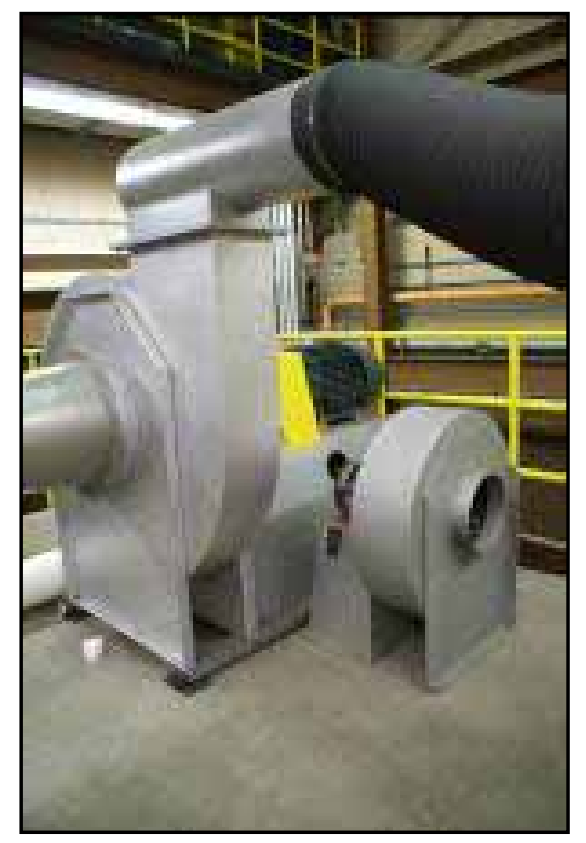

Figure 27: Variable speed blower

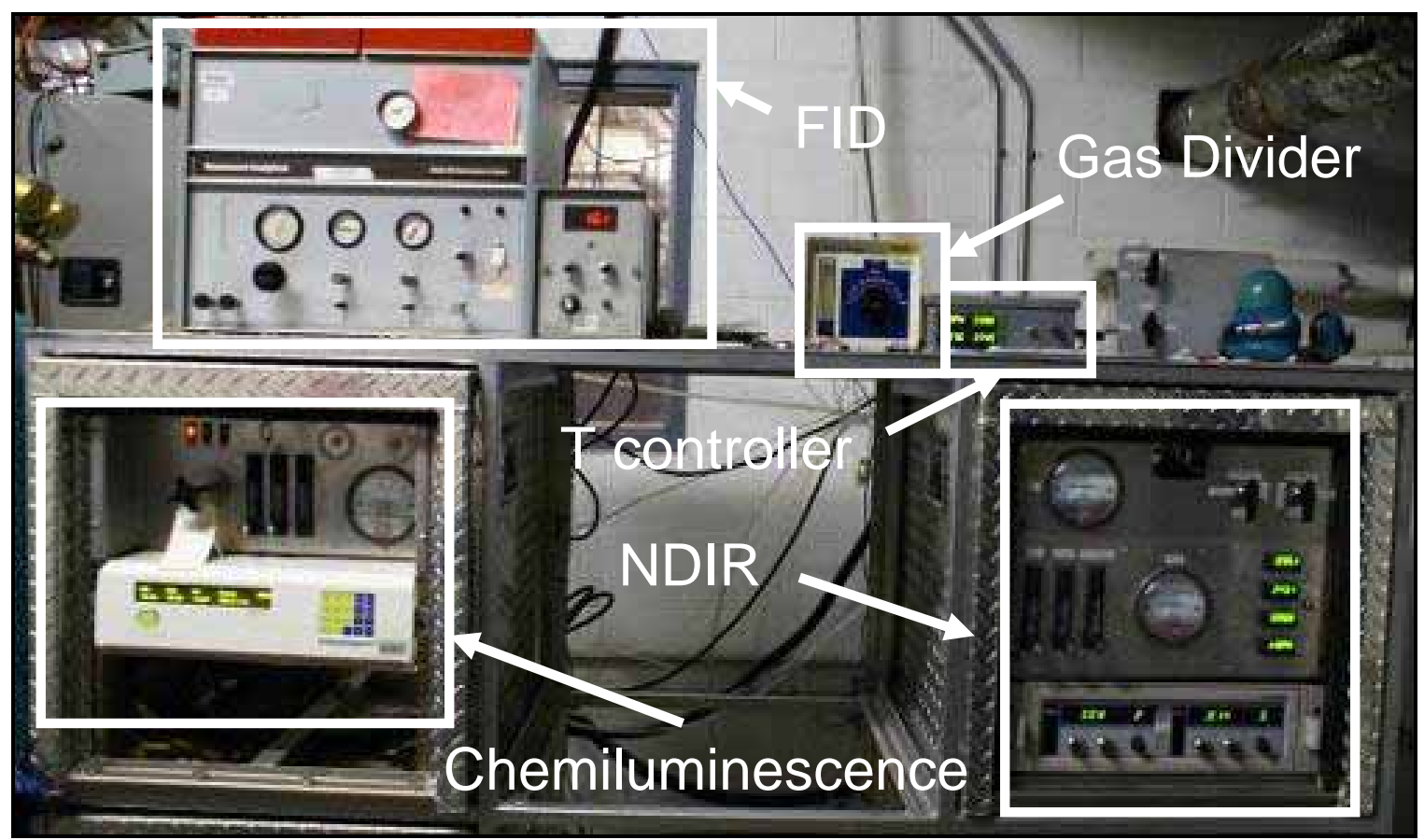

Figure 28: Analyzer bench (Chemiluminescence, FID, NDIR analyzers, gas divider, temp. controller box). 


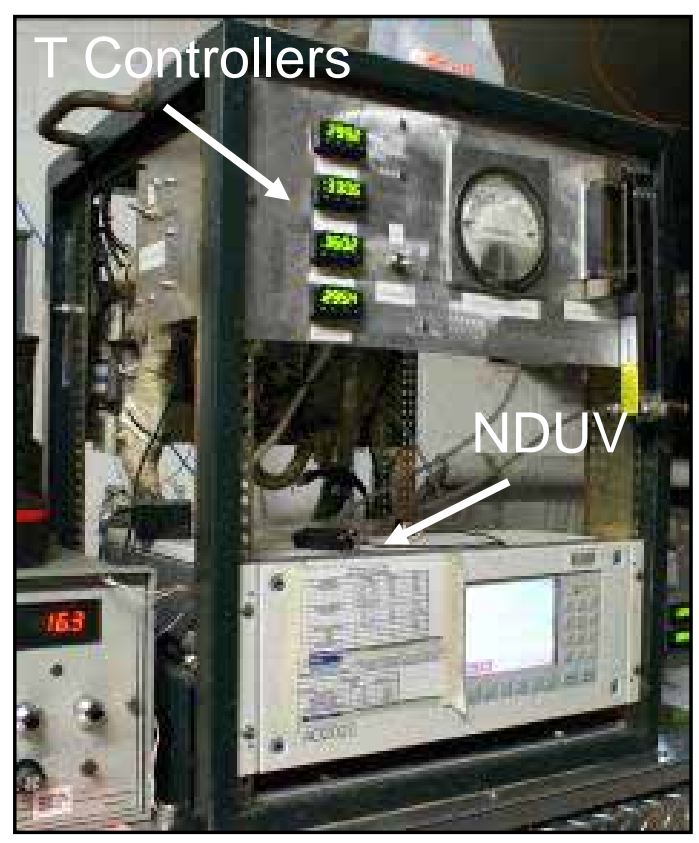

Figure 29: NDUV analyzer; ABB Limas 11 HW

PM was collected on $47 \mathrm{~mm}$ Teflo filters (see Figure 30). A slipstream of exhaust gases was drawn from the dilution tunnel and directed into the WVU 2007 compliant PM collection system (see Figure 31); particles with aerodynamic diameter with 50\% efficiency $\left(50^{\wedge \text { dae }}\right)$ are filtered through a broad cut cyclone. The sample flow rate was maintained constant through a mass flow controller. The filter face velocity was kept below $100 \mathrm{~cm} / \mathrm{sec}$ and the filter face temperature below $47 \pm 5^{\circ} \mathrm{C}$. 


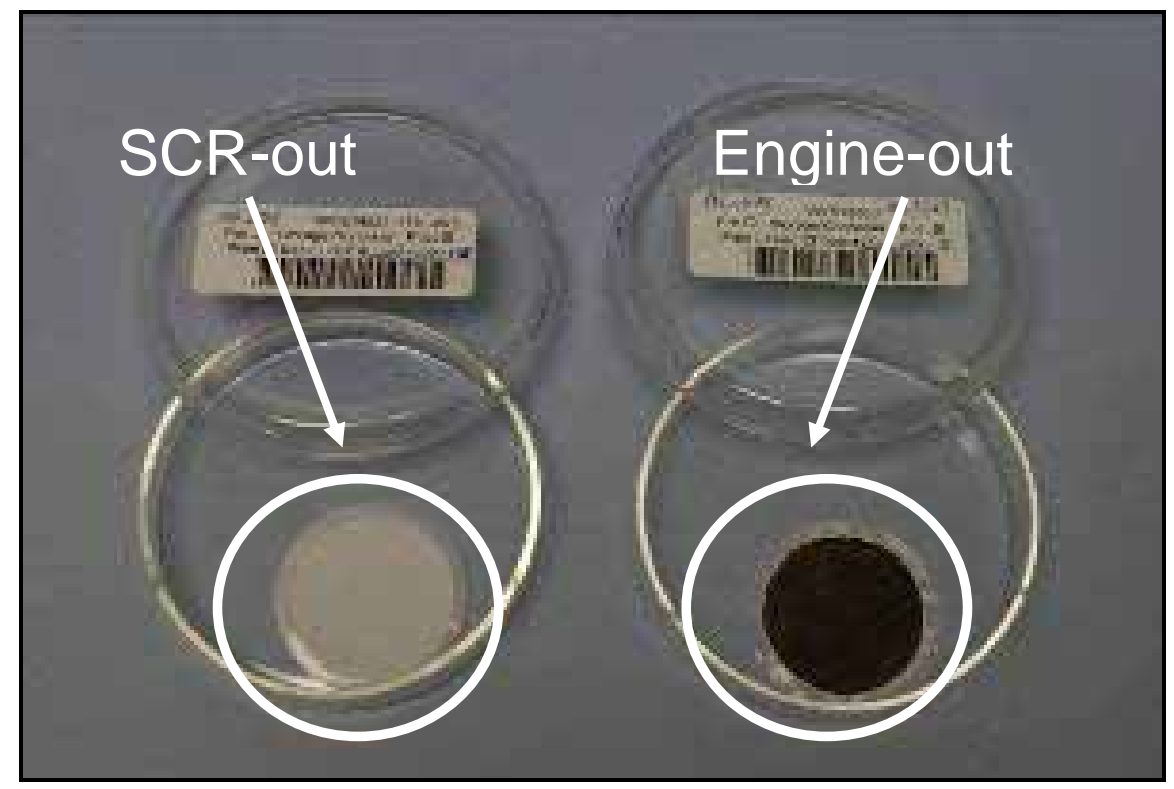

Figure 30: PM filters: 47 mm Teflo filters; engine-out, SCR-out collection

After each run the filter was removed from the PM box and kept in a class 1000 clean room (see Figure 32), where after proper conditioning it was measured with a high precision micro balance, in accordance with 40 CFR Part 1065.

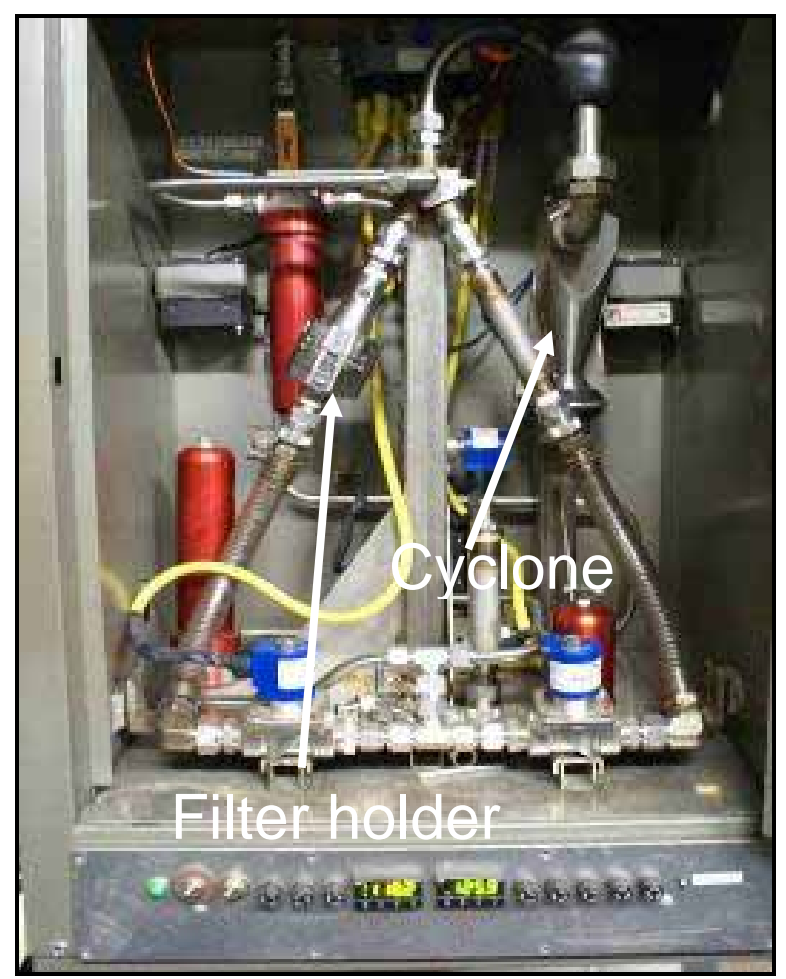

Figure 31: PM box for filter collection. 
The weighing room was maintained at temperature of $22{ }^{\circ} \mathrm{C} \pm 3$ and at a dew point temperature of $9.5^{\circ} \mathrm{C} \pm 1$. The dew point temperature in the room is allowed to vary only $1 \mathrm{deg}$, due to the interference between water vapor and the sulfur compounds present on the PM collected on the filters.

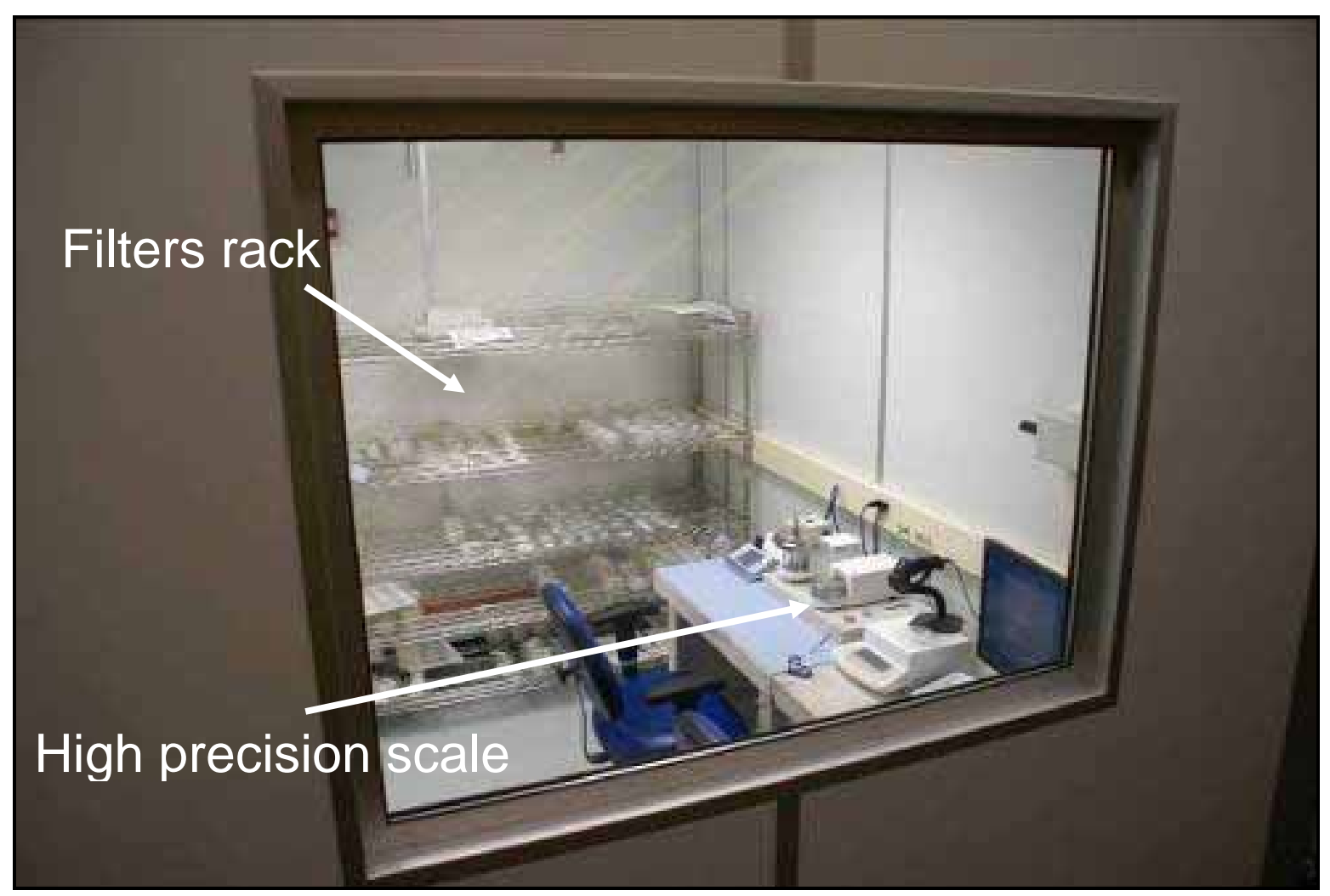

Figure 32: PM weighing room (view from the observation window)

The main engine calibrations developed in this study, low-NOx and low-FC, were tested with particle sampling devices; the results and the methodology are illustrated in R. Ardanese's work [53].

PM count and size-distributions are measured at the EERL with Scanning Mobility Particle Sizer (SMPS), Micro-Orifice Uniform Deposit Impactor (MOUDI), particle sizer, Tapered Element Oscillating Microbalance (TEOM) and Cambustion DMS-500 Fast Particulate Spectrometer. 


\section{CHAPTER 4 APPROACH}

This chapter describes procedures, which were adopted to optimize the MY04 engine over a single-mode and the MY07 engine over multi-modes. Moreover, two distinct calibrations (low-NOx, low-FC) are generated and evaluated through steady state and transient testing.

\subsection{Model Selection}

The first step was to select the modes over which the engine could be optimized. The first choice, since the testing was to be done over ESCs and FTPs, was to optimize the engine over modes selected among the ESC and AVL-8 mode cycles [59]. The AVL cycle is an 8-modes steady state cycle purposely designed to correlate with the emissions produced during an FTP; the overall emissions are calculated assigning to each mode the weights indicated in Figure 33.

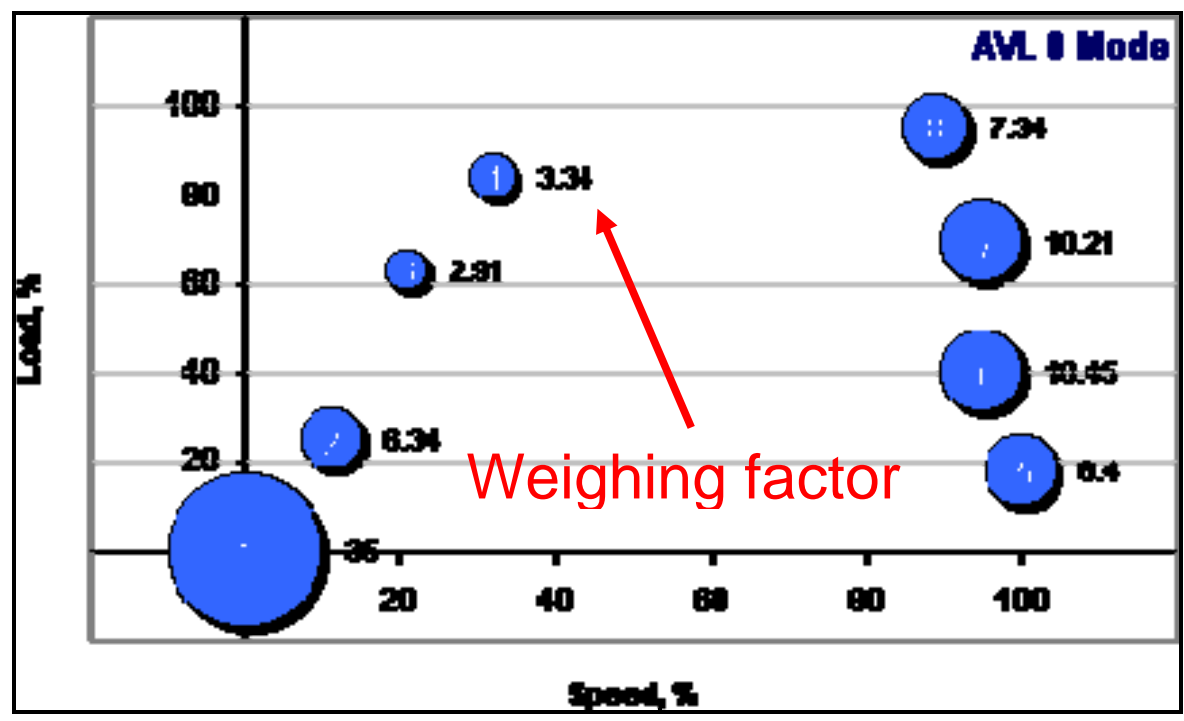

Figure 33: AVL cycle [59]

The combination of the selected modes is, therefore, spread out under the lug curve Figure 34. These points represent critical engine operating points for both steady state 
and transient certification testing. The engine was optimized over a significantly wider area around the selected engine points so that, ultimately, the entire area under the lug curve is subjected to modifications. Although the engine was apparently optimized for a restricted numbers of engine points (ESC and AVL modes), the calibration characterized the engine performance and its emissions over almost the entire span of its operation. Once the optimized engine settings were inserted in the engine map, they were interpolated with the values around them in order to maintain a similar level of engine drivability as the non-optimized map.

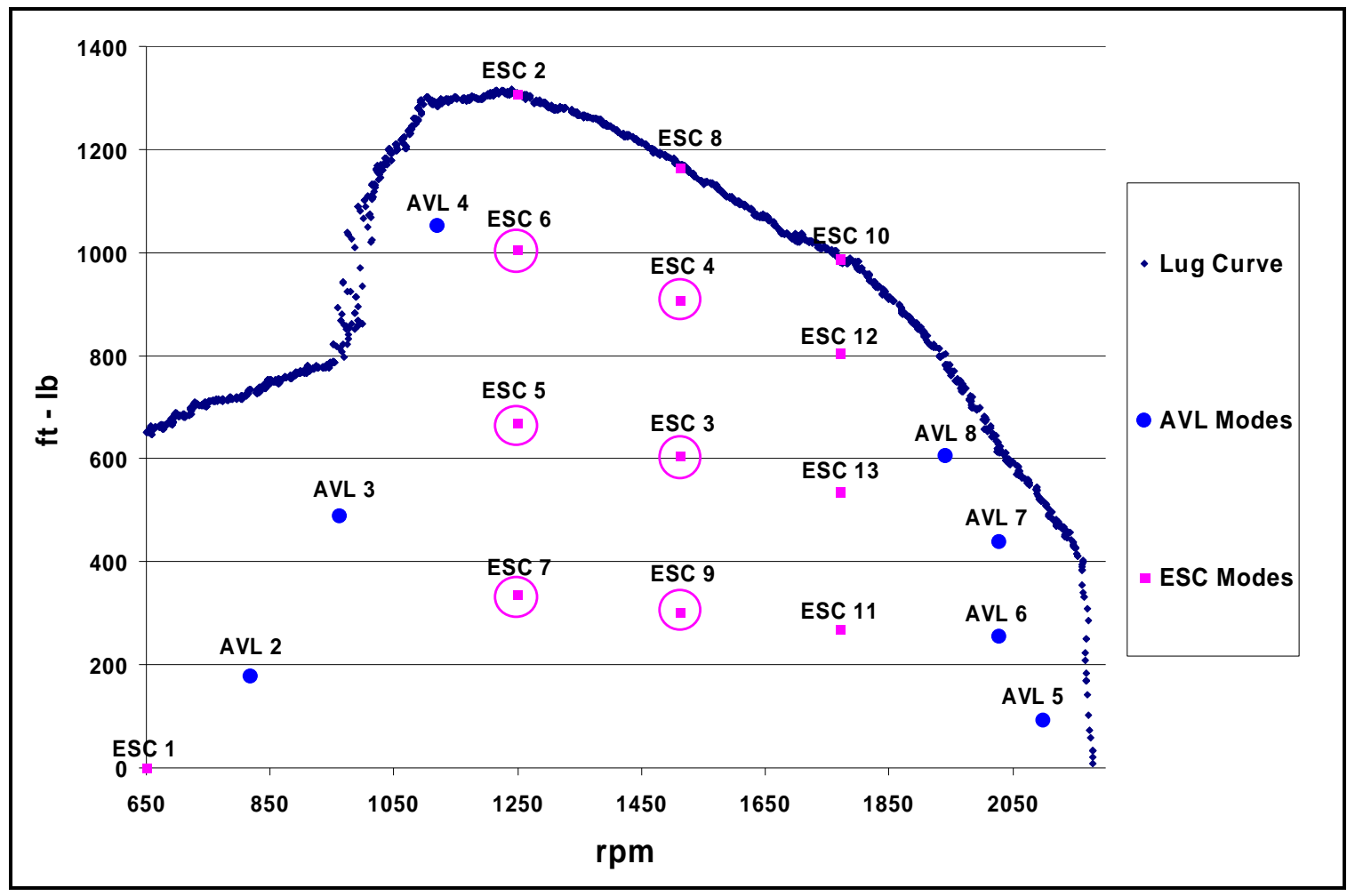

Figure 34: Selection of modes for low-NOx map (ESC circled and all AVL modes)

\subsection{Parameter Range Selection}

For each of the four engine parameters three levels of variation were selected [60]. Three levels are the least number of levels that can be used, without increasing enormously the number of experiments, in order to study non linear responses of the parameter effects. The values of the four parameters embedded in the engine maps "asreceived" (by WVU from Volvo) were called "baseline settings". The range for each 
parameter was selected so that the engine's physical limitations, such as exhaust temperature, smoke limits, turbine speed, engine speed and maximum cylinder pressure were not violated.

A sensitivity study (EGR flow scoping) was conducted to find out how, mode by mode, the EGR and VGT could be varied in order to produce more EGR flow rate.

A more opened position of the EGR valves drives more EGR flow; on the other hand, when the EGR valve is fully open, the pre-turbine pressure is lowered to the point that the lowest pressure gradient is present on the high pressure loop that drives the exhaust gases into the engine intake. But closing of the valve could also lead to an increase in the pressure gradient and induces higher boost, which could drive more exhaust flow rate, depending on the engine mode; this was found to be true for mode 3 of the ESC cycle (see Section 5.2.1). Higher values of EGR flow rate can be also obtained by further closing the VGT, since it increases the pre-turbo pressure and hence the pressure gradient across the engine, which in turn drives more exhaust gases into the engine.

No direct measurement of injection pressure was available; therefore, to determine the range for NOP, a simulation software (EUISIM), developed by Delphi/Volvo Powertrain, was used. EUISIM calculates the maximum injection pressure for a given level of NOP, based on maximum in-cylinder pressure measurement. The injection pressure limitation of 2400 bar, inherent to the fuel injection system available, limited the range of values for NOP. For low-FC calibration, where advanced injection was required, SOI was advanced until physical limitations of the system were encountered. For low-NOx calibration, since the strategy did not indicate any direction of SOI variation, the advance angle levels were chosen above and below the baseline value.

\subsection{Single Parameter Study on Combustion}

A "single parameter variation" testing was conducted. This study represents the traditional approach to evaluate the impact of engine parameter variation on exhaust emissions. It was performed by varying one parameter at a time and keeping fixed all the others. For instance, when NOP was varied over three levels the remaining parameters 
(SOI, EGR and VGT) were maintained at their baseline value (see Table 5). The impact of each parameter on the heat release and combustion process was studied.

Table 5: Single parameter variation

\begin{tabular}{|c|c|c|c|}
\hline NOP & SOI & EGR & VGT \\
\hline 1 & Baseline & Baseline & Baseline \\
\hline 2 & Baseline & Baseline & Baseline \\
\hline 3 & Baseline & Baseline & Baseline \\
\hline Baseline & 1 & Baseline & Baseline \\
\hline Baseline & 2 & Baseline & Baseline \\
\hline Baseline & 3 & Baseline & Baseline \\
\hline Baseline & Baseline & 1 & Baseline \\
\hline Baseline & Baseline & 2 & Baseline \\
\hline Baseline & Baseline & 3 & Baseline \\
\hline Baseline & Baseline & Baseline & 1 \\
\hline Baseline & Baseline & Baseline & 2 \\
\hline Baseline & Baseline & Baseline & 3 \\
\hline
\end{tabular}

This study was conducted over a single mode on MY04 Volvo engine. It was a preliminary exercise was done to assess the impact of each engine parameter variation on the emissions, but especially on the combustion process. The information gathered through this experiment could be also used to more accurately set up experiments, which include multivariate optimization of parameters.

\subsection{Level Assignment and Strategy Implementation}

The high EGR-high injection pressure strategy was implemented for the lowNOx map by strategically assigning the baseline value to the parameter levels. The baseline setting for NOP was assigned to "level 1"; hence, the remaining levels were assigned to higher injection pressure values, "level 2" and "level 3" (see Table 6). The strategy does not provide any indications regarding the direction of SOI variation, 
therefore baseline value was assigned to "level 2", which makes the algorithm search for values higher and lower than the baseline.

Table 6: High NOP-high EGR strategy implementation for Low-NOx map

\begin{tabular}{|c|c|c|c|}
\hline $\begin{array}{c}\text { Engine } \\
\text { Parameters }\end{array}$ & Lovel 1 & Level 2 & Level 3 \\
\hline sol & - & Baselne & + \\
\hline NOP & - & Bmoreine & + \\
\hline VeT & - & Basalne & + \\
\hline EER & - & Baseline & + \\
\hline $\begin{array}{c}\text { Engine } \\
\text { Paramaters }\end{array}$ & Leved 1 & Level 2 & Level 3 \\
\hline sol & - & Basedne & + \\
\hline NOP & Broeline & + & + \\
\hline VeT & - & - & Basollna \\
\hline EGR & Basellne & + & + \\
\hline
\end{tabular}

Baseline EGR valve and baseline VGT positions were assigned according to results of the sensitivity study that exhibited higher EGR flow rate.

The advanced injection-high injection pressure strategy was implemented for the low-FC map by strategically assigning the baseline value to the parameter levels, not unlike the assignments for high EGR-high injection pressure strategy. More advanced injection was implemented by assigning the SOI baseline value to the "level 1". Solution at higher injection pressures was found by assigning NOP baseline to "level 1" (see Table 7). The baseline values for EGR and VGT were reversed with respect to levels in Table 6 in order to obtain solutions at lower level of EGR flow. 
Table 7: Level assignment for low-FC map (high NOP-advanced injection)

\begin{tabular}{|cccc|}
\hline Engine Parameter & Level 1 & Level 2 & Level 3 \\
SOI & Baseline & + & ++ \\
NOP & Baseline & + & ++ \\
VGT & Baseline & + & ++ \\
EGR & -- & - & Baseline \\
\hline
\end{tabular}

\subsection{Orthogonal Matrix Testing}

The "orthogonal matrix" testing makes use of an orthogonal array design to isolate the main effects of a single parameter on the response function. Orthogonality is intended in a combinatoric sense: "for any pair of columns- in the array- all combinations of factors occur an equal number of times" [50]. The orthogonal array chosen is an $\mathrm{L}_{9}$ array (see Table 8). It is based on the assumption of "no interactions" between parameters, which in other terms implies that models used to fit the data collected do not include cross product terms between the parameters. However, the validity of this assumption needs to be proved, and this was done by comparing the model predictions with the measured points.

Table 8: Orthogonal array design, 9 experiments-4 control factors $\left(\mathrm{L}_{9}\right)$

\begin{tabular}{|c|c|c|c|c|c|c|}
\hline & NOP & VGT & EGR & SOI & NOx & FC \\
\hline $\mathbf{1}$ & 1 & 1 & 1 & 1 & NOx $_{1}$ & $\mathrm{FC}_{1}$ \\
\hline $\mathbf{2}$ & 1 & 2 & 2 & 2 & $\mathrm{NOx}_{2}$ & $\mathrm{FC}_{2}$ \\
\hline $\mathbf{3}$ & 1 & 3 & 3 & 3 & $\mathrm{NOx}_{3}$ & $\mathrm{FC}_{3}$ \\
\hline $\mathbf{4}$ & 2 & 1 & 2 & 3 & $\mathrm{NOx}_{4}$ & $\mathrm{FC}_{4}$ \\
\hline $\mathbf{5}$ & 2 & 2 & 3 & 1 & $\mathrm{NOx}_{5}$ & $\mathrm{FC}_{5}$ \\
\hline $\mathbf{6}$ & 2 & 3 & 1 & 2 & NOx $_{6}$ & $\mathrm{FC}_{6}$ \\
\hline $\mathbf{7}$ & 3 & 1 & 3 & 2 & $\mathrm{NOx}_{7}$ & $\mathrm{FC}_{7}$ \\
\hline $\mathbf{8}$ & 3 & 2 & 1 & 3 & $\mathrm{NOx}_{8}$ & $\mathrm{FC}_{8}$ \\
\hline $\mathbf{9}$ & 3 & 3 & 2 & 1 & $\mathrm{NOx}_{9}$ & $\mathrm{FC}_{9}$ \\
\hline
\end{tabular}


The engine was tested according to the nine different configurations indicated by the rows of the orthogonal array; NOx and FC were measured for each of the nine experiments (see Table 8) and then fed to the optimization algorithm.

\subsection{Identification of the Optimum Control Factor Levels}

The optimization algorithm processed the data collected according to the orthogonal array design in order to find solutions of improved robustness.

The emission concentrations were converted in decibel applying the logarithm, as follows:

$$
N O x d B=-10 \log (N O x)
$$

This helps reducing the effect of interactions between the control factors, since multiplicative changes in the argument of the logarithm are transformed to additive changes, thus making the metric more additive in a statistical sense [51]. It is implied that NOx and FC, which appear in the formulas of this chapter, are in decibels and the notation $\mathrm{dB}$ is omitted.

The first step to estimate the factor effect was to calculate the overall mean:

$$
\overline{N O} x_{\exp }=\frac{1}{9} \sum_{i=1}^{9} N O x_{i}
$$

The factor level response for each level was calculated using analysis of means (ANOM) as follows [51]:

$$
\begin{aligned}
& \overline{N O} x_{N O P 1}=\frac{1}{3} \sum_{i=1}^{3} N O x_{i}, \overline{N O} x_{N O P 2}=\frac{1}{3} \sum_{i=3}^{6} N O x_{i}, \overline{N O} x_{N O P 3}=\frac{1}{3} \sum_{i=6}^{9} N O x_{i}, \ldots . . \\
& \ldots . \overline{N O} x_{S O I 3}=\frac{1}{3}\left(N O x_{3}+N O x_{4}+N O x_{8}\right)
\end{aligned}
$$

Note, for instance, that the factor $\overline{\mathrm{NO}} x_{\text {SOI3 }}$ is given by the sum of all the NOx values in Table 8, which are associated with "level 3" of the SOI factor. The actual effect of the factor level is instead determined by its deviation from the overall mean; for instance, for the factor NOP at "level 1 " the $\triangle N O x_{N O P 1}$ is given by [51]:

$$
\Delta N O x_{N O P 1}=\overline{N O} x_{N O P 1}-\overline{N O} x_{\exp }
$$


The orthogonality of the array ensures that this method of estimating the factor effect is balanced since when the mean is calculated for a factor at a fixed level, the remaining factors assume the other levels an equal number of times. Once all the factor effects, or deviations from the overall mean, are calculated, they can be summarized as in Table 9.

The factor effect that presents the highest deviation from the overall mean is the optimal setting; therefore, for each factor the optimal level setting is the one to which is associated the highest value of $\triangle \mathrm{NOx}$ or $\triangle \mathrm{FC}$.

Table 9: Factor effects table

\begin{tabular}{|c|c|c|c|}
\hline \multirow{4}{*}{ Factor } & Level & $\Delta$ NOx & $\Delta$ FC \\
\hline \multirow{4}{*}{ NOP } & 1 & $\Delta$ NOx $_{\text {NOP1 }}$ & $\Delta$ FC $_{\text {NOP1 }}$ \\
\cline { 2 - 4 } & 2 & $\Delta$ NOx $_{\text {NOP2 }}$ & $\Delta$ FC $_{\text {NOP2 }}$ \\
\hline \multirow{4}{*}{ SOI } & 1 & $\Delta$ NOx $_{\text {NOP3 }}$ & $\Delta$ FC $_{\text {NOP3 }}$ \\
\cline { 2 - 4 } & 2 & $\Delta$ NOx $_{\text {SOI1 }}$ & $\Delta$ FC $_{\text {SOI1 }}$ \\
\cline { 2 - 4 } & 3 & $\Delta$ NOx $_{\text {SOI2 }}$ & $\Delta$ FC $_{\text {SOI2 }}$ \\
\hline \multirow{3}{*}{ EGR } & 1 & $\Delta$ NOx $_{\text {SOI3 }}$ & $\Delta$ FC $_{\text {SOI3 }}$ \\
\cline { 2 - 4 } & 2 & $\Delta$ NOx $_{\text {EGR1 }}$ & $\Delta$ FC $_{\text {EGR1 }}$ \\
\cline { 2 - 4 } & 3 & $\Delta$ NOx $_{\text {EGR2 }}$ & $\Delta$ FC $_{\text {EGR2 }}$ \\
\hline \multirow{3}{*}{ VGT } & 1 & $\Delta$ NOx $_{\text {EGR3 }}$ & $\Delta$ FC $_{\text {EGR3 }}$ \\
\cline { 2 - 4 } & 2 & $\Delta$ NOx $_{\text {VGT1 }}$ & $\Delta$ FC $_{\text {VGT1 }}$ \\
\cline { 2 - 4 } & 3 & $\Delta$ NOx $_{\text {VGT2 }}$ & $\Delta$ FC $_{\text {VGT2 }}$ \\
\hline
\end{tabular}

\subsection{Predictive Model}

A predictive model can be derived for the data collected according to the orthogonal array design of experiment. This very simple predictive model is based on the ANOM and expresses the target function (NOx and FC) as a sum of the overall mean and 
the deviation of each factor levels $\left(\mathrm{NOP}_{1}, \mathrm{NOP}_{2}, \mathrm{NOP}_{3}, \mathrm{EGR}_{1}, \mathrm{EGR}\right.$, etc.) from the average [51].

$$
\begin{aligned}
& N O x_{\text {pred }}=\overline{N O} x_{\exp }+\left(\overline{N O} x_{N O P}-\overline{N O} x_{\exp }\right)+\left(\overline{N O} x_{S O I}-\overline{N O} x_{\exp }\right)+.+\left(\overline{N O} x_{E G R}-\overline{N O} x_{\exp }\right) \\
& F C_{\text {pred }}=\overline{F C}_{\exp }+\left(\overline{F C}_{N O P}-\overline{F C}_{\exp }\right)+\left(\overline{F C}_{S O I}-\overline{F C}_{\exp }\right)+.+\left(\overline{F C}_{E G R}-\overline{F C}_{\exp }\right)
\end{aligned}
$$

where each term between brackets, for instance $\overline{N O}_{N O P}-\overline{N O}_{\exp }$, represents the sum of the factor level effects: $\left(\overline{N O}_{N_{N O P} 1}-\overline{N O}_{\exp }\right)+\left(\overline{N O}_{N_{N O P 2}}-\overline{N O}_{\exp }\right)+\left(\overline{N O} x_{N O P 3}-\overline{N O}_{\text {exp }}\right)$.

This model consists of the simple sum of the individual factor effects and does not include cross-terms, which instead, if they were present, would imply interactions between the factors.

The lowest NOx value or the lowest FC that can be achieved per mode is found by substituting the optimal settings, found applying the procedure described in Section 4.6, in the prediction models.

\subsection{Verification Test}

The empirical model produced by this technique predicted values of NOx and FC for every mode. Verification tests were conducted to confirm the model predictions for each of the calibrations generated. When the predictions of the model were not within the confidence levels, the assumption of "independency" of the parameters was rejected and the interaction among the parameters was assumed [3]. In this case a new orthogonal matrix was designed, which included parameter interactions in order to predict NOx and FC more accurately. The redesign of the orthogonal array to include interactions was done for a single mode.

The verification test allows confirming the additivity of the prediction model, which really means its freedom from interactions. If the verification test confirms the model prediction then the optimal solution found is robust, predictable and reproducible; it means that the control factor effects are well understood. On the other hand, a failure in the prediction can indicate a lack in robustness or that there are non negligible interactions, which mean lack of additivity. Establishing how close the prediction and verification results need to be in order to claim a success of the experiment is a difficult task. A method to make this decision is supplied by the ANOVA test [51]. 


\subsection{Analysis of Variance (ANOVA)}

The analysis of variance is a fundamental tool when dealing with DOE techniques. It allows decomposing variations observed in the data into contributions coming from the factor effects, interactions and the experimental error. The significance of each factor effect, indeed, is found by comparing the variance between the factor effects and the variance associated with the experimental data, which can come from a random error or from interactions among the control factors.

ANOVA employs variance to measure the strength of a control factor effect, and does that by means of sum of squares. Once the strongest control factors are identified, they can be used to build an accurate predictive model. The overall mean is used as a reference value from which the deviation of a control factor can be estimated by means of the sum of square. The grand total sum of squares is given by [51]:

$$
\text { GTSS }=\text { SS }+ \text { TotalSS }
$$

The "SS" component represents the sum of squares due to the overall mean:

$$
S S=n_{\exp } \times \overline{N O} x^{2}
$$

The "TotalSS" is given by the contribution to the variation about the mean of every single control factor:

$$
\text { TotalSS }=\sum_{i=1}^{9}\left(N O x_{i}-\overline{N O} x\right)^{2}
$$

For instance, considering NOP as control factor and $\mathrm{n}_{\mathrm{NOP} 1}, \mathrm{n}_{\mathrm{NOP} 2}$ and $\mathrm{n}_{\mathrm{NOP} 3}$ the number of experiments respectively at level 1,2 and 3, the sum of squares due to variation about the mean is given by:

$$
S S_{N O P}=\left(n_{N O P 1}\right)\left(\overline{N O} x_{N O P 1}-\overline{N O} x\right)^{2}+. .+\left(n_{\cdot_{N O P} 3}\right)\left(\overline{N O} x_{N O P 3}-\overline{N O x}\right)^{2}
$$

The $\mathrm{SS}_{\mathrm{NOP}}, \mathrm{SS}_{\mathrm{SOI}} \mathrm{SS}_{\mathrm{VGT}}$ and $\mathrm{SS}_{\mathrm{EGR}}$ become a measure of the relative significance of the control factors if they are compared to the TotalSS:

$$
S S_{\text {NOP }} \%=\left(\frac{S S_{\text {NOP }}}{\text { TotalSS }}\right) \times 100
$$




\subsubsection{Error Variance}

In order to understand whether the control factors are significant and can be used in the predictive model, the variance associated with the control factor ("MS") needs to be compared against the variation of the data due to experimental error and interactions (" $S_{e}{ }^{2}$ "). The F-test can be used for this purpose [51]:

$$
\begin{gathered}
F=\frac{M S}{S_{e}{ }^{2}} \\
M S=\frac{S S_{\text {factor }}}{D O F_{\text {factor }}} \\
S_{e}{ }^{2}=\frac{S S_{\text {error }}}{D O F_{\text {error }}}
\end{gathered}
$$

where MS is the mean square due to a control factor and $S_{e}{ }^{2}$ is the mean square due to experimental error. It is necessary to determine the magnitude of the experimental error and there are many ways to do that. The method used in this work is called "pooling". It consists in pooling the sum of the squares of the control factors which exhibited a small contribution in order to determine the experimental error. This method has been adopted because all the degrees of freedom available in the orthogonal matrix design were used to evaluate the factor effect.

The F-test can be used to determine the significance of a control factor in the predictive model. If $\mathrm{F}>>1$ the effect of a control factor outweighs the variance associated with the experiment and the factor should be used in the predictive model. On the other hand if $\mathrm{F}<2$ the factor effect is moderate compared to the error variance of the experiment, therefore can be neglected and the data gathered can be used to estimate the $S_{e}^{2}[51]$.

\subsection{Second Stage of Emission Reduction}

Further reduction in emissions was achieved using results of the orthogonal matrix optimization as a starting point (baseline values). Based on the ANOVA results the parameter with the most significant impact on emissions was used as a means to obtain further NOx reductions or improve FC (second stage optimization). This 
optimization stage consists basically of "single-parameter" variations. That is, the parameter indicated by the ANOVA analysis is varied until the targeted emissions level or the desired FC are achieved. The variation of the single parameter was interrupted when the engine physical limitations were met.

Once the engine calibrations were generated and evaluated over the certification test cycles (FTPs and ESCs) the engine was retrofitted with an aftertreatment system [see Section 3.4]. The development of the aftertreatment and the impact of the different calibrations on the integrated system (engine retrofitted with DPF and SCR) emissions and performance is described in another work [53].

\subsection{Engine Calibrations Evaluation}

The two calibrations generated were evaluated and compared over sets of steady state (ESC) and transient (FTP) tests. Concentration of the regulated gaseous emissions (NOx, $\mathrm{HC}, \mathrm{PM}, \mathrm{CO}$ ) and $\mathrm{CO}_{2}$ were measured and mass emissions were calculated. In particular, NOx emissions were measured with chemiluminescence and NDUV analyzers. The different calibrations were evaluated in terms of the following parameters:

1. Engine-out NOx produced, since higher NOx means higher urea consumption, which ultimately impacts the FC, making one calibration more advantageous than the other.

2. Engine-out PM level which is responsible for the soot loading of the DPF and hence the frequency of active and passive regeneration.

3. Exhaust temperature and $\mathrm{NO}_{2} / \mathrm{NO}$ ratio as they are considered critical factors for the SCR conversion efficiency [6]. 


\section{CHAPTER 5 RESULTS}

Presented in this chapter are results of the single-mode study on the MY04 engine, and the multimode optimization study on the MY07 engine. "Lessons learned" on the MY04 engine were carried over to the MY07 engine multimode exercise, which covered the entire domain of engine operation. Several calibrations, targeting low NOx emissions and fuel efficient solutions, were generated. Attempts to raise exhaust temperature for the fuel efficient maps were met with varying the timing of opening of the exhaust valve.

\subsection{Single Mode Study (MY04 Engine)}

This study was conducted on the MY04 Volvo engine. Due to the engine's limitations in regard to injection pressure and EGR levels, the engine was mainly used to test the potential of the optimization technique described in Chapter 4. This study focused on the sensitivity of the actuators responsible of the engine parameter variation and their effect on the combustion process.

\subsubsection{Mode Selection}

The selection of mode 3 (see Table 10) of the ESC cycle as the mode for choice of experiments based on the following considerations: it is a mode that produces high NOx levels, and therefore offered good potential for NOx reduction; it has a fairly high weighing factor assigned to it in the formula for the calculation of the cycle emissions; it falls within the NTE zone, and furthermore, it is a medium load-low speed mode, which has proven to be particularly suited for calibrations based on increase of injection pressure and EGR. 
Table 10: Mode 3 of ESC cycle

\begin{tabular}{|c|c|}
\hline MODE & 3 \\
\hline Speed & $1513 \mathrm{rpm}$ \\
\hline Torque & $877.2 \mathrm{Nm}(647 \mathrm{ft}-\mathrm{lbs})$ \\
\hline Indicated Torque & $1127.45 \mathrm{Nm}$ \\
\hline
\end{tabular}

For each parameter three levels of variation were chosen. The high EGR-high injection pressure strategy was implemented by selectively assigning the baseline values to parameter levels (see Table 11), as described in Section 4.4. Table 11 outlines the implemented strategy, which called for progressively closing the EGR valve ("Baseline"="Level 3") and progressively opening the VGT ("Baseline"="Level 1"). Higher values of EGR flow were instead obtained by further opening more the EGR valve and decreasing VGT; the latter had the effect of increasing the pre-turbo pressure, and hence, the pressure gradient across the engine, which in turn, drove more exhaust gases into the intake. Therefore, the EGR-VGT level assignment was made under erroneous assumptions. A preliminary sensitivity study on the actuators would have helped understand the direction of EGR and VGT variation in order to produce greater EGR flow rate. This lesson learned was applied in the multi-modes testing, as reported in Section 5.2.

Table 11: Strategy implementation for low-NOx optimization

\begin{tabular}{|c|c|c|c|}
\hline MODE 3 & LEVEL 1 & LEVEL 2 & LEVEL 3 \\
\hline VGT & Baseline & + & ++ \\
\hline EGR & -- & - & Baseline \\
\hline SOI & - & Baseline & + \\
\hline NOP & Baseline & + & + \\
\hline
\end{tabular}

Due to the level assignment configuration, the algorithm searched the possible solution among points at higher VGT, which ultimately resulted in lower EGR flow rates; therefore higher NOx emissions. 


\subsubsection{Orthogonal Array Testing and Optimal Solution}

The engine was tested according to the nine different configurations shown in the orthogonal array (see Table 12). Brake-specific NOx, PM and FC values were calculated for each test, and results are shown in Table 13.

Table 12: Orthogonal array parameter settings

\begin{tabular}{|c|c|c|c|c|c|}
\hline \multirow{22}{*}{ 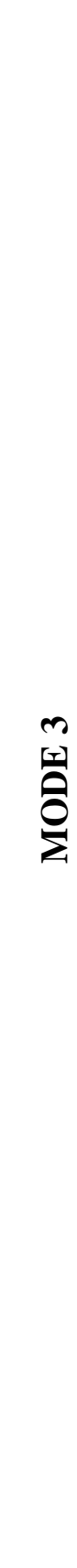 } & & $\begin{array}{l}\text { VGT } \\
\end{array}$ & EGR & SOI & NOP \\
\hline & 1 & idle & idle & idle & idle \\
\hline & 2 & 1 & 1 & 1 & 1 \\
\hline & 3 & 1 & 2 & 2 & 2 \\
\hline & 4 & 1 & 3 & 3 & 3 \\
\hline & 5 & 2 & 1 & 2 & 3 \\
\hline & 6 & 2 & 2 & 3 & 1 \\
\hline & 7 & 2 & 3 & 1 & 2 \\
\hline & 8 & 3 & 1 & 3 & 2 \\
\hline & 9 & 3 & 2 & 1 & 3 \\
\hline & 10 & 3 & 3 & 2 & 1 \\
\hline & & $\begin{array}{l}\text { VGT } \\
\text { (\%) }\end{array}$ & $\begin{array}{c}\text { EGR } \\
\text { (\%) }\end{array}$ & $\begin{array}{l}\text { SOI } \\
\text { (Deg) }\end{array}$ & $\begin{array}{l}\text { NOP } \\
\text { (Deg) }\end{array}$ \\
\hline & 1 & idle & idle & idle & idle \\
\hline & 2 & 43.8 & 55 & 4.4 & 5.4 \\
\hline & 3 & 43.8 & 75 & 8.4 & 7.7 \\
\hline & 4 & 43.8 & 95 & 12.4 & 10 \\
\hline & 5 & 57 & 55 & 8.4 & 10 \\
\hline & 6 & 57 & 75 & 12.4 & 5.4 \\
\hline & 7 & 57 & 95 & 4.4 & 7.7 \\
\hline & 8 & 70 & 55 & 12.4 & 7.7 \\
\hline & 9 & 70 & 75 & 4.4 & 10 \\
\hline & 10 & 70 & 95 & 8.4 & 5.4 \\
\hline
\end{tabular}


Table 13: Orthogonal array and NOx, PM and FC measurements

\begin{tabular}{|c|c|c|c|c|c|c|c|}
\hline & VGT & EGR & SOI & NOP & NOx & PM & FC \\
\hline & Level & Level & Level & Level & g/bhp-hr & mg/bhp-hr & g/bhp-hr \\
\hline $\mathbf{1}$ & 1 & 1 & 1 & 1 & 2.1 & 52.4 & 164.7 \\
\hline $\mathbf{2}$ & 1 & 2 & 2 & 2 & 3.6 & 26.3 & 147.3 \\
\hline $\mathbf{3}$ & 1 & 3 & 3 & 3 & 5.9 & 23.9 & 154.9 \\
\hline $\mathbf{4}$ & 2 & 1 & 2 & 3 & 8.3 & 23.6 & 168.7 \\
\hline $\mathbf{5}$ & 2 & 2 & 3 & 1 & 8.3 & 23.8 & 159.1 \\
\hline $\mathbf{6}$ & 2 & 3 & 1 & 2 & 4.7 & 19.2 & 152.9 \\
\hline $\mathbf{7}$ & 3 & 1 & 3 & 2 & 9.8 & 18.4 & 145.5 \\
\hline $\mathbf{8}$ & 3 & 2 & 1 & 3 & 6.8 & 19.3 & 140.1 \\
\hline $\mathbf{9}$ & 3 & 3 & 2 & 1 & 6.7 & 22.1 & 166.4 \\
\hline
\end{tabular}

Figure 35 displays the plots of the four different factor effects on three different characteristic functions: NOx, PM and FC.

The factor effect was calculated as described in Section 4.6. Figure 35 shows the negative logarithm of the average response. The optimal level for each control factor is the highest value of the characteristic function, which corresponds to the maximum value as seen in Figure 35. Four different optimal solutions were selected according to the characteristic functions, low-NOx, low-PM, low-FC, and low-NOx/low-PM, as shown in Table 14. 


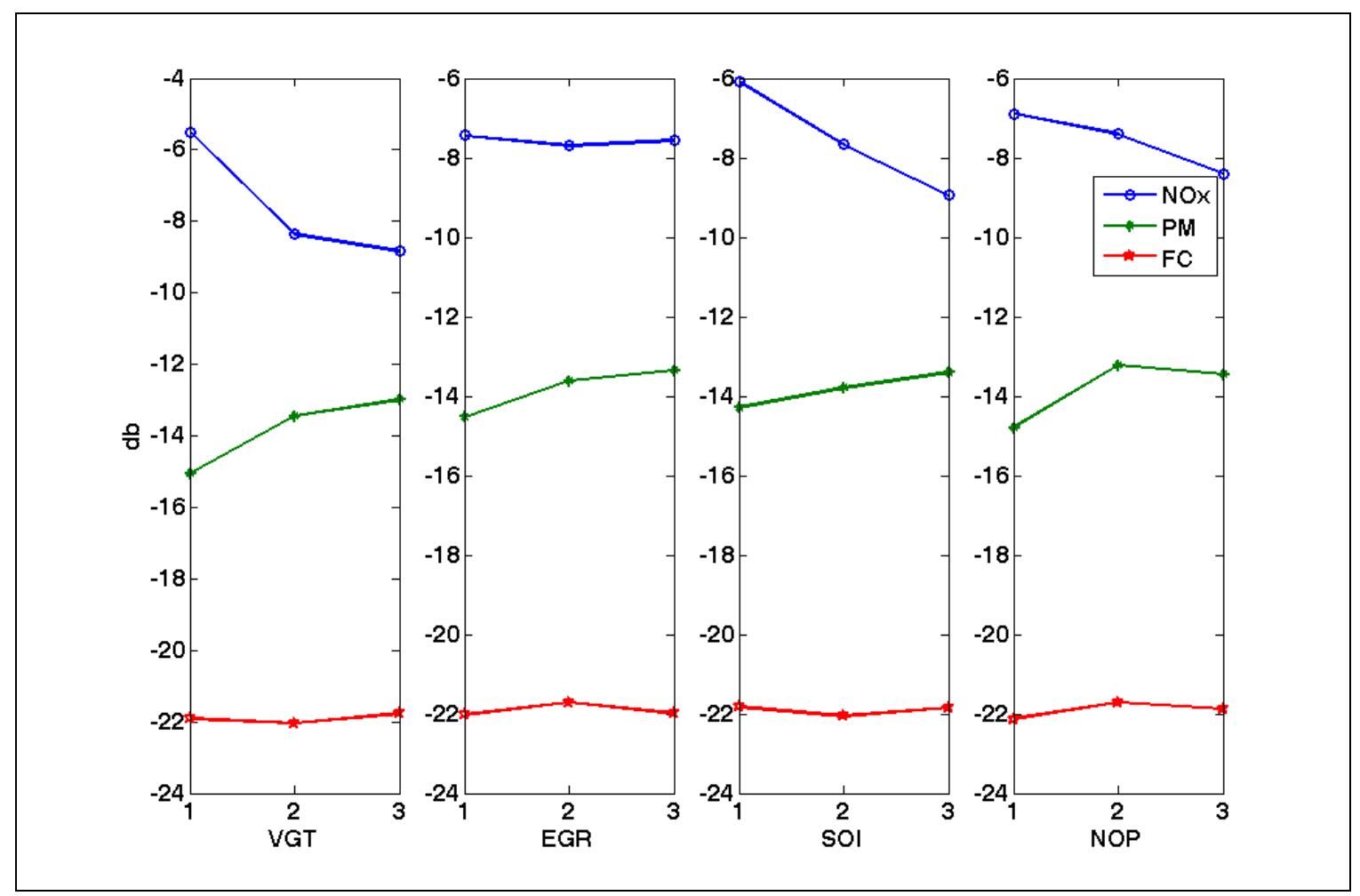

Figure 35: Control factor effects on NOx, PM and FC

Table 14: Optimal configuration for four different target functions

\begin{tabular}{|c|c|c|c|c|}
\hline & VGT & EGR & SOI & NOP \\
\hline low-NOx & 1 & 1 & 1 & 1 \\
\hline low-PM & 3 & 3 & 3 & 2 \\
\hline low-FC & 3 & 2 & 3 & 2 \\
\hline Low-NOx/low-PM & 1 & 3 & 1 & 2 \\
\hline
\end{tabular}

The first solution found in Table 14 indicates a configuration with the EGR valve at relatively closed position ("level 1"), and at retarded injection event ("level 1"). The algorithm could not find high EGR rates points; this may be due the fact that, as mentioned above, closing EGR or increasing VGT both contribute to higher NOx. The NOx reduction is, in this case, primarily due to retarded injection, which compensates for the higher NOx resulting from the closing of the EGR valve. The solution targeting lowPM instead calls for engine configuration with high NOP, VGT and advanced angle. High NOP contributes mainly to PM reduction, and an increase in VGT and the advanced 
injection both contribute to additional reduction in PM. On the other hand, both of these variations lead to higher NOx. The simultaneous optimization of NOx and PM, lowNOx-PM solution, led instead to the algorithm to find a solution at higher NOP and retarded injection. In summary, retarded injection timing turned out to be the only means available for NOx reduction, due to the erroneous level assignment for the EGR and VGT control factors.

\subsubsection{ANOVA of the Results}

Results in Table 13 can be further processed with ANOVA, which can reveal the contribution of each control factor to the responses. Table 15 are shows the degrees of freedom, "DF", the sum square, "SS", and the mean sum, "MS", all of which were discussed in Section 4.9. These values were employed to calculate the contributions of control factors in percent.

Table 15: ANOVA results table

\begin{tabular}{|l|c|c|c|c|c|c|c|c|c|c|}
\hline $\begin{array}{l}\text { Control } \\
\text { Factors }\end{array}$ & $\mathbf{D F}$ & $\mathbf{S S}_{\text {NOx }}$ & $\mathbf{M S}_{\text {NOx }}$ & $\mathbf{N O x}$ & $\mathbf{S S}_{\mathrm{PM}}$ & $\mathbf{M S}_{\mathrm{PM}}$ & $\mathbf{P M}$ & $\mathbf{S S}_{\mathrm{FC}}$ & $\mathbf{M S}_{\mathrm{FC}}$ & $\mathbf{F C}$ \\
\cline { 2 - 11 } & -- & $\mathbf{d B}^{2}$ & $\mathbf{d B}^{2}$ & $\mathbf{\%}$ & $\mathbf{d B}^{2}$ & $\mathbf{d B}^{2}$ & $\mathbf{\%}$ & $\mathbf{d B}^{2}$ & $\mathbf{d B}^{2}$ & $\mathbf{\%}$ \\
\hline VGT & 2 & 20.2 & 10.1 & 53.48 & 8.03 & 4.01 & 43.58 & 0.13 & 0.06 & 18.58 \\
\hline EGR & 2 & 0.82 & 0.41 & 2.18 & 3.14 & 1.57 & 17.02 & 0.18 & 0.09 & 25.63 \\
\hline SOI & 2 & 12.55 & 6.27 & 33.22 & 2.06 & 1.03 & 11.19 & 0.11 & 0.05 & 15.97 \\
\hline NOP & 2 & 4.2 & 2.1 & 11.12 & 5.2 & 2.6 & 28.2 & 0.27 & 0.14 & 39.82 \\
\hline
\end{tabular}

The highest contribution to NOx variation was attributed to VGT, as shown in Figure 36. Contribution of the EGR valve position was minimal. The potential of the VGT to effect NOx reduction was not fully exploited by the optimization search, since levels were assigned in a manner that limited the search toward higher values of VGT; hence, higher NOx. To take advantage of the VGT on NOx reduction, the VGT levels had to be reassigned. The optimal solution was found by varying the injection timing instead, which, according to the ANOVA test, showed it was the second largest contributor to NOx variation. The ANOVA test also showed that VGT, in the selected range and for the mode under investigation, had the highest weight in PM reduction (see Figure 37), which 
explains why the optimization effort found a solution with a more open VGT position. NOP and timing contributed significantly to PM variation, as well. The low PM calibration did not exploit the potential of EGR valve position in reducing PM.

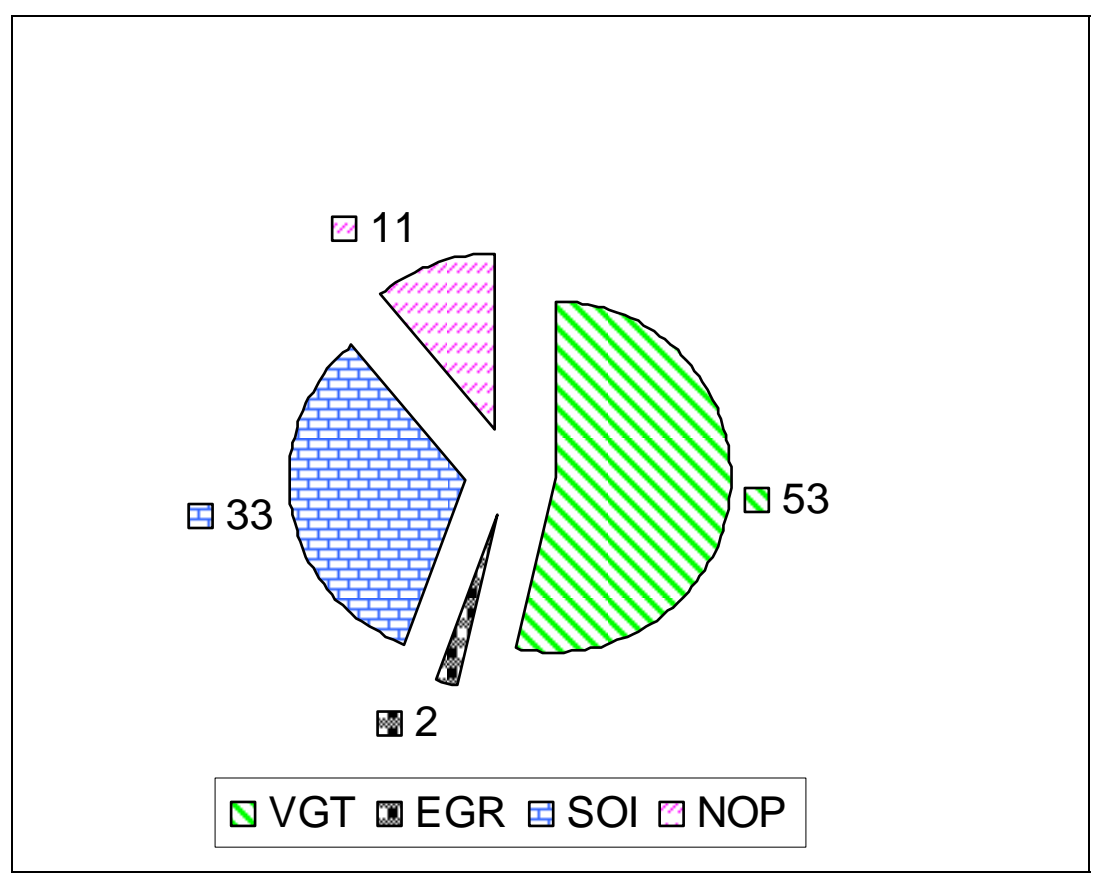

Figure 36: Factors contribution to NOx reduction

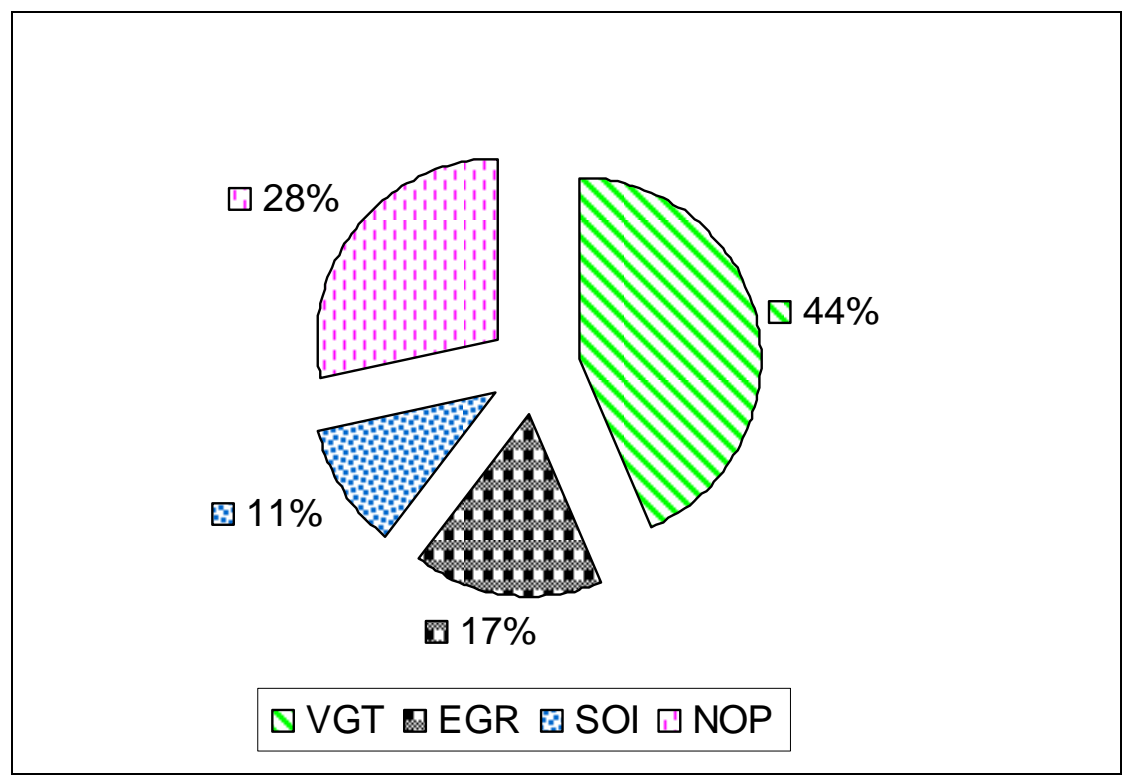

Figure 37: Factors contribution to PM variation 


\subsubsection{Verification Testing}

A model generated from the data shown in Table 13 was used to predict NOx, PM and FC for the four different optimal configurations found.

In Table 16 "NOxp" is the NOx predicted by the model and "NOx" is instead the actual measurement after the verification test, both expressed in $\mathrm{g} / \mathrm{bhp}$-hr to show the actual NOx, PM and FC levels obtained. The difference between the predicted and measured value is called "dell", and it should be less than the "Sigm1", level of confidence; both are left in $\mathrm{dB}$.

Table 16: NOx prediction results for the four characteristic functions

\begin{tabular}{|c|c|c|c|c|}
\hline \multirow{2}{*}{ Calibrations } & NOxp & NOx & Sigm1 & del1 \\
\cline { 2 - 5 } & g/bhp-hr & g/bhp-hr & $\mathbf{d B}$ & $\mathbf{d B}$ \\
\hline Low-NOx & 2.72 & 2.2 & $\mathbf{4 . 9 0}$ & $\mathbf{1 . 3 9}$ \\
\hline Low-PM & 11.16 & 9.17 & $\mathbf{4 . 9 0}$ & $\mathbf{1 . 3 8}$ \\
\hline Low-FC & 11.16 & 9.33 & $\mathbf{2 . 9 5}$ & $\mathbf{0 . 8 2}$ \\
\hline LowNOx/LowPM & 2.72 & 2.42 & $\mathbf{3 . 8 5}$ & $\mathbf{0 . 7 4}$ \\
\hline
\end{tabular}

Table 17 and Table 18 shows the measurements and predictions respectively of PM and $\mathrm{FC}$, for the low-NOx, low-PM, low-FC and low-NOx/low-PM characteristic functions.

Table 17: PM prediction results for the four characteristic functions

\begin{tabular}{|c|c|c|c|c|}
\hline \multirow{2}{*}{ Calibrations } & PMp & PM & Sigm2 & del2 \\
\cline { 2 - 5 } & mg/bhp-hr & mg/bhp-hr & dB & dB \\
\hline Low-NOx & 37.35 & 52.15 & $\mathbf{3 . 0 9}$ & $\mathbf{0 . 7 7}$ \\
\hline Low-PM & 16.09 & 18.51 & $\mathbf{8 . 0 1}$ & $\mathbf{1 . 1 4}$ \\
\hline Low-FC & 16.09 & 21.63 & $\mathbf{4 . 2 8}$ & $\mathbf{0 . 3 0}$ \\
\hline LowNOx/LowPM & 25.99 & 40.88 & $\mathbf{3 . 4 0}$ & $\mathbf{1 . 2 0}$ \\
\hline
\end{tabular}


Table 18: FC prediction results for the four characteristic functions

\begin{tabular}{|c|c|c|c|c|}
\hline \multirow{2}{*}{ Calibrations } & FCp & FC & Sigm3 & del3 \\
\cline { 2 - 5 } & g/bhp-hr & g/bhp-hr & $\mathbf{d B}$ & $\mathbf{d B}$ \\
\hline Low-NOx & 166.15 & 159.62 & $\mathbf{7 . 4 6}$ & $\mathbf{1 . 6 2}$ \\
\hline Low-PM & 149.87 & 159.52 & $\mathbf{1 5 . 1 0}$ & $\mathbf{2 . 5 6}$ \\
\hline Low-FC & 140.97 & 162.00 & $\mathbf{7 . 4 3}$ & $\mathbf{0 . 7 5}$ \\
\hline LowNOx/LowPM & 149.87 & 157.99 & $\mathbf{6 . 8 8}$ & $\mathbf{1 . 0 6}$ \\
\hline
\end{tabular}

Four tests were conducted to verify the model assumption; NOx, PM and FC were predicted accurately within the confidence levels of $68.2 \%(2 \sigma)$ for all the four optimal configurations. Therefore, the model assumption of independency of the control factor effects was valid.

A limitation to the $\mathrm{FC}$ results lays in the fact that $\mathrm{FC}$ was gravimetrically measured and the resolution of the scale did not allow sensing variations lower than 50g, which was the order of magnitude of the parameter effects on FC. An improvement in FC predictions can have been obtained by employing fuel metering instruments with better resolution.

Figure 38 shows the low-NOx optimal solutions. NOx, PM and FC model predictions are compared to their correspondent measured value. As can be seen in Figure 38 the predicted value, for all the response functions, falls within the confidence level $( \pm \sigma)$ indicated on the bars of the measured value. Results are expressed in $\mathrm{dB}$, considering the absolute value of NOx, PM and FC responses. 


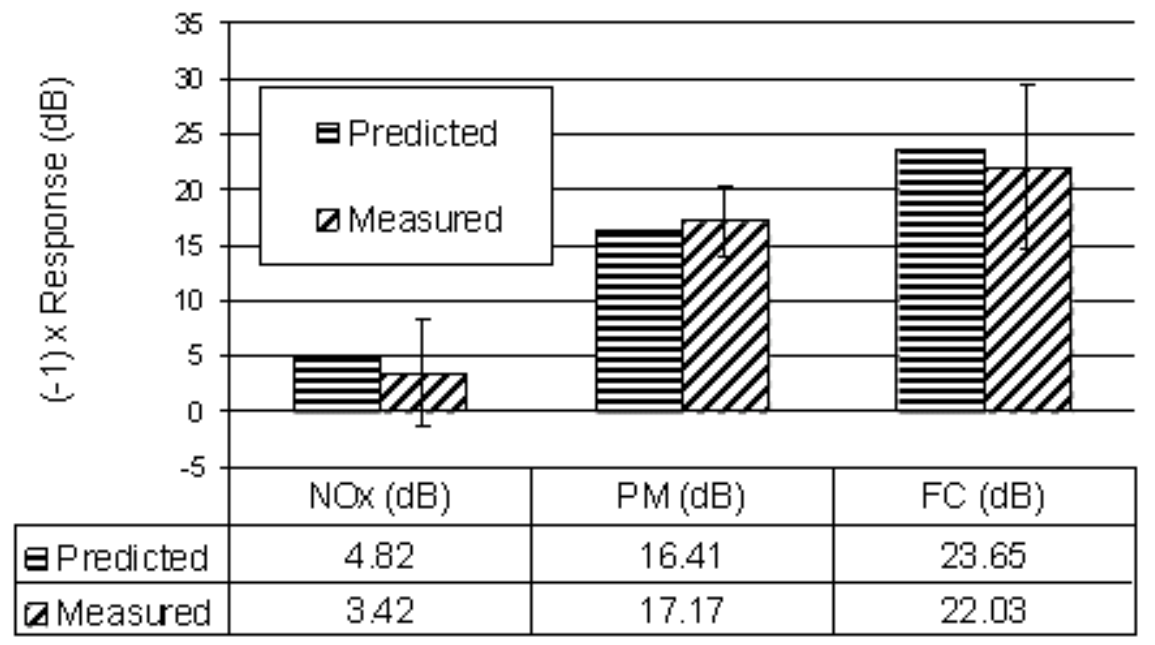

Figure 38: Model predictions and verification measurements for low-NOx optimal solution

\subsubsection{Analysis of the Optimal Engine Configurations}

The low-NOx configuration resulted in a NOx reduction of $10 \%$, an increase in PM of $11 \%$, and slight improvement in FC $(0.3 \%)$ from the baseline levels (see Table $19)$.

Table 19: Emission reduction and performance improvement of the optimal solutions

\begin{tabular}{|c|c|c|c|c|c|c|}
\hline \multirow{2}{*}{ Targets } & NOx & PM & FC & NOxred & PMred & FCred \\
\cline { 2 - 7 } & g/bhp-hr & mg/bhp-hr & g/bhp-hr & $\mathbf{\%}$ & $\mathbf{\%}$ & $\mathbf{\%}$ \\
\hline Low-NOx & 2.20 & 52.2 & 160 & 10.9 & -11 & 0.36 \\
\hline Low-PM & 9.17 & 18.5 & 159 & -271 & 60 & 0.42 \\
\hline Low-FC & 9.33 & 21.6 & 162 & -277 & 54 & -1.12 \\
\hline LowNOxPM & 2.42 & 40.9 & 158 & 2.02 & 13 & 1.38 \\
\hline Baseline & 2.47 & 46.8 & 160 & -- & -- & -- \\
\hline
\end{tabular}

The retarded injection made the main combustion shift from 8 to 10 deg after the TDC as shown in Figure 39. The result was lower in-cylinder pressure (see Figure 40). The combustion process was found to be characterized by lower premixed combustion and 
longer diffusion combustion. The low-PM optimal solution brought a reduction in PM of $60 \%$, an increase in NOx and a reduction in FC of $0.4 \%$. Advancing the injection brought the heat release peak to occur 2 deg before the TDC, as can be seen in Figure 39; hence, the combustion quality improved as the MEP and the maximum in-cylinder pressure increased (see Figure 40).

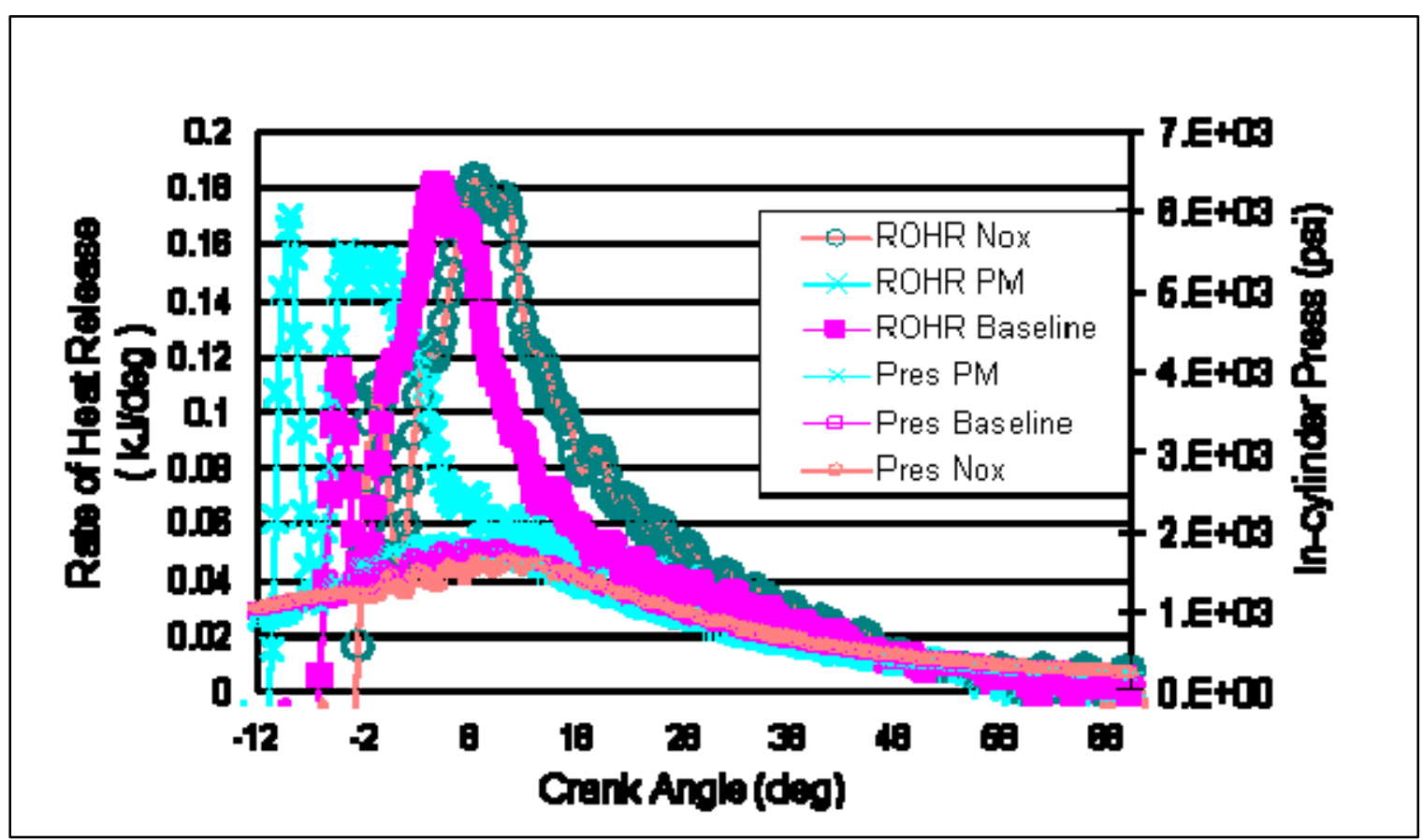

Figure 39: Heat Release curves for the four optimal configurations

The low-FC solution did not lead to any fuel economy improvement (1\% increase in FC). This could be attributed to the inadequate accuracy and resolution of the fuel measurement scale employed. The low-NOx/low-PM solution, instead, brought little reduction in NOx (2\%), a more significant reduction in PM (12\%) and improvements in FC (1\%).

Results showed that with only nine tests it was possible to search a solution space of 27 possible combinations, and to successfully find solutions, that yielded lower emissions and better FC. Furthermore, this approach allowed for development of an experimental NOx model with acceptable accuracy. The positive results of the single mode testing led to the decision to use the present methodology to develop an engine calibration. 


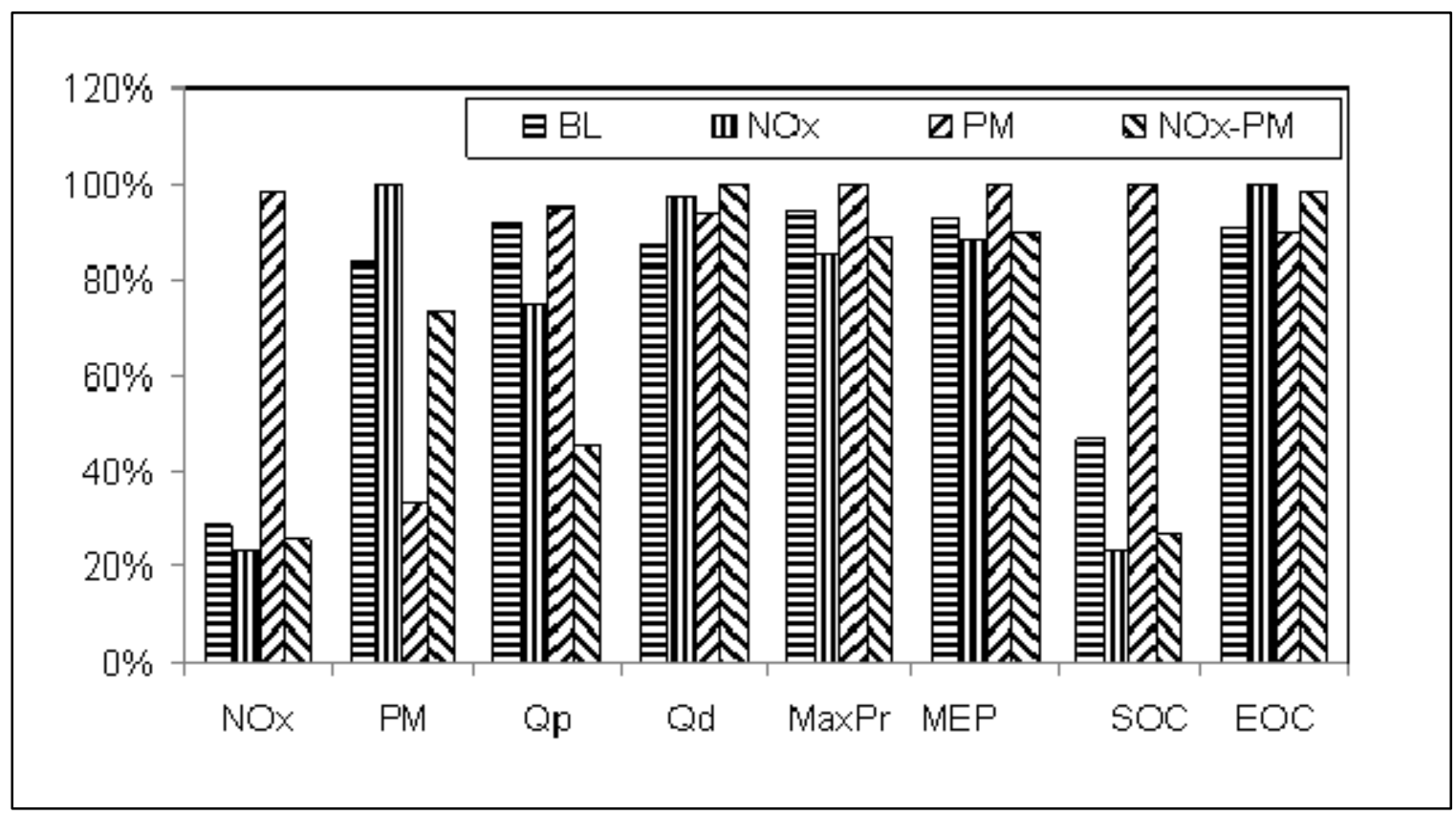

Figure 40: Combustion parameters for the four optimal configurations

\subsubsection{Study on the Single Parameter Effect}

Effect of VGT Variation: The increase of VGT from $43.8 \%$ to $70 \%$, with the other parameters being at their baseline values, had a significant impact on both NOx and PM emissions; NOx increased more than $60 \%$ and PM was reduced by almost the same amount (see Figure 41). This can be explained by the fact that the pre-turbo pressure dropped at higher values of VGT; hence, boost pressure and burned air fraction (BAF) decreased, thus having a major impact on NOx emissions. The lower EGR flow rate decreased the combustion flame temperature, which in turn resulted in lower NOx emissions. On the other hand, PM was reduced as a result of the drop of soot oxidation rate. The mean effective pressure ("MEP") and the AFR exhibited a non-linear trend with the increase of VGT. The rise in premixed combustion appeared to correlate with increase in NOx, just as a decrease in the diffusion combustion correlates with the lower PM emissions (see Figure 42). 
Table 20: Single parameter test matrix

\begin{tabular}{|c|c|c|c|c|c|}
\hline & & VGT & EGR & SOI & NOP \\
\hline & 1 & idle & idle & idle & idle \\
\hline & 2 & 1 & 3 & 2 & 1 \\
\hline & 3 & 2 & 3 & 2 & 1 \\
\hline & 4 & 3 & 3 & 2 & 1 \\
\hline & 5 & 1 & 1 & 2 & 1 \\
\hline & 6 & 1 & 2 & 2 & 1 \\
\hline & 7 & 1 & 3 & 1 & 1 \\
\hline & 8 & 1 & 3 & 3 & 1 \\
\hline & 9 & 1 & 3 & 2 & 2 \\
\hline & 10 & 1 & 3 & 2 & 3 \\
\hline${ }_{\Sigma}^{0}$ & & $\begin{array}{l}\text { VGT } \\
\text { (\%) }\end{array}$ & $\begin{array}{c}\text { EGR } \\
\text { (\%) }\end{array}$ & $\begin{array}{l}\text { SOI } \\
\text { (deg) }\end{array}$ & $\begin{array}{l}\text { NOP } \\
\text { (deg) }\end{array}$ \\
\hline & 1 & idle & idle & idle & idle \\
\hline & 2 & 43.8 & 95 & 8.4 & 5.4 \\
\hline & 3 & 57 & 95 & 8.4 & 5.4 \\
\hline & 4 & 70 & 95 & 8.4 & 5.4 \\
\hline & 5 & 43.8 & 55 & 8.4 & 5.4 \\
\hline & 6 & 43.8 & 75 & 8.4 & 5.4 \\
\hline & 7 & 43.8 & 95 & 4.4 & 5.4 \\
\hline & 8 & 43.8 & 95 & 12.4 & $\begin{array}{l}5.4 \\
\end{array}$ \\
\hline & 9 & 43.8 & 95 & 8.4 & 7.7 \\
\hline & 10 & 43.8 & 95 & 8.4 & 10 \\
\hline
\end{tabular}

Table 20 displays the settings of the four parameters as they were varied one-a-time over three levels, while the remaining factors were maintained at the baseline value (see Section 4.3).

Combustion duration and ignition delay did not exhibit a reduction, as expected, due to lower temperature and higher EGR rates. Both these factors contribute to increase 
the time required for injected fuel to burn. On the other hand, combustion duration and ignition delay were found to be $14 \%$ and $10 \%$ higher, respectively.

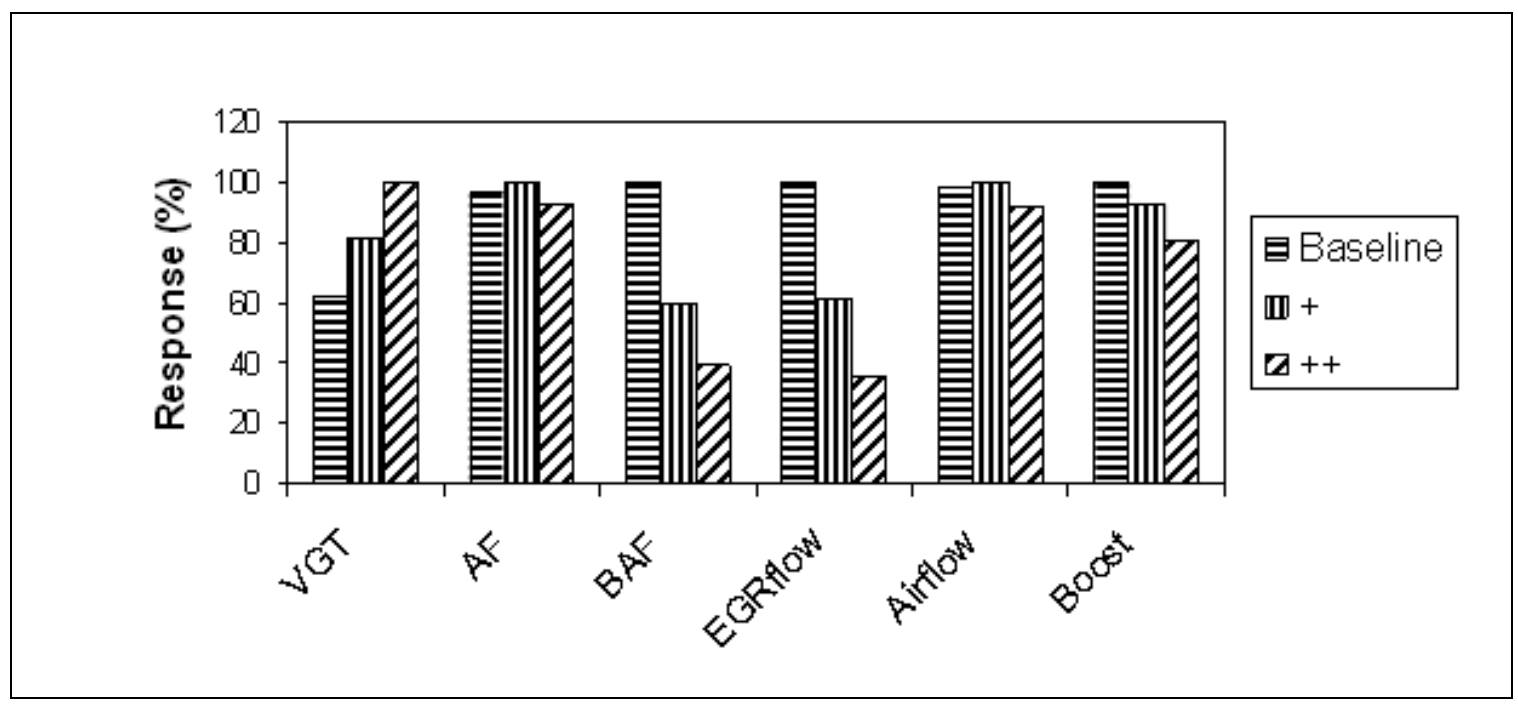

Figure 41: Effect of VGT variation on emission and combustion parameters (“+” and “++” indicates increasing values of VGT as shown in Table 11)

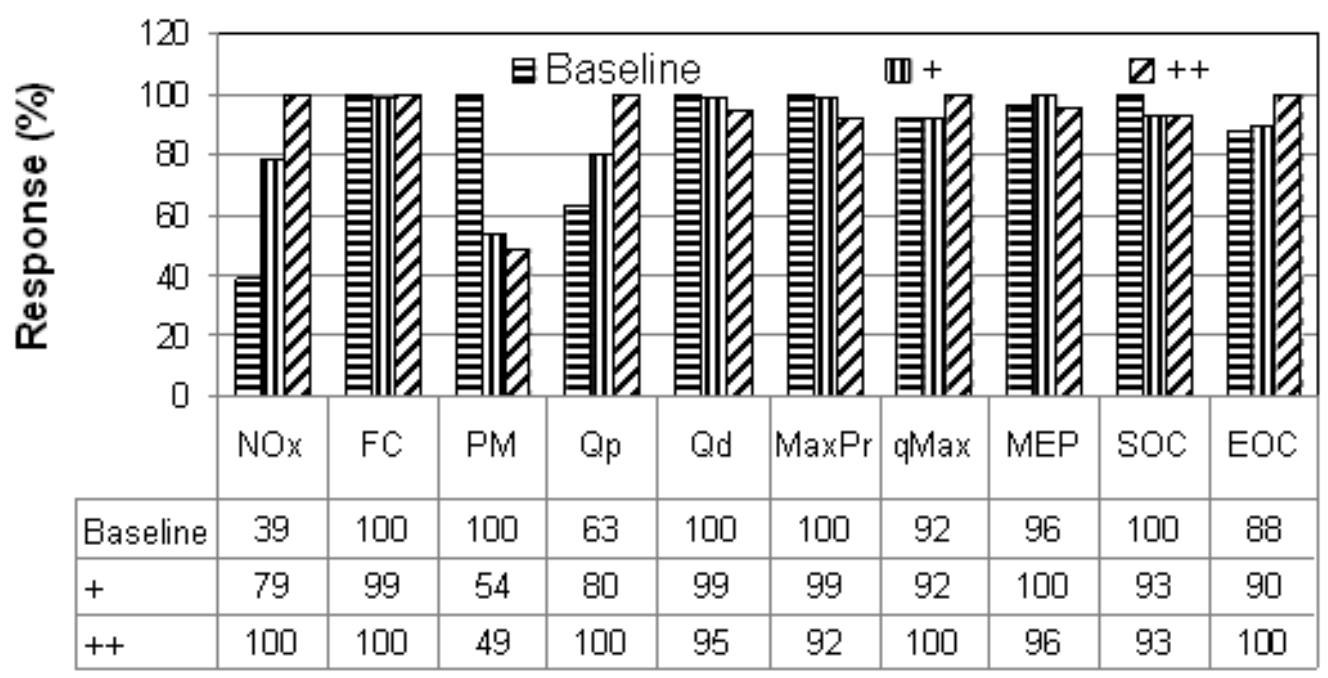

Figure 42: VGT effect on combustion parameter broadcasted by the ECU

Effect of EGR Valve Variation: The EGR valve was progressively closed from 95\% (baseline setting) down to 55\%, in two steps, while VGT was kept at its baseline 
position. This had a significant impact on PM (reduction of 35\%) and led to an increase in NOx emissions of $28 \%$. The increase in NOx was probably related to the reduction in BAF, which was also confirmed by the smaller EGR flow rate available. The slight boost variation correlated with the slight improvement in the AFR and the small increase in incylinder pressure [Figure 43].

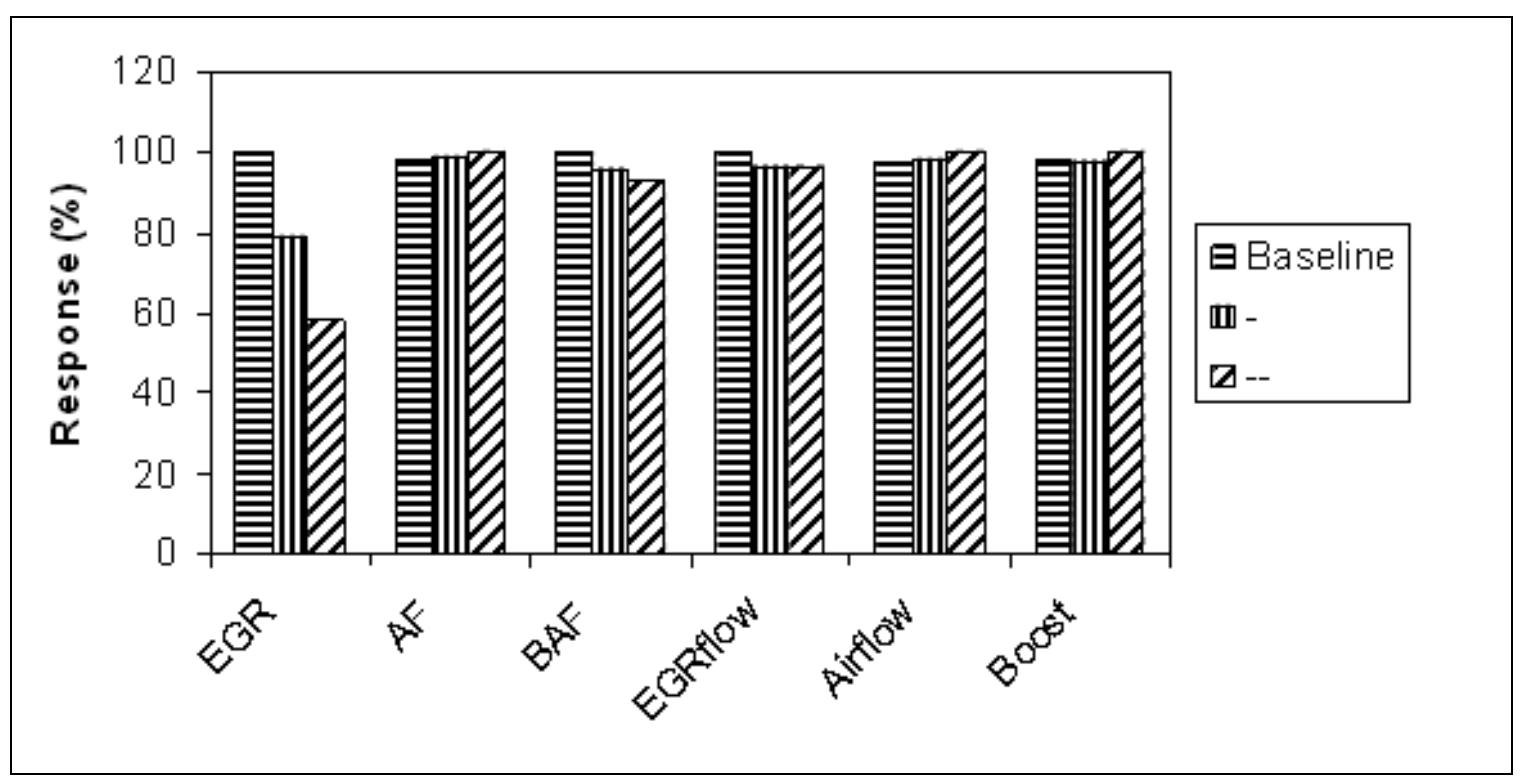

Figure 43: EGR effect on parameter broadcasted by the ECU (“-” and “--” indicates decreasing values of EGR as shown in Table 11)

Effect of SOI: SOI was retarded from the baseline value (crank angle, $8.4 \mathrm{deg}$ ) and then advanced by 4 deg. Retarding the injection resulted a significant reduction in NOx (12\%) and a significant increase in PM (30\%). Delaying the injection led the main combustion event to occur at $10 \mathrm{deg}$ after the TDC, as shown in Figure 44. As a consequence, the in-cylinder pressure peak and the MEP were reduced, and a reduction in in-cylinder temperature caused lower NOx. The loss of work appeared as an increase of FC (1.4\%). Lower pressure in the combustion chamber and lower temperatures resulted in lower combustion efficiency, and the increase in PM testified to the decreased combustion quality. 


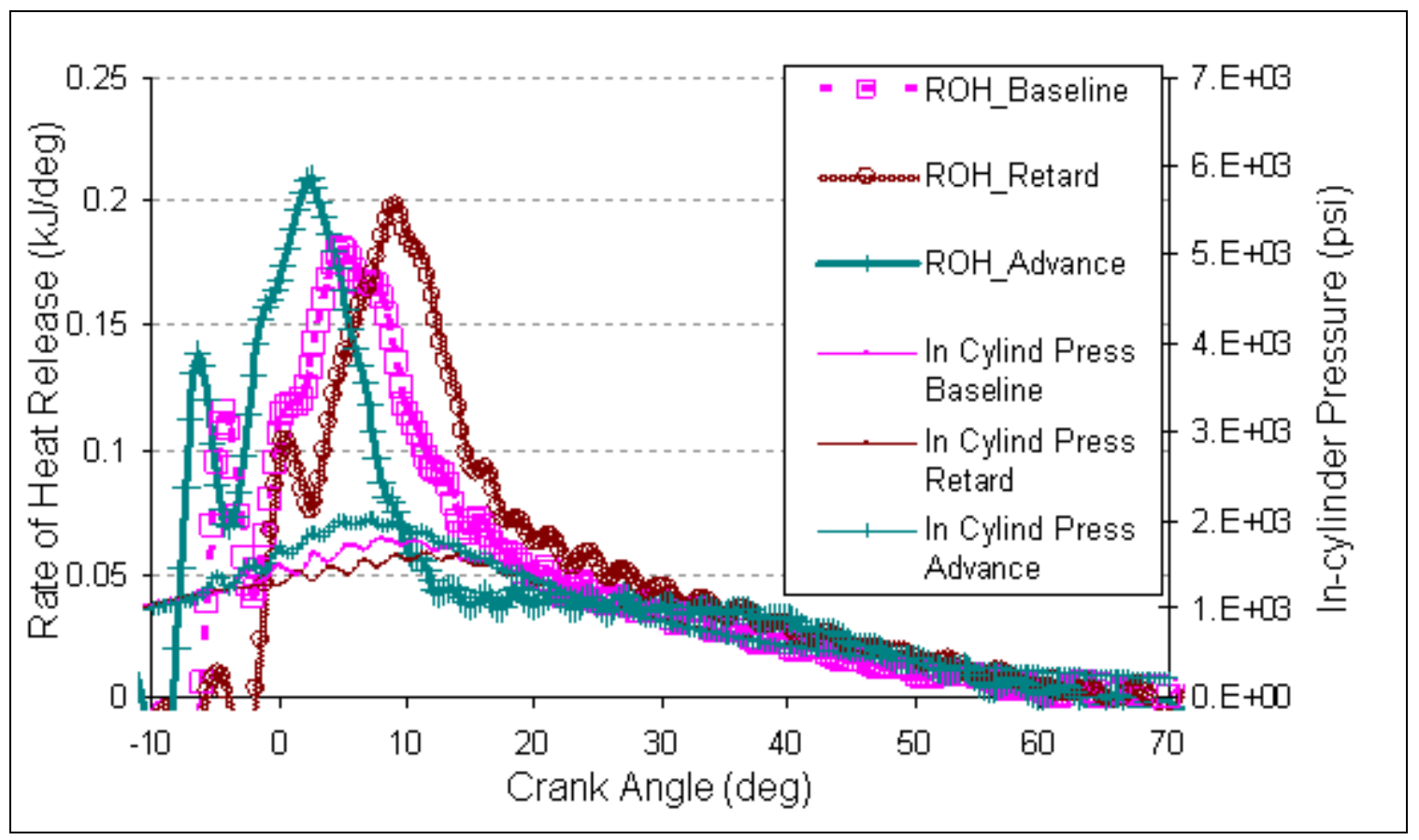

Figure 44: SOI variation effect on heat release curve

Slight increase in boost pressure correlated with the slightly higher AFR. Other effects of the injection retard can be seen on the small reduction in EGR flow rate and BAF, which contributed very little to NOx variation. The ignition delay, defined as the difference between the fuel injection and the start of combustion points, should have increased because with lower in-cylinder temperature, the entire chemical reaction should slow down. Instead ignition delay exhibited a value higher than 3\% from the baseline. The premixed and diffusion combustion were both slightly higher than the baseline and they did not correlate with NOx and PM variations, as expected.

Advancing the timing led NOx to increase (40\%), PM to decrease (33\%) and a reduction was observed in FC. The higher quality of combustion, as suggested by the lower PM and FC, may be attributed to the fact that the main combustion is closer to the TDC. Higher in-cylinder peak pressure and MEP caused the NOx to increase and this correlated well with the higher premixed portion. The lower PM observed instead, correlated with the lower diffusion portion of the combustion. The ignition delay was greater than $50 \%$ with respect to the baseline value, which probably explains the peak of premixed combustion. Lower ignition delay was expected since the combustion was accelerated bringing the heat release peak closer to the TDC. A small decrease in boost 
brought a slight decrease in AFR, BAF and EGR flow rate and subsequently a small contribution to NOx emissions.

Effect of NOP: As NOP was increased NOx was significantly affected (increase of $38 \%$ ), but a bigger impact was observed on PM, a reduction of $55 \%$. The average injection pressure increased from 1186 bar to 1384 bar and the injection duration was shortened, as can be seen in Figure 45. The higher level of injection pressure led to higher peak pressure and mean effective pressure (MEP).

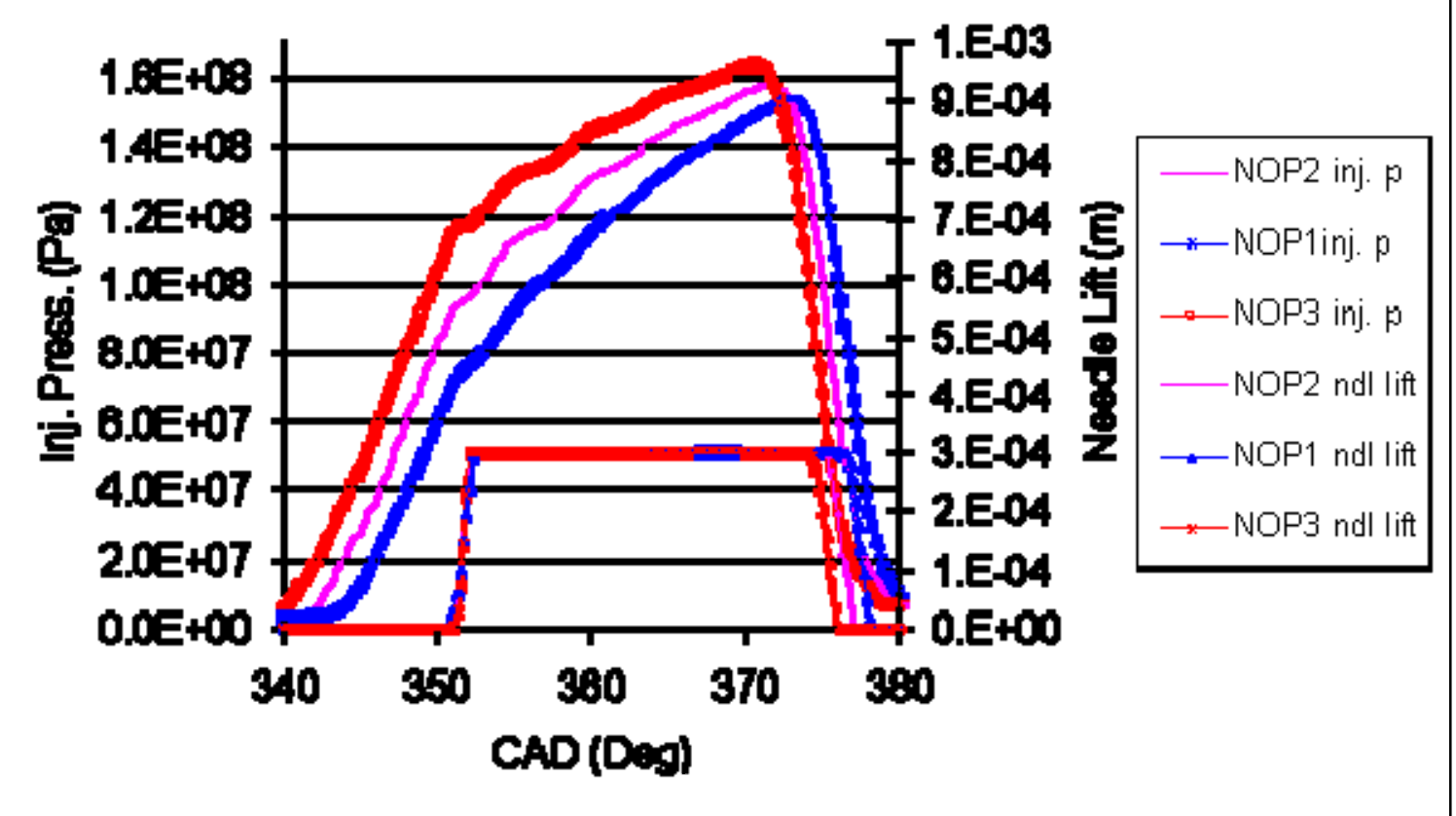

Figure 45: Effect of NOP on injection pressure and needle lift

Higher injection pressure resulted in better fuel atomization. This basically leads to a faster air-fuel mixing, hence better combustion. This was confirmed by the significant reduction in soot and improved FC (1.2\%) observed (see Figure 46). For intermediate NOP (NOP at "level 2") the ignition delay was reduced of $10 \%$. For high NOP (NOP at "level 3"), instead, the ignition delay was substantially unchanged from the baseline, but the premixed combustion peaked.

The effects of NOP increase on boost and AFR were negligible; the reduction of BAF and EGR flow instead had very little effect on NOx variation. 


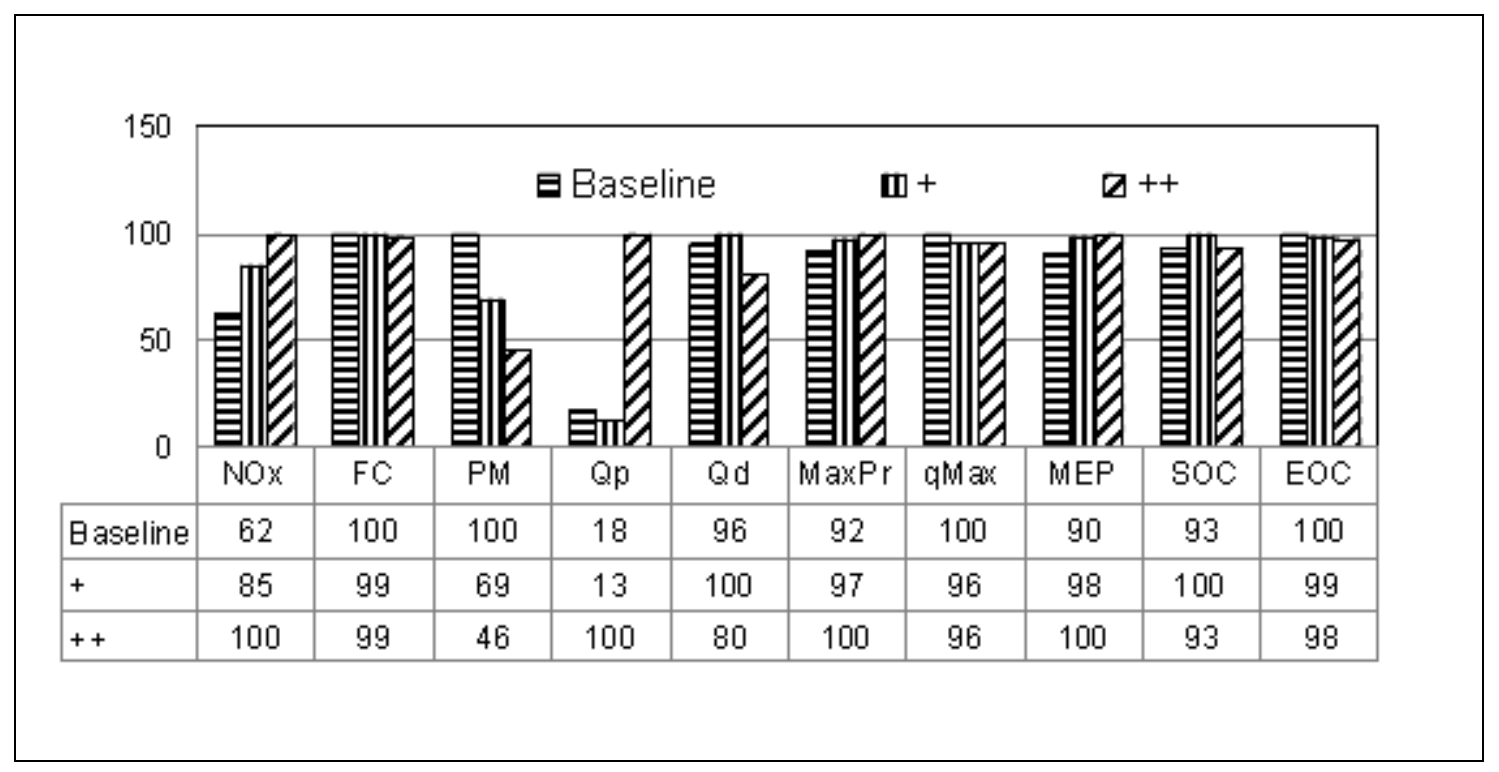

Figure 46: Effect of NOP on combustion parameters (“+” and “++” indicates increasing values of NOP as shown in Table 11)

Figure 47 and Figure 48 summarize the control factor effects in terms of NOx-PM and NOx-FC trade off.

VGT resulted to be a very effective means of NOx control (from 2.6 to $6.6 \mathrm{~g} / \mathrm{bhp}$ hr), with moderate effect on PM (44\%) and negligible impact on FC. On the other hand, high NOP affected significantly PM (181\% reduction), and FC (1\% reduction) with moderate variation in NOx (58\%). EGR valve had little impact on NOx and PM emissions, in the selected range, respectively $31 \%$ and $33 \%$. SOI was instead effective in controlling NOx with 19\% NOx reduction when retarded, and 77\% NOx increase when advanced; and in controlling PM, 44\% PM increase when retarded, and 47\% reduction when advanced.

Even though these results were obtained for just one mode of the ESC cycle, they show the NOx control potentials of VGT and the capability of PM reduction of NOP. 


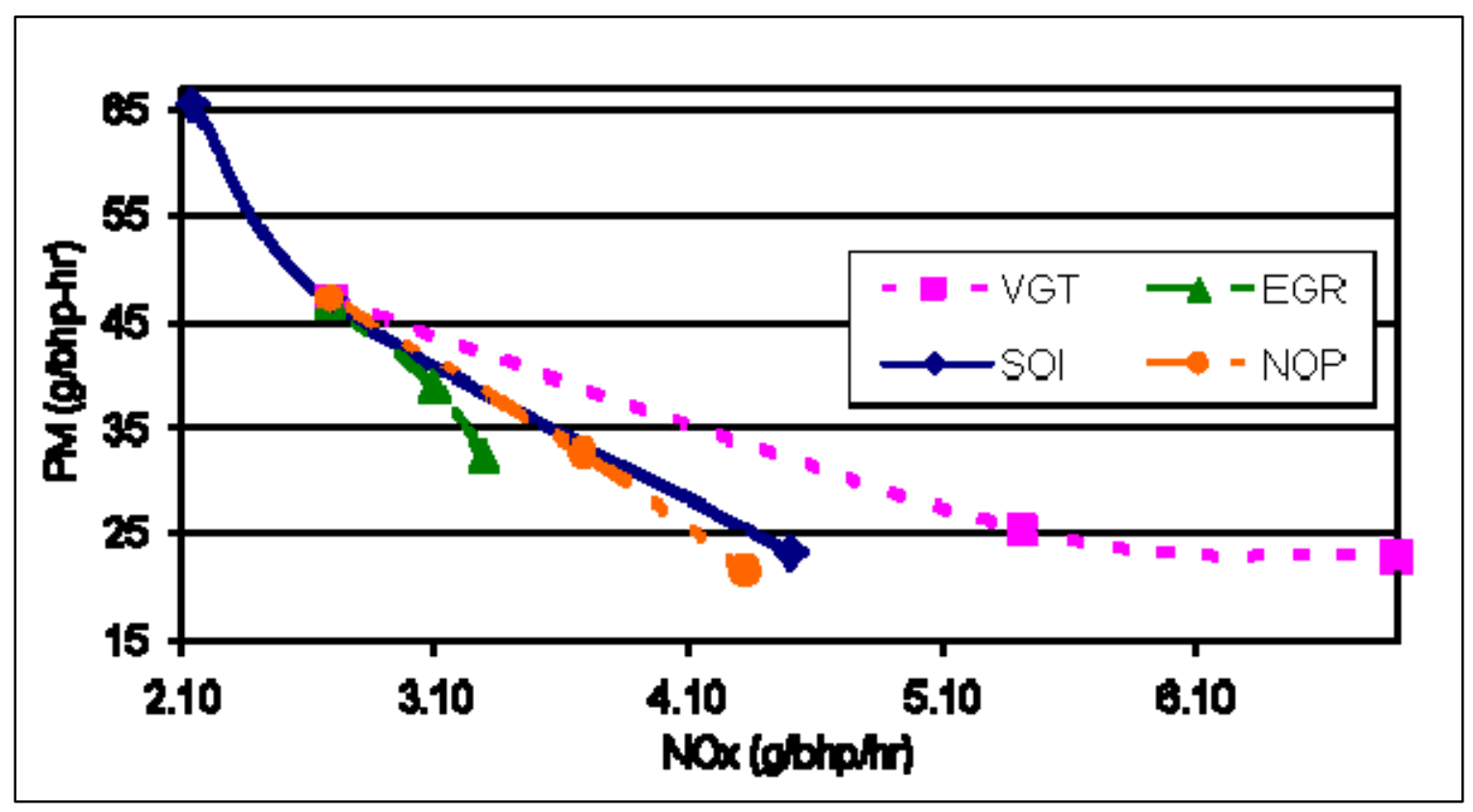

Figure 47: NOx-PM trade off for the different control factors

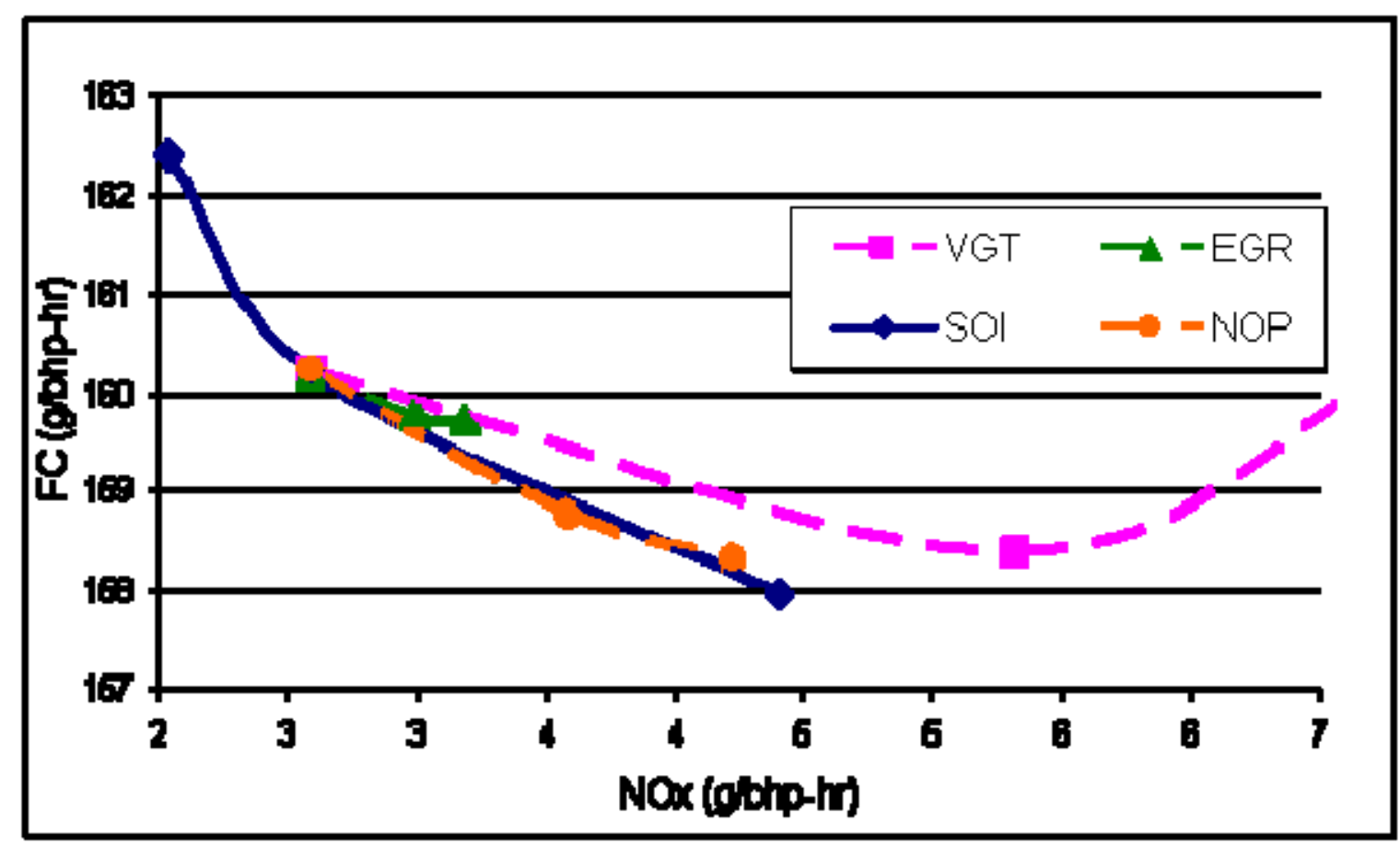

Figure 48: NOx-FC trade off for the different control factors 


\subsection{Multi-mode Study to Optimize the MY07 Volvo MD11 Engine}

The single-mode study on MY04 Volvo engine proved that the optimization technique that was employed was successful and it could be used to optimize the engine over the remaining modes of the ESC and the AVL cycles. Work on the MY04 engine showed how critical it was to understand the direction of EGR and VGT variations in order to allow the algorithm to search in the zones suggested by the emission reduction strategy. It was understood that EGR and VGT have to be varied in order to make enhance the EGR flow rate. It was also understood that the change that would significantly affect NOx emissions may depend upon the engine mode. Therefore, a study was conducted on the sensitivity of the two actuators for each of the engine operation modes that were involved in the optimization process.

\subsubsection{EGR Flow Sensitivity Study}

As is evident in Figure 49 , setting the EGR valve to a more open position, compared to the baseline value, drastically increased the EGR flow rate and reduced NOx emissions. This was found to be true for all modes that were optimized except for mode 3 (ESC cycle). For mode 3, progressive opening of the EGR valve led to a reduction in EGR flow rate; hence, an increase in NOx. On the other hand, higher values of VGT yielded lower EGR flow rate; hence, higher NOx (see Figure 50). Large steps of EGR valve variation impacted NOx in a manner, very similar to what small increments of VGT did. Therefore, a wider range was associated with EGR valve position. Furthermore, it was noticed that VGT exhibited a more linear relationship with EGR flow rate, and ultimately with NOx concentrations, than EGR valve position. 


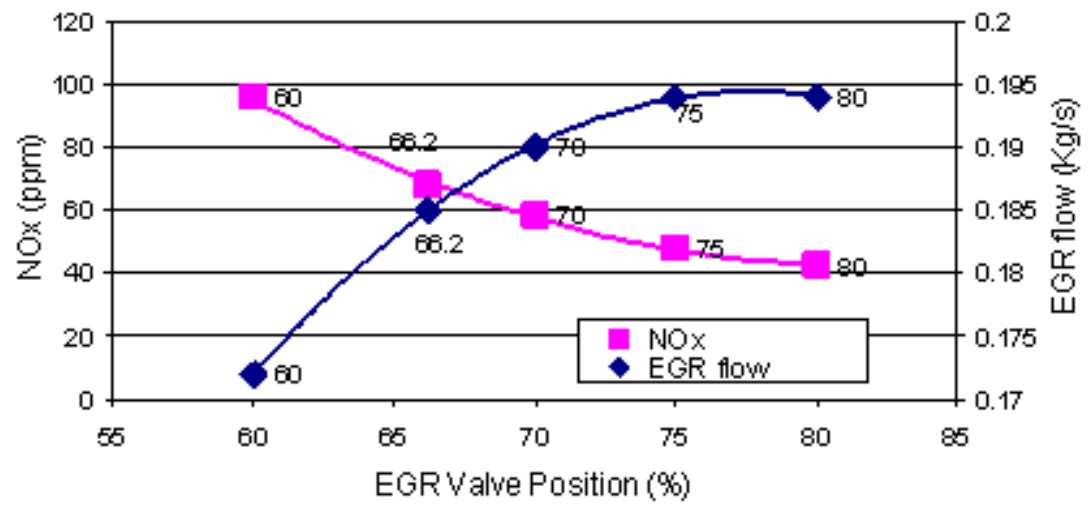

Figure 49: Effect of EGR valve sweep on NOx and EGR flow, MODE 10

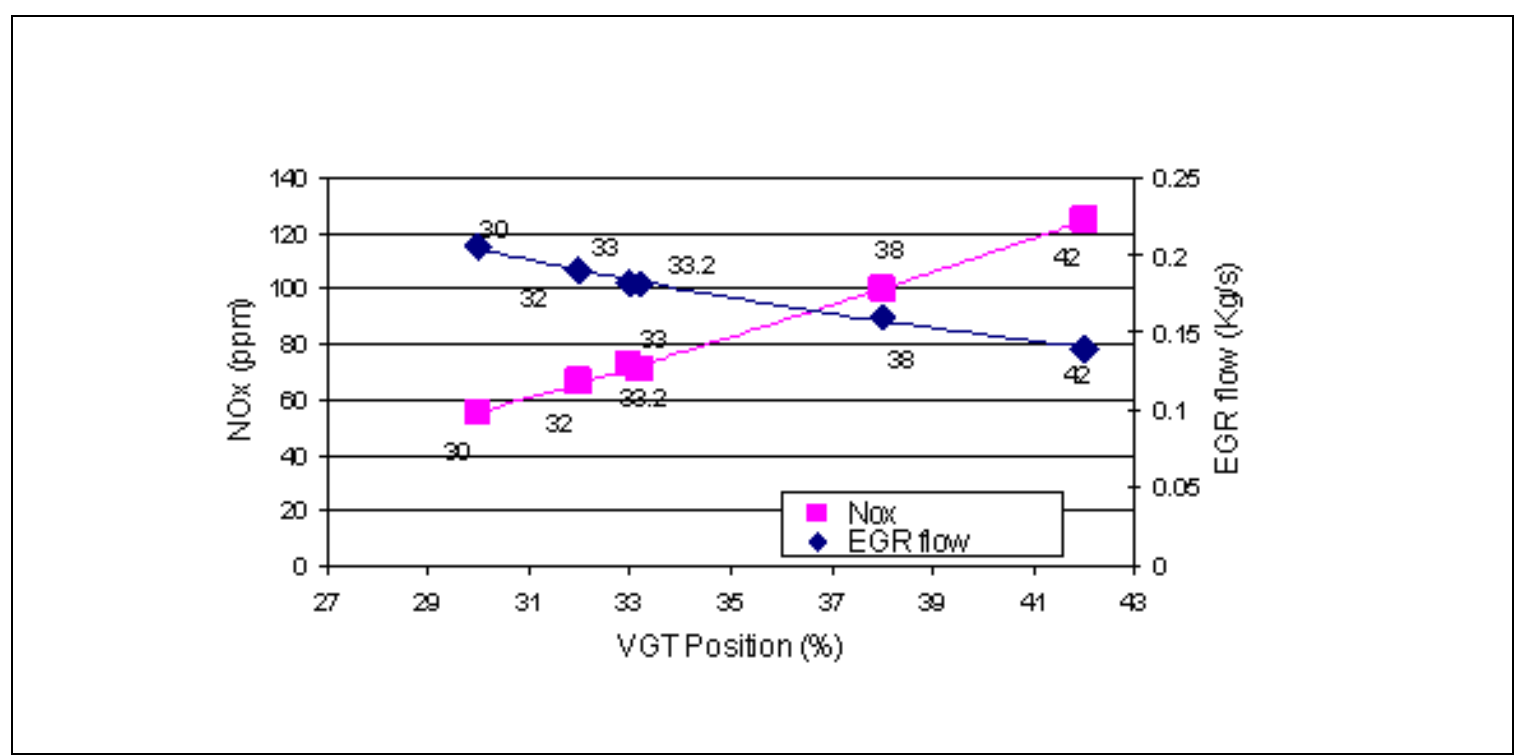

Figure 50: Effect of VGT sweep on EGR flow and NOx (MODE 10)

NOx emissions exhibit a high sensitivity to VGT variations. Further the ANOVA identified VGT as one of the main contributors in the characteristic function variations, as discussed in Section 5.2.3. 


\subsubsection{Level Assignment Matrixes}

The implementation of NOx and FC reduction strategies is shown in Table 21 and Table 22. Baseline values were assigned to each of the control factors, for every ESC and AVL mode. Baseline settings are shown as bold values in Table 21. High injection pressure and high EGR rate strategy was implemented for the low-NOx calibrations and high injection pressure and advanced injection timing strategy was implemented for the low-FC calibrations as described in Section 4.4. Note that only six modes, among the low and intermediate load modes of the ESC cycle were optimized for the low-NOx calibration (see Table 21). For the high load modes, namely modes 2, 8 and 10, it was observed that a slight increase in EGR flow rate, by means of EGR valve and/or VGT variation, induced the engine control to activate an "engine protection mode". This caused the fuel to be reduced and it was difficult to maintain the same load setting when this occurred. The "engine protection mode" is typically enabled when engine physical limitations, such as in-cylinder pressure limit or turbo-wheel speed limit and compressor discharge temperature are violated. The main engine parameters were constantly monitored, and none of them exceeded the limitations prescribed; therefore, the limited information available on the dynamics of the engine control imposed to exclude the highload modes from the optimization process. This problem did not occur for the low-FC calibration, since the algorithm searched for solutions at lower EGR rate; therefore, all the ESC and AVL modes could be optimized (see Table 22). 
Table 21: Level assignment for low-NOx calibration, (6 ESC modes).

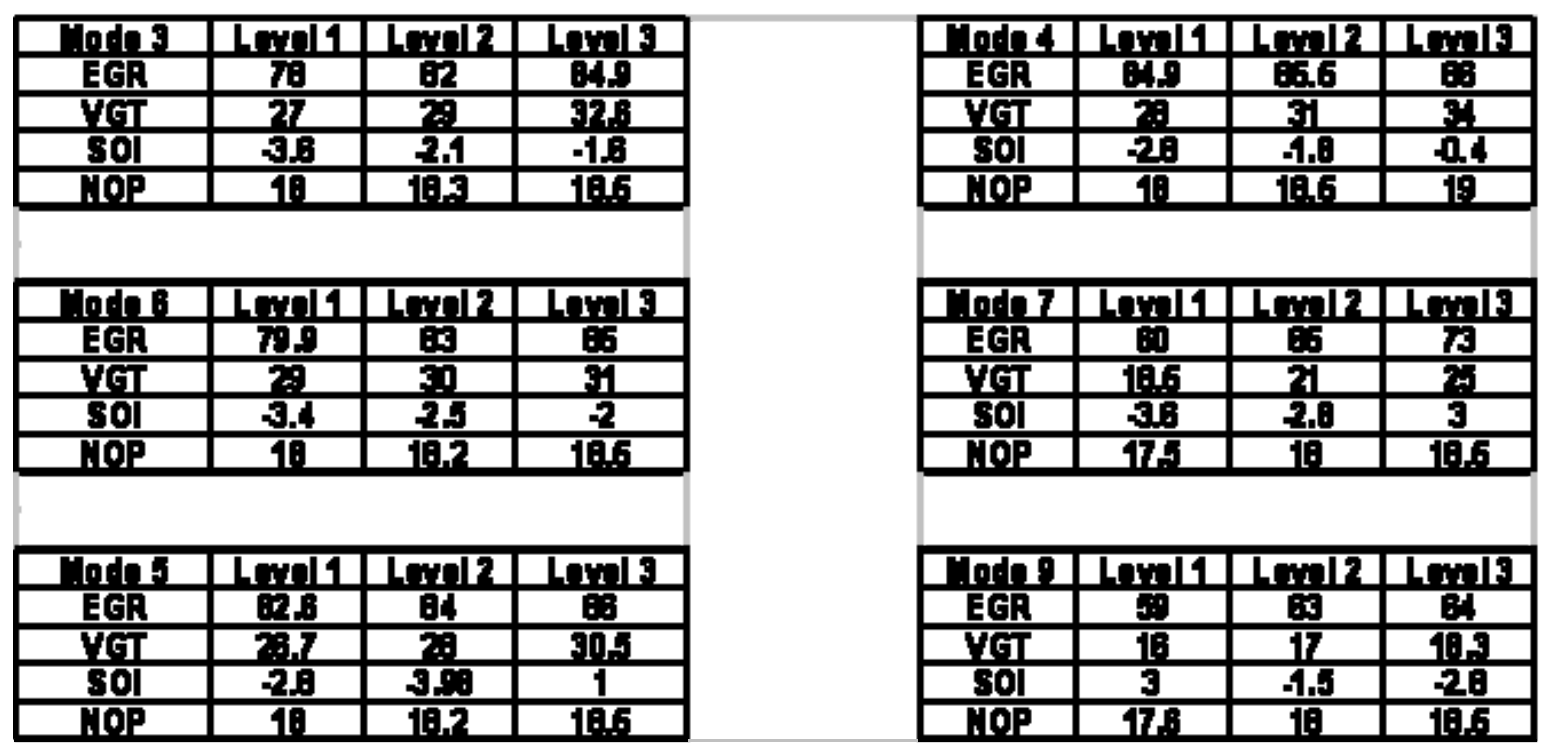

Another issue associated with "engine protection mode" was encountered while testing the low-NOx calibration. After many hours of operation the engine control was restricting the fuel flow during the high power section of the test cycles; this was attributed to the compressor discharge temperature, which exceeded the acceptable limit. The sensor wired to the engine control unit (ECU) detected a temperature significantly higher than the one measured with laboratory thermocouples. The discrepancy between the two temperature readings is to attribute to a lack of accuracy of the engine sensor. The testing of the low-NOx calibration, at high EGR flow rate, probably caused collection of soot in the intake line, which ultimately affected the compressor discharge sensor operation. 
Table 22: Level assignment for low-FC calibration, ESC modes

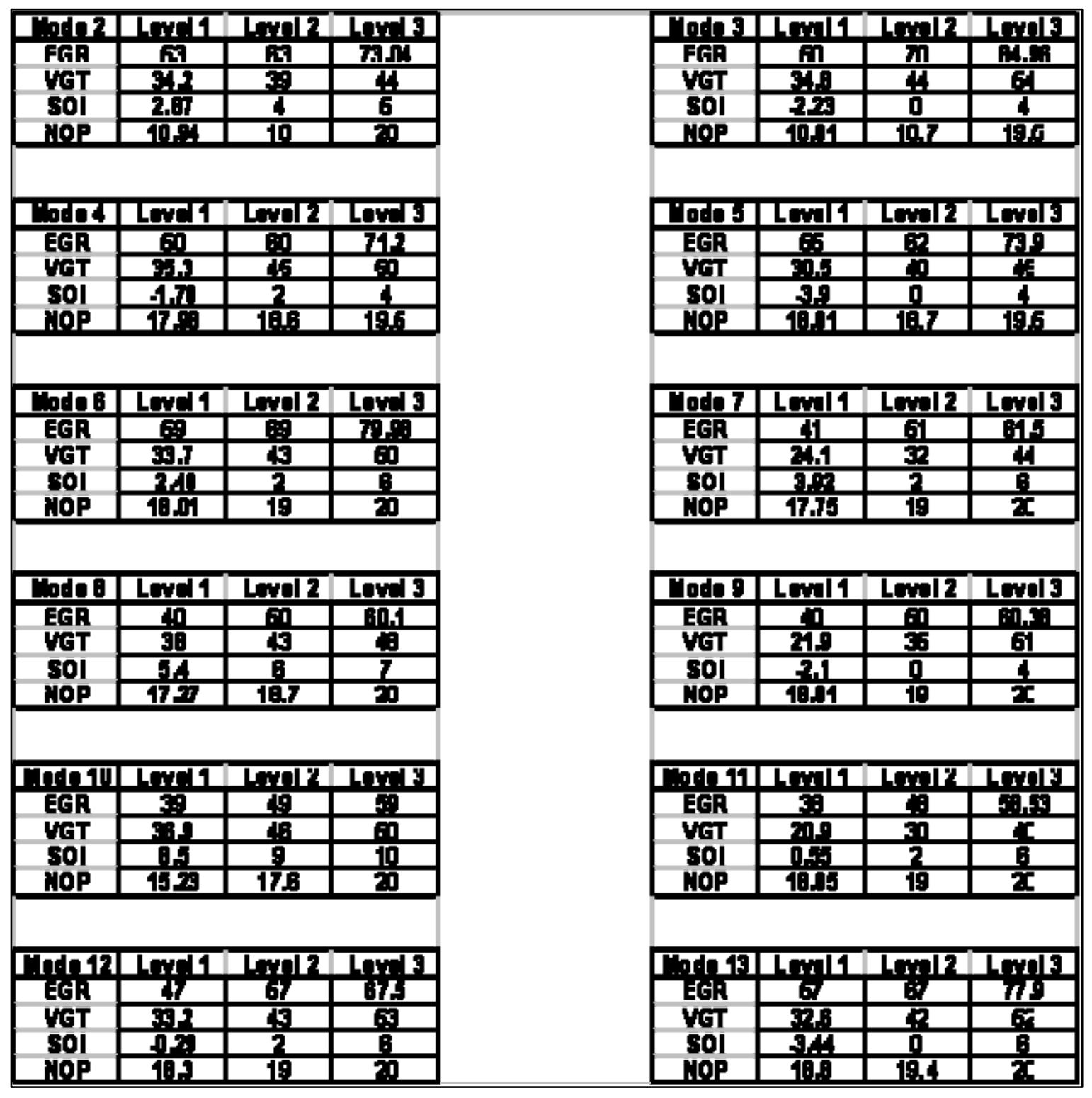

The control factor level assignments for the AVL modes for both calibrations are not reported here for brevity.

\subsubsection{Optimal Settings Selection and Verification Test}

The low-NOx optimal settings found for the six modes of the ESC cycle are shown in Table 23. Mode 2 was optimized, but during the verification test the engine control enabled the "engine protection mode." Although Table 23 shows the optimized 
setting, for Mode 2, the verification analysis was not completed. Almost all modes exhibited high EGR flow rate, obtained by more open EGR valve position (EGR=level 3) and less VGT (VGT=level 1), compared to the baseline settings. The injection pressure was increased for modes 5,6 and 7. The injection timing was almost always advanced, except for mode 9, where it was retarded, and for mode 7 timing remained unchanged from its baseline value. The ANOVA results, also displayed in Table 23, revealed that the control factors that provided the most relevant contribution to NOx reduction were VGT and EGR. Much smaller weight was assigned to SOI and NOP; hence, these parameters were employed to estimate the experimental error in the predictive model. The model generated was able to accurately predict NOx, within the confidence levels, which means "Delta1"< "Sigma" in Table 23 and as described in more detail in Section 5.1.4. Accurate predictions were obtained for all the modes optimized, as shown in Figure 51.

The low-FC results are displayed for the ESC modes in Table 24. For almost all modes the most fuel efficient engine configuration was determined by advancing injection timing and lowering EGR rates, which was realized by reducing VGT. For mode 6 a reduction of EGR rate was performed by varying EGR valve, as well. For mode 8 the optimal solution also included higher level of injection pressure. The model predicted accurately FC for all the 13 modes. 
Table 23: Verification test for the low-NOx calibration (ESC modes)

\begin{tabular}{|c|c|c|c|c|c|c|c|c|c|c|}
\hline \multirow{2}{*}{ Mode } & \multirow{2}{*}{ Calibrations } & VGT & EGR & SOI & NOP & Prediction & Baseline NOx & Meas NOx & Sigma1 & Del1 \\
\hline & & $(\%)$ & $(\%)$ & (Deg) & (Deg) & (ppm) & (ppm) & (ppm) & (dB) & (dB) \\
\hline \multirow{3}{*}{ MODE 2} & Low NOx & 30 & 82 & 1.2 & 18.2 & & 75.5 & 44.5 & & \\
\hline & Level & 1 & 3 & 2 & 3 & & & & & \\
\hline & ANOVA & & & & & & & & & \\
\hline & & & & & & & & & & \\
\hline \multirow{3}{*}{ MODE 3} & Low NOx & 27 & 78 & -3.6 & 18 & 9.32 & 26.2 & 14.8 & 2.95 & 2.01 \\
\hline & Level & 1 & 1 & 1 & 1 & & & & & \\
\hline & ANOVA & 87.94 & 0.49 & 6.83 & 4.74 & & & & & \\
\hline \multirow{3}{*}{ MODE 4} & Low NOx & 28 & 86 & -2.8 & 18 & 13.78 & 45.4 & 13.3 & 4.72 & 0.15 \\
\hline & Level & 1 & 3 & 1 & 1 & & & & & \\
\hline & ANOVA & 98.34 & 0.02 & 1.54 & 0.1 & & & & & \\
\hline \multirow{3}{*}{ MODE 5} & Low NOx & 26.7 & 86 & -3.98 & 18.2 & 1463 & 306 & 151 & 2.91 & 0.14 \\
\hline & Level & 1 & 3 & 2 & 2 & & & & & \\
\hline & ANOVA & 92.71 & 0.55 & 6.59 & 0.14 & & & & & \\
\hline & & & & & & & & & & \\
\hline \multirow{3}{*}{ MODE 6} & Low NOx & 29 & 85 & -3.4 & 18.5 & 31.66 & 43.9 & 25.7 & 3.43 & 0.91 \\
\hline & Level & 1 & 3 & 1 & 3 & & & & & \\
\hline & ANOVA & 94.6 & 3.49 & 1.68 & 0.23 & & & & & \\
\hline & & & & & & & & & & \\
\hline \multirow{3}{*}{ MODE 7} & Low NOx & 18.5 & 73 & -2.8 & 18 & 2.86 & 12.2 & 3.3 & 4.87 & 1.37 \\
\hline & Level & 1 & 3 & 2 & 2 & & & & & \\
\hline & ANOVA & 58.83 & 33.37 & 7.34 & 0.46 & & & & & \\
\hline \multirow{4}{*}{ MODE 9} & & & & & & & & & & \\
\hline & Low NOx & 16 & 64 & -2.8 & 17.6 & 3.4 & 13.5 & 3.3 & 7.82 & 0.7 \\
\hline & Level & 1 & 3 & 3 & 1 & & & & & \\
\hline & ANOVA & 71.32 & 18.67 & 9.32 & 0.69 & & & & & \\
\hline
\end{tabular}


Table 24: Verification test for the low-FC calibration (ESC modes)

\begin{tabular}{|c|c|c|c|c|c|c|c|c|c|c|}
\hline Mode & Calibration & VGT & EGR & sol & NOP & Prediction & Baseline $\mathrm{CO}_{2}$ & Meas $\mathrm{CO}_{2}$ & Sigma1 & Del1 \\
\hline & & & & & & [ppm] & [ppm] & [ppm] & $\mathrm{dB}$ & $\mathrm{dB}$ \\
\hline \multirow{3}{*}{ MODE 2} & Low FC & 44 & 73 & 5 & 16.9 & 23684 & 23883 & 23037 & 0.46 & 0.23 \\
\hline & Level & 3 & 3 & 3 & 1 & & & & & \\
\hline & ANOVA & 75.35 & 1.31 & 12.45 & 10.87 & & & & & \\
\hline \multirow{3}{*}{ MODE 3} & Low FC & 54 & 85 & 4 & 18 & 12547 & 13865 & 12542 & 0.48 & 0.13 \\
\hline & Level & 3 & 3 & 3 & 1 & & & & & \\
\hline & ANOVA & 27.32 & 2.35 & 65.52 & 4.8 & & & & & \\
\hline \multirow{3}{*}{ MODE 4} & Low FC & 50 & 71 & 4 & 18 & 18805 & 20349 & 18358 & 0.59 & 0.25 \\
\hline & Level & 3 & 3 & 3 & 1 & & & & & \\
\hline & ANOVA & 25.64 & 0.97 & 70.46 & 2.93 & & & & & \\
\hline \multirow{4}{*}{ MODE 5} & & & & & & & & & & \\
\hline & Low FC & 54 & 74 & 4 & 18 & 10314 & 11599 & 10102 & 0.7 & 0.3 \\
\hline & Level & 3 & 3 & 3 & 1 & & & & & \\
\hline & ANOVA & 54.38 & 1.37 & 31.37 & 12.88 & & & & & \\
\hline & & & & & & & & & & \\
\hline \multirow{3}{*}{ MODE 6} & Low FC & 50 & 59 & 6 & 18 & 15823 & 18832 & 15569 & 1.5 & 0.4 \\
\hline & Level & 3 & 1 & 3 & 1 & & & & & \\
\hline & ANOVA & 31.53 & 0.13 & 65.78 & 2.56 & & & & & \\
\hline \multirow{3}{*}{ MODE 7} & Low FC & 44 & 62 & 2 & 17.8 & 6338 & 7023 & 6420 & 0.56 & 0.12 \\
\hline & Level & 3 & 3 & 2 & 1 & & & & & \\
\hline & ANOVA & 54.3 & 5.19 & 20.63 & 19.88 & & & & & \\
\hline \multirow{3}{*}{ MODE 8} & Low FC & 48 & 60 & 7 & 20 & 27737 & 29520 & 26896 & 0.5 & 0.31 \\
\hline & Level & 3 & 3 & 3 & 3 & & & & & \\
\hline & ANOVA & 61.21 & 19.43 & 18.4 & 0.95 & & & & & \\
\hline & & & & & & & & & & \\
\hline \multirow{3}{*}{ MODE 9} & Low FC & 51 & 60 & 4 & 18 & 6598 & 8613 & 6627 & 1.45 & 0.39 \\
\hline & Level & 3 & 3 & 3 & 1 & & & & & \\
\hline & ANOVA & 66.64 & 5.36 & 16.67 & 11.33 & & & & & \\
\hline \multirow{3}{*}{ MODE 10} & Low FC & 50 & 59 & 10 & 20 & 29510 & 32470 & 28080 & 0.69 & 0.33 \\
\hline & Level & 3 & 3 & 3 & 3 & & & & & \\
\hline & ANOVA & 62.01 & 19.96 & 9.36 & 8.67 & & & & & \\
\hline \multirow{3}{*}{ MODE 11} & & & & & 19 & 7176 & 0616 & 7468 & 125 & 202 \\
\hline & $\frac{\text { Low FC }}{\text { Level }}$ & $\frac{40}{3}$ & $\frac{59}{3}$ & $\frac{6}{3}$ & $\frac{19}{2}$ & $71 / 6$ & 9616 & 1468 & 1.25 & 0.24 \\
\hline & ANOVA & 66.71 & 19.58 & 4.22 & 9.49 & & & & & \\
\hline & & & & & & & & & & \\
\hline \multirow{3}{*}{ MODE 12} & Low FC & 53 & 68 & 6 & 18.3 & 20510 & 24050 & 20049 & 0.82 & 0.3 \\
\hline & Level & 3 & 3 & 3 & 1 & & & & & \\
\hline & ANOVA & 35.72 & 3.05 & 60.23 & 0.6 & & & & & \\
\hline \multirow{3}{*}{ MODE 13} & Low FC & 52 & 78 & 6 & 18.8 & 13255 & 15506 & 13204 & 0.66 & 0.12 \\
\hline & Level & 3 & 3 & 3 & 1 & & & & & \\
\hline & ANOVA & 11.4 & 1.38 & 86.74 & 0.48 & & & & & \\
\hline
\end{tabular}




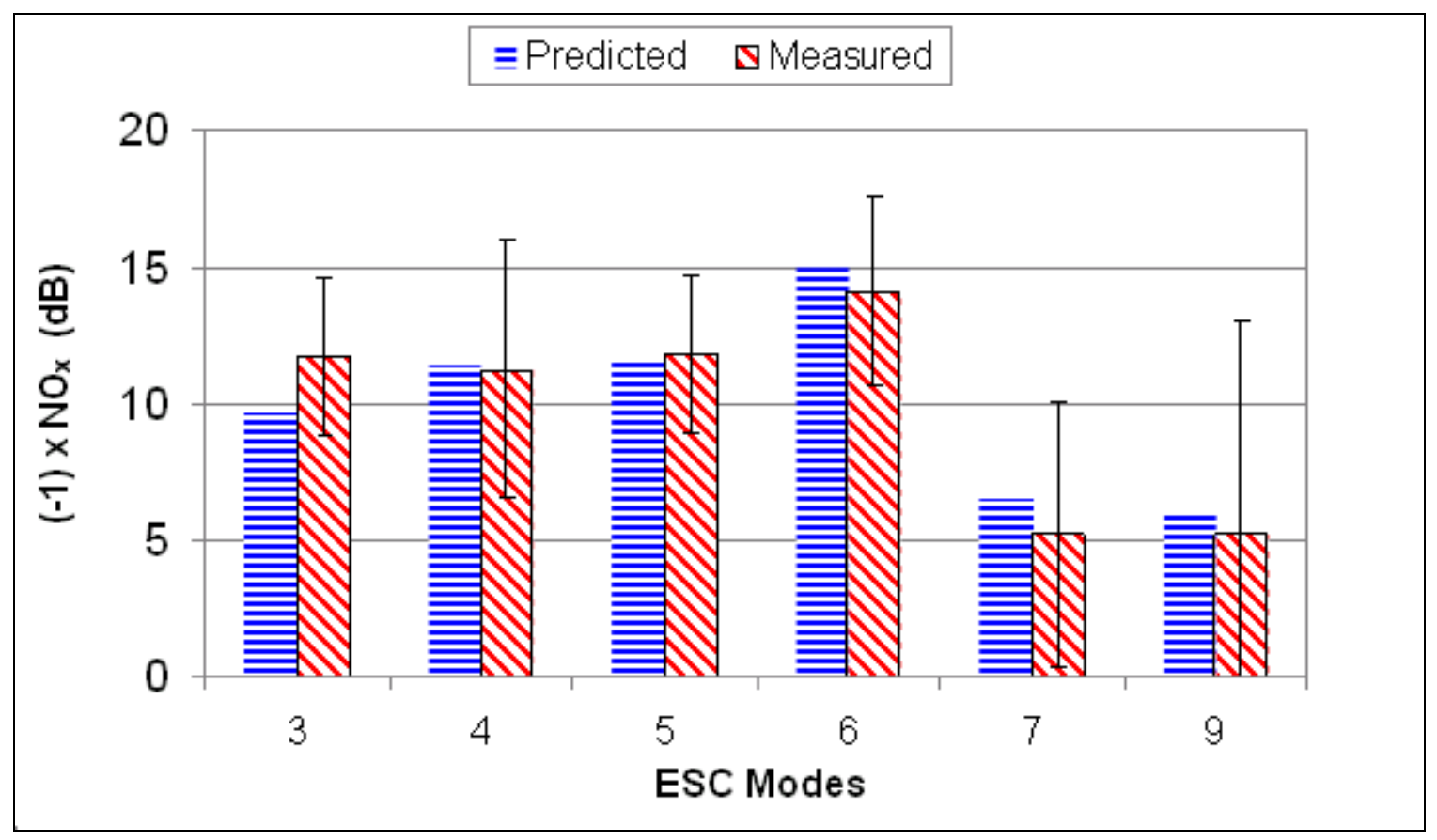

Figure 51: Prediction and verification measurements for ESC modes, low-NOx map

The ANOVA test results confirmed that VGT and SOI played major roles in the minimization of the FC. At times EGR was also significant. For each mode the DOF of two control factors was exploited to predict the experimental error.

The control factor which contributed the highest to NOx and FC variation, per ANOVA results, was further varied to achieve even lower values of the characteristic functions. This was done for the engine modes for which the NOx and FC were not being significantly minimized by the optimization procedure (second stage optimization).

\subsection{Engine Map Optimization}

The final optimal settings found with the orthogonal array experiments were implemented in the engine maps. The modified maps were then loaded on the ECU. Associated with each control factor, EGR, VGT, SOI and NOP, were two types of engine maps, static and dynamic maps. The static maps are typically enabled by the engine control when stationary conditions are present, which means that non-significant fluctuations in the indicated engine torque are recorded. On the other hand, instability of indicated torque calculated by the ECU, activates the dynamic maps. Very often during an FTP the settings of the engine actuators are taken off the dynamic maps, whereas 
during ESC cycle the reference maps are the static maps. The latter were optimized mainly over selected ESC modes. The dynamic maps, instead, were modified around ESC and AVL points. The implementation of the optimal settings in the engine maps was done according to the following procedure:

1. Optimal factor levels were inserted directly in the engine maps, in correspondence with engine speed and load points of the optimized mode (ESC and AVL).

2. The optimal setting was assigned to a large speed-load region around the optimized points in order to make sure that the engine would read from the map in the desired region, even in the event of torque and speed errors due to dynamometer control or engine control response instabilities.

3. The speed-load region around the optimized point was refined by interpolating values existing on the map with the optimal settings from the orthogonal array experiments. This step was included to prevent rapid changes in the engine operations (improved drivability).

The step 3 was performed only on the low-NOx calibration, because it was the engine calibration that had to satisfy more specific requirements.

From Figure 52 to Figure 59 show 3D-graphs of the static and dynamic maps optimized for the four control factors. The ECU accesses the maps based upon the engine speed and indicated torque. The latter is estimated by the ECU based on the calculation of the indicated work. The outputs of the map are the actuator settings. 


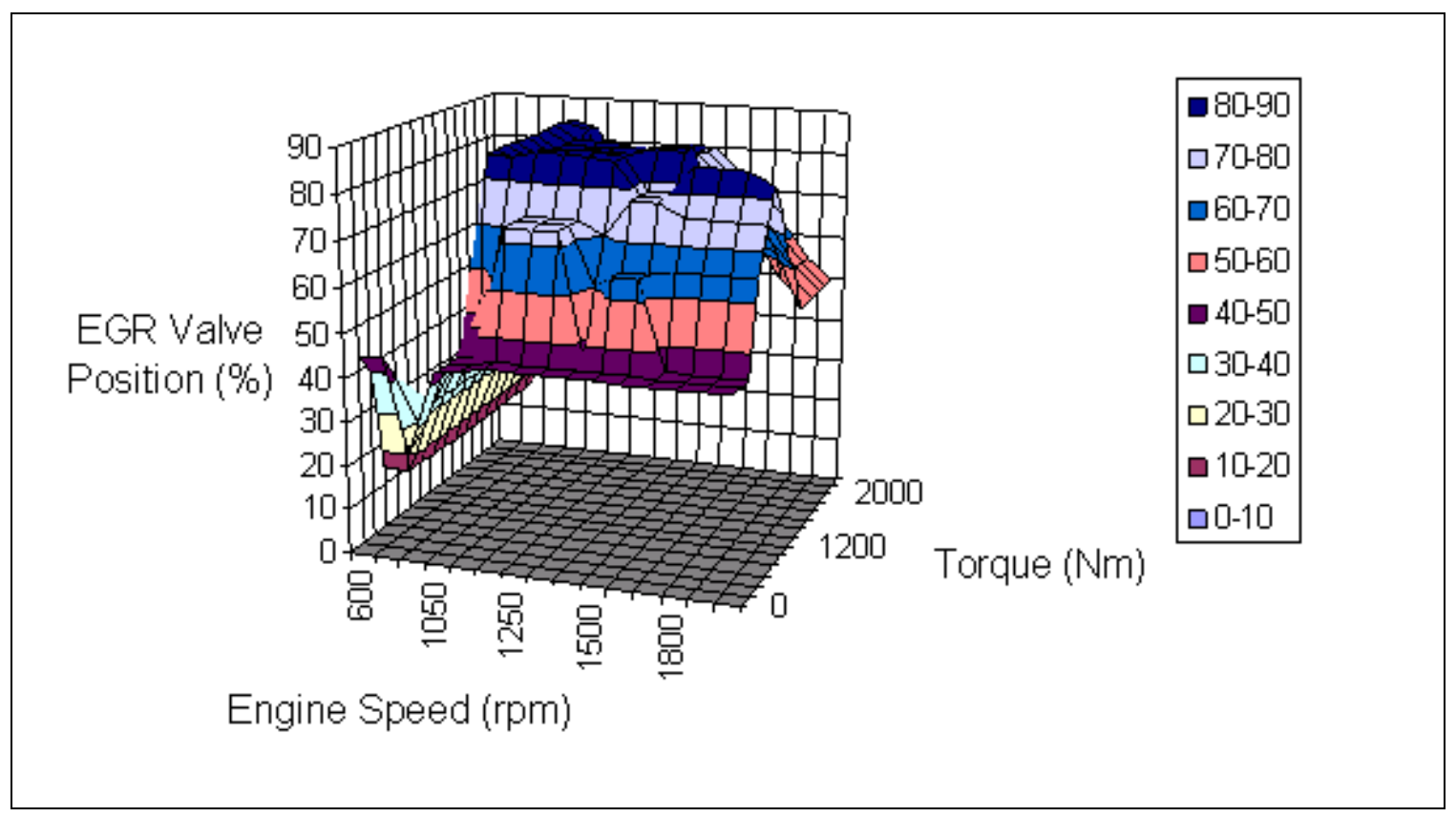

Figure 52: EGR static optimized map, low NOx calibration.

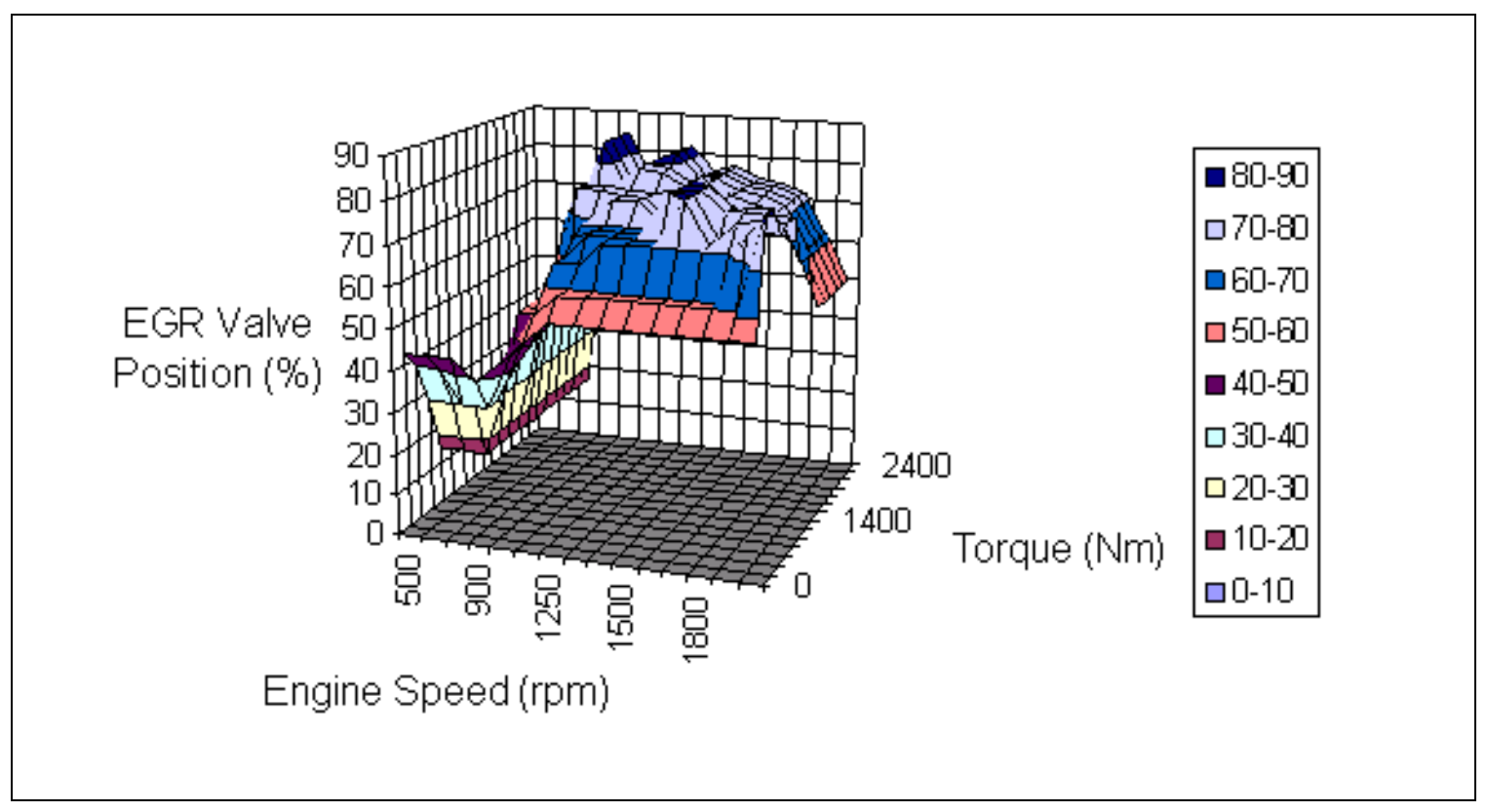

Figure 53: EGR dynamic optimized map, low NOx calibration. 


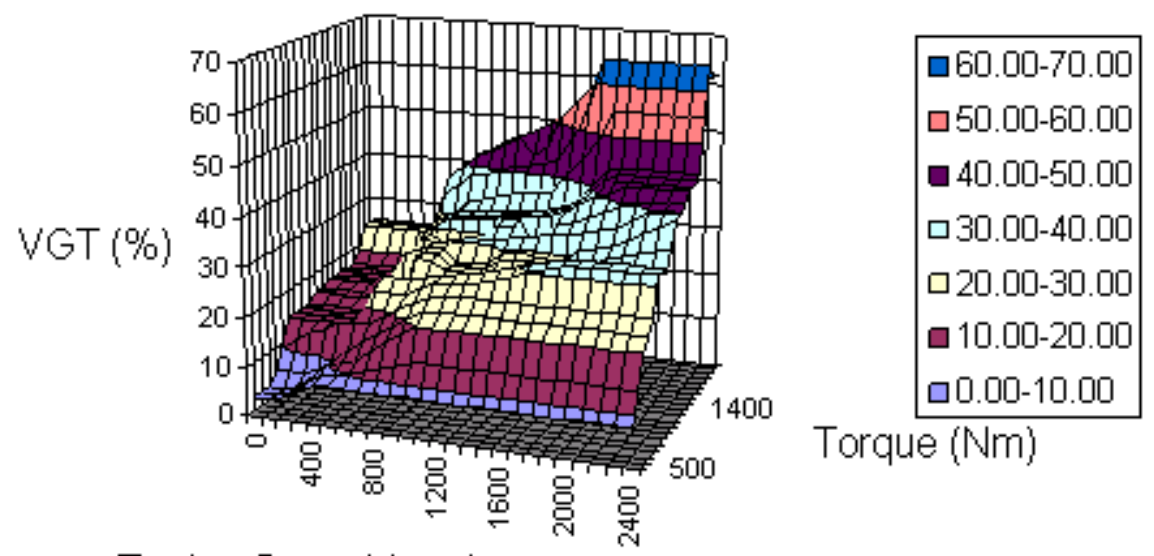

Engine Speed (rpm)

Figure 54: VGT static optimized map, low NOx calibration.

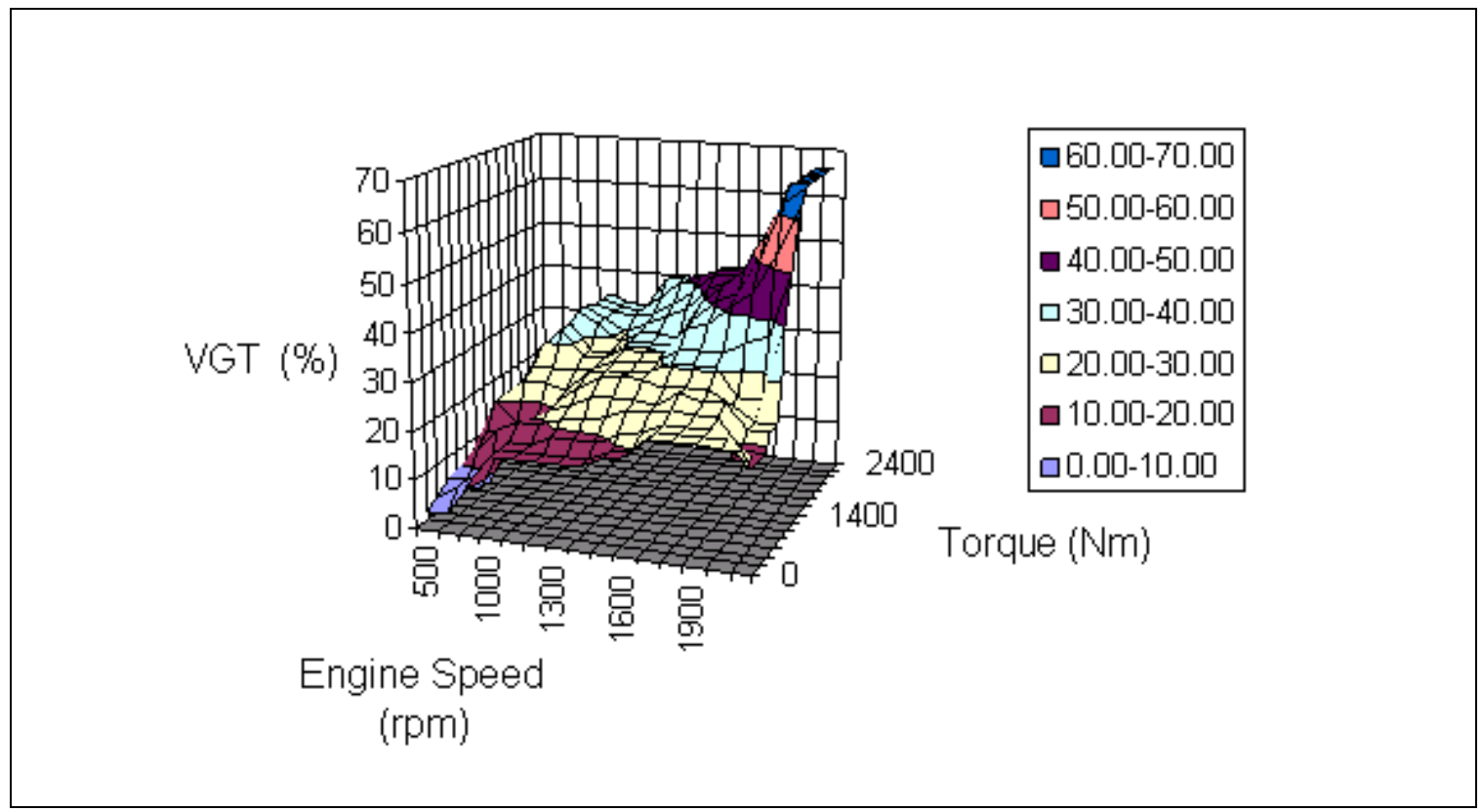

Figure 55: VGT dynamic optimized map, low NOx calibration. 


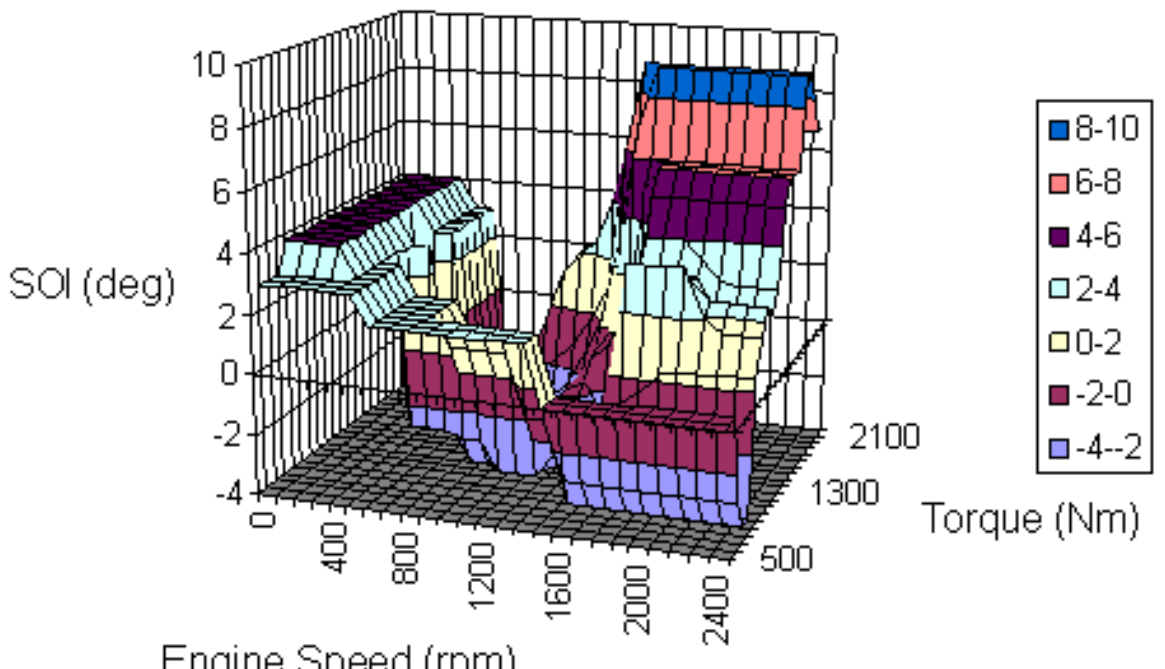

Engine Speed (rpm)

Figure 56: SOI static optimized map, low NOx calibration.

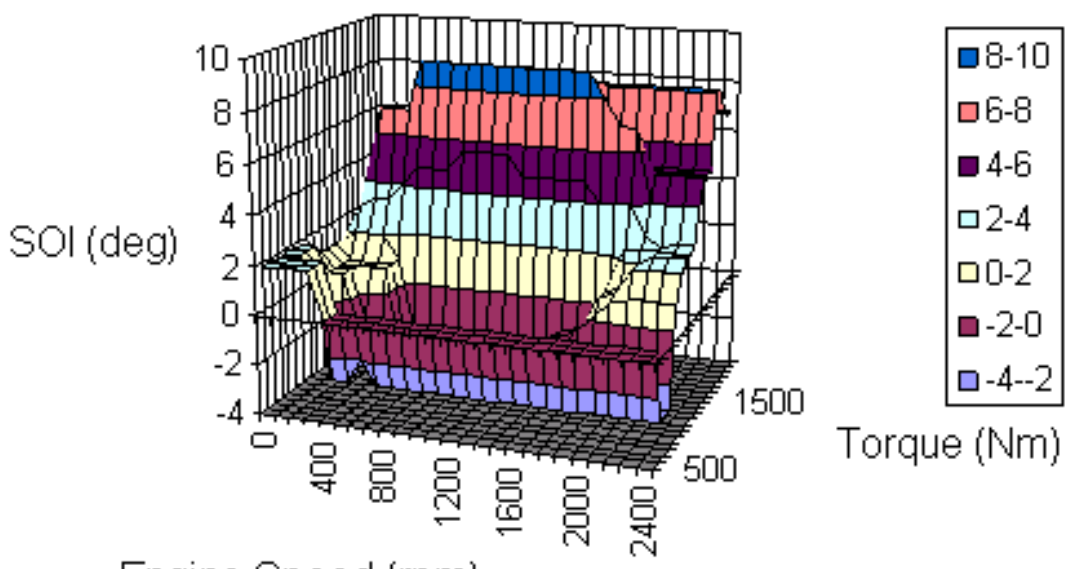

Engine Speed (rpm)

Figure 57: SOI dynamic optimized map, low NOx calibration. 


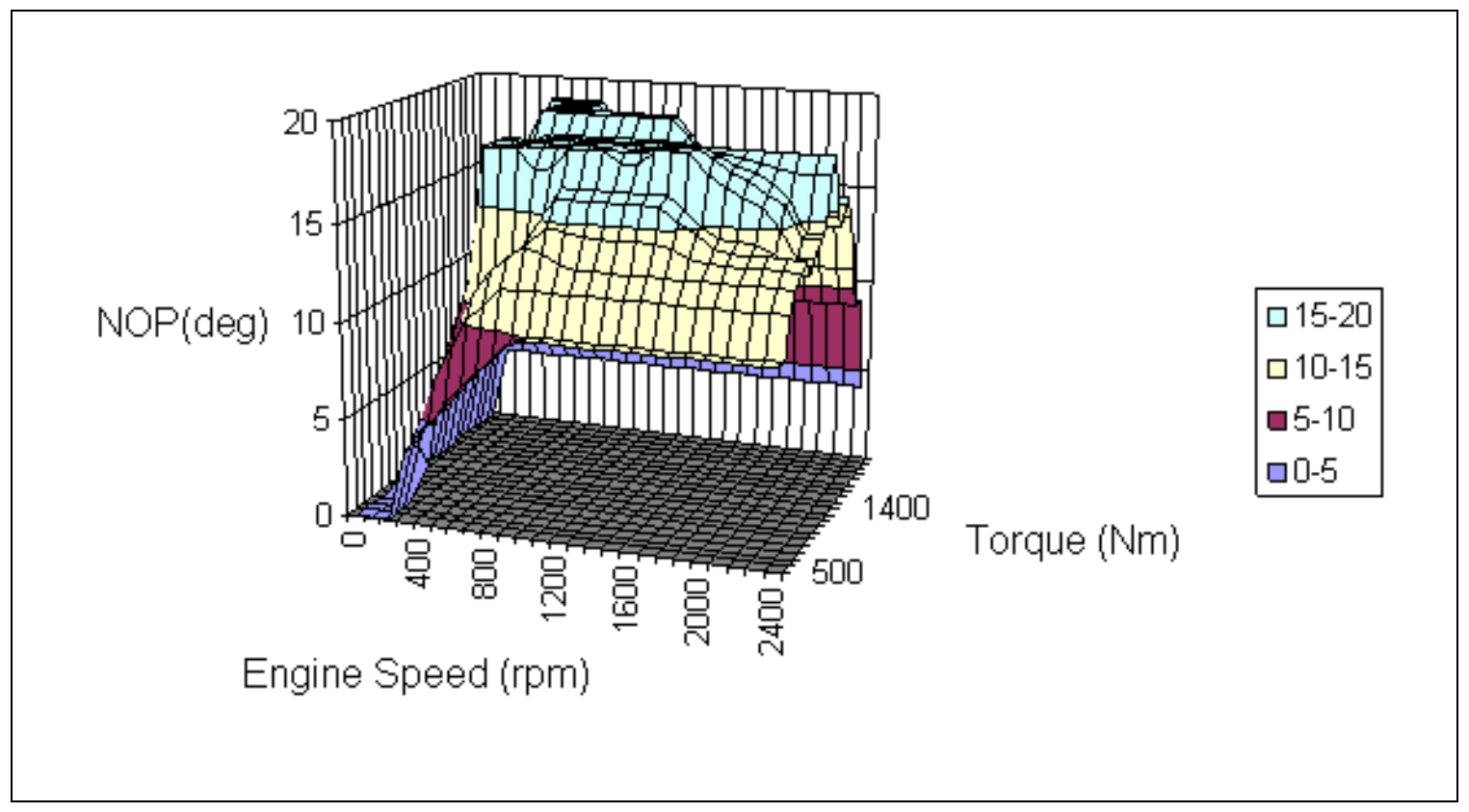

Figure 58: NOP static optimized map, low NOx calibration.

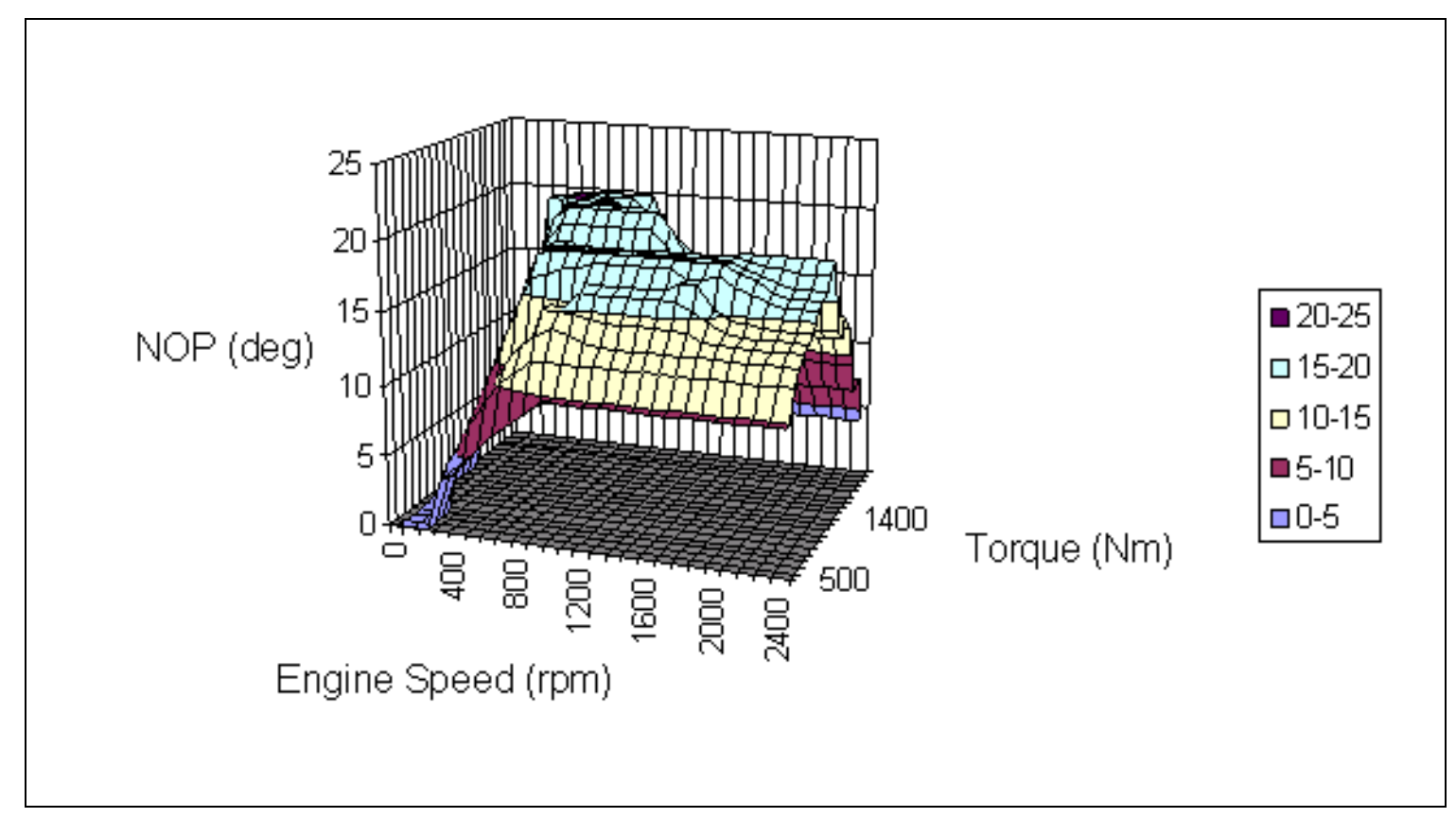

Figure 59: NOP dynamic optimized map, low NOx calibration.

One of the major difficulties encountered in having the engine continually operate in accordance with the modified engine maps was the conflict with the engine control. The engine control was not reading from the optimized maps when $\mathrm{A} / \mathrm{F}$ ratio and burned fraction $(\mathrm{BF})$ limits were being violated by the engine operation. To force the engine 
control to access the optimized maps during such events, it was necessary to change the limits of $\mathrm{BF}$ and $\mathrm{A} / \mathrm{F}$ ratio specified in the corresponding maps; hence, two additional maps, namely A/F and BF maps (Figure 60 and Figure 61) were modified.

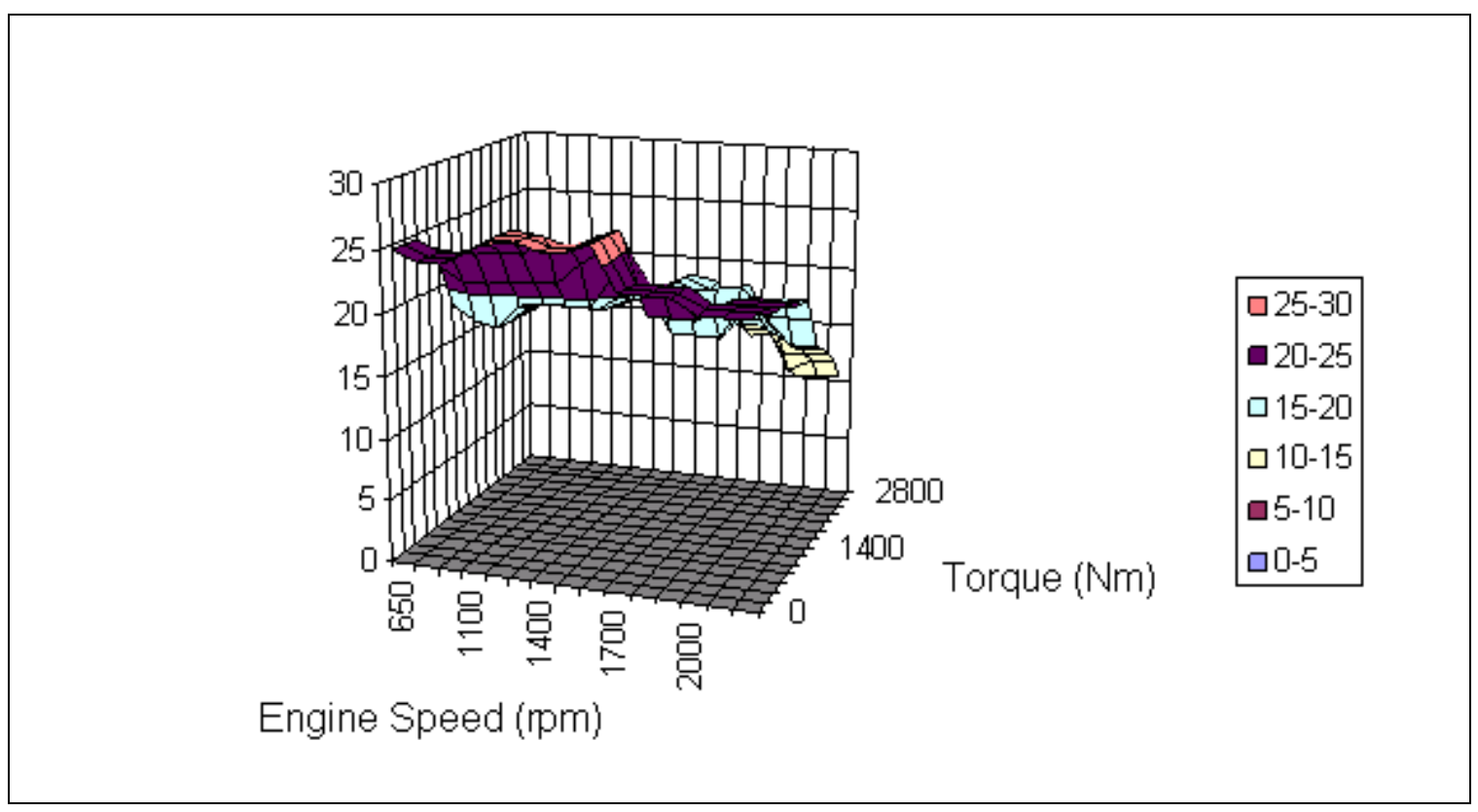

Figure 60: A/F ratio optimized map, low NOx calibration.
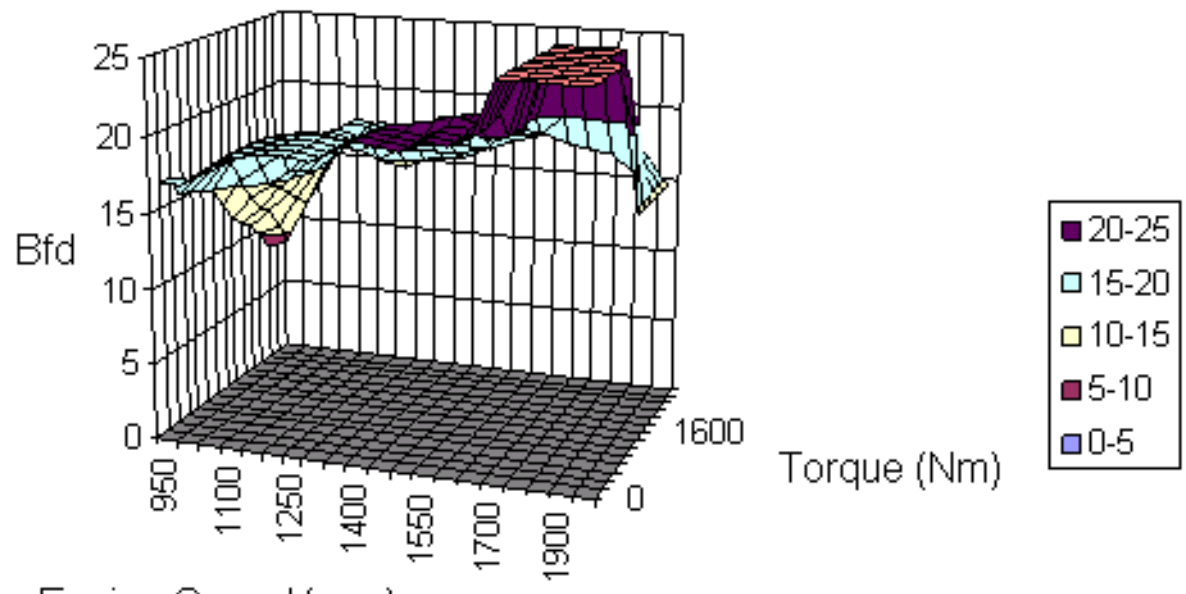

Engine Speed (rpm)

Figure 61: Burned fraction optimized map, low NOx calibration. 


\subsection{Evaluation of the Engine Calibrations (FTP/ESC cycles)}

The engine was programmed with baseline, low-NOx and low-FC calibrations and exhaust emissions were characterized over ESC and FTP cycles, and cold start (CS) and hot start (HS) runs. Table 25 summarizes the emissions results, displaying the average of consecutive hot starts. Higher coefficient of variation (COV) was recorded for measurements of the regulated pollutants (an average of 2\% higher) for low-NOx and low-FC compared to the baseline calibration. This could be attributed to the frequent interaction of the engine control as mentioned in Section 5.3.

The baseline engine was found to produce a level of bsNOx, which was slightly higher than a 2007 compliant engine: $1.44 \mathrm{~g} / \mathrm{bhp}$-hr for FTP and $1.24 \mathrm{~g} / \mathrm{bhp}$-hr for the ESC 
Table 25: Emissions levels in g/bhp-hr for low-NOx, low-FC and Baseline calibrations

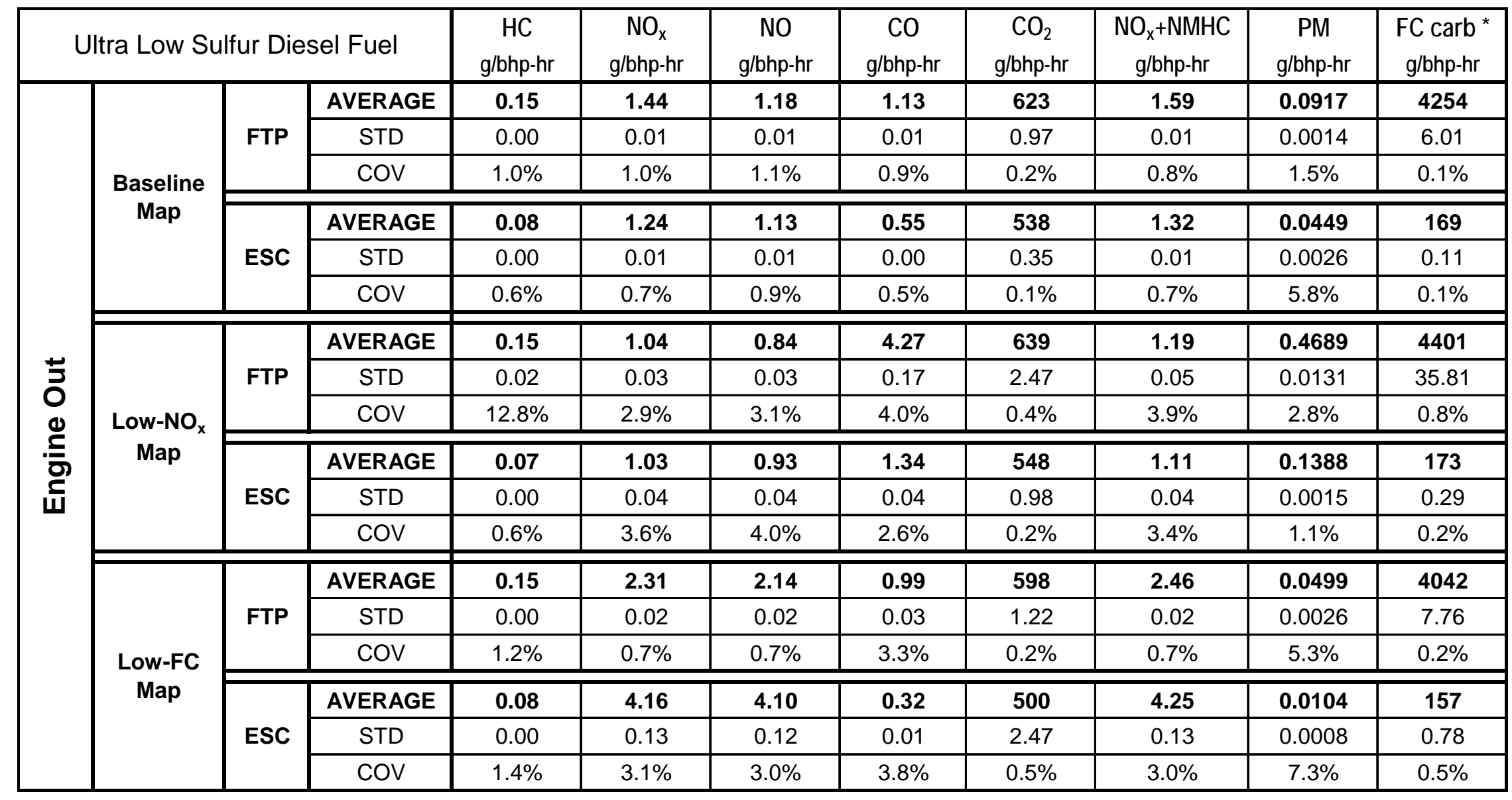


The low-NOx calibration managed to lower NOx down to about $1 \mathrm{~g} / \mathrm{bhp}-\mathrm{hr}$ (see Figure 62 ), which was a target set in the objectives of the ADECS project [52]. However, this was done at the expense of $\mathrm{CO}$, which increased drastically (see Figure 63). The differences among the calibrations in a transient cycle are greater during peak events and during the "Los Angeles Free Way" portion of the FTP [61]. Furthermore, higher FC (less than 3\%) and higher gravimetric PM were detected for low-NOx calibration. PM was measured $0.14 \mathrm{~g} / \mathrm{bhp}-\mathrm{hr}$ for ESC and about $0.47 \mathrm{~g} / \mathrm{bhp}$-hr for FTP. Low-FC calibration instead, produced very little PM mass, maintaining PM levels below 0.05 g/bhp-hr (see Figure 64 and Figure 65). On the other hand, FC was improved of about $6 \%$, and for the known trade-off with NOx emissions, the latter increased drastically; NOx recorded was $2.31 \mathrm{~g} / \mathrm{bhp}-\mathrm{hr}$ and $4.16 \mathrm{~g} / \mathrm{bhp}$-hr respectively for FTP and ESC cycles. The very high NOx value measured over an ESC test, could be attributed to the fact that a much larger parameter range, than the one used in the low-NOx calibration, was selected for each control factor in the low-FC calibrations.

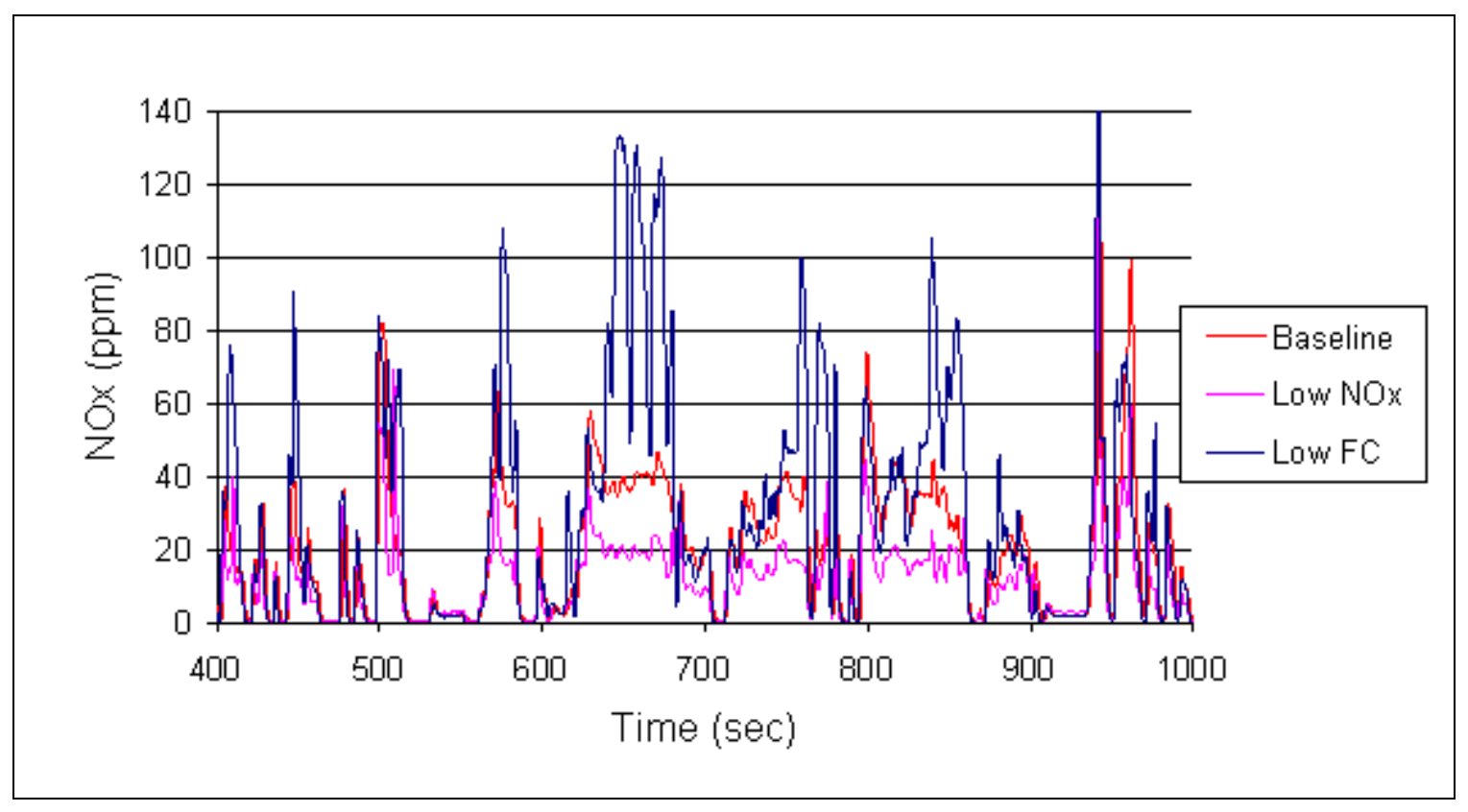

Figure 62: NOx emissions comparison over FTP 


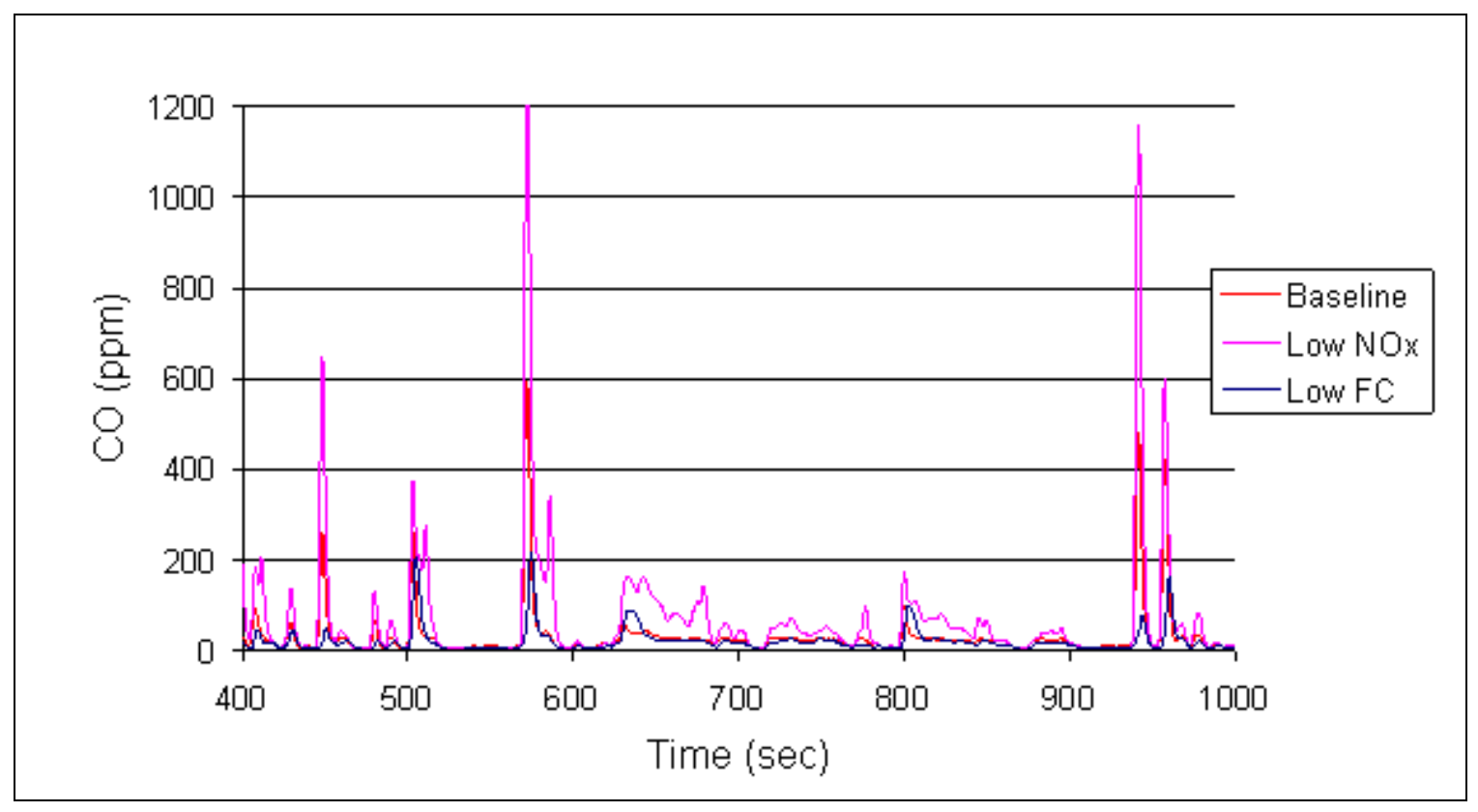

Figure 63: CO emissions comparison over FTP

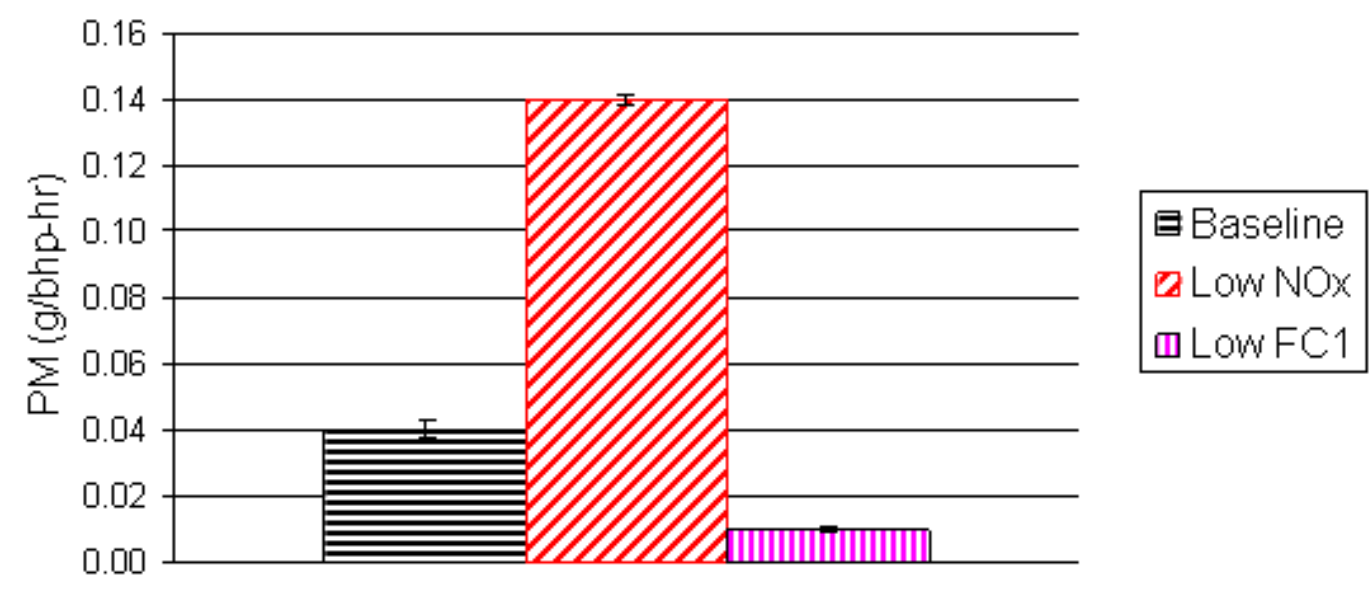

Figure 64: PM for low-NOx and low-FC on ESC test 


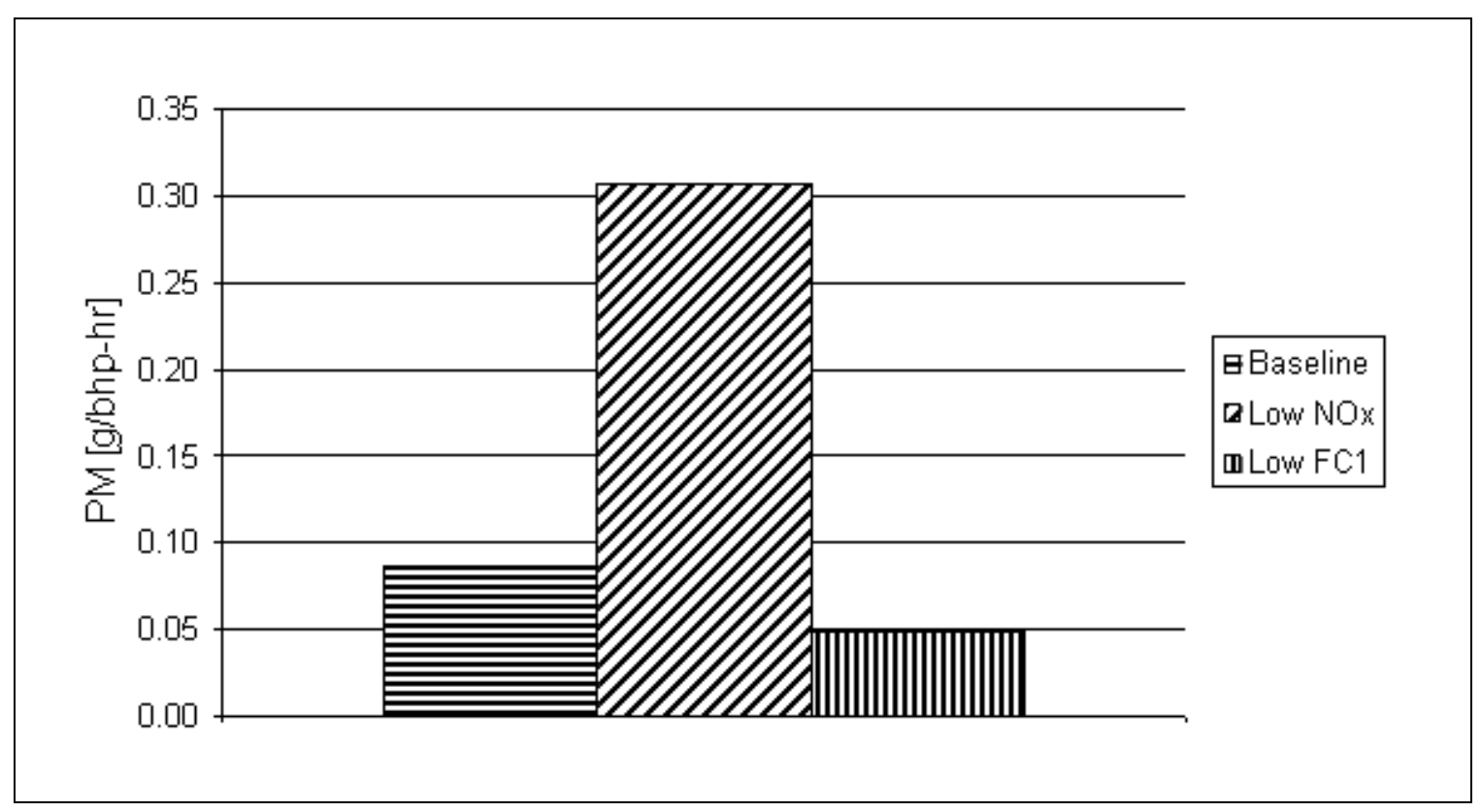

Figure 65: PM for low-NOx and low-FC on FTP test

Therefore, the algorithm found fuel efficient solutions far from the baseline settings; thus, increasing significantly the level of bsNOx. No significant variations were detected in $\mathrm{HC}$ measurement for either the two calibrations.

Low-NOx calibration exhibited consistently higher exhaust temperatures for both ESC and FTP cycles (Figure 66 and Figure 67).

In case of Low-NOx calibration, higher fuel was consumed per mode, which resulted in higher exhaust temperature. For a fixed amount of work the low-FC consumed less fuel; therefore, exhaust temperature were lower. The different oxygen content and temperature of the exhaust gases, due to the different calibrations, affected the $\mathrm{NO}_{2} / \mathrm{NO}$ ratio levels, as well. These differences observed among the baseline, low-NOx and lowFC $\mathrm{NO}_{2} / \mathrm{NO}$ plots in Figure 68, which are minimal at the engine-out, are rather significant when the exhaust stream flows through a DOC [53].

Problems were encountered due to the extensive use of the low-NOx calibration. For instance the high temperature related wear of the rubber hoses in the EGR line, which were not designed to handle higher temperatures resulting from the increased EGR rates. 


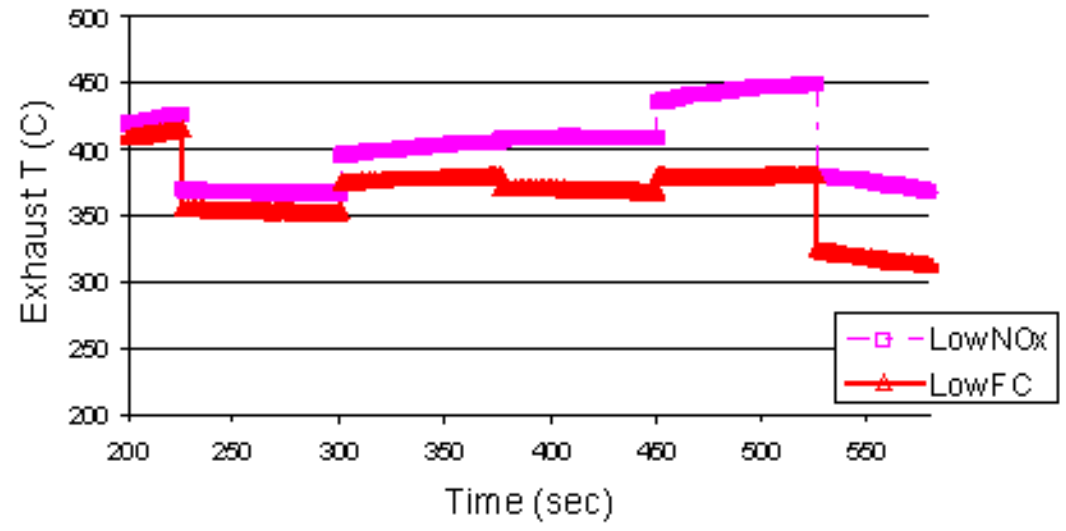

Figure 66: Exhaust temperature comparison over ESC

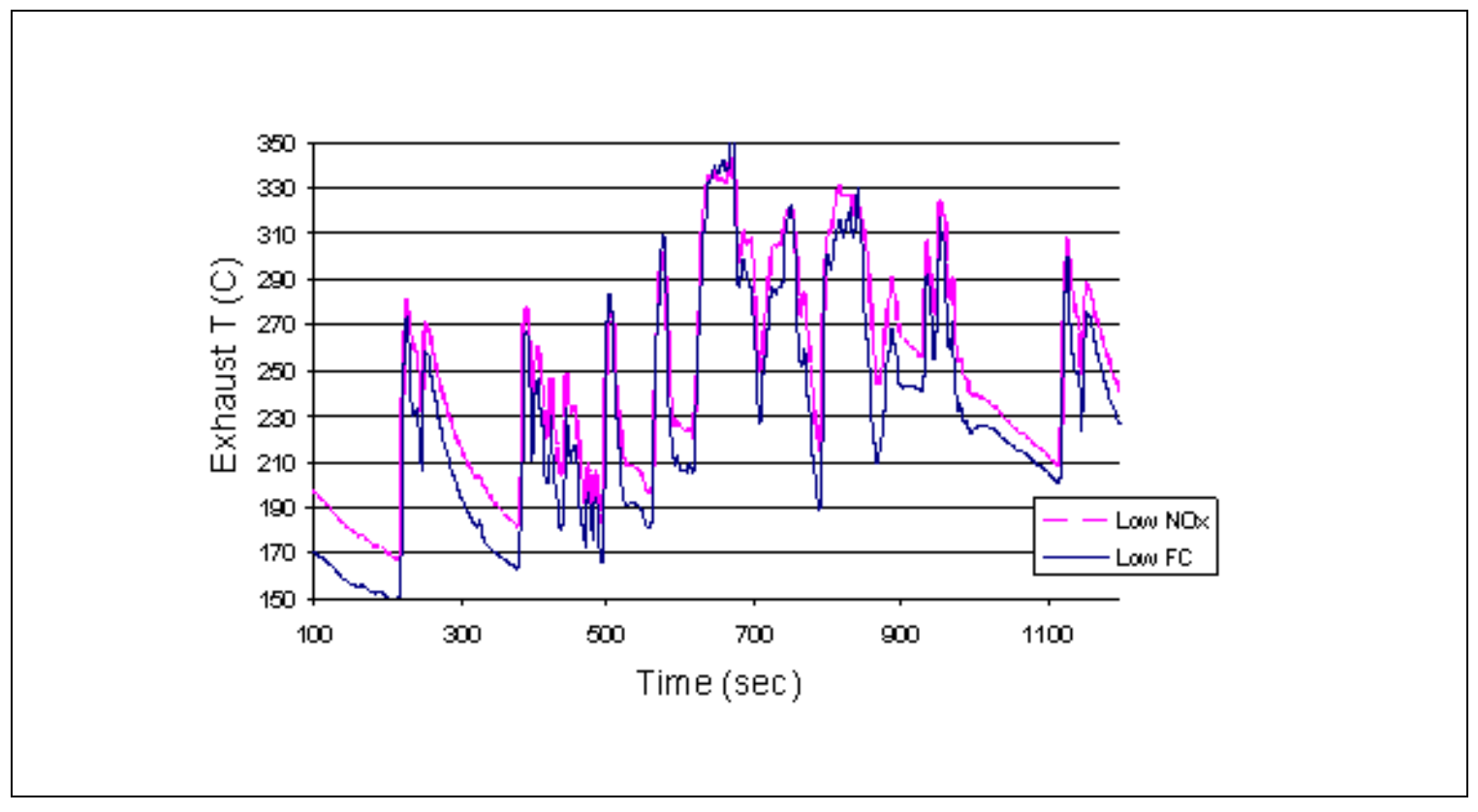

Figure 67: Exhaust temperature comparison over FTP 


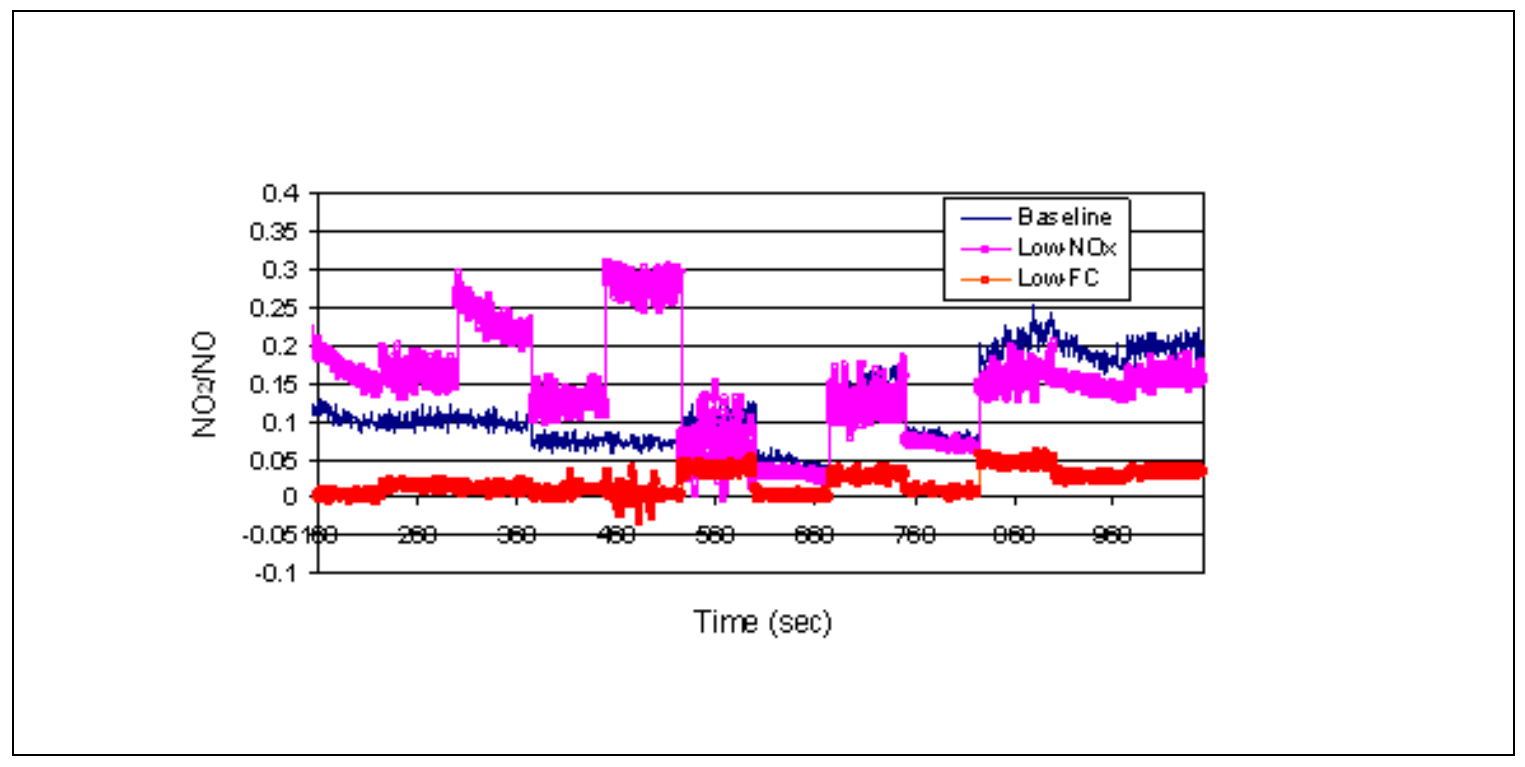

Figure 68: Comparison engine-out $\mathrm{NO}_{2} / \mathrm{NO}$ ratio

\subsection{Low-FC Calibration at Higher Exhaust Temperature}

Another calibration was developed to minimize FC, yet provide for higher temperatures in the exhaust stream. This calibration was developed with the ultimate goal of increasing SCR efficiency to compensate for the higher engine-out NOx produced. The calibration was generated following to the procedure illustrated in Section 4.6. The main difference between the low-NOx calibration, and the low-FC calibration described above was that the exhaust manifold pressure and the boost pressure, rather than NOx concentration, were considered as characteristic functions in the low-FC calibration work. Exhaust manifold pressure, rather than exhaust temperature, can better represent small variations in the combustion process, and is directly linked to in-cylinder pressure and temperature. The exhaust temperature instead, depends also on the history of the engine operations, and on the thermal inertia of the combustion chamber and the devices in the exhaust stream. A reduction in FC (>3\%) was and an increase in MEP $(>5 \%)$ were observed, which led to an increase in in-cylinder temperature (Table 26 and Figure 69). Contrary to what was expected, the rise of in-cylinder temperature did not lead to the desired increase in exhaust temperature (see Figure 70).

Higher boost and intake flow rate were measured, but the heat release curve did not exhibit any significant variations. Most likely, the higher heat available in the combustion 
chamber, due to higher temperatures, was exchanged with a larger intake mass flow rate, which caused the exhaust temperature to be lower.

Even though this calibration did not exhibit higher exhaust temperatures, it successfully reduced FC (1.3\% from the baseline), and produced a lower NOx at the engine-out over the FTP, $2.57 \mathrm{~g} / \mathrm{bhp}-\mathrm{hr}$, if compared to the FC calibration described in Section 5.2.3 (Figure 71).

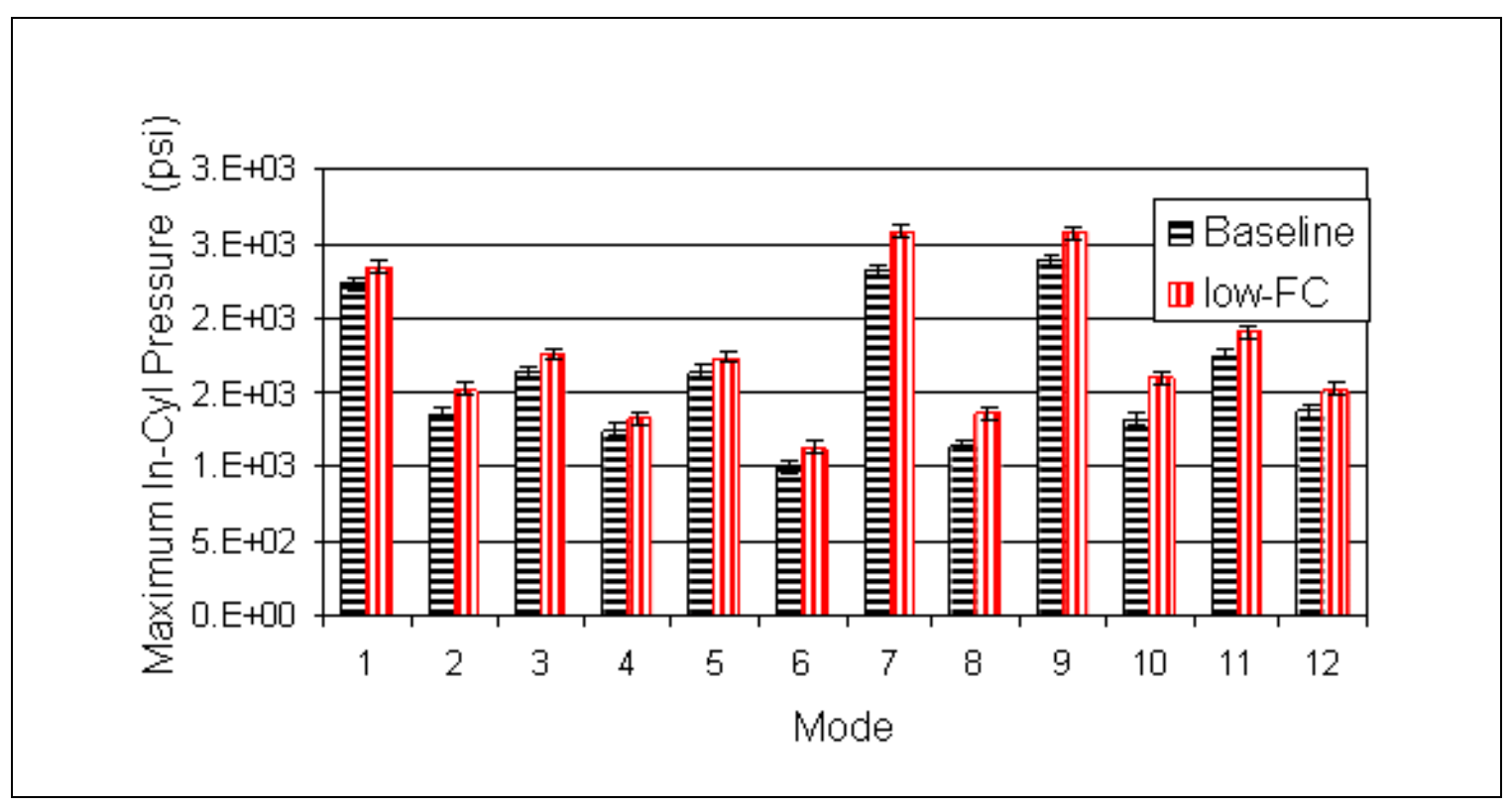

Figure 69: Maximum in-cylinder pressure for low-FC at higher boost pressure 
Table 26: Comparison of low-FC at higher in-cylinder pressure with the baseline.

\begin{tabular}{|c|c|c|c|c|c|c|}
\hline \multirow{3}{*}{ Mode } & Baseline & Low-FC & Difference & Baseline & Low-FC & Difference \\
\cline { 2 - 7 } & Max Press & Max Press & Max Press & MEP & MEP & MEP \\
\cline { 2 - 7 } & $\mathbf{( p s i )}$ & $\mathbf{( p s i )}$ & & $\mathbf{( p s i )}$ & $\mathbf{( p s i )}$ & \\
\hline $\mathbf{2}$ & 2232 & 2347 & $5 \%$ & 296 & 311 & $5 \%$ \\
\hline $\mathbf{3}$ & 1347 & 1515 & $11 \%$ & 147 & 158 & $7 \%$ \\
\hline $\mathbf{4}$ & 1627 & 1759 & $7 \%$ & 199 & 208 & $4 \%$ \\
\hline $\mathbf{5}$ & 1238 & 1317 & $6 \%$ & 141 & 146 & $3 \%$ \\
\hline $\mathbf{6}$ & 1630 & 1735 & $6 \%$ & 208 & 216 & $3 \%$ \\
\hline $\mathbf{7}$ & 988 & 1122 & $12 \%$ & 90 & 98 & $8 \%$ \\
\hline $\mathbf{8}$ & 2318 & 2583 & $10 \%$ & 296 & 316 & $6 \%$ \\
\hline $\mathbf{9}$ & 1135 & 1349 & $16 \%$ & 99 & 111 & $11 \%$ \\
\hline $\mathbf{1 0}$ & 2388 & 2575 & $7 \%$ & 272 & 283 & $4 \%$ \\
\hline $\mathbf{1 1}$ & 1313 & 1585 & $17 \%$ & 94 & 109 & $14 \%$ \\
\hline $\mathbf{1 2}$ & 1747 & 1910 & $8 \%$ & 194 & 200 & $3 \%$ \\
\hline $\mathbf{1 3}$ & 1365 & 1509 & $10 \%$ & 128 & 139 & $8 \%$ \\
\hline
\end{tabular}

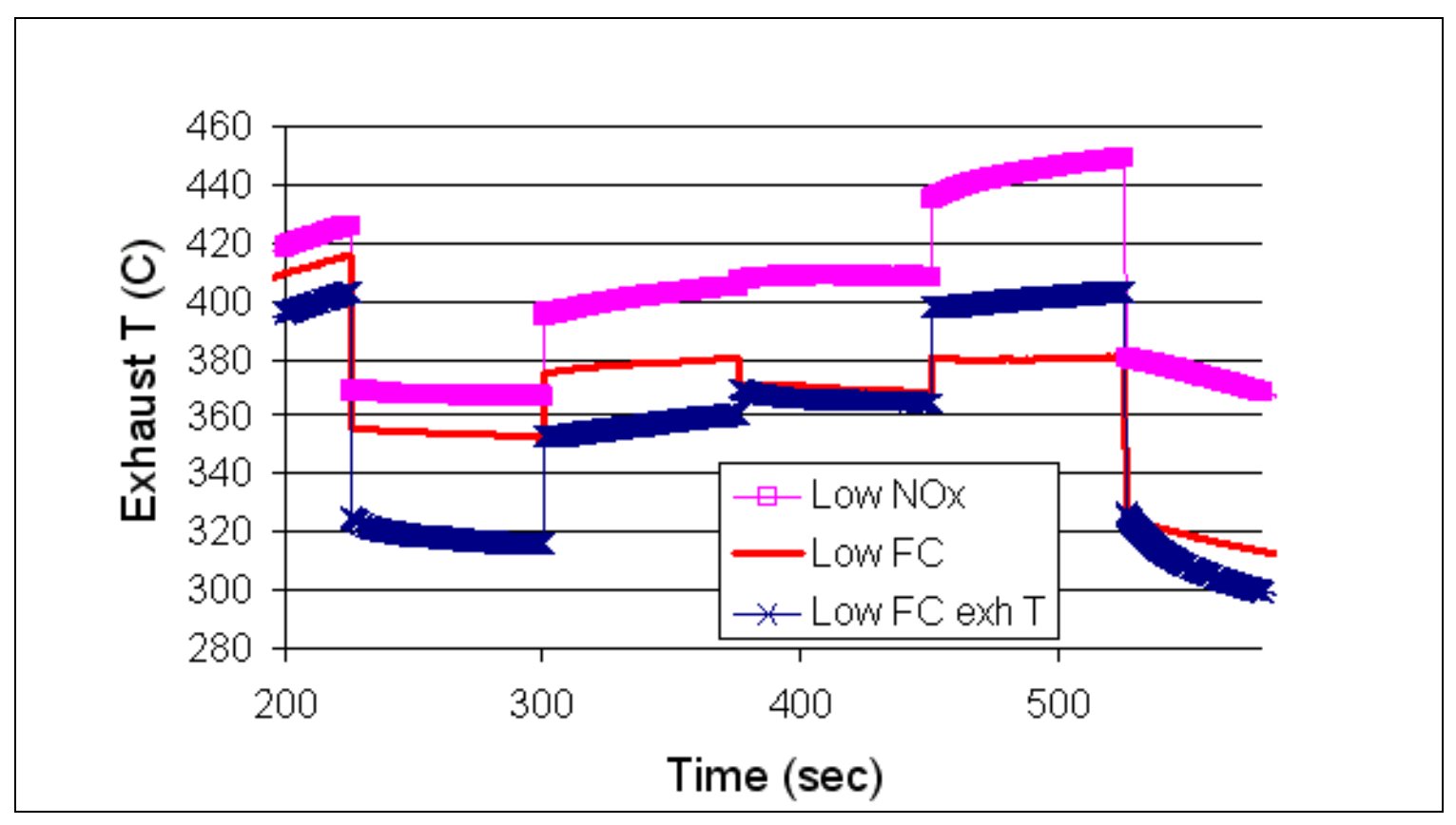

Figure 70: Effect on exhaust temperature of low-FC calibration which targets high exhaust temperature 


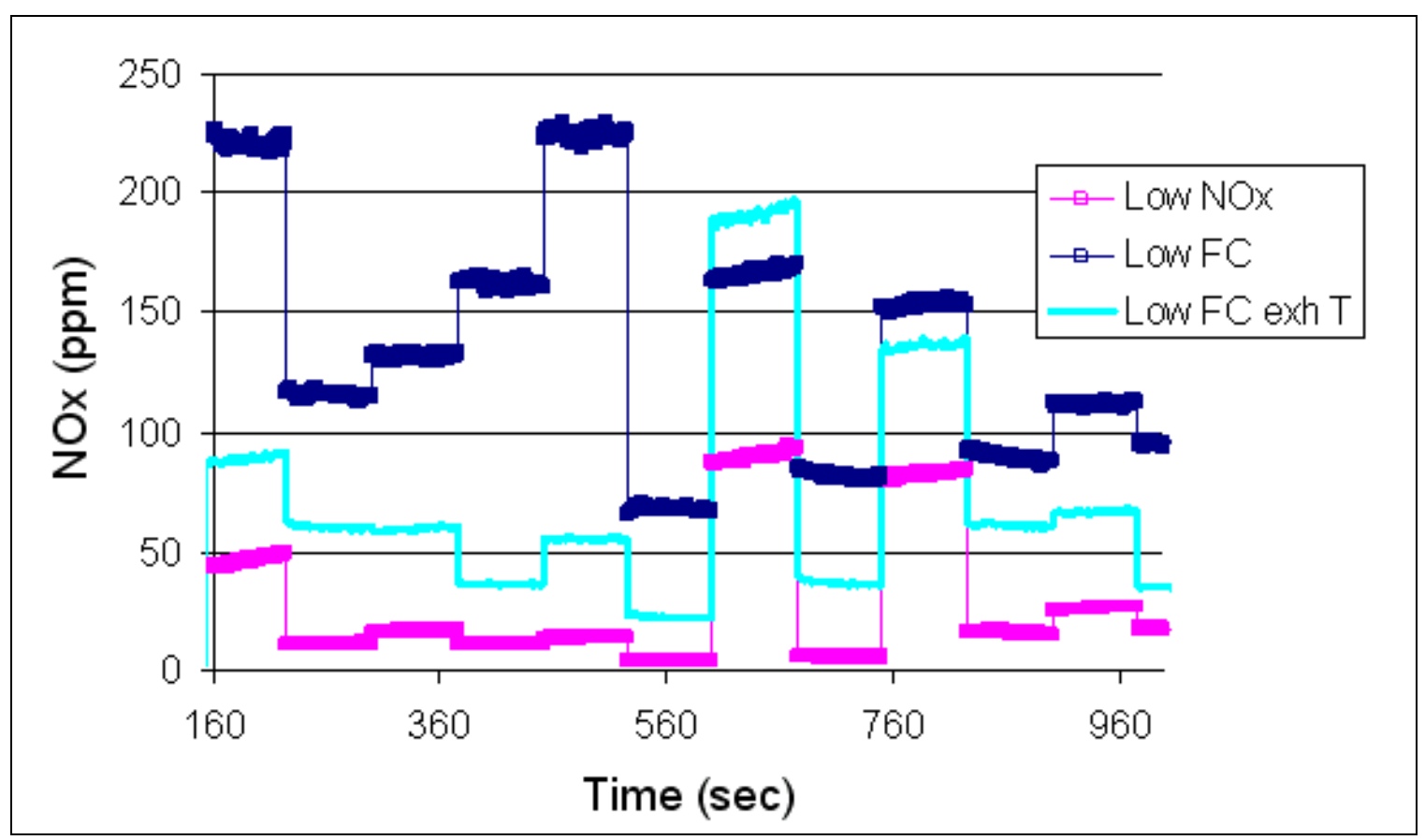

Figure 71: Effect on NOx concentration of low-FC/exh. temp. calibration

The reduction in FC obtained with the low-FC calibration at higher boost, came with slight increase in PM, as can be seen in Figure 72.

Another attempt was made to generate a calibration with higher exhaust temperature and lower FC. The fuel injected per mode, rather than the work was fixed, rather than the work, and the algorithm searched for the optimal combination of the factor levels, which minimized FC. Factor levels that produced higher torque, for the fixed amount of fuel, were found; thus, achieving a more efficient combustion. The verification tests could not be run successfully, due to the engine control conflicting with the prescribed settings, as discussed in Section 5.3. It was suspected that the engine control interacts with a fuel map, thus conflicting with the setting specified in the actuator maps previously described.

The dynamics of this interaction was not fully understood; therefore, the optimization could not be completed. 


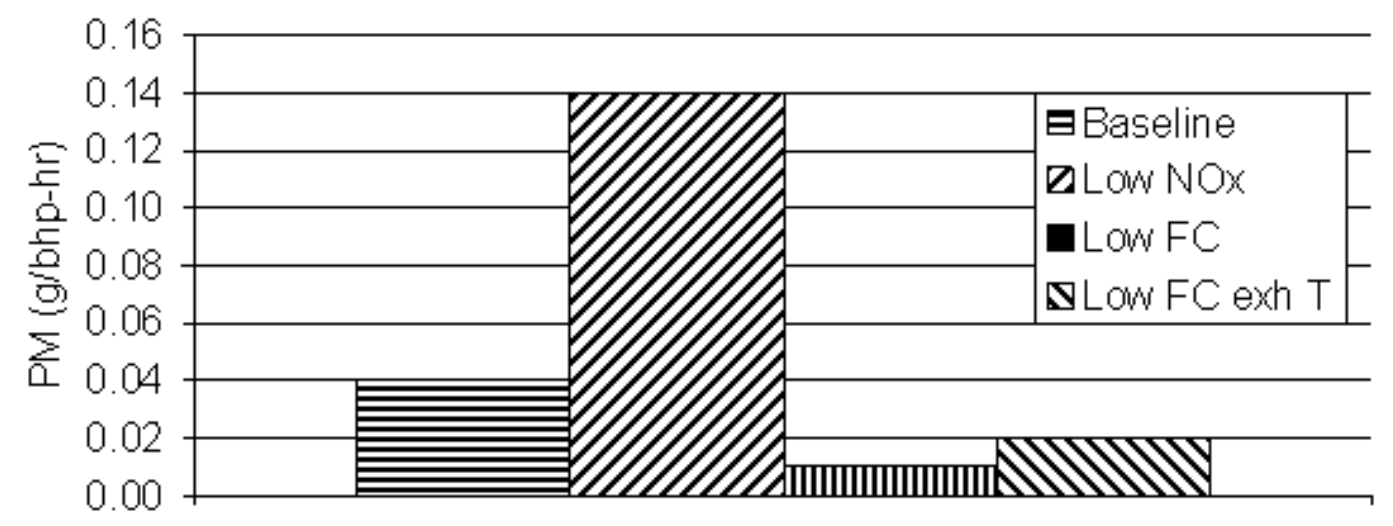

Figure 72: Effect on PM of low-FC/exh. temp. calibration

It is suggested that the points on the lug curve be optimized. This would help finding settings that would give higher torque at full throttle, but with the same amount of fuel. This would lead to a more fuel efficient engine at higher power settings. Thus, the ESC points coming from the modified lug curve, are higher load points, even though they require the same amount of fuel. This calibration would produce more work per cycle, and higher exhaust temperatures and ultimately would have better FC.

\subsection{Alternative Methods to Generate Heat in the Exhaust Stream}

An entirely different approach was pursued by Volvo Powertrain on the MY04 Volvo engine to raise the temperature of the exhaust stream. The camshaft profile was modified to allow for early opening of the exhaust valve in order to have more heat available. The injection pressure was simultaneously increased to compensate for the drop in in-cylinder pressure, which could have resulted in a drop of cycle work. The modified and the original camshaft were alternated during the testing that occurred at the EERL.

The needle lift curve in Figure 73 shows the early opening of the exhaust valve. The "on" configuration is with the modified camshaft, whereas the "off" configuration is the baseline camshaft. The exhaust valve opens earlier and closes later as it can be seen 
by the larger area under the valve lift curve. Also, the in-cylinder pressure is higher due to the higher NOP provided.

Figure 74 shows the main engine parameters, namely intake and exhaust manifold pressure and temperature and pre-turbo pressure and temperature, measured with laboratory equipment. It can be seen that, for idle, the exhaust temperature increased from $220\left({ }^{\circ} \mathrm{F}\right)$ to $250\left({ }^{\circ} \mathrm{F}\right)$ (Figure 74$)$, and few other parameters of the exhaust stream were also affected. For example, the pre-turbo temperature increased from 240 (F) to $290(\mathrm{~F})$.

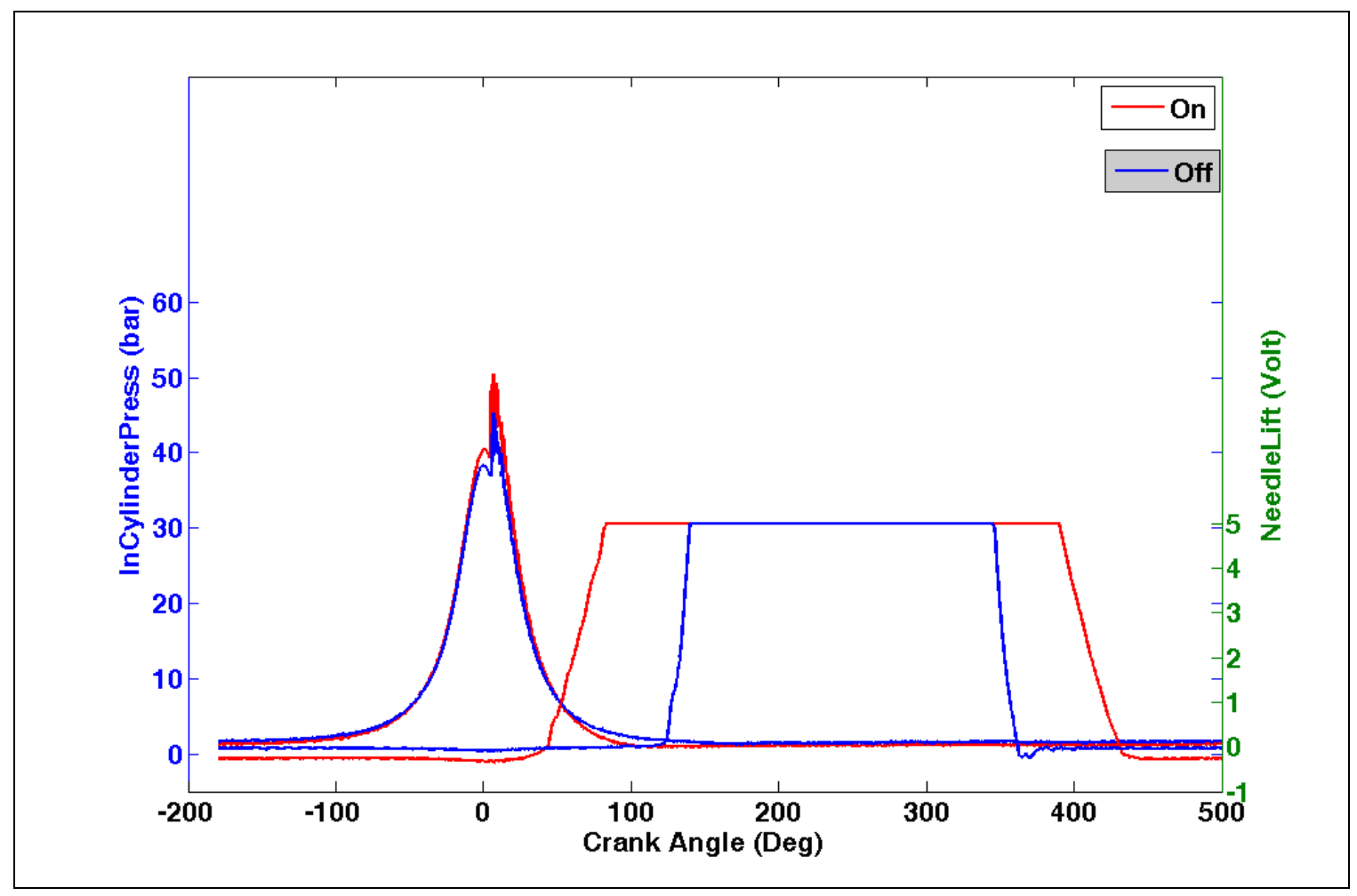

Figure 73: Exhaust valve early opening, idle mode, at constant flow 

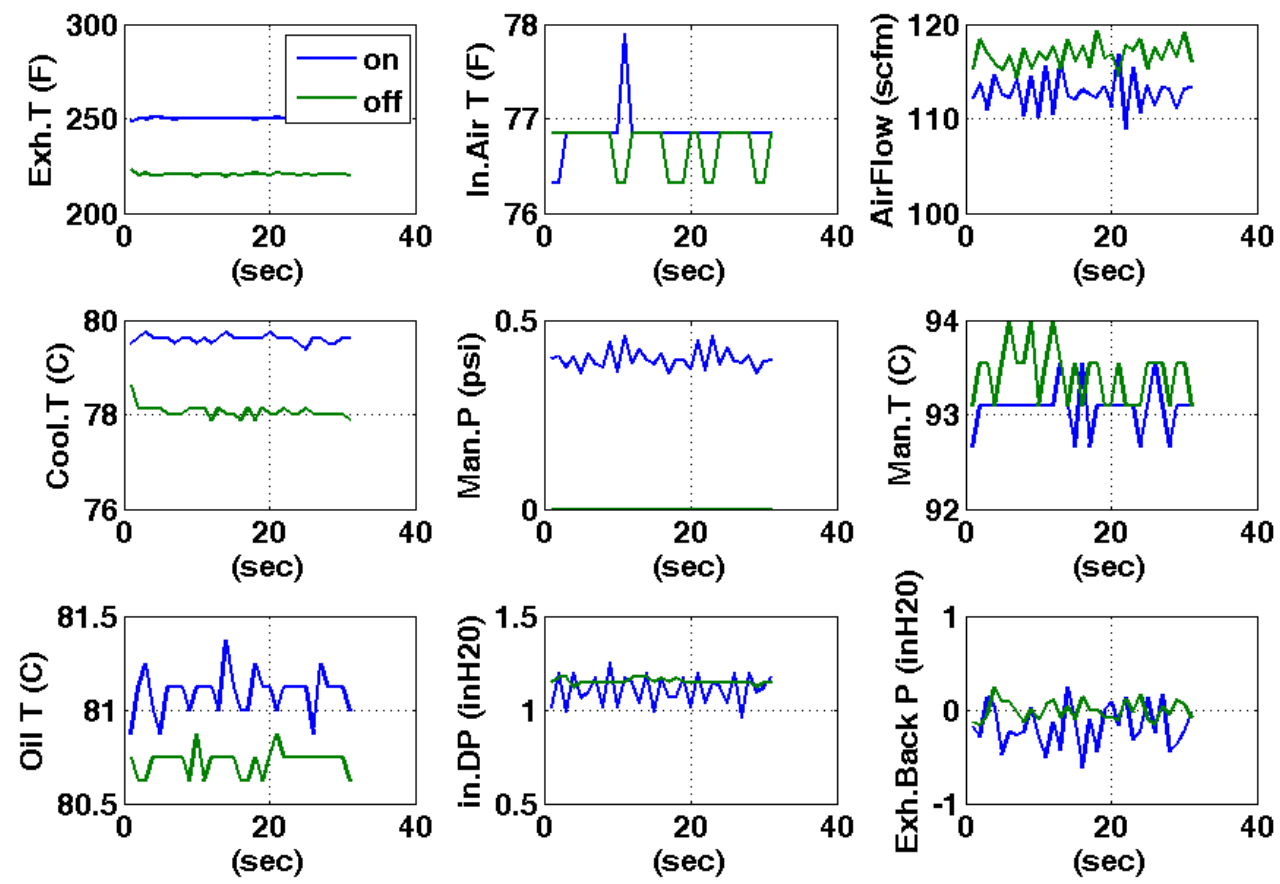

Figure 74: Laboratory data during early opening of exhaust valve at idle mode and constant flow

The two camshafts were tested under three different load conditions and three different engine speed conditions. From Figure 75 to Figure 78 show the effect of the engine loads. Tests were conducted at different levels of injection timing as well. The results are displayed from Figure 79 to Figure 82.

At more advanced injection timing and at higher load the effect of the modified camshaft on the exhaust temperatures was higher. 


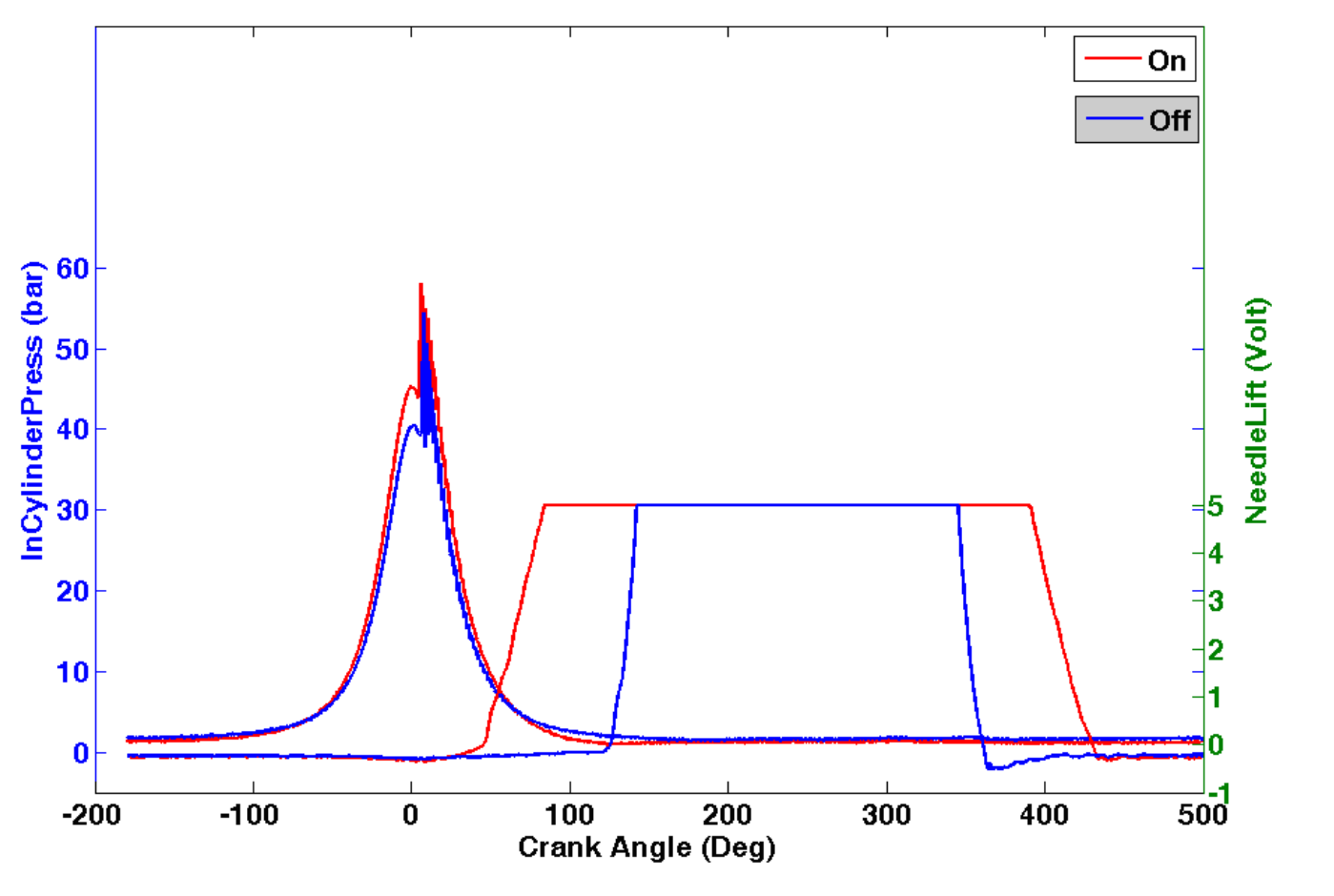

Figure 75: Early exhaust valve opening at $1000 \mathrm{rpm}, 10 \mathrm{Nm}$ load; heat release and needle lift curve

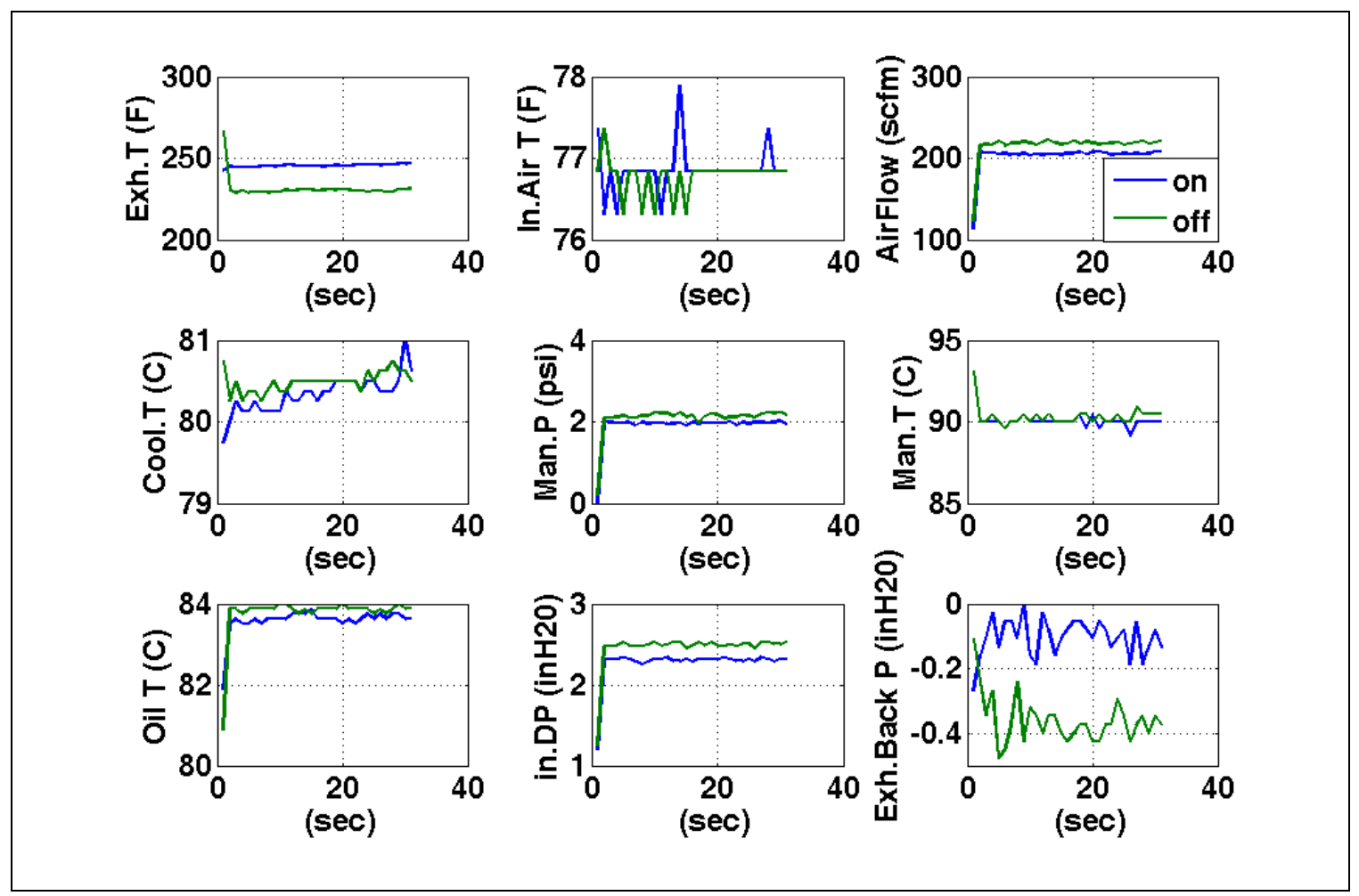

Figure 76: Laboratory data during early opening of exhaust valve at $1000 \mathrm{rpm}, 10 \mathrm{Nm}$ load 


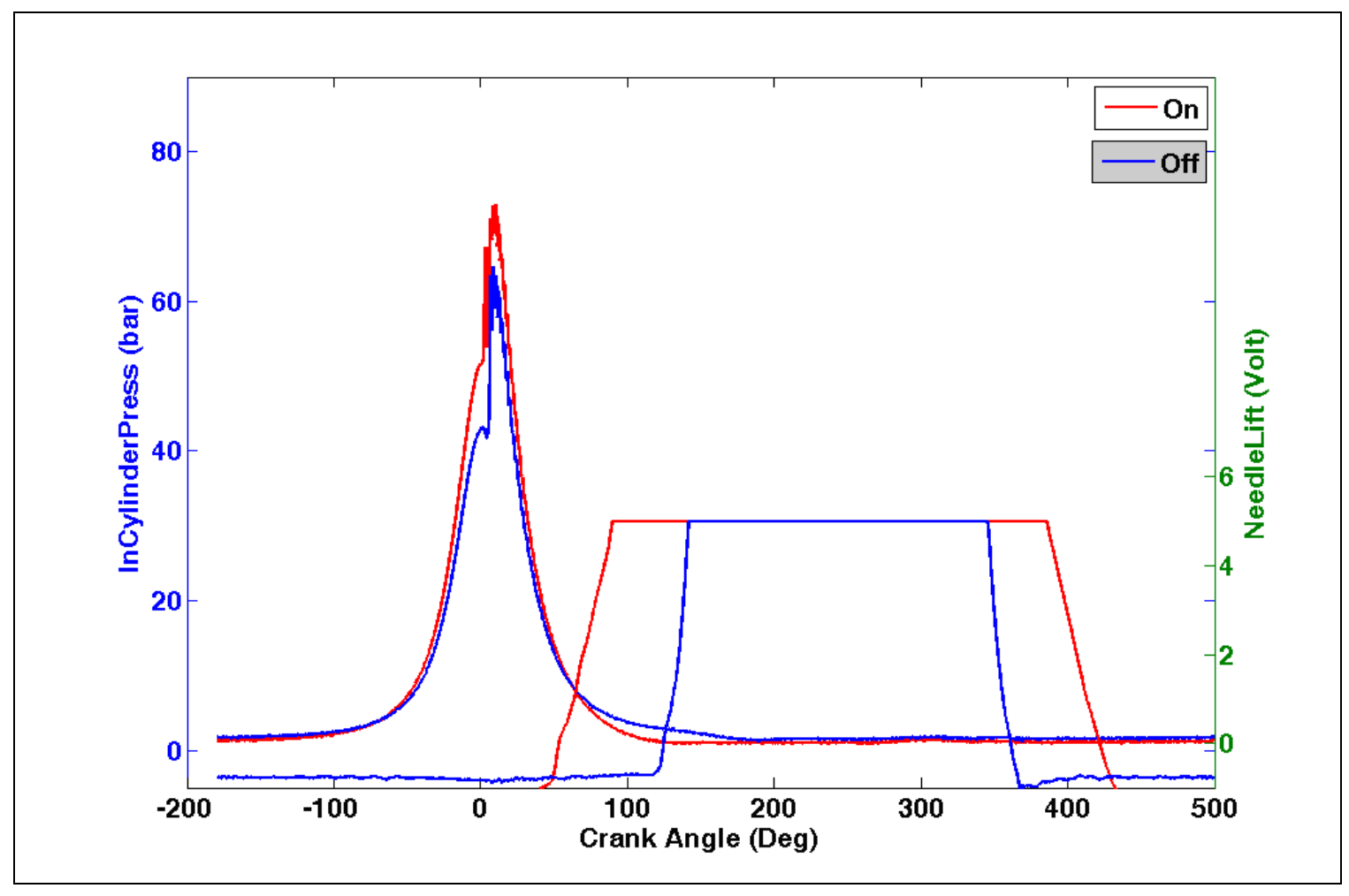

Figure 77: Early exhaust valve opening at $1000 \mathrm{rpm}, 200 \mathrm{Nm}$; heat release and needle lift curve 

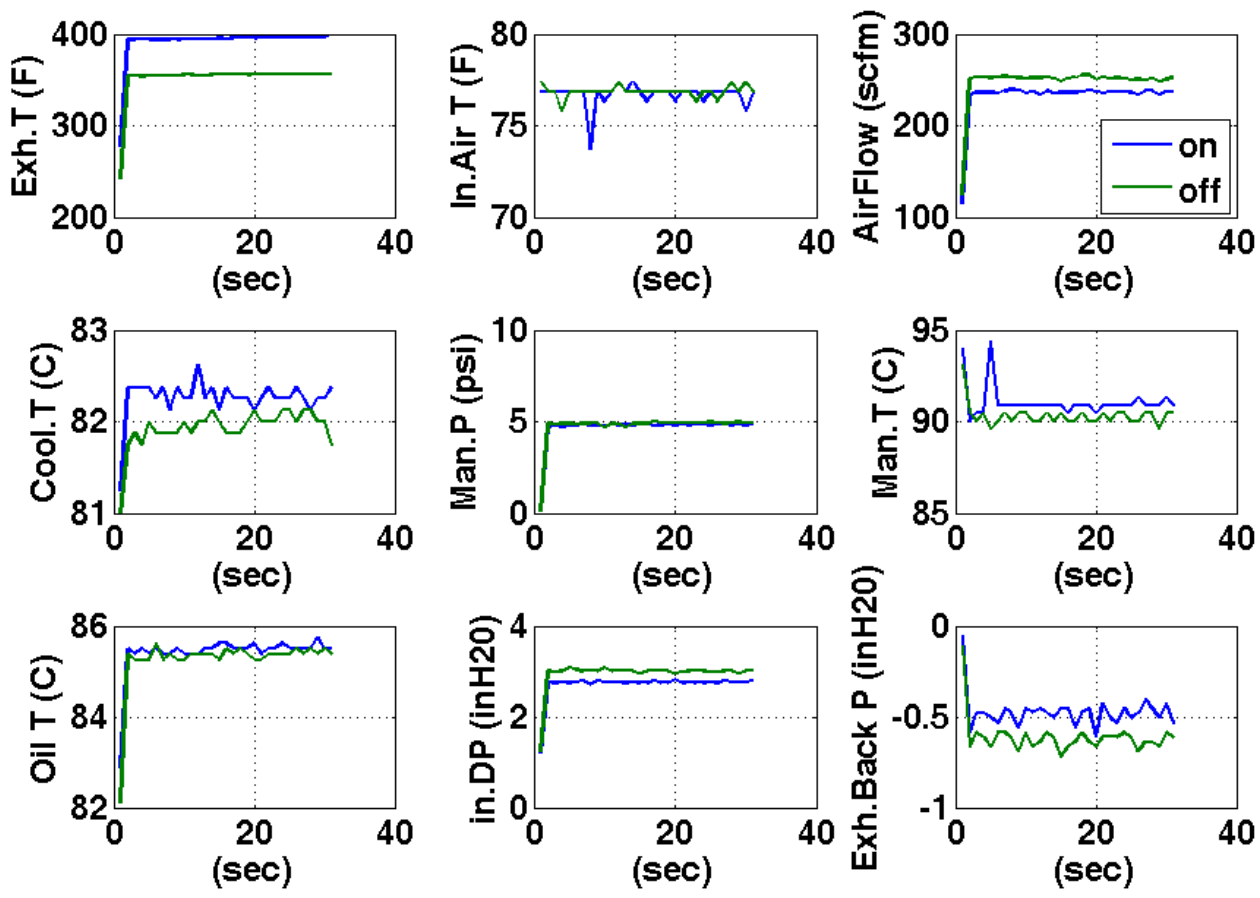

Figure 78: Laboratory data during early opening of exhaust valve at $1000 \mathrm{rpm}$ and $200 \mathrm{Nm}$

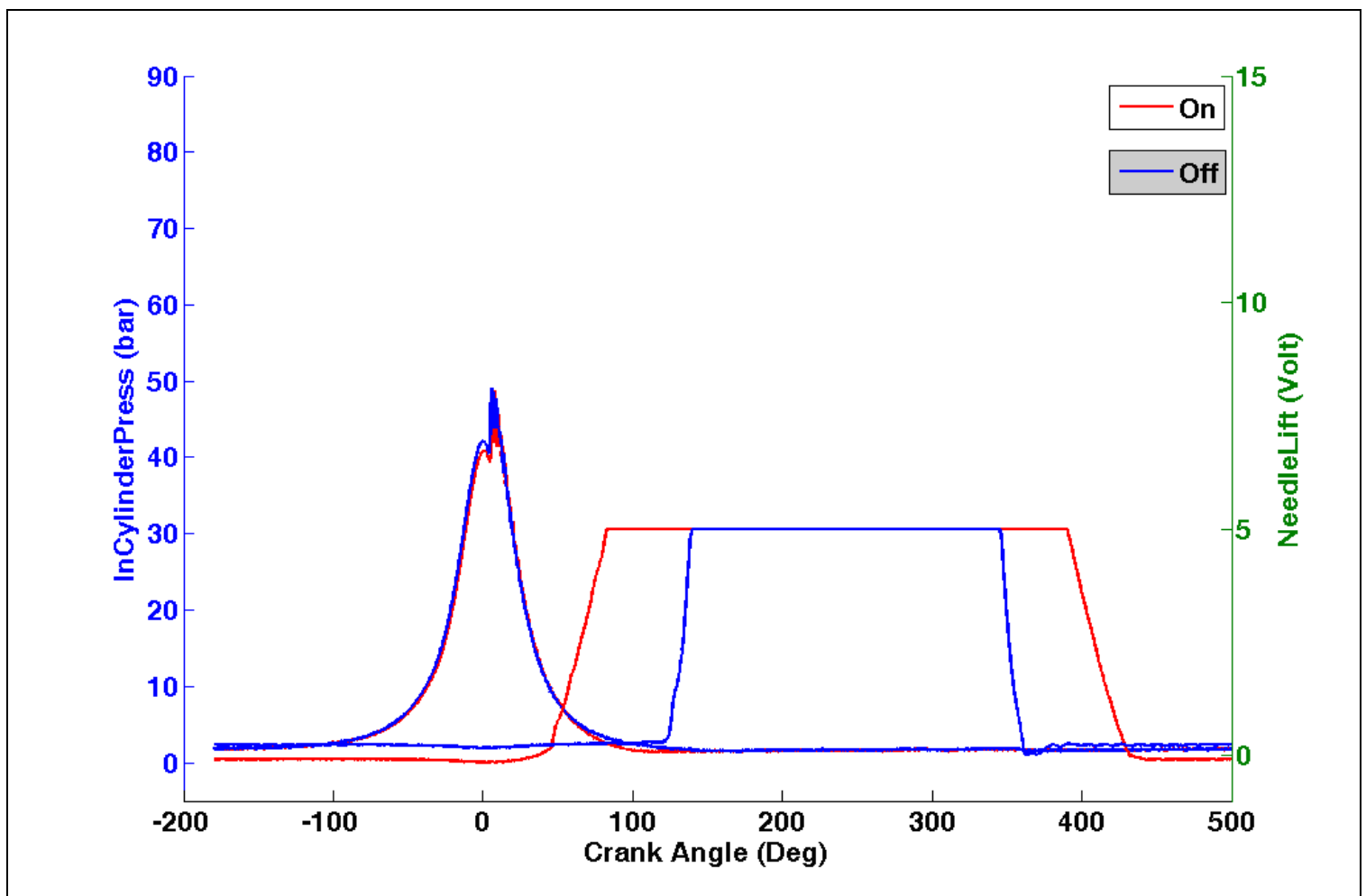

Figure 79: Early exhaust valve opening at $650 \mathrm{rpm}, 0$ deg timing; heat release and needle lift curve. 


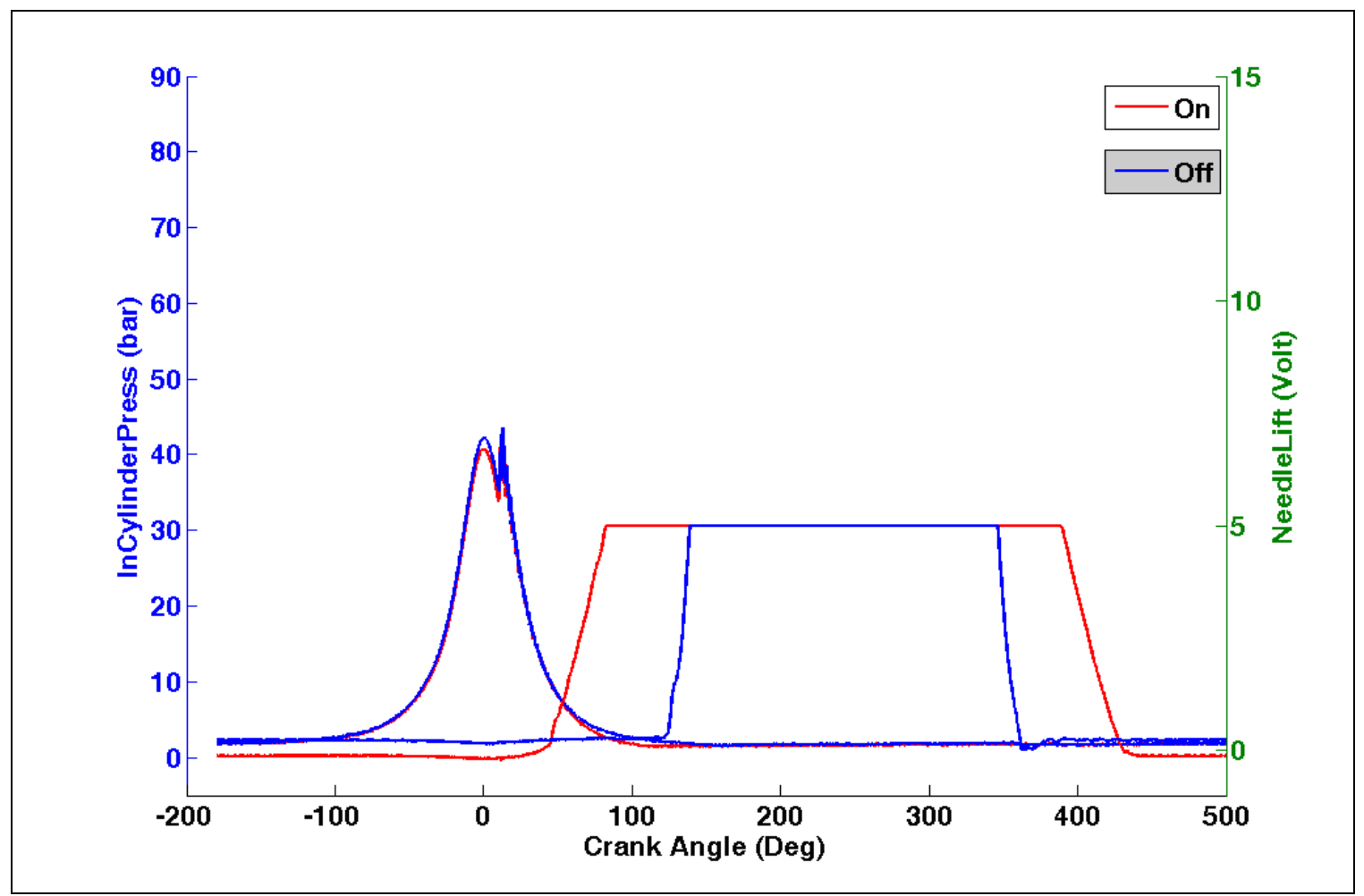

Figure 80: Early exhaust valve opening at $650 \mathrm{rpm}, 5$ deg timing; heat release and needle lift curve.

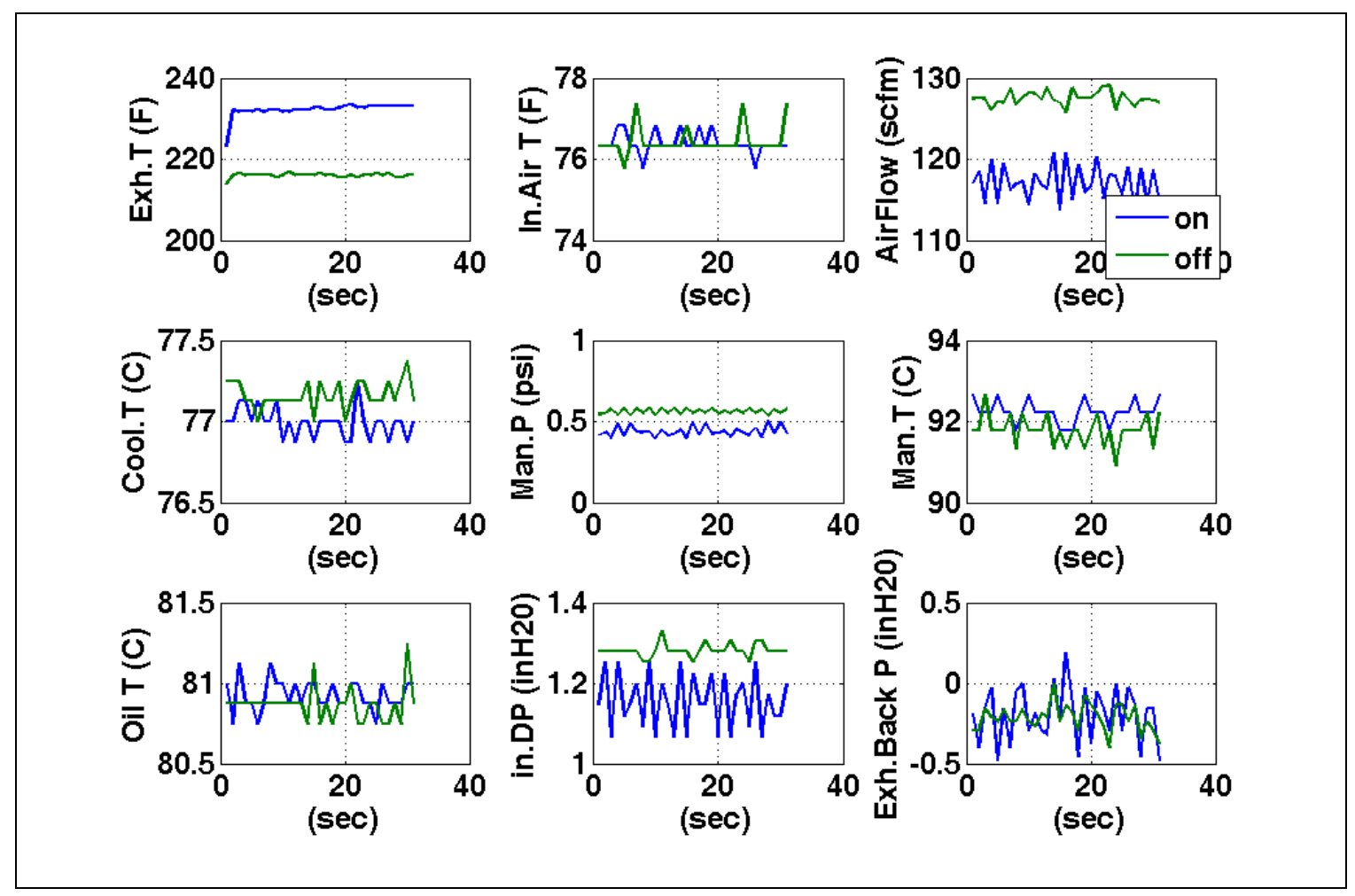

Figure 81: Laboratory data during early opening of exhaust valve at $650 \mathrm{rpm}, 0 \mathrm{deg}$ 


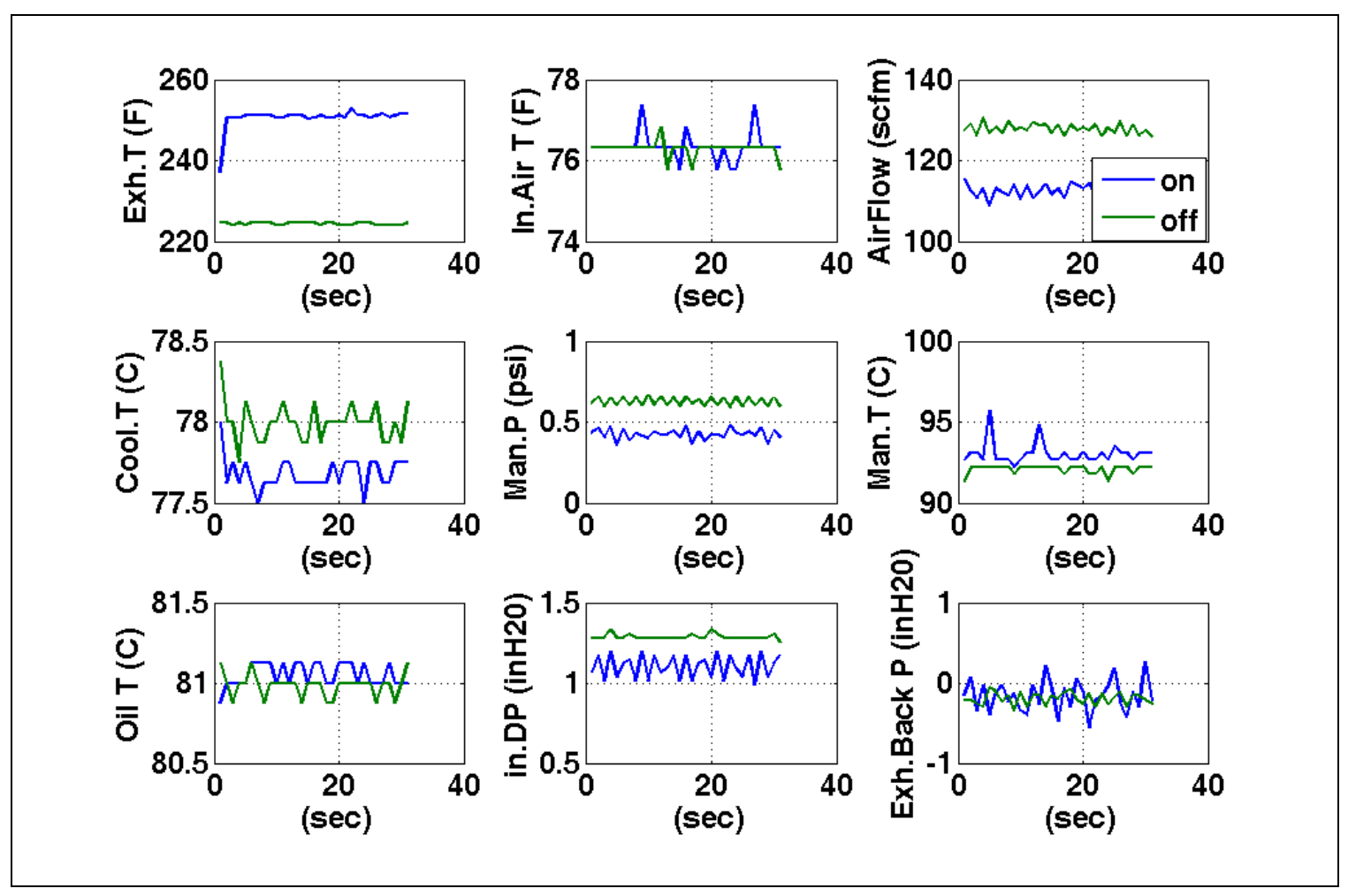

Figure 82: Laboratory data during early opening of exhaust valve at $650 \mathrm{rpm}$ and $5 \mathrm{deg}$ 


\subsection{Evaluation of the Calibrations over ETC Cycle}

Calibrations were developed by optimizing the engine over steady state modes, which were selected from the ESC and AVL cycles. Another exercise was undertaken to determine if emissions produced by such calibrations, which were optimized only on ESC and FTP cycles, were cycle dependent. The fact that the engine calibrations affected the whole area under the lug curve, leads one to believe that emissions would not exceed the set target under "off-cycle" operation. Hence, the engine was tested over the European Transient Cycle (ETC) [62]. Results in Figure 83 show that the bsNOx over the FTP and ETC differed by $18 \%$ with the low-NOx map, and by $15 \%$ with low-FC map.

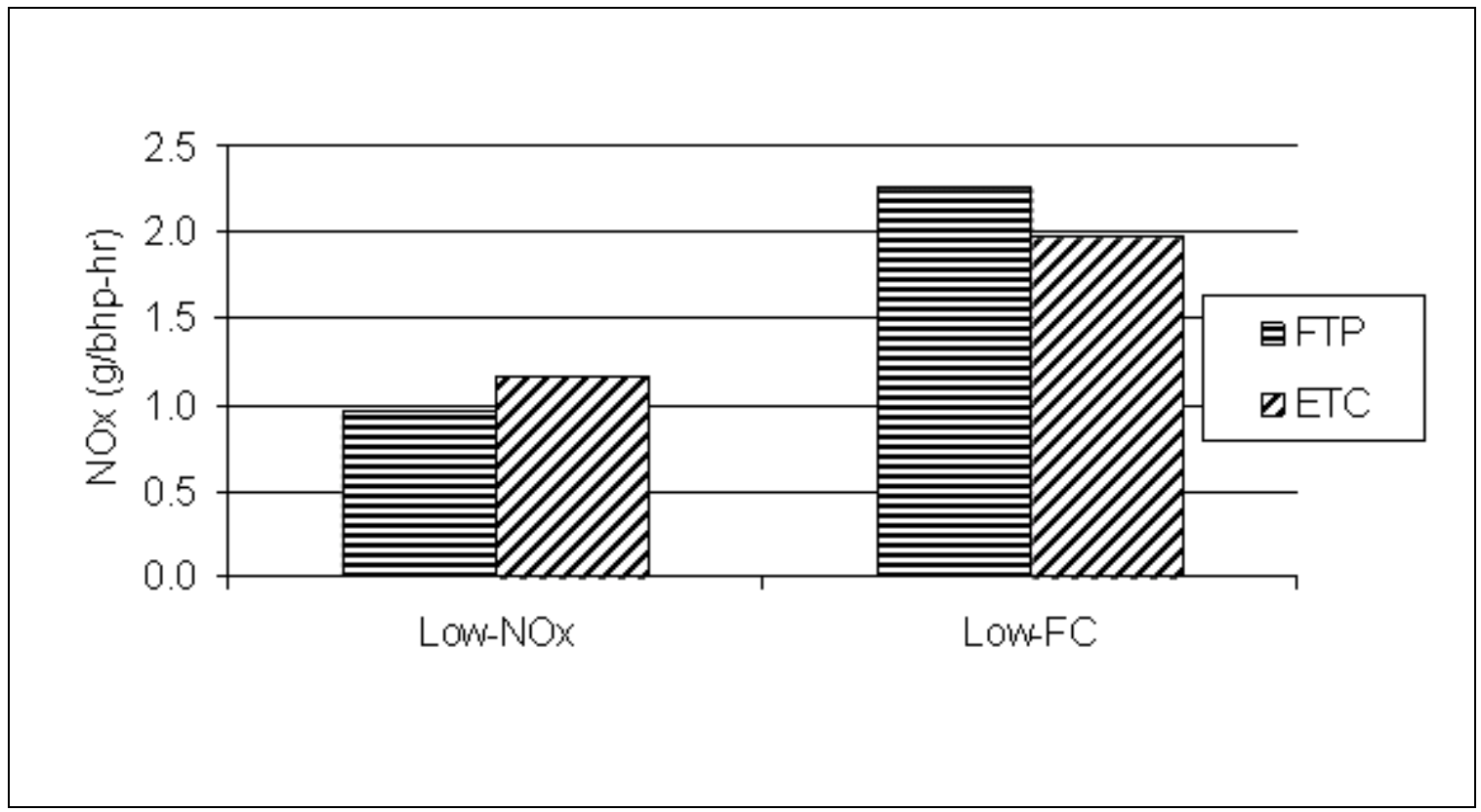

Figure 83: FTP and ETC NOx emissions for low-NOx and low-FC

The bsNOx emissions measured over FTP and ETC cycle are comparable, considering that the two cycles differ significantly in the load-speed conditions. The most frequently encountered engine speeds in the ETC cycle are speeds that correspond to peak torque and the intermediate speed. 
The two calibrations, evaluated over the ETC, exhibited similar behavior as the one observed when tested over the FTP. Figure 84 shows the comparison between the low-NOx and low-FC in terms of NOx concentrations.

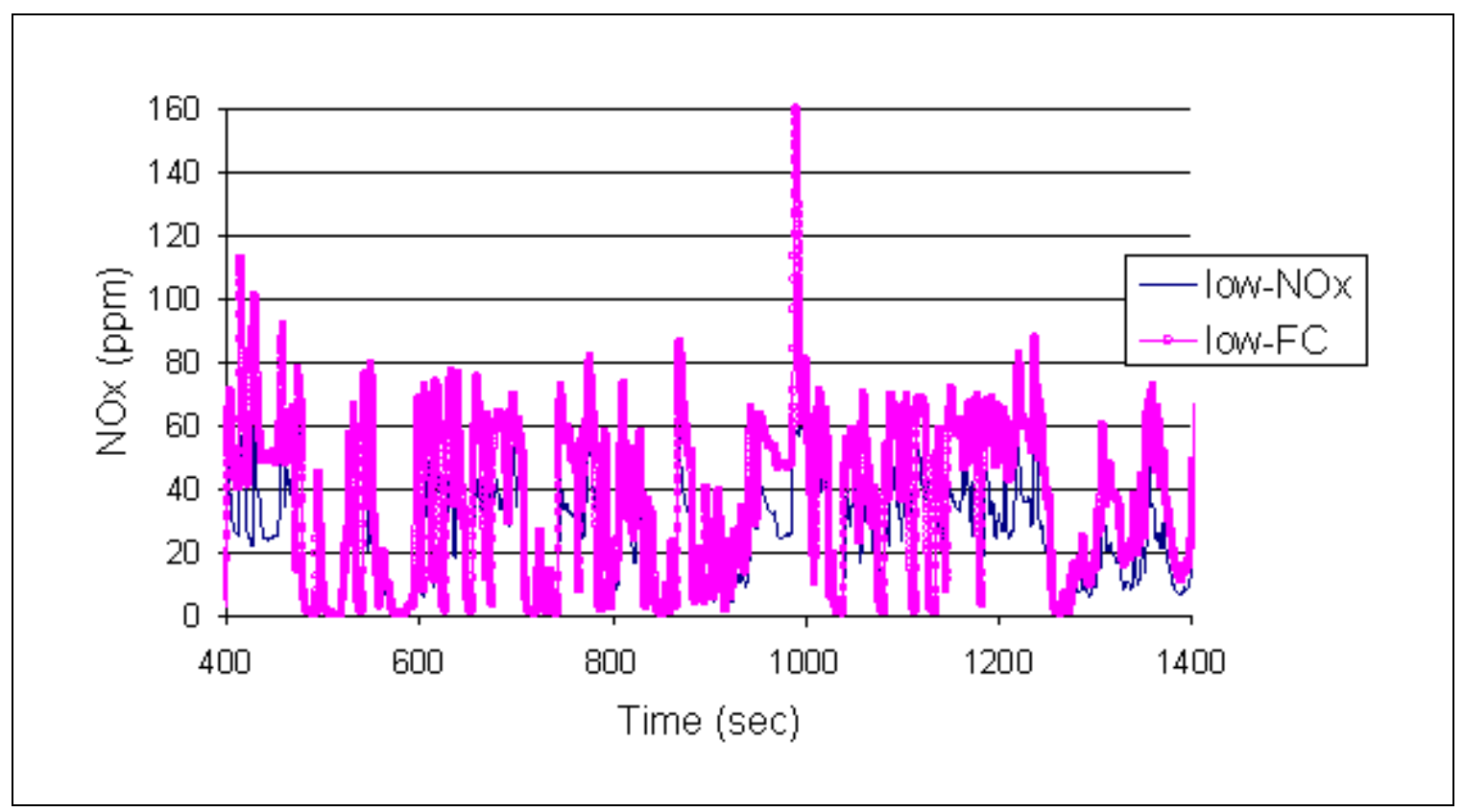

Figure 84: NOx concentration over ETC cycle; low-NOx, low-FC

Table 27: NTE events during ETC and FTP cycle

\begin{tabular}{|c|c|c|c|c|c|}
\hline Test & Total Time & $\begin{array}{c}\text { Total \# of } \\
\text { NTE } \\
\text { windows }\end{array}$ & $\begin{array}{c}\text { Total \# of } \\
\text { continuous } \\
\text { NTE } \\
\text { windows }\end{array}$ & $\begin{array}{c}\text { Time in } \\
\text { NTE zone }\end{array}$ & $\begin{array}{c}\text { Percentage } \\
\text { of total time } \\
\text { in the NTE } \\
\text { zone }\end{array}$ \\
\hline & sec & -- & -- & sec & $\%$ \\
\hline FTP & 1199 & 46.2 & 4 & 162.2 & 13.5 \\
\hline ETC & 1800 & 66.2 & 5 & 211.2 & 11.7 \\
\hline
\end{tabular}

During the ETC, the engine spent $11 \%$ of its operational time in the NTE zone, with a total of 66 NTE events and 5 continuous NTE windows (see Table 27 and Figure 85). Similar values were found for the FTP cycle. For both cycles the engine spends most of the time outside the NTE region. These cycles, together with the ESC cycle provide limited representation of the real-world in-use engine operation [63]. On the other hand, 
the cycles are also employed for engine certification. The value of bsNOx emissions measured over the ETC cycle (1.19 g/bhp-hr) approaches the bsNOx emissions measured over an FTP (1.04 g/bhp-hr). If the ETC were to be considered as the "off cycle" operation, then the bsNOx within the NTE region was $0.95 \mathrm{~g} / \mathrm{bhp}-\mathrm{hr}$ (Table 28), which is below the study's $1.00 \mathrm{~g} / \mathrm{bhp}$-hr target for pre-SCR emissions value.

Table 28: Brake specific NOx emissions within the NTE region

\begin{tabular}{|c|c|c|c|c|}
\hline \multirow{2}{*}{ Test } & NOx & NTE work & $\begin{array}{c}\text { NTE NOx } \\
\text { corrected }\end{array}$ & NTE NOx \\
\cline { 2 - 5 } & g/bhp-hr & bhp-hr & $\mathbf{g}$ & $\mathbf{g} /$ bhp-hr \\
\hline FTP & 1.04 & 3.11 & 1.70 & 0.55 \\
\hline ETC & 1.19 & 4.23 & 4.00 & 0.95 \\
\hline
\end{tabular}

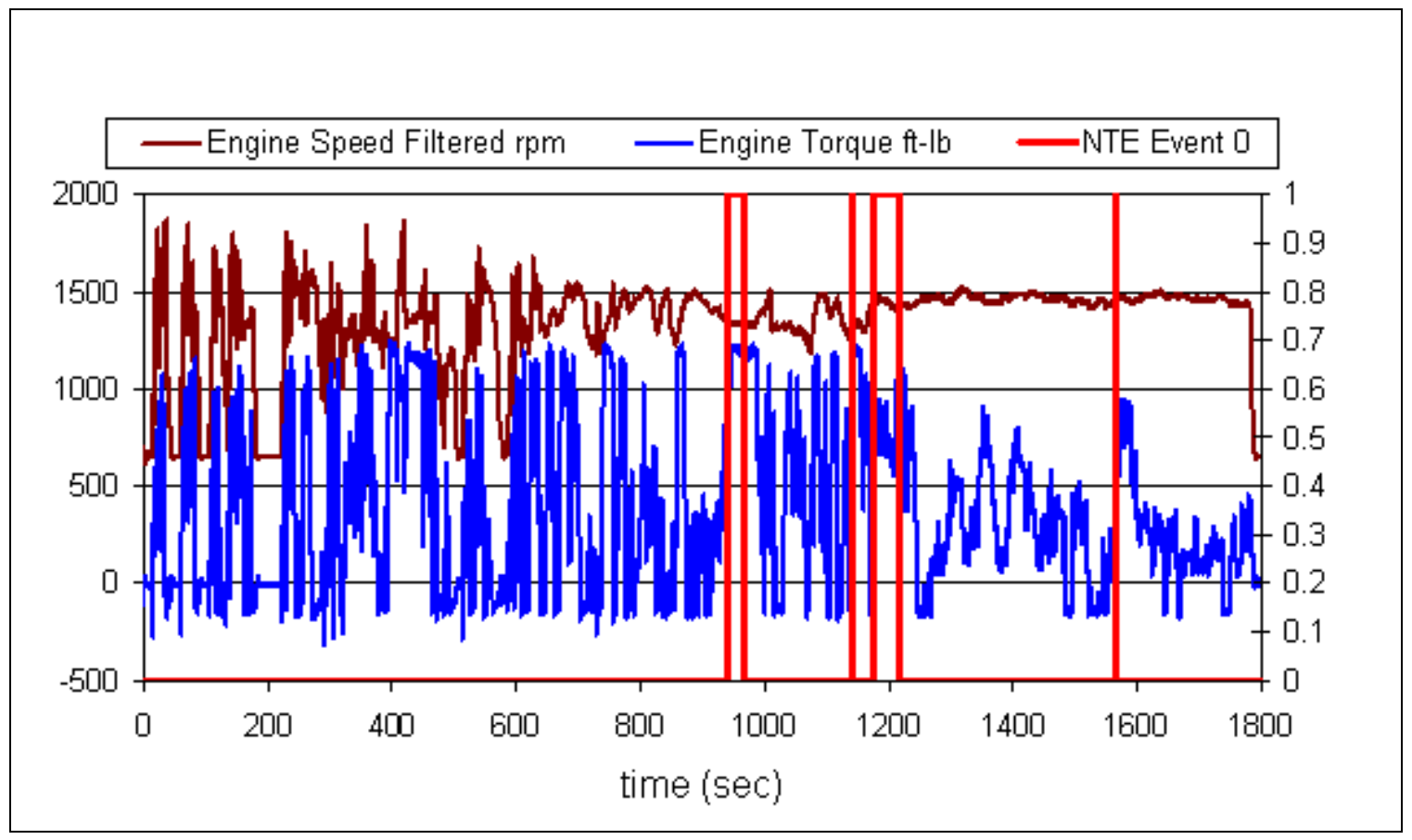

Figure 85: NTE events during ETC cycle 


\section{CHAPTER 6 CONCLUSIONS AND RECOMMENDATIONS}

\subsection{Conclusions}

The high NOx reduction efficiency achieved by the SCR system probably makes it the most suitable technology to meet the Euro V and US 2010 emission legislations. Since the exhaust aftertreatment efficiency is strictly dependent upon the thermodynamic conditions of the engine exhaust, the SCR must be integrated with the engine through calibrations designed to meet the aftertreatment requirements.

- The low-NOx calibration, which was developed by raising the injection pressure and increasing EGR rates, led to NOx reduction greater than $20 \%$, with a fuel economy penalty of less than $3 \%$ and higher bsPM. This calibration yields a bsNOx of $1 \mathrm{~g} / \mathrm{bhp}$-hr for both the ESC and FTP cycle. The 2010 emissions standards for bxNOx could be met if the engine were integrated with an SCR system whose efficiency ranges from $75 \%$ to $80 \%$. Furthermore, this calibration produced an exhaust temperature $4 \%$ higher than the fuel efficient (low-FC) calibration. These two characteristics, the lower engine-out NOx and the higher exhaust temperature, make the low-NOx a suitable calibration for conditions considered critical for SCR optimal performance, such as the first $600 \mathrm{sec}$ of the US FTP; or during any engine operation involving low loads for extended periods.

- The low-FC calibration was generated by advancing injection timing and increasing injection pressure. It brought a reduction in $\mathrm{FC}$ of about $6 \%$, but lower exhaust temperature and higher NOx emissions were measured. This map can be used when there are more favorable conditions for urea decomposition. That is, the low-FC calibration may be applied when the engine operation involves high loads. 
- Attempts to raise the exhaust temperatures, to enable higher SCR efficiencies did not meet with much success. However, a calibration was generated that led to an improvement of greater than $3 \%$ in FC, and increased the in-cylinder temperature and pressure by more than 5\%. However, this did not result in an actual increase in the exhaust temperature. More successful was the attempt to increase the exhaust temperature by means of variable timing of the exhaust valve, which brought an increase of exhaust temperature from 220 to $250^{\circ} \mathrm{F}$ under idle conditions..

- The developed technique took little calibration work, cutting down testing time and could be easily implemented. Only four engine parameters, namely SOI, VGT, EGR and NOP were varied, and the test cell time to generate calibration was considerably reduced.

- The technique led to the development of robust calibrations, with low sensitivity to factors level variation. The technique showed satisfactory results on both MY04 and MY07 engines. Robust calibrations are needed, such that emissions measured on an engine test bed, will be similar to emissions from an engine installed in a vehicle, and operating under real-world conditions.

- This technique generated an additive model, which was accurate in predicting NOx and FC for all modes of the ESC and AVL cycles. The technique appeared to exhibit a high degree of flexibility in the selection of the target to optimize. It was used to generate calibrations targeting several characteristic functions, such as the low-NOx, low-NOx/low-PM, low-NOx/low-FC and low-FC/high-exhaust temperature.

- The two main calibrations were also tested over an alternative cycle (ETC), exhibiting comparable emissions. This showed that even though the engine was optimized on ESC and AVL points, the emission levels were not dependent upon the engine cycles over which the engine was tested.

\subsection{Recommendations}

- Further improvement in the low-NOx engine map can be obtained if engine-out PM level is targeted along with a specific NOx level, since the soot produced 
affects the frequency of DPF active regeneration, which ultimately weighs on the fuel economy.

- Improvements in the low-FC calibrations are necessary, since no specific target levels were set for engine-out bsNOx. The optimization algorithm minimized FC, regardless of the NOx levels. A further step in the optimization of this map would be to set the engine-out NOx level based upon the measured SCR efficiency, levels of urea injected and the desired NOx tailpipe level. Urea consumption should be included in the list of critical factors to consider in the choice of the combustion strategy.

- It is believed that the variable exhaust valve opening, accompanied with selected engine calibrations, could represent a very efficient way to supply heat to the exhaust in case of low load conditions.

- In order to make the engine maps even more robust and insensitive to variations that may occur during in-field applications, the noise factors should be first identified and then implemented in the orthogonal matrix. The maps optimized in the engine dynamometer test cell could be tested while the engine is on a truck through chassis dynamometer testing, or during actual in-use engine operation with on-board measurement systems. In such conditions, if a failure of the emissions target is experienced, the cause should be identified and then assigned to the noise factor in the design of the orthogonal array. The optimization resulting from this new orthogonal design will lead to significantly more robust calibrations.

- The empirical model generated can be improved by redesigning the orthogonal array, such that interactions between control factors are included [Appendix D]. In addition, better predictions are also expected if a more accurate method, other than the "pooling method", is engaged to estimate the experimental error. The "pooling method", described in Section 4.9.1, is based on some arbitrary choices; a parameter neglected in the additive model, because it is believed, according to the ANOVA test, to contribute minimally to the characteristic function variation, may reveal to be important. In such a case, excluding this control factor and exploiting its degrees of freedom to estimate the experimental error would result 
in a significant error in the model predictions. An alternative way to deal with the experimental error is to measure it directly through replicate tests. Moreover, the experimental error could be estimated by treating it as a control factor and assigning it to an empty column in the orthogonal matrix. The $\mathrm{L}_{18}$ orthogonal array described in Appendix D, represents a good candidate to generate a model with improved accuracy, as it provides empty columns that could be dedicated to error analysis and account for interactions as well.

Ultimately, the technique should produce a number of calibrations such that an engine can be matched with an aftertreatment system by producing optimal engine-out exhaust conditions. The calibrations could target more specific parameters of aftertreatment performance, such as exhaust temperature, urea level, $\mathrm{NO}_{2} / \mathrm{NO}$ ratio, and frequency of DPF regeneration. The multiple calibrations generated could be alternatively used by the engine control system depending upon the thermodynamic conditions of the exhaust stream at the inlet of the SCR system 


\section{REFERENCES}

1. Yamamoto, M., Yoneya, S., Matsuguchi, T. and Kumagai, Y., (2002), “Optimization of Heavy Duty Diesel Engine Parameter for Low Exhaust Emissions Using The Design of Experiments," SAE 2002-01-1148.

2. Shayler, P.J., Tinwell, P.R., Dixon, J. and Eade, D., (1994), “A Development Methodology for Improving the Cold Start Performance of Spark Ingnition Engines," SAE 940084.

3. Gardner, T.P., (1992), "Investigation of the Effects of Engine Design Parameters on Diesel Combustion and Emission Using Taguchi Methods,” SAE 920116.

4. Yamaoka, S., Kakuya, H., Nakagawa, S., Okada, T., Shimada, A. and Kihara, Y., (2005), "HCCI Operation Control in a Multi-Cylinder Gasoline Engine," SAE 2005-01-0120.

5. Conway, R. and Chatterjee, S., (2005), "Combined SCR and DPF Technology for Heavy Duty Diesel Retrofit," SAE 2005-01-1862.

6. SCR System for Mobile Engines, revision 2005, www.dieselnet.com.

7. Servati, H., Petreanu, S. and Marshall, S., (2005), "A NOx Reduction Solution for Retrofit Application: A Simple Urea SCR Technology," SAE Paper No. 2005-011857.

8. Hirata, K. and Masaki, N., (2005), "Development of Urea-SCR System for Heavy-Duty Commercial Vehicles," SAE 2005-01-1860.

9. “Engine Design for NOx Control”, revision 2002, www.dieselnet.com.

10. Hunter, C.E., Gardner, T.P. and Zakrajsek, C.E., (1992), "Simultaneous Optimization of Diesel Engine Parameters for Low Emissions Using Taguchi Methods," SAE 902075.

11. "Exhaust Gas Recirculation", revision 2006, www.dieselnet.com.

12. Ladommatos, N., Abdelhalim, S M., Zhao, H. and Hu, Z., (1997), “The Dilution, Chemical, and Thermal Effects on Exhaust Gas Recirculation on Diesel Engine Emissions--Part 3: Effects of Water Vapor,” SAE 971659. 
13. Ladommatos, N., Abdelhalim, S M., Zhao, H. and Hu, Z., (1996a), "The Dilution, Chemical, and Thermal Effects of Exhaust Gas Recirculation on Diesel Engine Emissions--Part 2: Effects of Carbon Dioxide," SAE 961167.

14. Ladommatos, N., Abdelhalim, S. M., Zhao, H. and Hu, Z., (1996), "The Dilution, Chemical, and Thermal Effects of Exhaust Gas Recirculation on Diesel Engine Emissions-Part 1: Effect of Reducing Inlet Charge Oxygen.” SAE 961165.

15. Ladommatos, N., Abdelhalim, S M., Zhao, H. and Hu, Z., (1997a), “The Dilution, Chemical, and Thermal Effects of Exhaust Gas Recirculation on Diesel Engine Emissions--Part 4: Effects of Carbon Dioxide and Water Vapor," SAE 971660.

16. Zhao, H., Hu, J. and Ladommatos, N. (2000), "IN-CYLINDER STUDIES OF THE EFFECTS OF CO2 IN EXHAUST GAS RECIRCULATION ON DIESEL COMBUSTION AND EMISSIONS," Proc Instn Mech Engrs, Vol 214 Part D, pg. 405-419.

17. Jacobs, T.J., Assanis, D.N. and Filipi, Z.S., (2003), "The Impact of Exhaust Gas Recirculation on Performance and Emissions of a Heavy-Duty Diesel Engine," SAE 2003-01-1068.

18. Idicheria, C.A. and Pickett, L.M., (2005), "Soot Formation in Diesel Combustion Under High-EGR Conditions," SAE 2005-01-3834.

19. Eastwood, P., "CRITICAL TOPICS IN EXHAUST GAS AFTERTREATMENT," Ford Motor Company, Research Studies Press LTD., England, 2000.

20. Lemaire J., Mustel, W. and Zelenka, P. (1994), "Fuel Additive Supported Particulate Trap Regeneration Possibilities by Engine Management System Measures," SAE 942069.

21. Montgomery, D. T. and Reitz, R. D., (2001), "Effects of Multiple Injections and Flexible Control of Boost and EGR on Emissions and Fuel Consumption of a Heavy-Duty Diesel Engine," SAE 2001-01-0195.

22. Khair, M.K., (1997), "Technical and Synergistic Approaches Towards the 21st Century Diesel Engine," SAE Technical Paper 972687. 
23. Hawley, J.G., Wallace FW, Cox A, Horrocks RW and Bird GL, (1999), "Reduction of Steady State NOx Levels from an Automotive Diesel Engine Using Optimized VGT/EGR Schedules," SAE 1999-01-0835.

24. Schubiger, R., Bertola, A. and Boulouchos, K., (2001), "Influence of EGR on Combustion and Exhaust Emissions of Heavy Duty DI-Diesel Engines Equipped with Common-Rail Injection System," SAE 2001-01-3497.

25. Baert R.S.G., Beckman, D.E. and Veen, A. (1999), "Efficient EGR Technology for Future HD Diesel Engine Emission Targets," SAE 1999-01-0837

26. Yokomura, H., Kohketsu, S. and K. Mori, (2003), "EGR System in a Turbocharged and Intercooled Heavy-Duty Diesel Engine: Expansion of EGR Area with Venturi EGR System,” Mitsubishi Technical Review, 2003 No. 15, http://www.mitsubishimotors.com.

27. “EGR System \& Components,” revision 2008, www.dieselnet.com.

28. Heywood, J.B., (1988). “INTERNAL COMBUSTION ENGINE FUNDAMENTALS," McGraw-Hill, New York.

29. Schwitzer, (1991), "INTRODUCTION TO TURBOCHARGERS," Schwitzer Turbochargers, Indianapolis, Indiana.

30. “Turbochargers for Diesel Engines", Revision 2004, www.dieselnet.com.

31. Pfeifer, A., Smeets, M., Herrmann, H., Tomazic, D., Richert, F. and Schlober, A., (2002), “A New Approach to Boost Pressure and EGR Rate Control Development for HD Truck Engines with VGT," SAE 2002-01-0964.

32. Khair, M.K., (1993), "Diesel Engine Technology", SAE Seminar, April 1993.

33. Rente, T., Gjirja, S. and Denbratt, I., (2004), "Experimental Investigation of the effect of Needle Opening (NOP) Pressure on Combustion and Emissions Formation in a Heavy Duty DI Diesel Engine," SAE 2004-01-2921.

34. Henein, N.A. and Patterson, D.J., (1972), "EMISSIONS FROM COMBUSTION ENGINES AND THEIR CONTROL," Ann Arbor Science Publishers Inc.

35. Khan, I.M., Grigg, H.C., (1971), "Progress of Diesel Combustion Research," CIMAC, 9th International Congress on Combustion Engines, Stockholm, Sweden, Paper No. A-18, May 1971. 
36. Greeves, G., Tullis, S. and Barrie Barker, (2003), “Advanced Two-Actuator EUI and Emission Reduction for Heavy-Duty Diesel Engines," SAE 2003-01-0698.

37. Hountalas, D., T., Kouremenos, D.A., Binder, K.B., Schwarz, V. and Mavropoulos, G.C., (2003), "Effect of Injection Pressure on the Performance and Exhaust Emissions of a Heavy Duty DI Diesel Engine,” SAE 2003-01-0340.

38. "Combustion in Diesel Engines," revision 2008, www.dieselnet.com.

39. Gekas, I., Gabrielsson, P., Johannsen, K., Nyengaard, L. and Lund, T., (2002), "Urea-SCR Catalyst System Selection for Fuel and PM Optimized Engines and a Demonstration of a Novel Urea Injection System," SAE 2002-01-0289.

40. Song, Q. and Zhu, G, (2002), "Model-Based Closed-Loop Control of Urea SCR Exhaust Aftertreatment System for Diesel Engine," SAE 2002-01-0287.

41. Khair, M.K. and Sharp, C., (2004), "Update on Progress of APBF-DEC EGR/DPF/SCR Demonstration Program at SwRI," US DOE, 10th Diesel Engine Emissions Reduction Conference (DEER), San Diego, CA, August 2004, http://www.eere.energy.gov.

42. Hirata, K., Masaki, N., Ueno, H. and Akagawa, H., (2005), "Development of Urea-SCR System for a Heavy-Duty Commercial Vehicles," SAE 2005-01-1860.

43. Dodge, L.G., Simescu, S., Neely, G.D., Maymar, M.J., Dickey, D.W. and Savonen, C., L., (2002), "Effect of Small Holes and High Injection Pressures on Diesel Engine Combustion," SAE 2002-01-0494.

44. Yun, H. and Reitz, R.D., (2003), "An Experimental Study on Emissions Optimization Using Micro-Genetic Algorithms in a HSDI Diesel Engine," SAE 2003-01-0347, 2003.

45. Munnannur, A., Kong, S.C. and Reitz, R.D., (2005), "Performance Optimization of Diesel Engines with Variable Intake Valve Timing Via Genetic Algorithm," SAE 2005-01-0374.

46. Tiax, (2003), "SCR-Urea Infrastacture Implementation Study," Final Report, TIAX LLC, Cupertino, California, July 30, 2003, www.enginemanufacturers.org.

47. Miller, W.R., Klein, J.T., Mueller, R., Doelling, W. and Zuerbig, J., "The Development of Urea-SCR Technology for US Heavy Duty Trucks," SAE 20001-0190. 
48. Hiroyasu, T., Miki, M., Kim, M., Watanabe, S., Hiroyasu, H. and Miao, H., (2004), "Reduction of Heavy Duty Diesel Engine Emission and Fuel Economy with Multi-Objective Genetic Algorithm and Phenomenological Model," SAE 2004-01-0531.

49. Rose, T. and Jebasinski, R., (2003), "Design of Experiment - Application of a Statistical Evaluation Method to Optimize the Tailpipe Noise of an Exhaust System," SAE 2003-01-1655.

50. Taguchi, G., "SYSTEM OF EXPERIMENTAL DESIGN : ENGINEERING METHODS TO OPTIMIZE QUALITY AND MINIMIZE COSTS," White Plains, N.Y., 1987, Vol. 1, pp. 143-146, 148-149, 165-168, 173-176.

51. Fowlkes, W. and Creveling, C., "ENGINEERING METHODS FOR ROBUST PRODUCT DESIGN. USING TAGUCHI METHODS IN TECHNOLOGY AND PRODUCT DEVELOPMENT," Corporate \& Professional Publishing Group, Addison Wesley Longman, Inc, Massachusetts, 2000.

52. "The Development of an Advanced Diesel Emission Control System for a LowSulfur Diesel-fueled Heavy-Duty Engine," August 2008, www.aqmd.gov.

53. Ardanese, R., (2008) "Impact on performance, Emissions and PM Size Distribution of Aftertreatment System Fitting a 2010 Compliant Heavy-duty Diesel Engine Programmed with Different Engine-out Calibrations," Dissertation, West Virginia University, 2008.

54. "VGT," August 2008, www.originalturbosdirectltd.co.uk.

55. "VGT," August 2008, www.holset.co.uk.

56. “Diesel Engine Management System,” August 2008, www.delphi.com.

57. Henriksson, C. and Sherafat-Hosseiny, S., (2004), "Modeling End of Injection," Master Thesis, Chalmers University of Technology, Goteborg, Sweden, 2004.

58. “ThermoCOMP-Quartz Pressure Sensor,” Kistler data sheet, www.kistler.com. 59. "AVL-8 mode Heavy-Duty Cycle", August 2008, www.dieselnet.com.

60. Yan, J., Rogalla, R. and Kramer, T., (1993) "Diesel Combustion and Transient Emissions Optimization Using Taguchi Methods," SAE 930600.

61. "Heavy -Duty Transinet Cycle," August 2008, www.dieselnet.com.

62. "European transient cycle," August 2008, www.dieselnet.com. 
63. Shade, B., (2006), "A Work-Based Window Method for Calculating In-Use Brake-Specific Oxides of Nitrogen Emissions of Heavy-Duty Diesel Engines," Dissertation, West Virginia University.

64. Brunt, M. and Platts, K., "Calculation of Heat Release in Direct Injection Diesel Engines,” Warrendale, PA, SAE Paper No. 1999-01-0187, 1999.

65. Brunt, M. and Pond, C., "Evaluation of Techniques for Absolute Cylinder Pressure Correction," Warrendale, PA, SAE Paper No. 970036, 1997.

66. Woschni, G., "A Universally Applicable Equation for the Instantaneous Heat Transfer Coefficient in the Internal Combustion Engine," Warrendale, PA, SAE 670931, 1967.

67. Miyamoto, N., Chikahisa, T., Murayama, T., and Sawyer, R., "Description and Analysis of Diesel Engine Rate of Combustion and Performance Using Weibe's Functions," Warrendale, PA, SAE 850107, 1985.

68. Schreiner, K., "Equivalent Combustion Rate with the Polygon-Hyperbola Function: Investigations into the Dependence of the Parameters in the Performance Map," Proc $5^{\text {th }}$ Symposium, "The Working Process of the Internal Combustion Engine," Technical University Graz, Austria, pp 239-257, 1995.

69. "Electronic Code of Federal Regulation, e-CFR," August 2008, www.ecfr.gpoaccess.gov.

70. Foulkes, D.M., (1995), "Developing Light-Duty Diesel Engines For Low Emissions and High Fuel Economy," Internal Report, Ford Motor Company.

71. Yokomura, H., Kohketsu, S. and Mori, K., (2001), "EGR System in a Turbocharged and Intercooled Heavy-Duty Diesel Engine- Expansion of EGR Area with Venturi EGR System," Proceedings JSAE Annual Congress, S0434A, Vol.72 No. 1, page 1-4, 2001. 


\section{APPENDIX A Heat Release Calculation}

The calculation of the heat release from the in-cylinder pressure trace was been done taking into consideration the accuracy and errors [64] of heat release analysis attributed to the pressure correction [65], specific heat ratio, encoder alignment, and pressure smoothing. The first law of thermodynamics in Equation 21, represents the energy balance while the intake valve is closing and exhaust valve is opening; it is applied to a single zone mixture inside the cylinder and neglects kinetic and potential energy effects. Any mass loss from the cylinder rings and the sensible energy coming from the fuel mass injected are neglected. Replacing $\mathrm{dU}$ with $\mathrm{d}\left(\mathrm{mC}_{\mathrm{v}} \mathrm{T}\right)$ in Equation 21, the Equation 22 can be obtained. At this point, making use of the ideal gas law and assuming $\mathrm{C}_{\mathrm{v}}$ and $\mathrm{R}$ as constants, Equation 23 can be derived. Using the ratio of specific heats and substituting the variable of time with crank angle, the standard equation for the net heat release was found (Equation 24). The gross heat release in equation 25, instead, represents the total heat released, including the energy loss at the cylinder walls.

$$
\begin{gathered}
\frac{d U}{d t}=\frac{d Q}{d t}-\dot{W}+\sum_{\text {in }}\left[\frac{d m_{i}}{d t} * h_{i}\right]-\sum_{\text {out }}\left[\frac{d m_{i}}{d t} * h_{i}\right] \\
\frac{d Q}{d t}=\frac{d\left(m C_{v} T\right)}{d t}+p \frac{d V}{d t} \\
\frac{d Q}{d t}=\frac{C_{v}}{R}\left(P \frac{d V}{d t}+V \frac{d P}{d t}\right)+p \frac{d V}{d t} \\
{\left[\frac{d Q}{d \theta}\right]_{\text {net }}=\left(\frac{\gamma}{\gamma-1}\right) * P * \frac{d V}{d \theta}+\left(\frac{1}{\gamma-1}\right) * V * \frac{d P}{d \theta}} \\
{\left[\frac{d Q}{d \theta}\right]_{\text {gross }}=\left(\frac{\gamma}{\gamma-1}\right) * P * \frac{d V}{d \theta}+\left(\frac{1}{\gamma-1}\right) * V * \frac{d P}{d \theta}+\left[\frac{d Q}{d \theta}\right]_{h t}}
\end{gathered}
$$

21

Typically, to model the heat transfer coefficient the well-known Woschni model [66] is used, together with the mean gas cylinder temperature. Common mathematical representations of the heat release curve are given by the double Weibe function [67] and the polygon-hyperbola combustion profile [68]. This work made use of the double Weibe function represented in Equation 26. 


$$
\begin{aligned}
& {\left[\frac{d Q}{d \theta}\right]_{g r o s s}} \\
& =a Q_{p}\left(m_{p}+1\right)\left(\frac{\theta-\theta_{s o c, p}}{\Delta \theta_{c, p}}\right)^{m_{p}} \exp \left[-a\left(\frac{\theta-\theta_{s o c, p}}{\Delta \theta_{c, p}}\right)^{m_{p}+1}\right] \\
& +a Q_{d}\left(m_{d}+1\right)\left(\frac{\theta-\theta_{s o c, d}}{\Delta \theta_{c, d}}\right)^{m_{d}} \exp \left[-a\left(\frac{\theta-\theta_{s o c, d}}{\Delta \theta_{c, d}}\right)^{m_{d}+1}\right]
\end{aligned}
$$

Initially, the corrected in-cylinder pressure data was used to calculate the combustion heat release (HR). The second step was to identify the heat release curve by means of the Weibe function.

Pressure Trace: In-cylinder pressure was acquired with a high speed data acquisition system. A piezoelectric pressure transducer was placed in combustion chamber, and a phase alignment with the crank angle was performed. An optical encoder was utilized to trigger the data acquisition sampling. The resolution of the system is 0.125 degree. Intake manifold pressure was simultaneously acquired in order to reference the absolute in-cylinder pressure at the bottom dead center (pegging).

Heat Release Analysis (HR): Results obtained were based on the following assumptions: thermodynamic equilibrium at each instant, uniform and homogeneous mixture of air and combustion products, ideal gas behavior and specific heat ratio considered constant or temperature dependent.

The first law of thermodynamics, in the form of Equation 25, can thus be solved, considering $\mathrm{P}$ as in-cylinder pressure, $\mathrm{V}$ as cylinder volume, gamma as specific heat ratio and $\theta$ as crank angle degree. The heat transferred from the wall to the gas $(\mathrm{Qw})$ was neglected; the volume was calculated from geometrical relations knowing the crank angle provided from the encoder. Gamma was calculated from the temperature trace or can also be considered constant as a first approach. The derivative of the pressure is evaluated from the in-cylinder pressure data, and was determined with a finite difference method. A significant portion of the noise was introduced from the pressure gradient. Frequency analysis and filtering was applied to the pressure rate. Results less affected by noise were obtained when the filtered pressure rate was used to calculate the heat release rate. 
Weibe Function: The common way to fit the Weibe function to the experimental heat release equation is though the least squares. The combustion process was modeled by the sum of two Weibe functions that represent the double behavior of the combustion process: premixed and diffusion burning [Equation 26]. The equation includes a premix and a diffusion portion. The coefficient "a" was taken equal to 6.908 , which implies a conversion efficiency of the fuel energy to heat of $99.9 \%$. The eight fitting parameters are the following: premix portion heat released $\left(\mathrm{Q}_{\mathrm{p}}\right)$, shape parameter $\left(\mathrm{m}_{\mathrm{p}}\right)$, start of combustion $\left(\theta_{\text {soc,p }}\right)$, length of combustion $\left(\Delta \theta_{\mathrm{p}}\right)$, diffusion portion heat released $\left(\mathrm{Q}_{\mathrm{d}}\right)$, shape parameter $\left(\mathrm{m}_{\mathrm{d}}\right)$, start of combustion $\left(\theta_{\mathrm{soc}, \mathrm{d}}\right)$, and length of combustion $\left(\Delta \theta_{\mathrm{d}}\right)$.

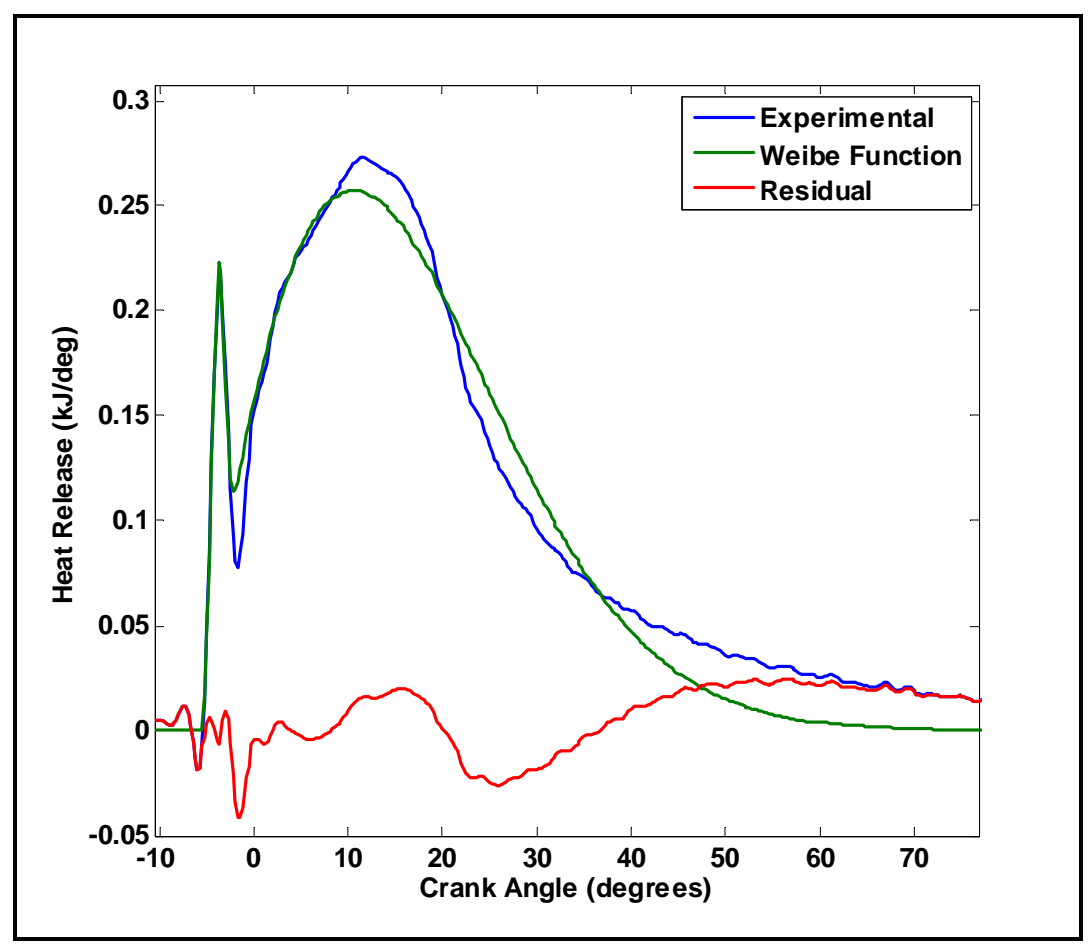

Figure 86: Experimental heat release and Weibe function fit using least squares method 


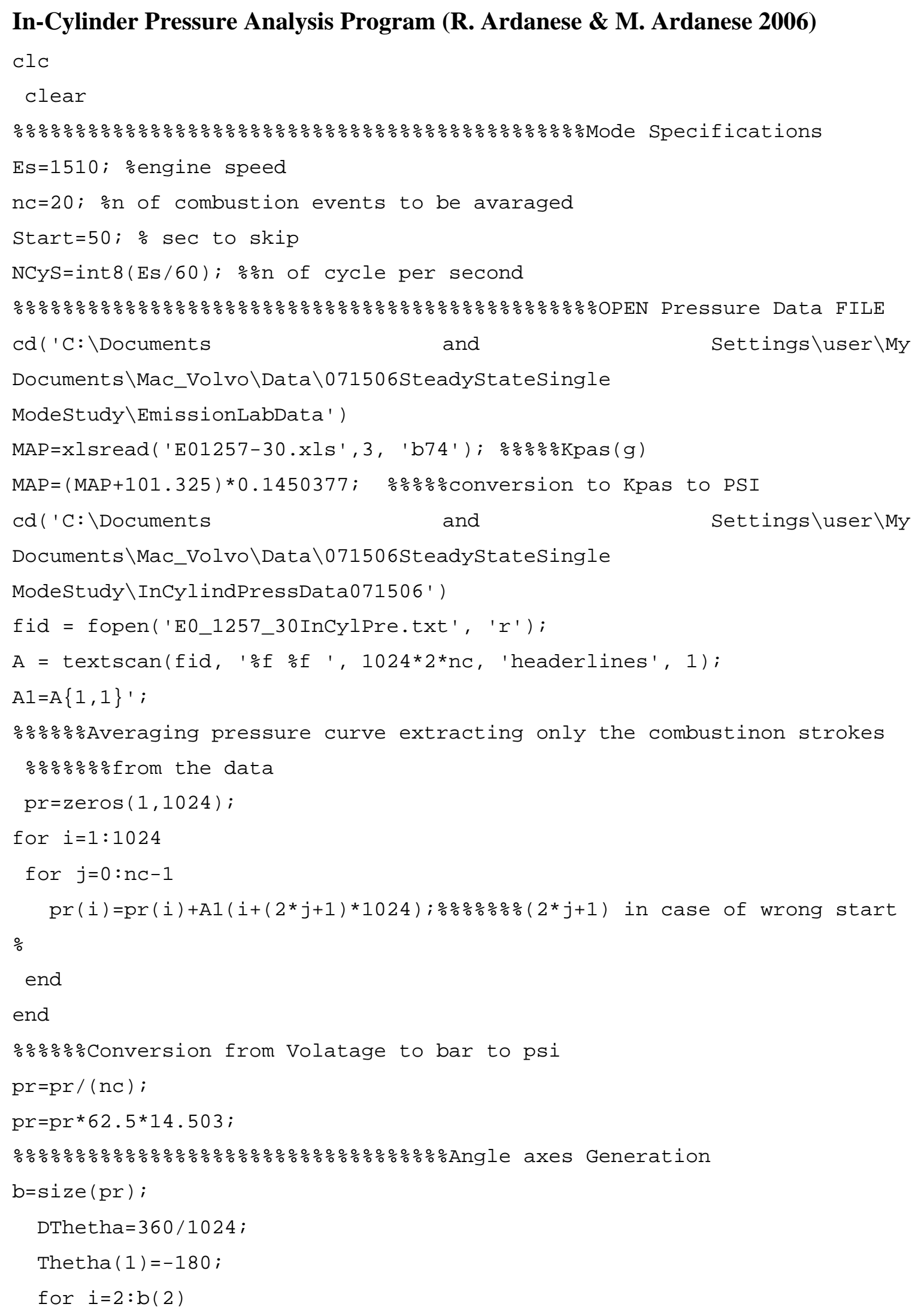


Thetha $(i)=$ Thetha $(i-1)+$ DThetha;

end

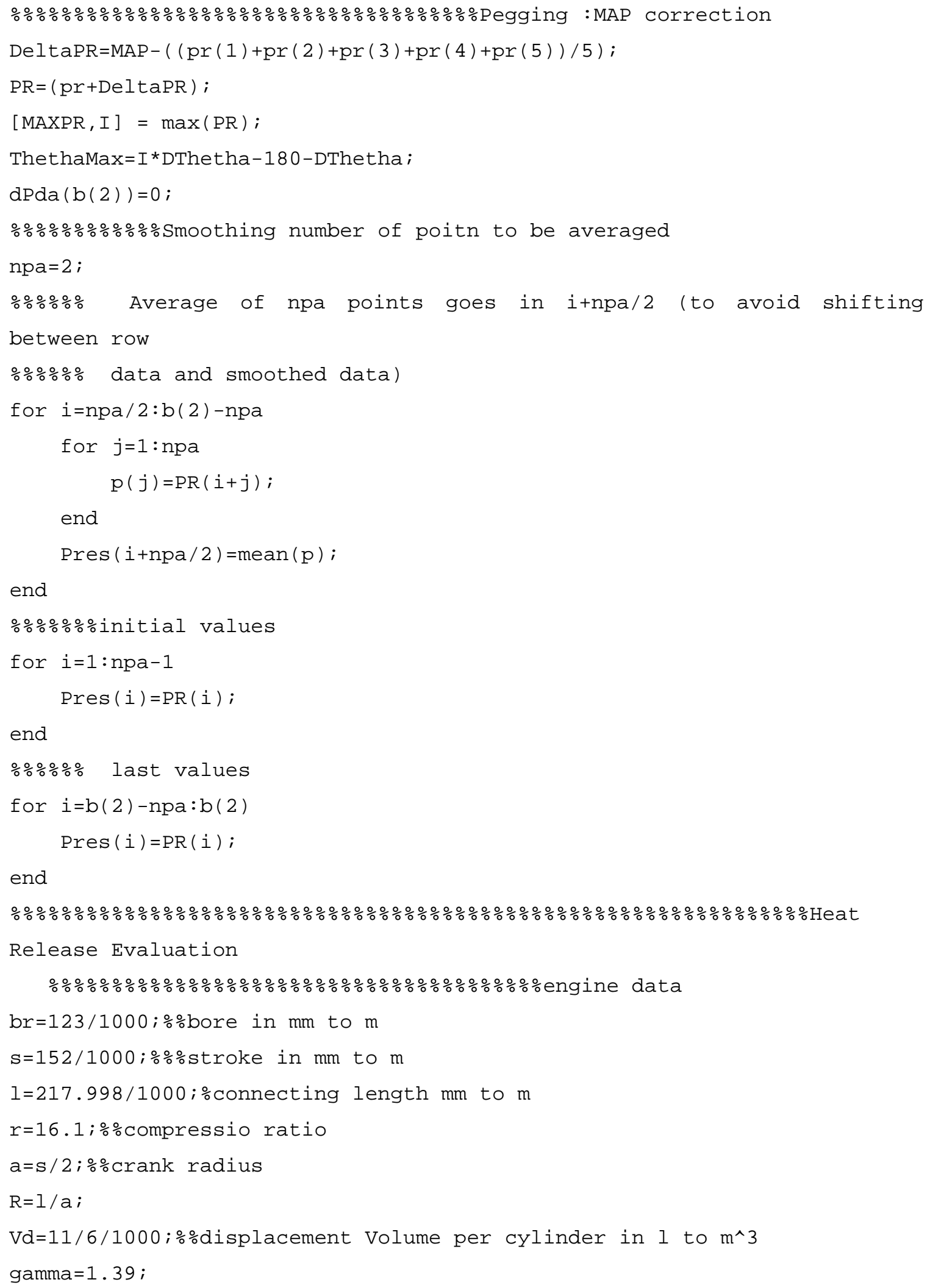




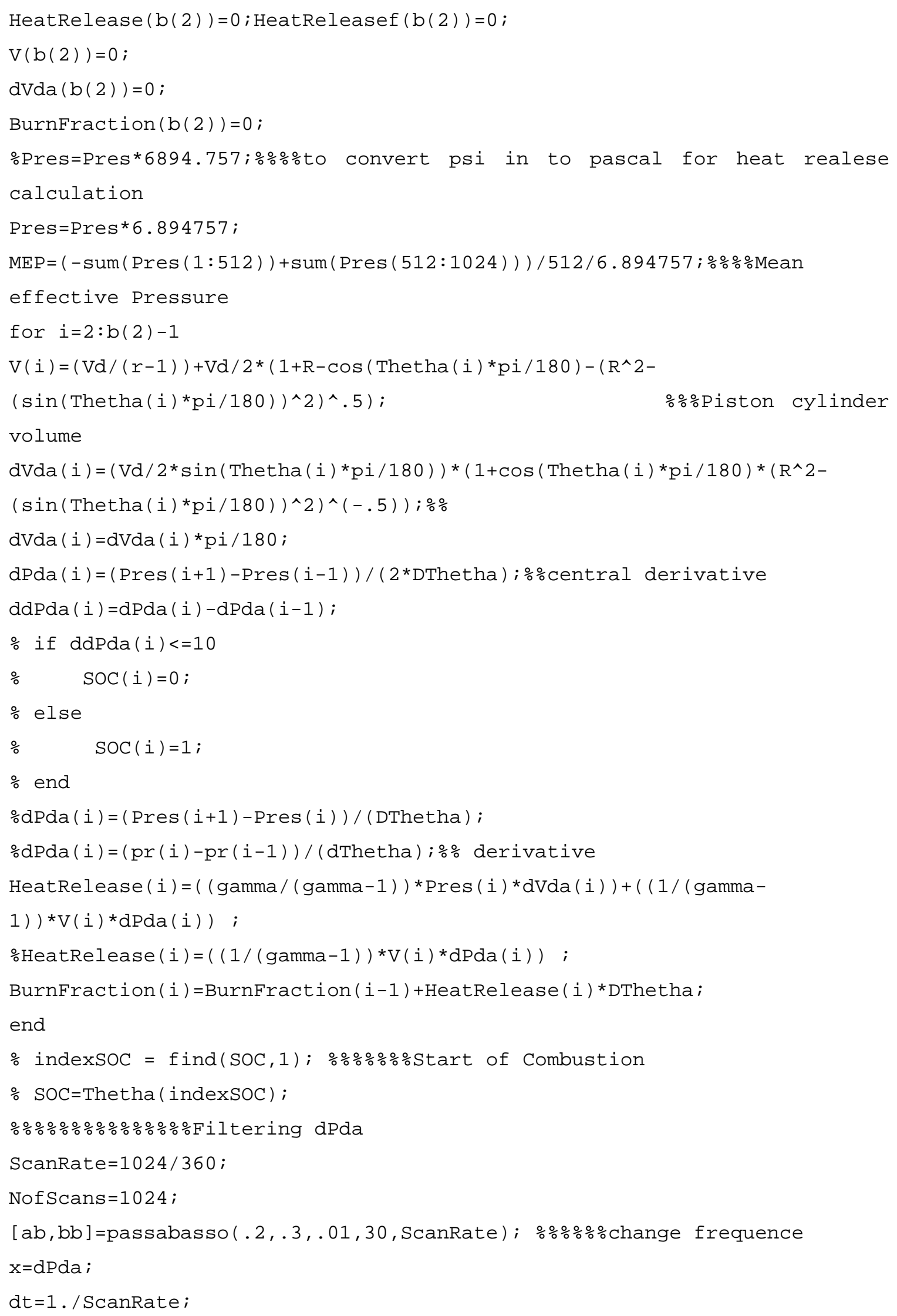




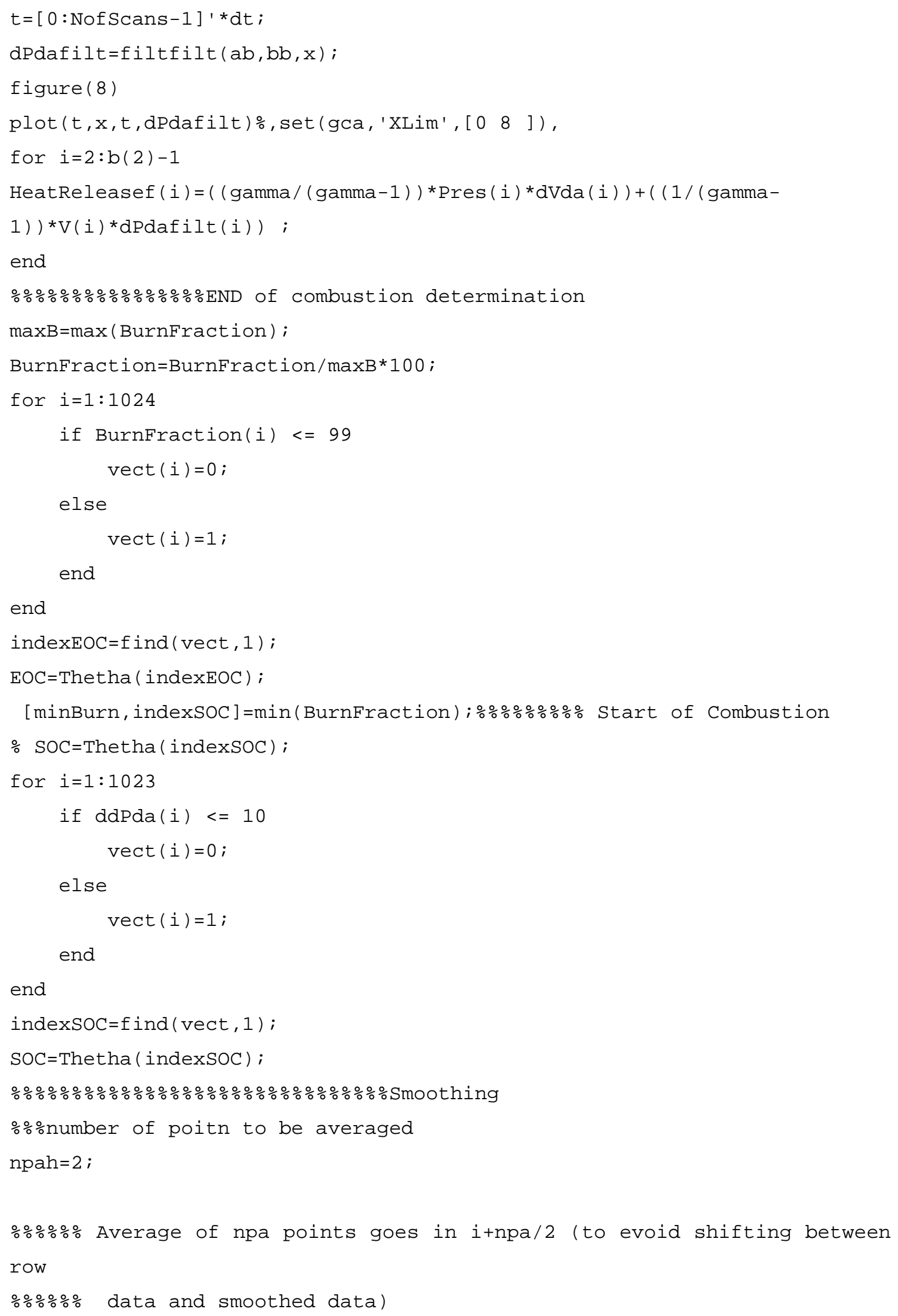




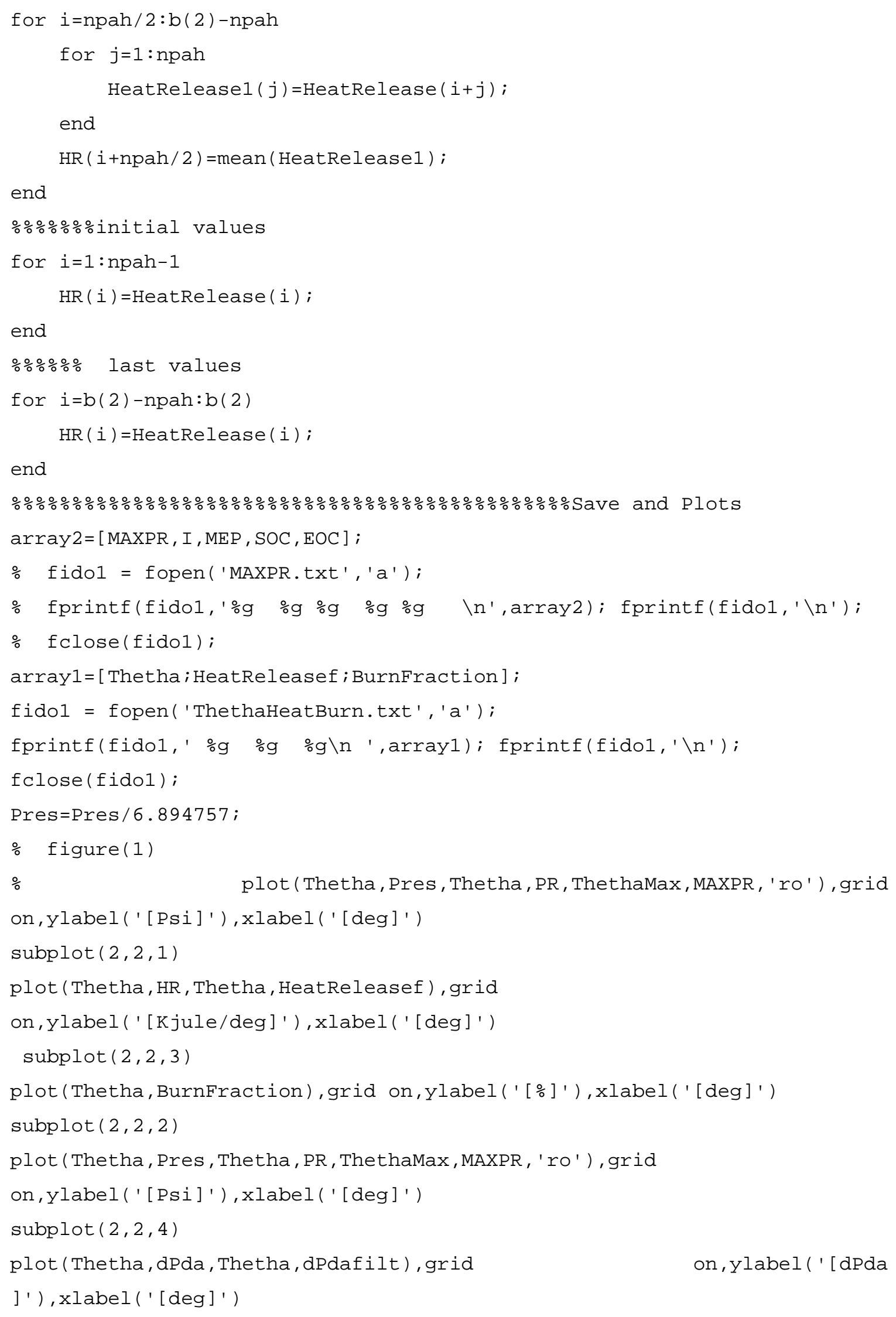




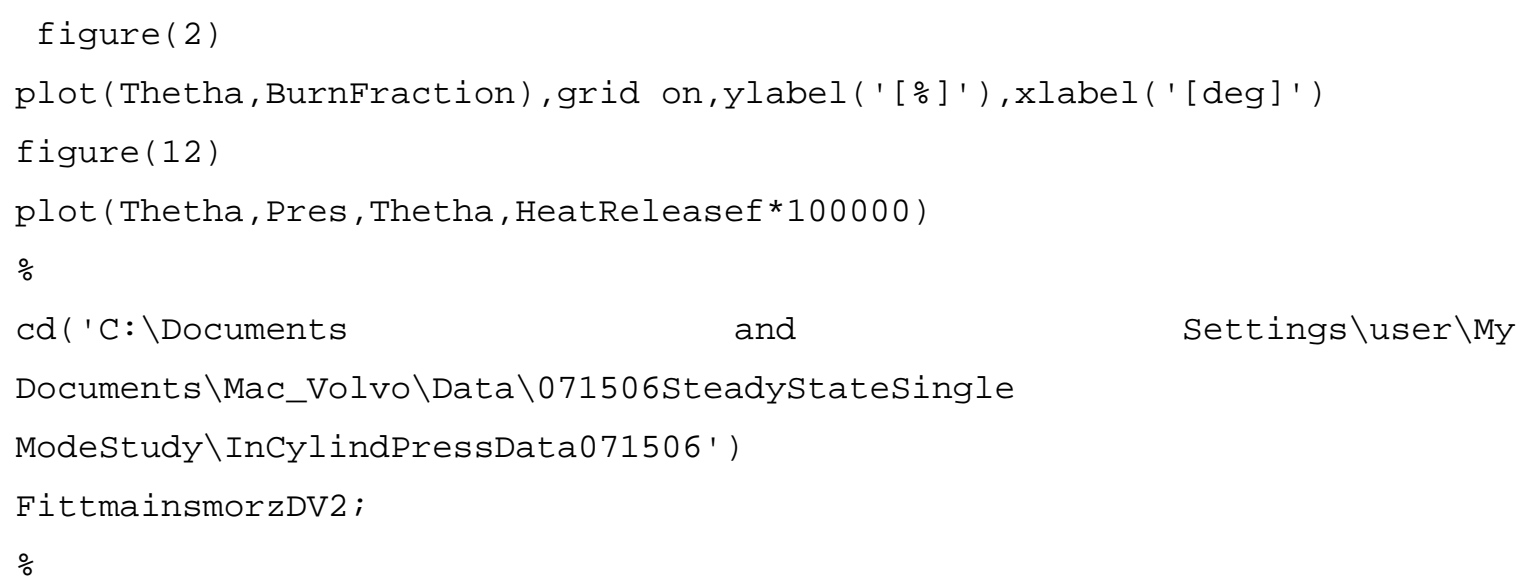




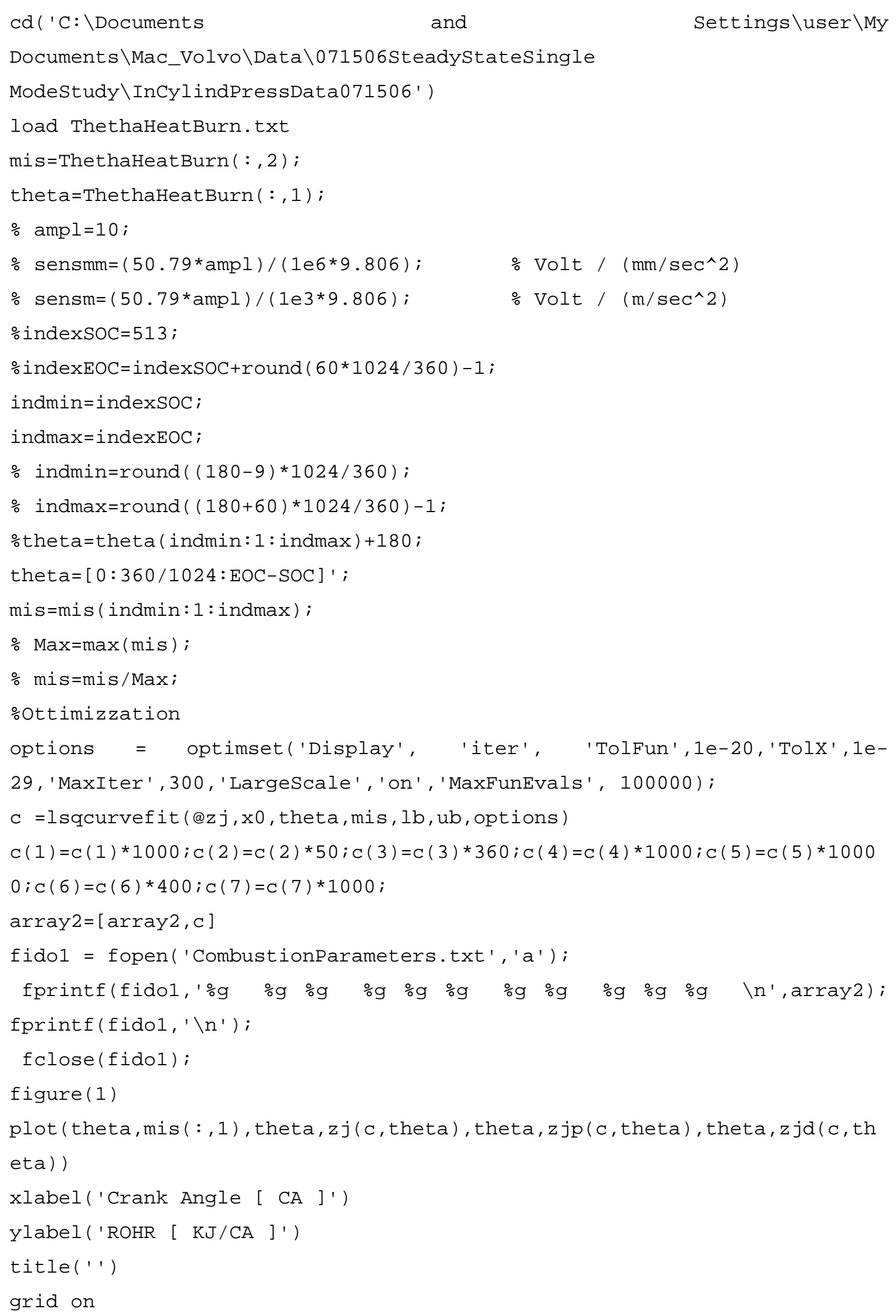




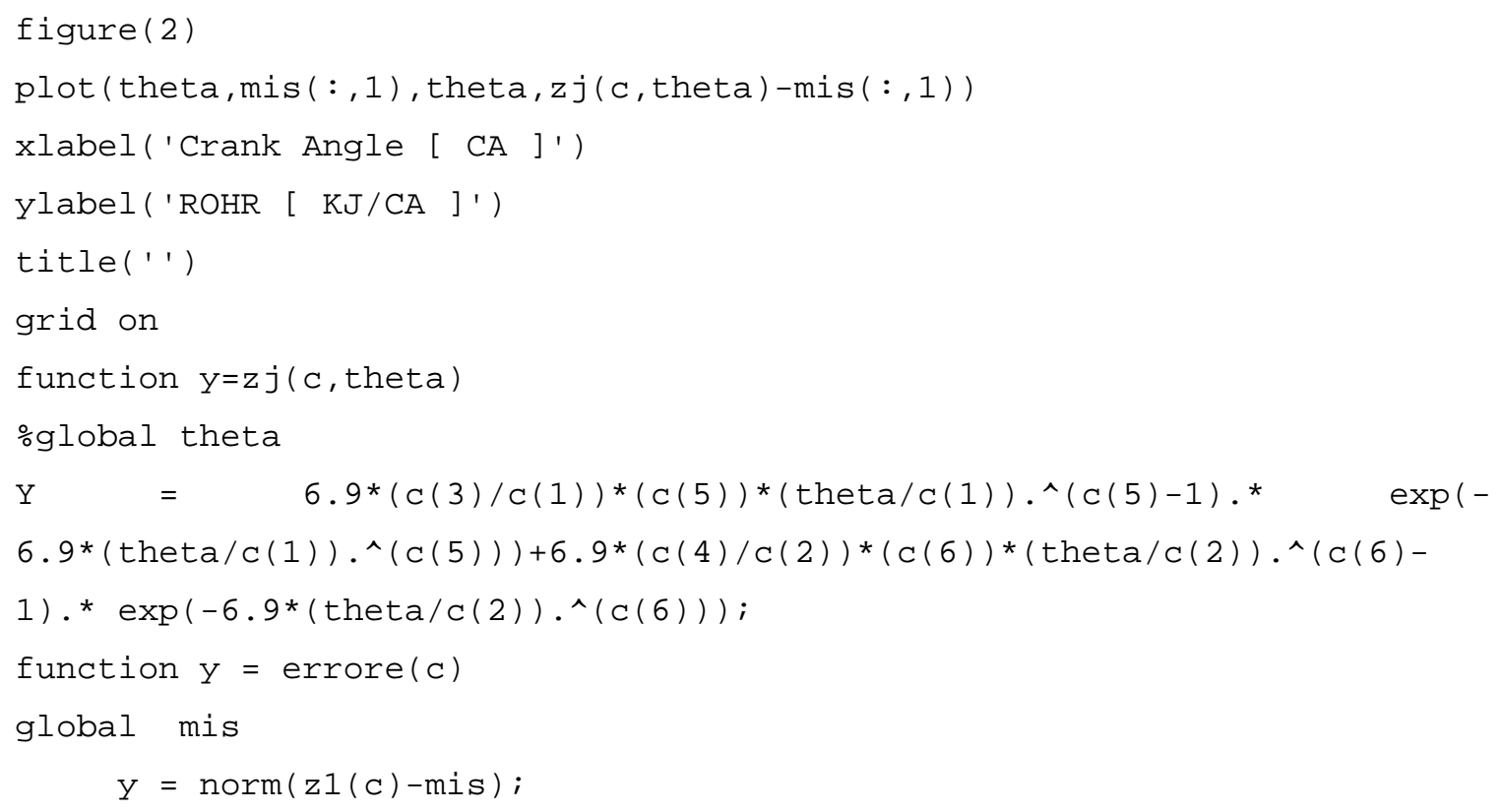

Filter to clean the Heat Release Signal from Noise. 
\%clear all

ScanRate $=1024 / 360$;

NofScans $=1024$;

$[a b, b b]=$ passabasso $(.4, .5, .01,50$, ScanRate $)$;

$\mathrm{x}=\mathrm{dPda}$;

$\mathrm{dt}=1 . /$ ScanRate;

$\mathrm{t}=[0: \text { NofScans }-1]^{\prime *} \mathrm{dt}$;

$z 18=f i l t f i l t(a b, b b, x)$;

figure(1)

$\operatorname{plot}(t, x-m e a n(x), t, z 18) \%, \operatorname{set}\left(g c a,{ }^{\prime} X L i m ',\left[\begin{array}{ll}0 & 8\end{array}\right]\right)$, 


\section{APPENDIX B High-speed in-Cylinder Pressure Acquisition Program}

The three main programs responsible for the high-speed acquisition and reduction of the in-cylinder pressure and valve lift signals were written in Labview environment. The first program (Figure 87 and Figure 88) consists of a front panel and of the actual code. The front panel displays the in-cylinder pressure signal converted to engineering units as a function of time, and of crank angle. The program acquires two analog signals, from the in-cylinder pressure sensor and from the valve lift sensor; the latter was available only during the testing described in Section 5.6.

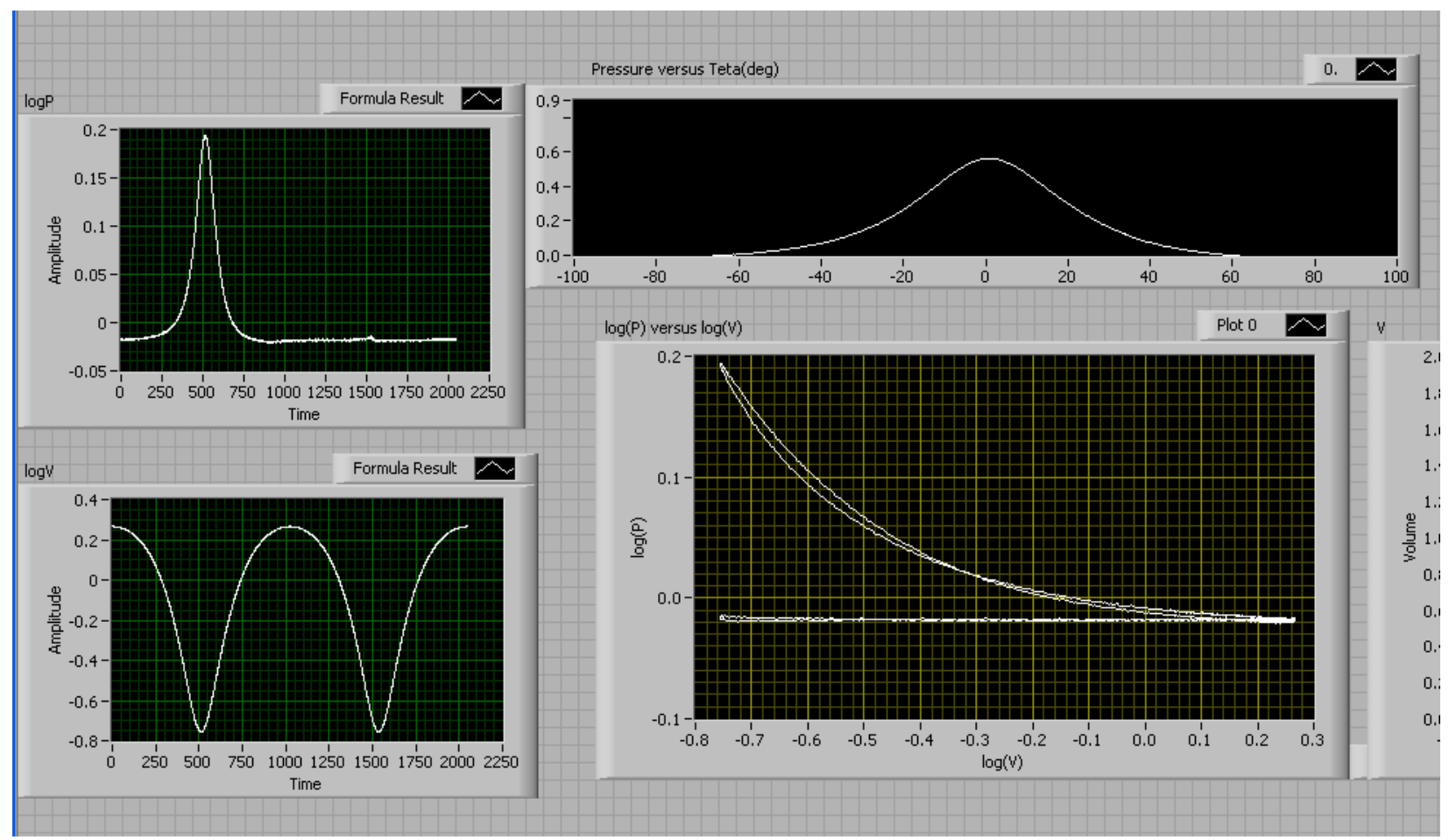

Figure 87: Front panel of the high-speed acquisition program 


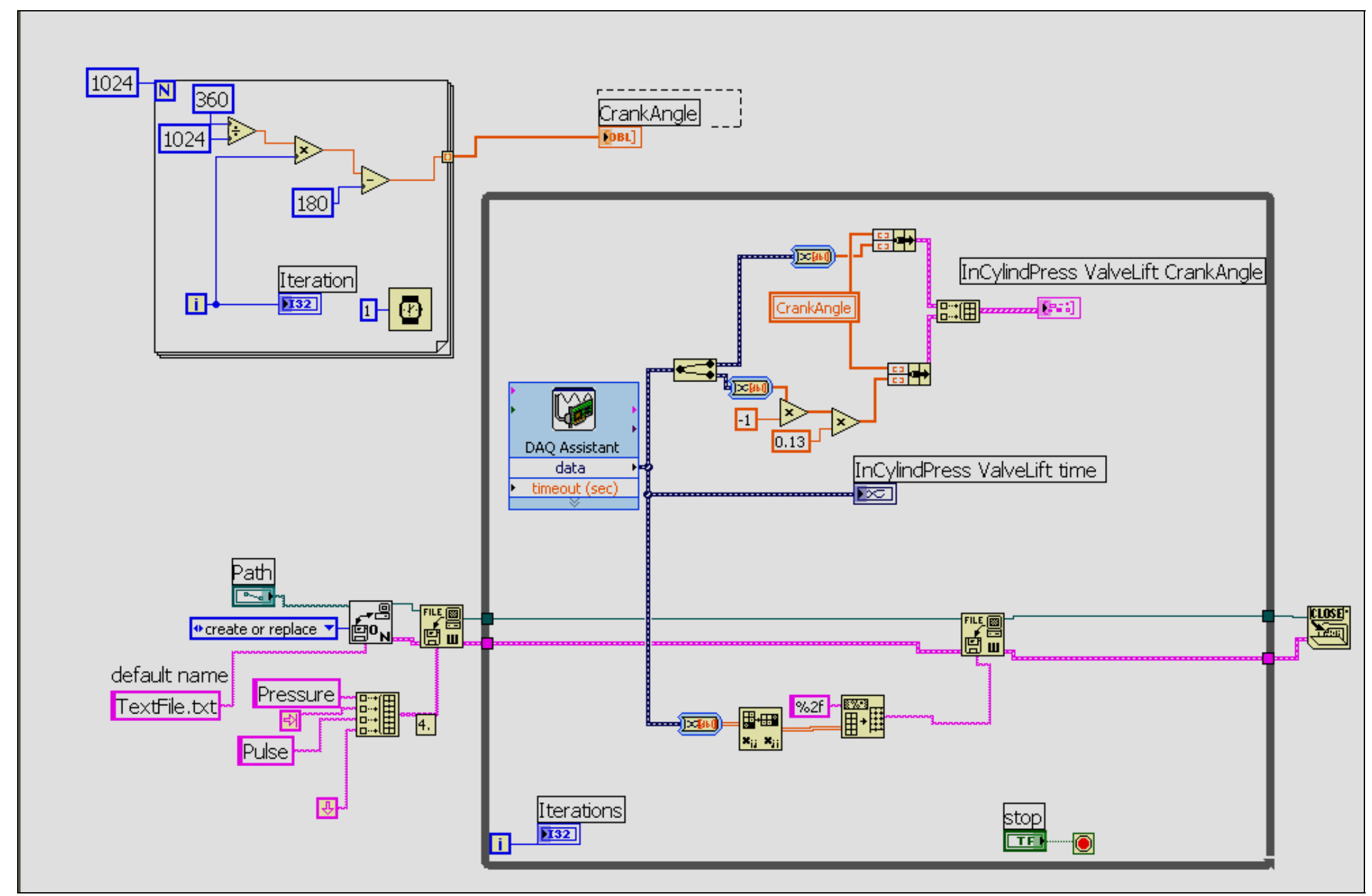

Figure 88: Acqusition Pressure Main Code 


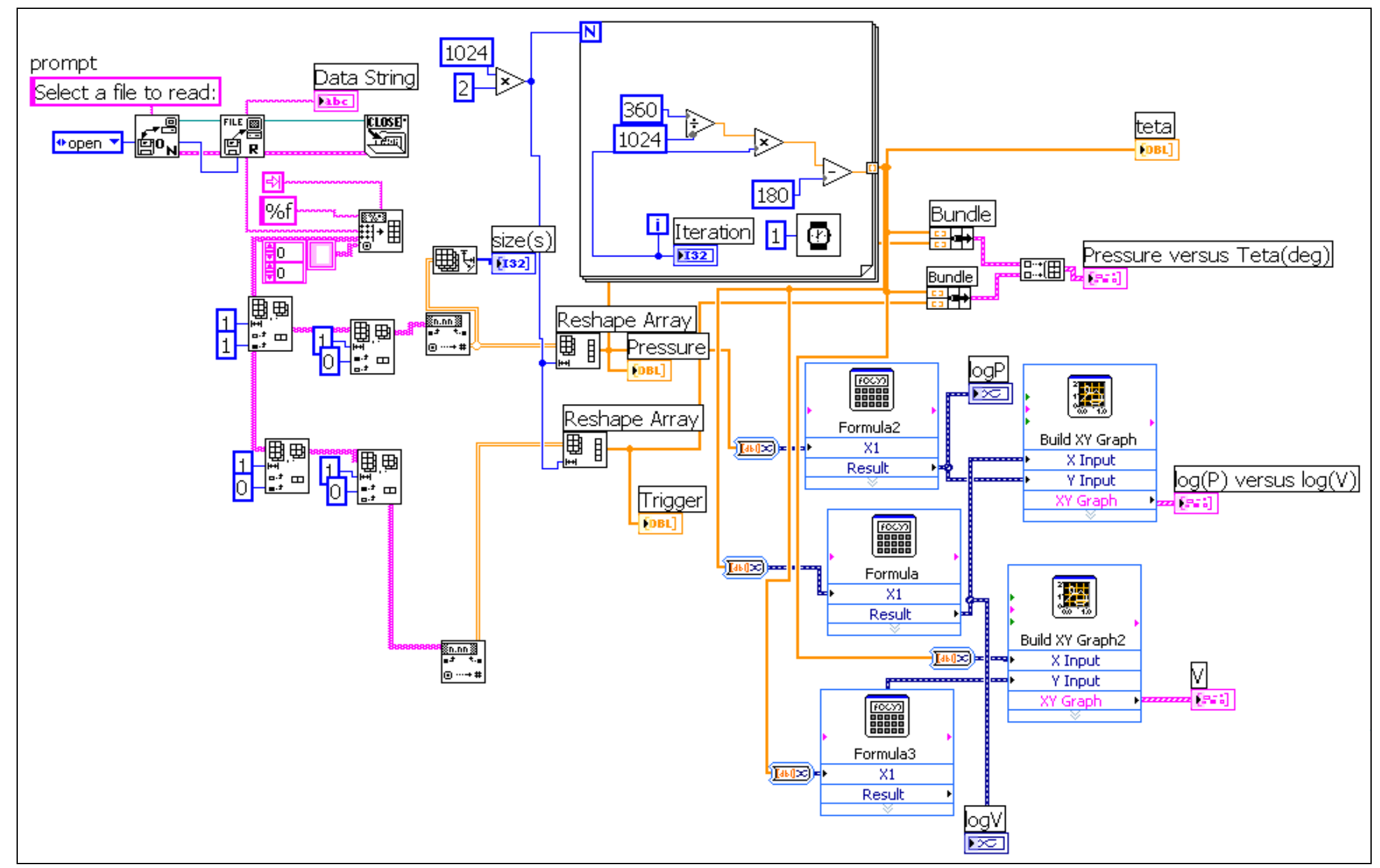

Figure 89: Encoder Calibration Main Code 
The data were simultaneously saved on a text file and displayed in real time on the front panel.

The second program (Figure 89) read and processed from the text file the incylinder pressure signal. The logarithm of the pressure was then plotted versus the logarithm of the crank angle (log p/log $\mathrm{v}$ plot), and this plot was used for the encoder calibration. The encoder was manually adjusted, while the engine was motoring, until the area between the compression curve and the expansion curve (bottom right graph in Figure 87) was minimized and the curves overlap. The encoder was calibrated aligning the in-cylinder pressure peak with the TDC.

The last program, illustrated in Figure 90, retrieved the raw data form the text file, processed and plotted them in engineering units. It also calculated the maximum incylinder pressure. This information was used during the engine map development to estimate the injection pressure with software provided by Volvo Powertrain (EUSIM). 


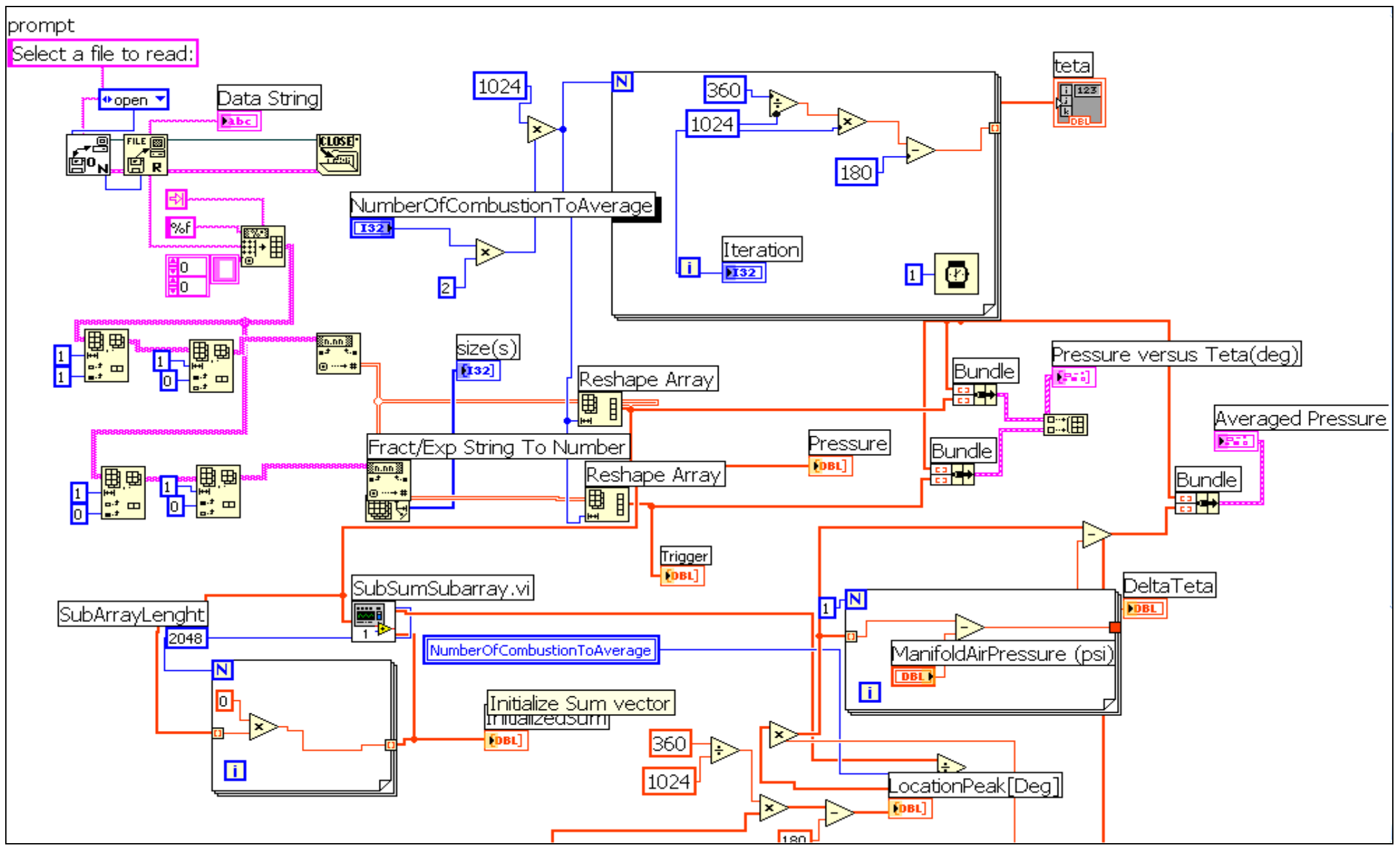

Figure 90: Maximum Pressure Program 


\section{APPENDIX C Optimization Algorithm Program}

The following program was written in Matlab environment; it processes the results of the orthogonal matrix testing and finds the optimum setting of EGR, NOP, SOI and VGT that minimize either FC or NOx. Additionally generates an empirical model for the predictions of $\mathrm{FC}$ and $\mathrm{NOx}$, which needs to be validated via verification experiments. An ANOVA test was performed on the data collected, in order to estimate the contribution of single parameter to the characteristic function variation. The ANOVA test is also used to estimate the error of the experimental data.

This software was used during the development of the engine calibrations. At a fixed mode NOx and FC were measured, after the $\mathrm{L}_{9}$ test was conducted, and inserted as additional columns in the orthogonal array, as described in Section 4.5. This array was used as input to the program, which calculated the factor effect via the signal to factor $(\mathrm{S} / \mathrm{N})$ function, and selected the parameter levels that provided the highest effect. The optimal solution was then tested on the engine and results were fed as input to the program to verify the empirical mode predictions.

The program also did an ANOVA test which was used in two ways:

1. by estimating the factors which played a critical role in the characteristic function variation allowed identification of those that could be used to calculate the experimental error, as described in detail in Section 4.9.1

2. by identifying factors that were more important for the reduction of NOx and FC, allowed the second stage optimization to be performed, as described in Section 4.10 


\section{Optimization Program and ANOVA Program (R. Ardanese \& M. Ardanese)}

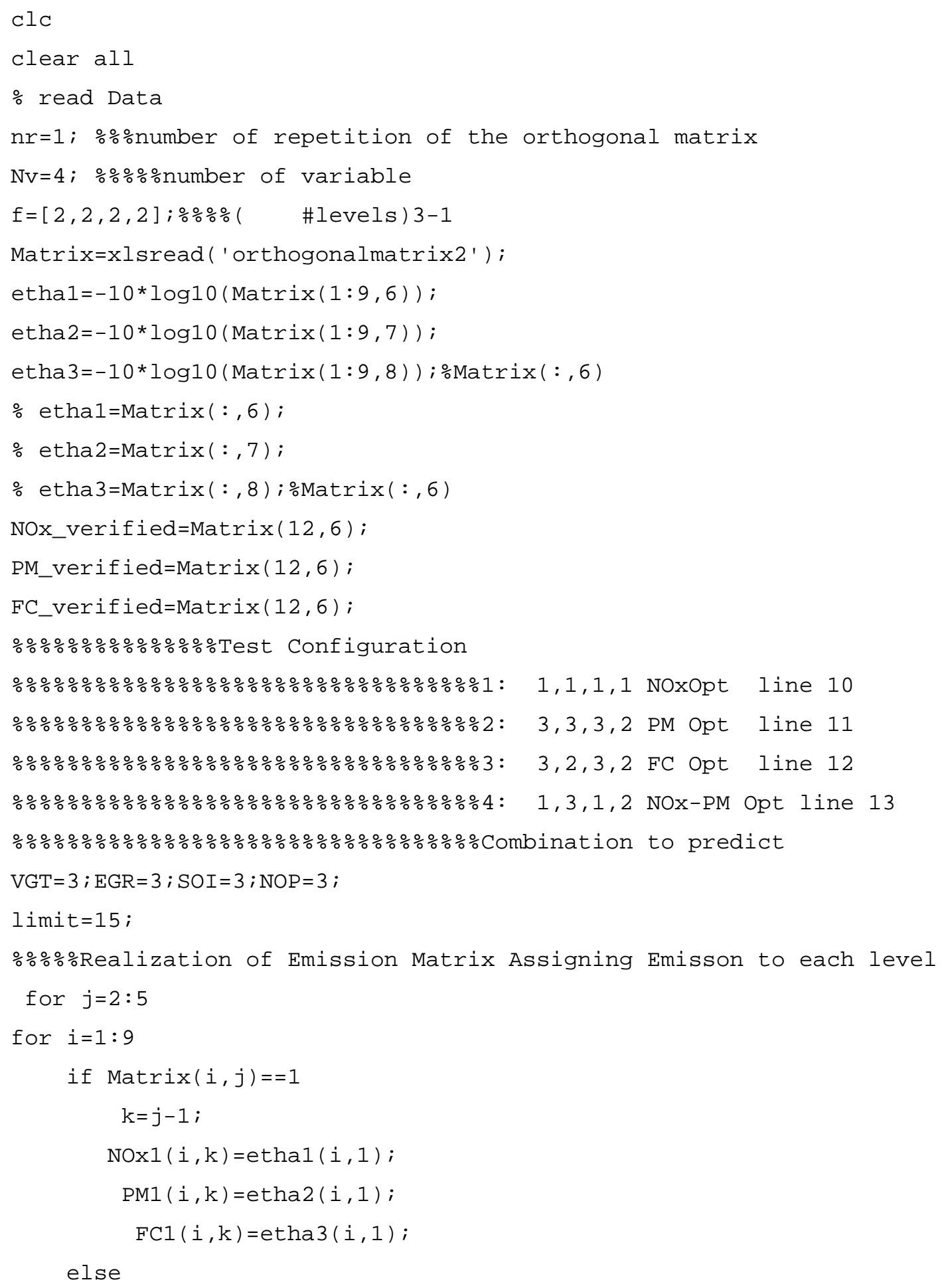




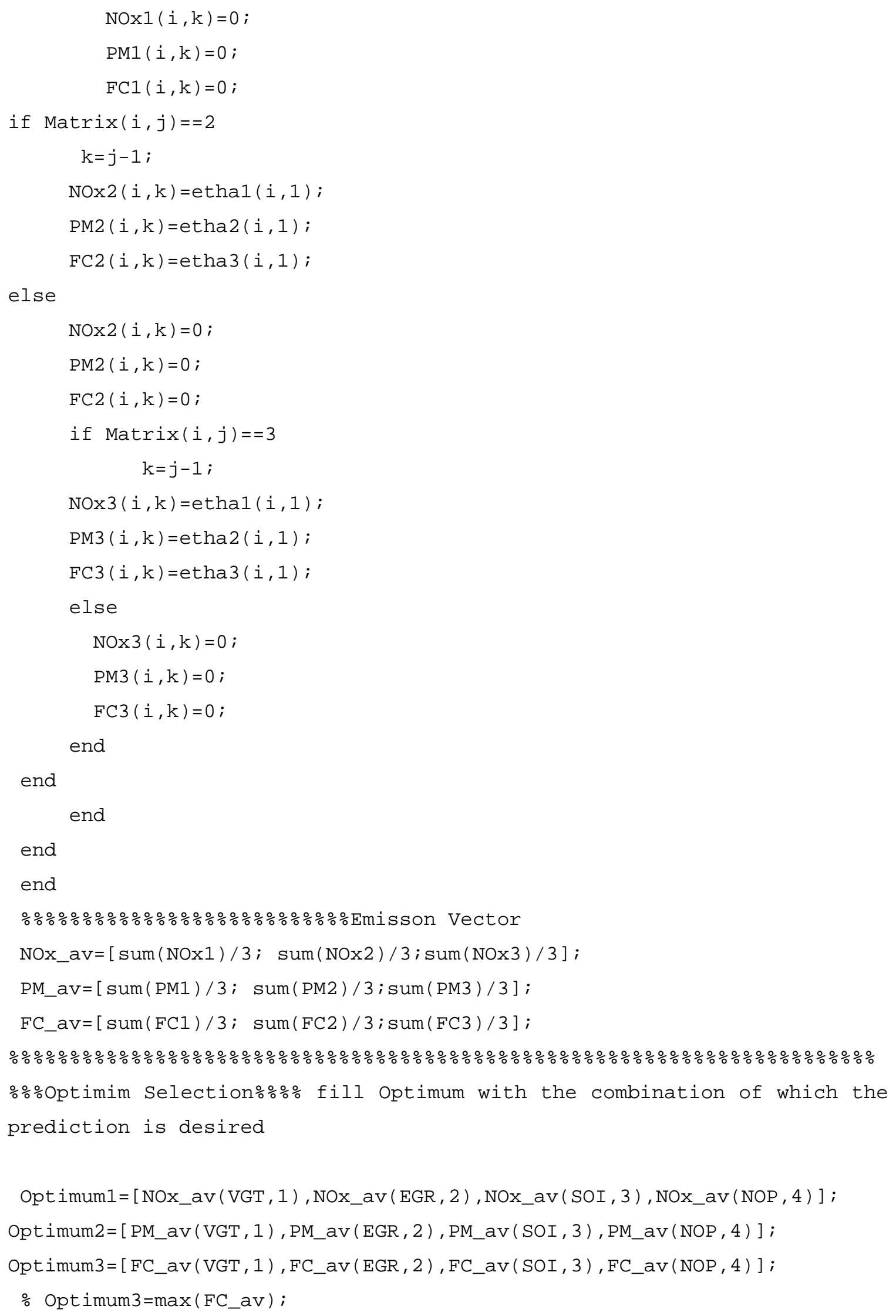




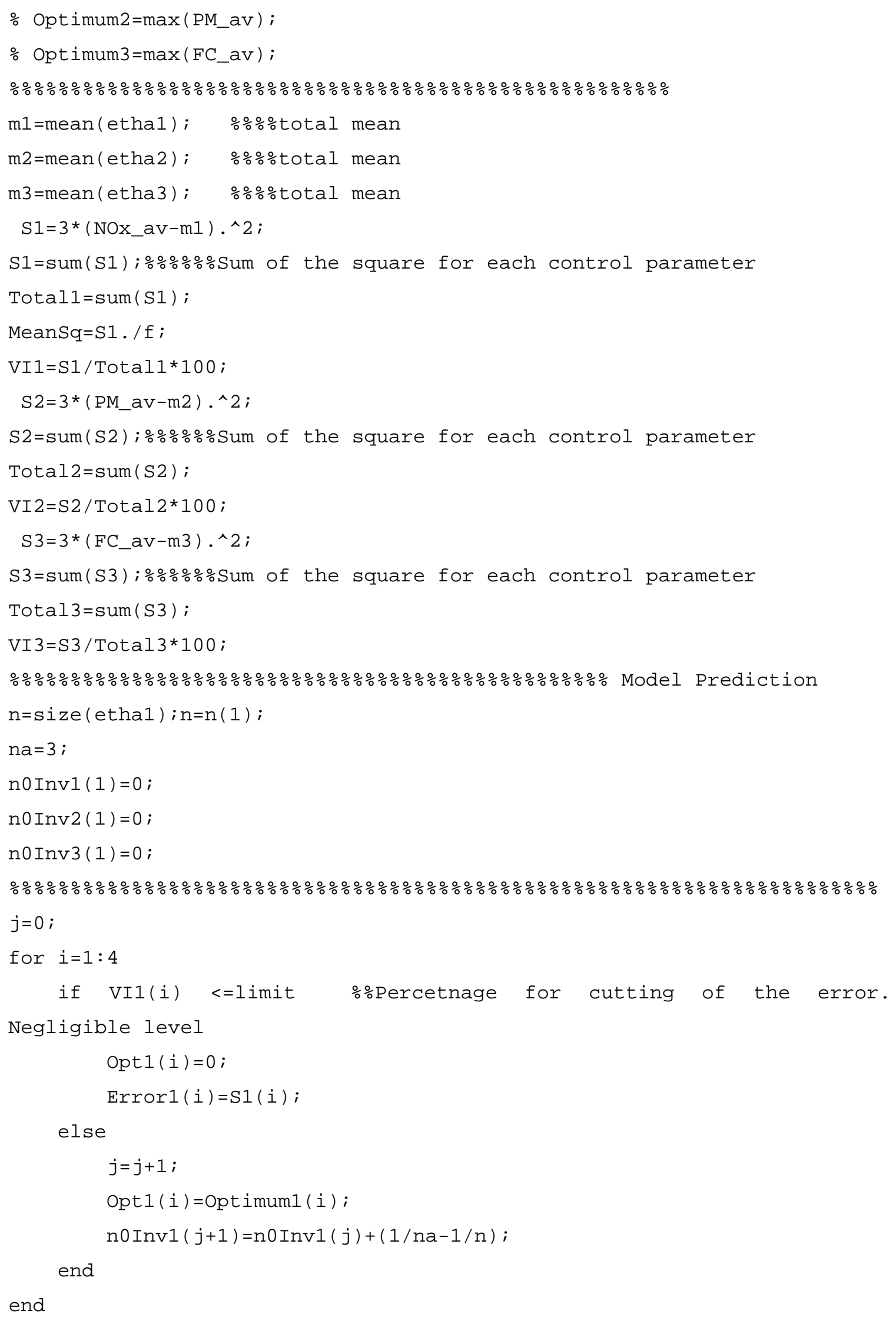




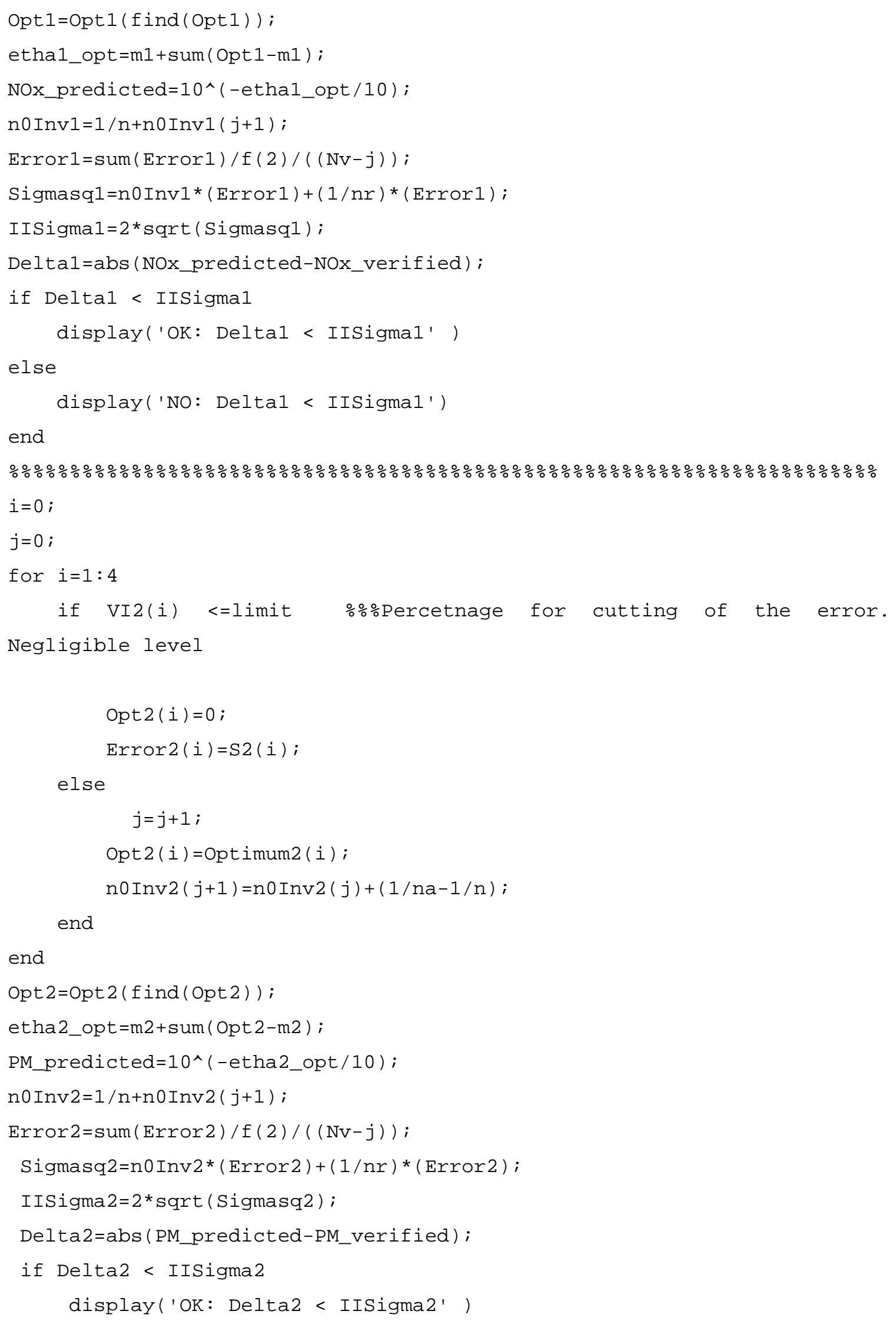




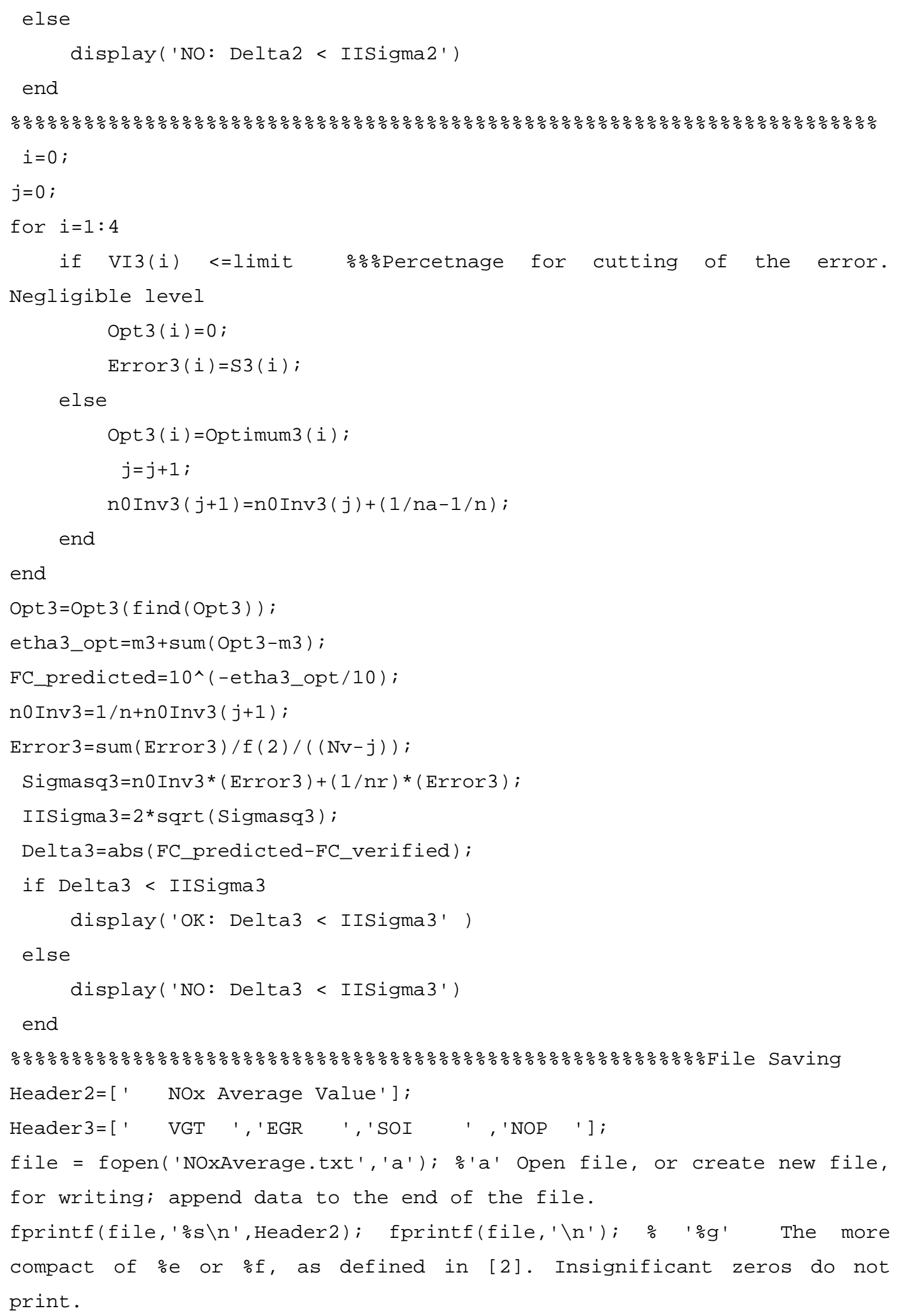


fprintf(file, '\%s \%s \%s \%s \n',Header3); fprintf(file, '\n'); \% '\%g' The more compact of \%e or \%f, as defined in [2]. Insignificant zeros do not print.

fprintf(file, '\%6.2f \%6.2f \%6.2f $\% 6.2 f \quad \backslash n '$ ', Nox_av'); fprintf(file, '\n'); \% '\%g' The more compact of \%e or \%f, as defined in [2]. Insignificant zeros do not print.

fclose(file);

\%\%\%\%\%\%\%\%\%\%\%\%\%\%\%\%\%\%\%\%\%\%\%\%\%\%\%\%\%\%\%\%\%\%\%\%\%\%\%\%\%\%\%\%\%\%\%\%\%\%\%\%\%\%\%\%\%\%\%\%\%\%\%\%\%

$\% \mathrm{Table}=[\mathrm{f} ; \mathrm{S} 1 ; \mathrm{S} 1 / 2 ; \mathrm{VI} 1 ; \mathrm{S} 2 ; \mathrm{S} 2 / 2 ; \mathrm{VI} 2 ; \mathrm{S} 3 ; \mathrm{S} 3 / 2 ; \mathrm{VI} 3]$;

$\%$ Header $2=\left[\begin{array}{ll}1 & \text { ANOVA TABLE Test ' }] \text {; }\end{array}\right.$

$\%$ Header3=[' DF ',' SS1 ',' MS1 ' , '\%1 ',' SS2 ', ' MS2 ' ' '\%2 ',' SS3 ',' MS3 ', ' \%3 '];

$\%$ file $=$ fopen('NOX ANOVA TABLE.txt','a'); \%'a' Open file, or create new file, for writing; append data to the end of the file.

\% fprintf(file, '\%s \n', Header2); fprintf(file, '\n'); \% '\%g' The more compact of \%e or \%f, as defined in [2]. Insignificant zeros do not print.

\% fprintf(file, '\%s \%s $\%$ s $\% s \quad \% s \quad \% s \quad \% s \quad \% s \quad \% s \quad \% s \backslash n '$, Header $)$; fprintf(file, '\n'); \% '\%g' The more compact of \%e or $\% f$, as defined in [2]. Insignificant zeros do not print.

\% fprintf(file, '\%6.2f \%6.2f \%6.2f \%6.2f \%6.2f \%6.2f \%6.2f \%6.2f \%6.2f \%6.2f \n', Table); fprintf(file,'\n'); \% '\%g' The more compact of \%e or $\% f$, as defined in [2]. Insignificant zeros do not print.

$\%$ fclose(file);

\%\%\%\%\%\%\%\%\%\%\%\%\%\%\%\%\%\%\%\%\%\%\%\%\%\%\%\%\%\%\%\%\%\%\%\%\%\%\%\%\%\%\%\%\%\%\%\%\%\%\%\%\%\%\%\%\%\%\%\%\%\%\%\%\%\%\%

\%\%\%\%\%\%\%\%\%\%\%\%\%\%\%\%\%\%\%\%\%\%\%\%\%\%\%\%\%\%\%\%\%\%\%\%\%\%\%\%\%\%\%\%\%\%\%\%\%\%\%\%\%\%\%\%\%\%\%

Table1=[N0x_predicted ; N0x_verified ; IISigma1;Delta1;PM_predicted;PM_veri

fied; IISigma2; Delta2;FC_predicted;FC_verified; IISigma3;Delta3] ;

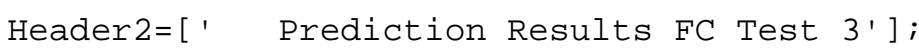

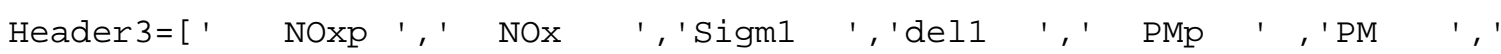
Sigm2 ',' del2 ',' FCp ',' FC ',' Sigm3 ',' del3 '];

file = fopen('Prediction Resutls.txt','a'); \%'a' Open file, or create new file, for writing; append data to the end of the file.

fprintf(file, '\%s\n', Header 2); fprintf(file, '\n'); \% '\%g' The more compact of \%e or \% $\mathrm{f}$, as defined in [2]. Insignificant zeros do not print.

fprintf(file, '\%s $\%$ s $\%$ \%s $\quad \% s \quad \% s \quad \% s \quad \% s \%$ ss $\% s \quad \% s \backslash n '$, Header3); fprintf(file, '\n'); \% '\%g' 


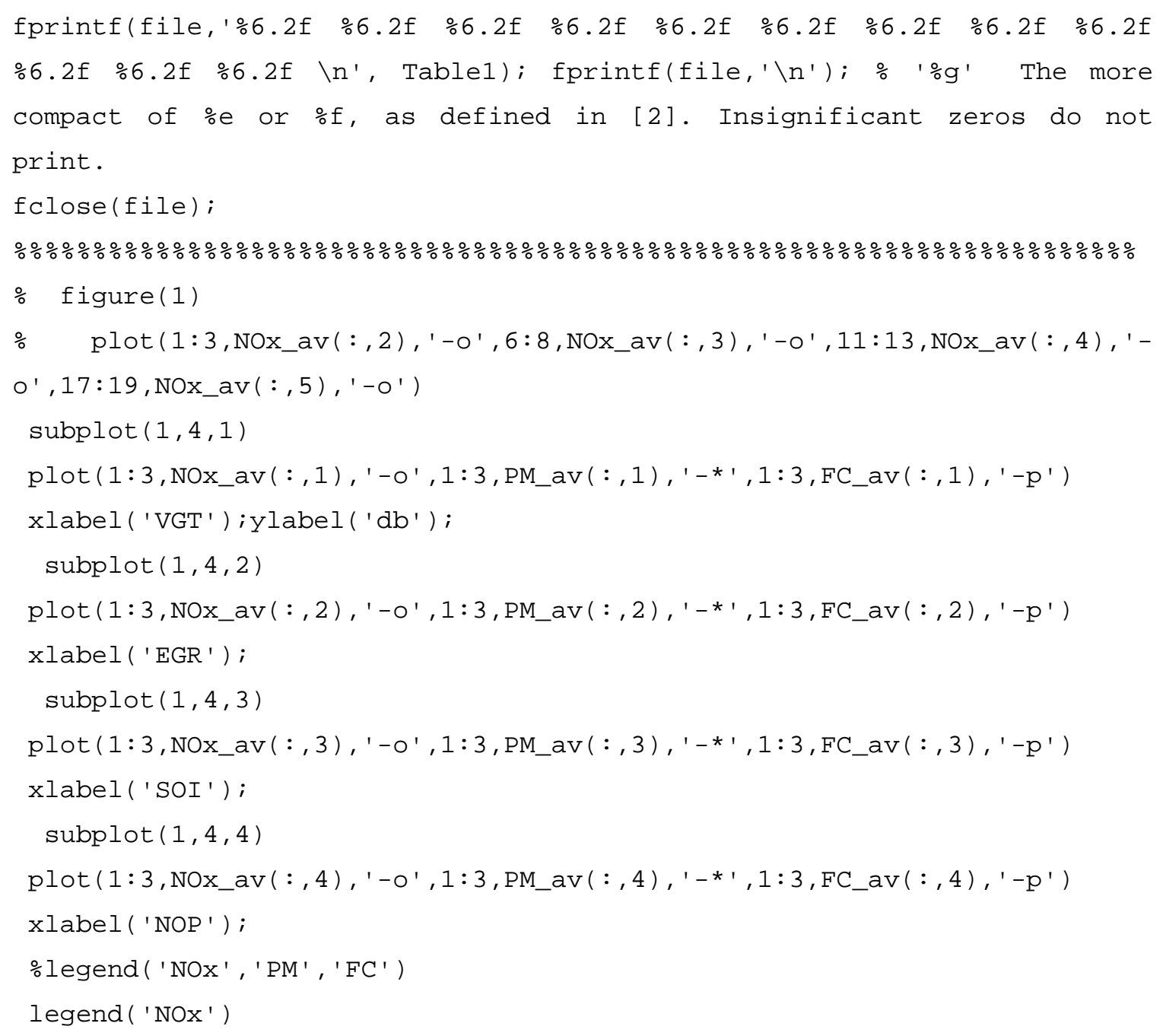




\section{APPENDIX D Orthogonal Array with Interactions $\left(\mathrm{L}_{18}\right)$}

Interactions are most likely to be the cause of the deviation of the additive model predictions from the actual response. DOE is typically not designed to minimize interactions but to evaluate and study them [51]. On the other hand, DOE with an orthogonal matrix design with additive models intends to focus on the main effects; on effects that overcome the noise coming from experimental error and interactions.

The additive model predictions, discussed in Section 4.7, can be improved by considering the presence of interactions. The interaction between two control factors consists in the dependency of the variation of one factor upon the level of the other factor.

For instance, the effect of EGR on NOx emissions depends upon the level of VGT. Two main types of interactions can be identified: antisynergistic and synergistic interactions. The antisynergistic interaction consists in a strong type of interaction; the slope of the EGR effect, in Figure 91, is affected by the level VGT, therefore when VGT changes, from low to high level, NOx may not get to its optimum level [51].

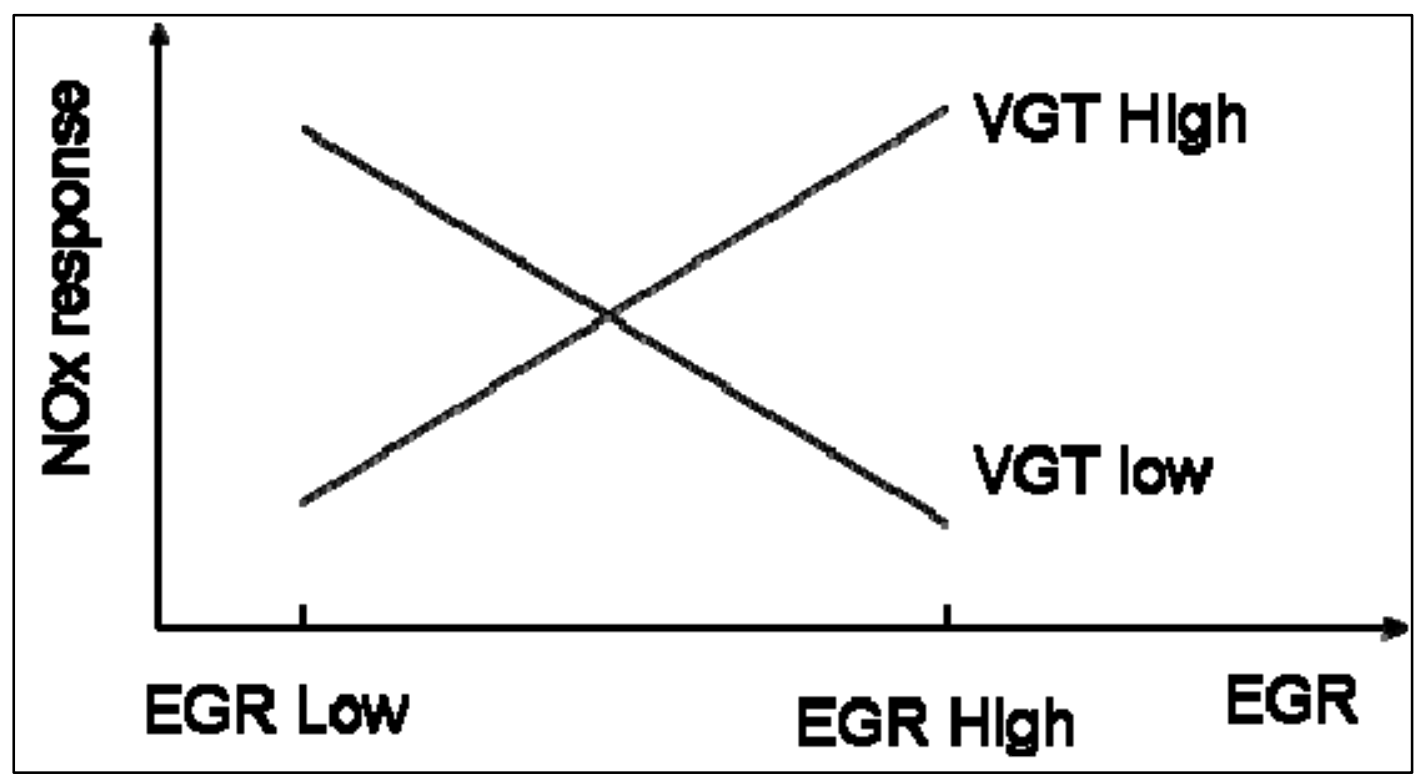

Figure 91: Antisynergistic interactions between NOP and EGR 
If an entire engine calibration is considered, an accidental change in one of the actuator settings could mean that, if antisynergistic interactions are present, the calibration needs to be re-optimized. On the other hand, in a robust calibration, the change in the level of one parameter affects only that particular parameter effect, and the optimization previously done on the remaining factors still holds.

The synergistic interaction is a milder interaction, in which the optimum level of one factor does not depend upon the level of the other factor (see Figure 92); therefore, optimum levels stay the same and there is no need of re-optmimization even if a factor level has changed [51].

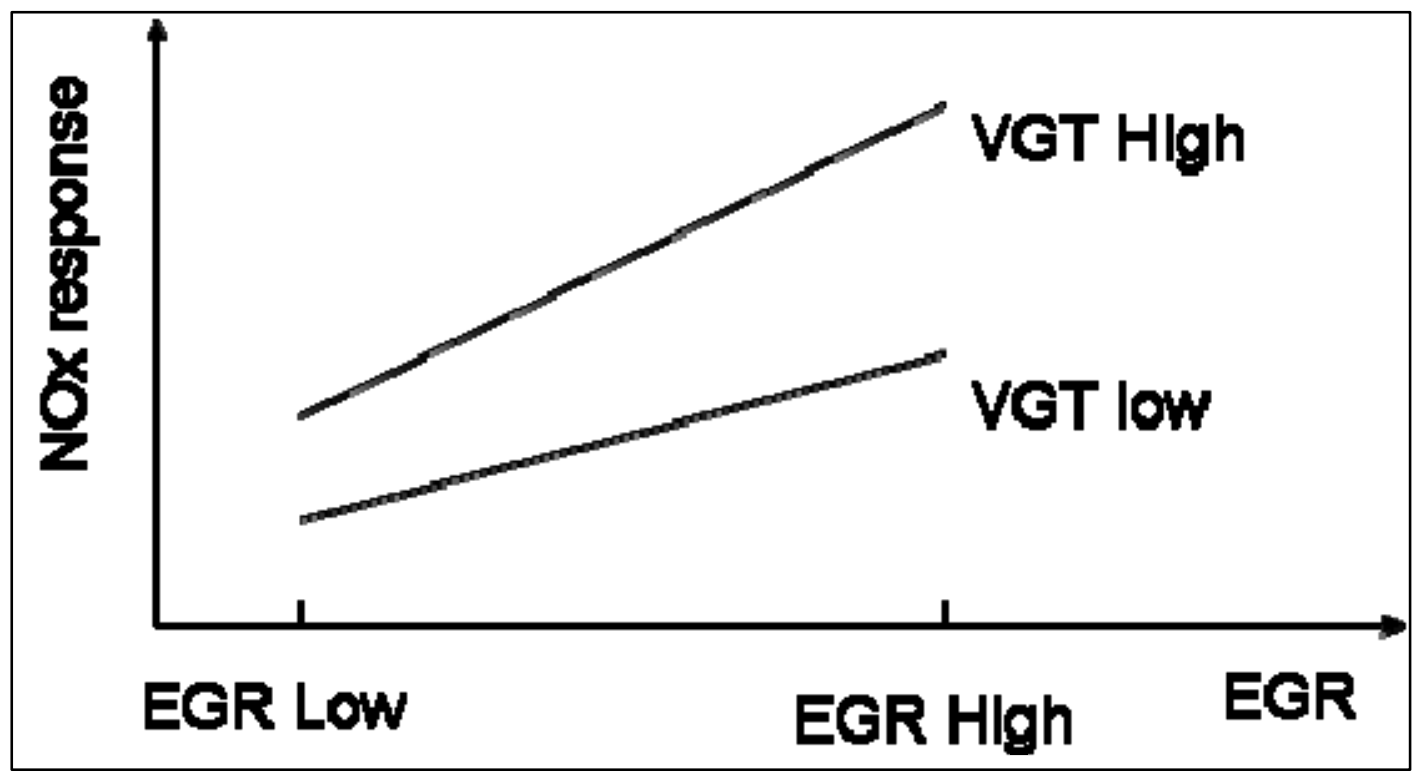

Figure 92: Synergistic interactions between NOP and EGR

The orthogonal array described in 4.5 can be modified in order to evaluate the interactions during experimentation. A three level interaction to be evaluated needs 2 DOF; therefore the array needs to dedicate two columns per interaction. The first interaction that can be studied could be the one between EGR and VGT.

Table 29 shows an $\mathrm{L}_{18}$ orthogonal array, which accounts for the interaction between EGR and VGT. The 18 experiments of the orthogonal array could be run for each of the modes for which the additive model failed to predict the correct emissions levels. Improvements of the model predictions are expected. 
Table 29: Orthogonal matrix, $L_{18}$, with interaction between EGR and VGT

\begin{tabular}{|c|c|c|c|c|c|c|c|c|}
\hline Run & Empty & EGR & VGT & $\begin{array}{c}\text { EGR } \\
\mathbf{V G T}\end{array}$ & $\begin{array}{c}\mathbf{X G T} \\
\mathbf{E G R}\end{array}$ & $\mathbf{S O I}$ & NOP & $\begin{array}{c}\text { Experimental } \\
\text { Error }\end{array}$ \\
\hline $\mathbf{1}$ & 1 & 1 & 1 & 1 & 1 & 1 & 1 & 1 \\
\hline $\mathbf{2}$ & 1 & 1 & 2 & 2 & 2 & 2 & 2 & 2 \\
\hline $\mathbf{3}$ & 1 & 1 & 3 & 3 & 3 & 3 & 3 & 3 \\
\hline $\mathbf{4}$ & 1 & 2 & 1 & 1 & 2 & 3 & 3 & 3 \\
\hline $\mathbf{5}$ & 1 & 2 & 2 & 2 & 3 & 2 & 1 & 1 \\
\hline $\mathbf{6}$ & 1 & 2 & 3 & 3 & 1 & 1 & 2 & 2 \\
\hline $\mathbf{7}$ & 1 & 3 & 1 & 2 & 1 & 3 & 2 & 3 \\
\hline $\mathbf{8}$ & 1 & 3 & 2 & 3 & 2 & 1 & 3 & 1 \\
\hline $\mathbf{9}$ & 1 & 3 & 3 & 1 & 3 & 2 & 1 & 2 \\
\hline $\mathbf{1 0}$ & 2 & 1 & 1 & 3 & 3 & 2 & 2 & 1 \\
\hline $\mathbf{1 1}$ & 2 & 1 & 2 & 1 & 1 & 3 & 3 & 2 \\
\hline $\mathbf{1 2}$ & 2 & 1 & 3 & 2 & 2 & 1 & 1 & 3 \\
\hline $\mathbf{1 3}$ & 2 & 2 & 1 & 2 & 3 & 1 & 3 & 2 \\
\hline $\mathbf{1 4}$ & 2 & 2 & 2 & 3 & 1 & 2 & 1 & 3 \\
\hline $\mathbf{1 5}$ & 2 & 2 & 3 & 1 & 2 & 3 & 2 & 1 \\
\hline $\mathbf{1 6}$ & 2 & 3 & 1 & 3 & 2 & 3 & 1 & 2 \\
\hline $\mathbf{1 7}$ & 2 & 3 & 2 & 1 & 3 & 1 & 2 & 3 \\
\hline $\mathbf{1 8}$ & 2 & 3 & 3 & 2 & 1 & 2 & 3 & 1 \\
\hline & & & & & & & \\
\hline
\end{tabular}




\section{APPENDIX E Uncertainty Analysis}

An uncertainty study is conducted on the brake specific NOx emissions reported in this work and collected during FTP test at the SCR-out.

(add an explanation on the different types of uncertainties)

The brake specific NOx (bsNOx) is obtained as follow:

bsNOx $=\frac{g N O x-g N O x_{b}}{\text { Wark }}$

Where gNOx $(\mathrm{g})$ is the mass of NOx collected during the test at the SCR-out and $\mathrm{gNOx}_{\mathrm{b}}$

(g) is the background NOx. Expanding the terms in the equation [69]:

$g N O x=K_{h}^{*} \cdot \sum_{t} \frac{N O x_{i}}{10^{5}} \cdot n_{t} \cdot M_{N O x} \cdot \hat{t}_{t}$

$g N O x_{b}=K_{h} \cdot \frac{N O x_{b}}{10^{5}} \cdot n_{t o t^{\prime}} M_{N O x^{\prime}}\left(1-\frac{1}{D F}\right)$

Work $=\frac{2 \cdot T \cdot T \cdot N}{60 \cdot 550}$

Where $\mathrm{K}_{\mathrm{h}}$ is the humidity correction factor, $\mathrm{NOx}_{\mathrm{i}}(\mathrm{ppm})$ the instantaneous $\mathrm{NOx}$ concentration and $\dot{n}(\mathrm{~mole} / \mathrm{sec})$ the molar flow rate of the diluted exhaust stream through the CVS. $\mathrm{M}_{\mathrm{NOx}}(\mathrm{g} / \mathrm{mol})$, the NOx molecular weight, and $\mathrm{t}(\mathrm{sec})$, the time, are assumed to be exact, therefore not subjected to uncertainty [63]. DF is the dilution factor and $\mathrm{NOx}_{\mathrm{b}}$ (ppm) the background NOx. T (ft-lbs) and $\mathrm{N}(\mathrm{rpm})$ are respectively torque and engine speed.

\section{E.1 First Level of Uncertainty $\left(\Delta K_{h}, \Delta D F, \Delta \dot{n}\right)$}

The uncertainty on the bsNOx can be defined as [63]:

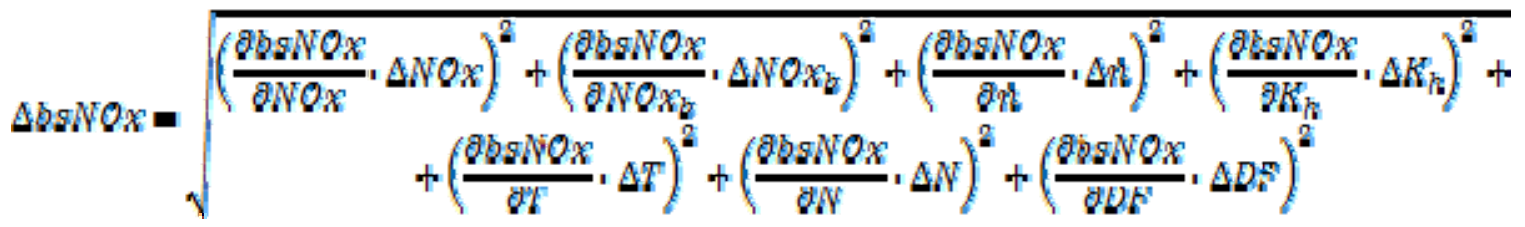

Therefore, $\triangle b s N O x$ is a function of seven uncertainties (level 1):

\section{$\triangle b S N O x=f\left(\Delta N O x_{r} \Delta N O x_{b r} \Delta n_{r} \Delta R_{k} \Delta T_{r} \Delta N_{i} \Delta D F^{\prime}\right)$}

Some of the uncertainties can be easily assessed, since the correspondent parameters were directly measured. In such a case, the uncertainty can be considered to 
be the maximum error, or more simply $2 \%$ of the maximum measured value, of the calibration performed on the measuring device:

$\triangle N O x=2 \%$ of fwhlrange (Span wahe of NOX andiyzr)

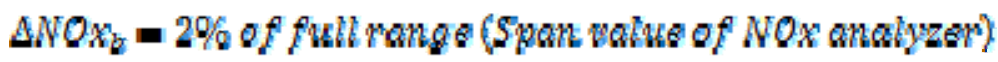

$\Delta T=2 \%$ of full range (Maxmmon torque rahe)

$\Delta N=2 \%$ of full range (Maxtmum spoఠd rahu)

On the other hand, some other parameters $\left(\mathrm{K}_{\mathrm{h}}, \mathrm{DF}\right.$ and $\left.\dot{n}\right)$ are derived from other variables, therefore the assessment of their uncertainty requires further processing:

$$
\begin{aligned}
& R_{h}=\frac{1}{1-0.0026 \cdot(H-75)} \\
& D F=\frac{13.4}{\left(C Q_{2}+H C+C O\right) \cdot 10^{-4}} \\
& n=C_{d} \cdot C_{F} \cdot \frac{A_{t} \cdot \eta_{m}}{\sqrt{2 \cdot M_{m i x} \cdot H \cdot T_{m}}}
\end{aligned}
$$

Where $\mathrm{H}$ is the absolute humidity of the engine intake air, $\mathrm{C}_{\mathrm{d}}$ the discharge coefficient and $C_{f}$ the flow coefficient. $A_{t}$ is the venturi throat area; $p_{i n}$ and $T_{\text {in }}$ are respectively the venturi inlet pressure and temperature. $\mathrm{M}_{\text {mix }}(\mathrm{g} / \mathrm{mol})$ is the molecular weigh of the dilution air and exhaust mixture, but here is considered only as the molecular weigh of a mixture of water vapor and air, since the venturi calibration was performed with dilution air. $\dot{n}$ was expressed as a function of Reynolds number (Re), according to the following fifth order polynomials:

$$
C_{d}=\sigma_{0}+\alpha_{1} \cdot R \theta+\sigma_{2} \cdot R \theta^{2}+\sigma_{2} \cdot R \theta^{a}+\sigma_{4} \cdot R \theta^{4}
$$

Where the coefficients were obtained from the curve fitting of venturi calibration data:

$$
\begin{aligned}
& \alpha_{0}=0.846880200247941 \\
& \alpha_{1}=1.00226827422465 \cdot 10^{-6} \\
& \alpha_{2}=-2.64841834295467 \cdot 10^{-12} \\
& \alpha_{2}=3.07155154948231 \cdot 10^{-18} \\
& a_{4}=-1.31603498362462 \cdot 10^{-24}
\end{aligned}
$$

\section{E.2 Second Level of Uncertainty $(\Delta H, \Delta \mu, \Delta M$ mix, $\Delta \delta)$}

The fact that $\mathrm{K}_{\mathrm{h}}$, DF and $\dot{n}$ are not directly measured induce the calculation of a second set of uncertainties (level 2): 


$$
\begin{aligned}
& \Delta K_{n}-\sqrt{\left(\frac{\partial K_{k}}{\partial H} \cdot \Delta H\right)^{2}} \\
& \Delta D F=\sqrt{\left(\frac{\partial D F}{\partial \mathrm{CO}_{2}} \cdot \Delta C \mathrm{O}_{2}\right)^{2}+\left(\frac{\partial D F}{\partial C O} \cdot \Delta C O\right)^{2}+\left(\frac{\partial D F}{\partial H C} \cdot \Delta H C\right)^{2}}
\end{aligned}
$$

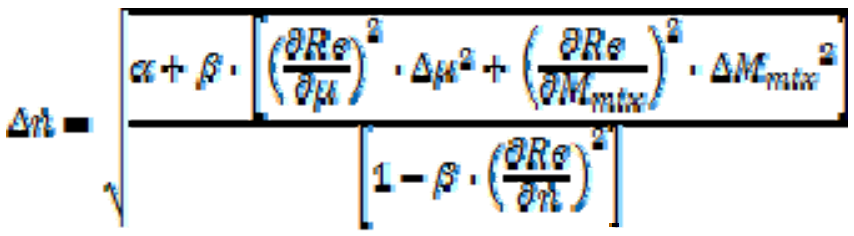

Where $\alpha$ and $\beta$ are function of the venturi calibration coefficients $\left(a_{0}, a_{1}, a_{2}, a_{3}\right.$ and $\left.a_{4}\right)$ and partial derivatives of $\dot{n}$ and $\mathrm{C}_{\mathrm{d}}$ :

$$
\begin{aligned}
& \omega=\left(\frac{\partial n}{\partial \rho}\right)^{2} \cdot \Delta \delta^{2}+\left(\frac{\partial \eta}{\partial C_{d}}\right)^{2} \cdot\left[\left(\frac{\partial C_{d}}{\partial a_{Q}}\right)^{2} \cdot \Delta \sigma_{Q}^{2}+\cdots+\left(\frac{\partial C_{d}}{\partial \alpha_{4}}\right)^{2} \cdot \Delta \sigma_{4}^{2}\right] \\
& \beta=\left(\frac{\partial n}{\partial C_{d}}\right)^{2} \cdot\left(\frac{\partial C_{d}}{\partial R_{\ell}}\right)^{2}
\end{aligned}
$$

The uncertainty of venturi calibration coefficients is easily assessed by the uncertainty of the venturi calibration; on the other hand, $\mathrm{H}, \mu$ and $\mathrm{M}_{\text {mix }}$ depends upon other parameters, as follow:

$$
\begin{aligned}
& H=\frac{(43.478) \cdot R_{t} \cdot p_{d}}{v_{E}-p_{\alpha} \cdot\left(\frac{E_{f}}{100}\right)} \\
& \mu=\mu_{0} \cdot\left(\frac{T_{m}}{T_{0}}\right)^{2} \cdot\left(\frac{T_{0}+S}{T_{m}+S}\right) \\
& M_{m i x}=M_{a t r} \cdot\left(1-x_{E 2 O}\right)+M_{L 2 O} \cdot x_{H Z O}
\end{aligned}
$$

Where $\mathrm{R}_{\mathrm{i}}(\%)$ and $\mathrm{p}_{\mathrm{d}}(\mathrm{mmHg})$ are respectively the relative humidity and the satured vapor pressure of the engine intake and $\mathrm{p}_{\mathrm{b}}(\mathrm{Pa})$ the barometric pressure. Tin $(\mathrm{K})$ is the venturi inlet absolute temperature and S is Sutherland constant [69].

\section{E.3 Third Level of Uncertainty $\left(\Delta R_{i}, \Delta p_{d}, \Delta p_{B}, \Delta x_{\mathrm{H} 20}, \Delta C_{\mathrm{f}}\right)$}

The dependency of $\mathrm{H}, \mu, \mathrm{M}_{\operatorname{mix}}$ and $\alpha$ by more basic variables requires the calculation of a third level of uncertainties (level 3):

$\left.\Delta \mu-\sqrt{\left(\frac{\partial \mu}{\partial T_{t n}} \cdot \Delta T_{i n}\right.}\right)^{2}$ 


$$
\begin{aligned}
& \Delta K=\sqrt{\left(\frac{\partial H}{\partial R_{i}}, \Delta R_{l}\right)^{2}+\left(\frac{\partial H}{\partial p_{d}}, \Delta p_{d}\right)^{2}+\left(\frac{\partial H}{\partial p_{Q}}, \Delta p_{E}\right)^{2}} \\
& \Delta M_{m b x}=\sqrt{\left(\frac{\partial M_{m i v}}{\partial x_{E 20}} \cdot \Delta x_{E 20}\right)^{2}} \\
& \Delta \delta=\sqrt{\left(\frac{\partial \theta}{\partial C_{f}} \cdot \Delta C_{f}\right)^{2}+\left(\frac{\partial S}{\partial p_{i n}} \cdot \Delta p_{i n}\right)^{2}+\left(\frac{\partial \delta}{\partial T_{i n}} \cdot \Delta T_{i n}\right)^{2}+\left(\frac{\partial S}{\partial M_{m i x}} \cdot \Delta M_{m i x}\right)^{2}}
\end{aligned}
$$

The uncertainty on $T_{\text {in }}$ is easily assessed by means of the maximum error of the venturi inlet temperature sensor (RTD) calibration curve. However, $\mathrm{R}_{\mathrm{i}}, \mathrm{x}_{\mathrm{H} 2 \mathrm{O}}, \mathrm{p}_{\mathrm{d}}, \mathrm{p}_{\mathrm{b}}$ and $\mathrm{C}_{\mathrm{f}}$ are derived variables:

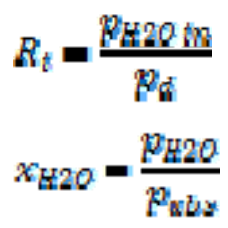

where $\mathrm{p}_{\mathrm{d}}, \mathrm{p}_{\mathrm{H} 2 \mathrm{O}}(\mathrm{KPa})$ and $\mathrm{p}_{\mathrm{H} 2 \mathrm{Oin}}(\mathrm{KPa})$ are obtained by the formula below, by inserting respectively the dry bulb temperature, the dew point temperature of the plenum and the dry bulb temperature of the engine intake:

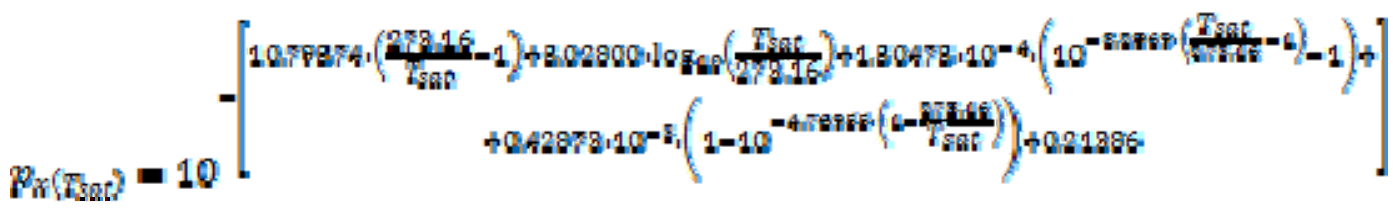

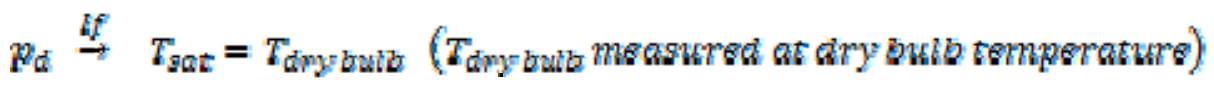

$p_{\text {H2O }} \stackrel{\text { if }}{\rightarrow} T_{\text {SQE }}=T_{\text {eew }}\left(T_{\text {dew }}\right.$ mensured at plenum $)$

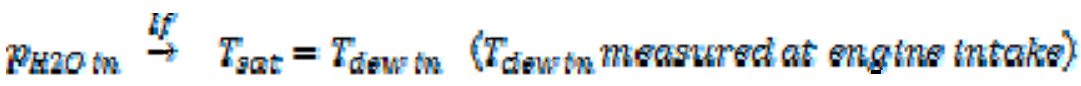

$$
c_{f}=\sqrt{\frac{2 \cdot \eta \cdot\left(r^{\frac{v^{2}}{\gamma}}-1\right)}{(\gamma-1) \cdot\left(\omega^{4}-r^{\frac{\sigma^{2}}{\gamma}}\right)}}
$$

Where $\gamma$ is the ratio of specific heat at constant pressure and at constant volume; $r$ depends upon the differential pressure across the venturi and the inlet venturi pressure; $\omega$ is the ratio of venturi throat and inlet section area. 
$\alpha=\frac{A_{t}}{A_{t w}}$

$r=1-\frac{d p}{p_{m}}$

$\gamma=\frac{\epsilon_{\mathrm{p}}}{\epsilon_{\mathrm{y}}}=$ const, $=1.399$

\section{E.4 Forth Level of Uncertainty $(\Delta r)$}

The dependency of $\mathrm{R}_{\mathrm{i}}, \mathrm{x}_{\mathrm{H} 2 \mathrm{O}}, \mathrm{C}_{\mathrm{f}}$ and $\mathrm{p}_{\mathrm{x}}$ by more basic variables leads to the calculation of another level of uncertainties (level 4):

$\Delta K_{t}=\sqrt{\left(\frac{\partial R_{t}}{\partial p_{H 2 O \mathrm{in}}} \cdot \Delta p_{\mathrm{H} 2 \mathrm{O}}\right)^{2}+\left(\frac{\partial R_{i}}{\partial p_{d}} \cdot \Delta p_{d}\right)^{2}}$

$\Delta x_{H 2 O}=\sqrt{\left(\frac{\partial x_{H 2 O}}{\partial p_{H 2 O}}, \Delta p_{H 2 O}\right)^{2}+\left(\frac{\partial x_{H 2 O}}{\partial p_{\alpha b O}}, \Delta p_{a b s}\right)^{2}}$

Where $\Delta \mathrm{p}_{\mathrm{abs}}$ is given by the uncertainty associated to the pressure sensor calibration and the $\Delta \mathrm{p}_{\mathrm{H} 2 \mathrm{O}}$ and $\Delta \mathrm{p}_{\mathrm{d}}$ can easily be assed by using the formula:

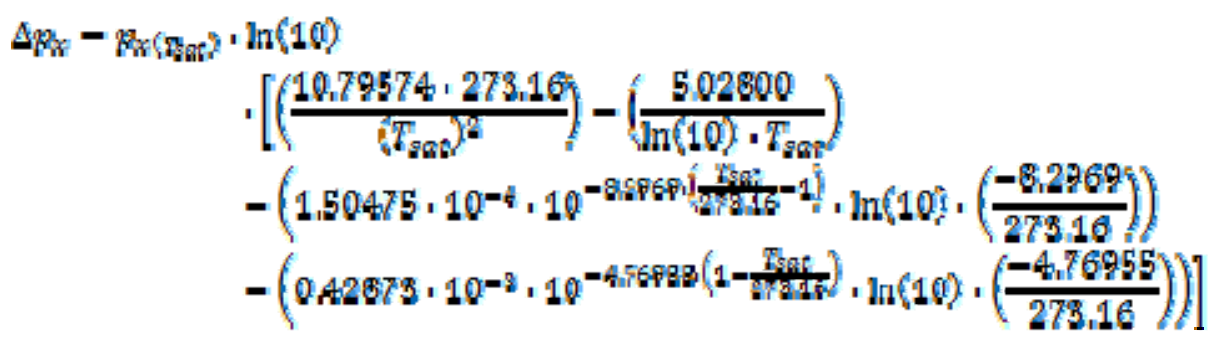

The temperature at dry bulb can be used to determine $\Delta \mathrm{pd}$ and temperature of the intake air dew point to determine $\Delta \mathrm{p}_{\mathrm{H} 2 \mathrm{O}}$ as follow:

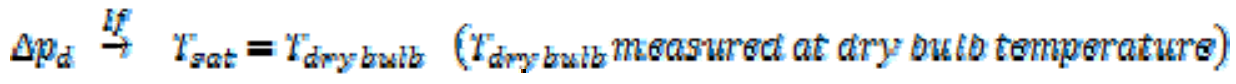

$\Delta p_{H 20 \text { in }} \stackrel{\text { If }}{\rightarrow} T_{s a t}=T_{\text {dew th }}\left(T_{\text {dew }}\right.$ measured at engine intake $)$.

To calculate the $\Delta \mathrm{C}_{\mathrm{f}}$ is needed the $\Delta \mathrm{r}$ :

$\Delta C_{f}=\sqrt{\left(\frac{\partial C_{f}}{\partial r} \cdot \Delta r\right)^{2}}$

\section{E.5 Final Level of Uncertainty}

The only uncertainty left to estimate is $\Delta \mathrm{r}$, which can be obtained by the formula: 
$\Delta r=\sqrt{\left(\frac{\partial r}{\partial d p} \cdot \Delta d p\right)^{2}+\left(\frac{\partial r}{\partial p_{i n}} \cdot \Delta p_{i n}\right)^{2}}$

Where $\Delta \mathrm{dp}$ and $\Delta$ pin are respectively the uncertainties of venturi differential and inlet pressure, which are easily assessable form the pressure sensors calibration curve.

The bsNOx uncertainty assessed for measurement downstream of the SCR was 0.0618 $\mathrm{g} / \mathrm{bhp}-\mathrm{hr}$. The uncertainty on $\dot{n}$, DF and $\mathrm{K}_{\mathrm{h}}$ was respectively $0.057 \%(0.0235 \mathrm{~mol} / \mathrm{s}), 5 \%$ and $0.072 \%$. 
Table 30: Uncertainties of pressure and temperature sensors

List of instruments used for differential \& absolute pressure and temperature measurement

\begin{tabular}{|l|c|c|c|c|}
\hline \multicolumn{1}{|c|}{ Source } & Manufacturer & Model & Accuracy \\
\hline Differential Pressure & Heise & HQS-1 & $\pm 0.06 \%$ of Span & $0-50$ "H20 \\
\hline Absolute Pressure & Heise & HQS-2 & $\pm 0.025 \%$ of Span & $0-30$ psi ABS \\
\hline Temperature & Fluke & 714 Thermocouple Calibrator & $\pm 0.025 \%$ of Reading & \\
\hline
\end{tabular}

Errors in absolute pressure measurement

\begin{tabular}{|c|c|c|c|c|}
\hline Source & Manufacturer & Model Number & Applied Error \% of full scale & Notes \\
\hline Absolute Pressure Sensor & Viatran & $245 \mathrm{ACA}$ & $\pm 0.05 \%$ of Full scale reading & $0-15$ psi \\
\hline DAQ Board & National Instruments Inc. & NI-SCXI-1001 & $\pm 0.024 \%$ & \\
\hline
\end{tabular}

Errors in differential pressure measurement

\begin{tabular}{|c|c|c|c|c|}
\hline Source & Manufacturer & Model Number & Applied Error \% of full scale & Notes \\
\hline Differential Pressure Sensor & Omega Inc. & PX654 & $\pm 0.5 \%$ of Full scale reading & \\
\hline DAQ Board & National Instruments Inc. & NI-SCXI-1001 & $\pm 0.024 \%$ & \\
\hline
\end{tabular}

\section{Errors in RTD measurement}

\begin{tabular}{|l|c|c|c|}
\hline \multicolumn{1}{|c|}{ Source } & Manufacturer & Model Number & Applied Error \% of full scale \\
\hline RTD Sensor & Omega Inc. & PT100 & $\pm 0.5 \%$ \\
\hline Signal Conditioner Module & Omega Inc. & DRG-SC-RTD & $\pm 0.1 \%$ \\
\hline DAQ Board & National Instruments Inc. & NI-SCXI-1001 & $\pm 0.024 \%$ \\
\hline
\end{tabular}

Errors in Dew Point I Temperature (Chilled mirror) measurement

\begin{tabular}{|l|c|c|c|}
\hline \multicolumn{1}{|c|}{ Source } & Manufacturer & Model Number & Applied Error \% of full scale \\
\hline Drybulb Sensor & GE General Eastern & Dew-10-2A1 & $\pm 0.7 \%$ \\
\hline DAQ Board & National Instruments Inc. & NI-SCXI-1001 & $\pm 1^{\circ} \mathrm{F}$ over op. range $136^{\circ} \mathrm{F}$ \\
\hline
\end{tabular}


Table 31: Uncertainties of temperature sensors, gas analyzers, gas dividers and acquisition system

Errors in temperature measurement

\begin{tabular}{|l|c|c|c|c|}
\hline \multicolumn{1}{|c|}{ Source } & Manufacturer & Model Number & Applied Error \% of full scale & Notes \\
\hline Temperature Sensor & Omega Inc. & K-Type & $\pm 0.4 \%$ & \\
\hline Signal Conditioner Module & National Instruments Inc. & NI-SCXI-1303 & $\pm 0.08 \%$ & \\
\hline DAQ Board & National Instruments Inc. & NI-SCXI-1001 & $\pm 0.024 \%$ & \\
\hline
\end{tabular}

Specifications of instruments used in gaseous concentration measurement

\begin{tabular}{|l|c|c|c|c|}
\hline \multicolumn{1}{|c|}{ Source } & Manufacturer & Model Number & Applied Error & Notes \\
\hline Calibration Gas & Scott Speciality Gases & -- & $\pm 1.00 \%$ & \\
\hline GaS Divider & STEC Inc. & SGD-710C & $\pm 0.54 \%$ & MFG.NO. 1833369 \\
\hline DAQ Board & National Instruments Inc. & NI-SCXI-1001 & $\pm 0.024 \%$ & \\
\hline
\end{tabular}

\section{Specifications of gas analyzers used}

\begin{tabular}{|l|c|c|c|c|}
\hline \multicolumn{1}{|c|}{ Analyzer } & Manufacturer & Model Number & \% Error & Notes \\
\hline NOx & Eco Physics & CLD822CMh & $\pm 2.00 \%$ of Full scale reading & 822 CMh0279 \\
\hline CO2 & Horiba & AlA-220 & $\pm 1.00 \%$ of Full scale reading & $\mathrm{J} 000 \mathrm{~J} 8 \mathrm{M} 5$ \\
\hline $\mathrm{CO}$ & Horiba & AlA-220 & $\pm 1.00 \%$ of Full scale reading & $\mathrm{J} 000 \mathrm{~J} 8 \mathrm{M} 5$ \\
\hline $\mathrm{HC}$ & Rosemount & 402 & $( \pm 1.00 \%$ of Full scale reading $)$ & 1000438 \\
\hline
\end{tabular}

